Taylla Klei Felix Souza

\title{
AVALIAÇÃO DA TÉCNICA DE MAGNETO HIPERTERMIA NO TRATAMENTO DE GLIOBLASTOMA EM MODELO ANIMAL: estudo in vitro e in vivo
}

\author{
Dissertação apresentada à Sociedade \\ Beneficente Israelita Brasileira Albert \\ Einstein para obtenção do Título de Mestre \\ em Ciências da Saúde.
}

São Paulo 
Taylla Klei Felix Souza

\title{
AVALIAÇÃO DA TÉCNICA DE MAGNETO HIPERTERMIA NO TRATAMENTO DE GLIOBLASTOMA EM MODELO ANIMAL: estudo in vitro e in vivo
}

\author{
Dissertação apresentada à Sociedade \\ Beneficente Israelita Brasileira Albert \\ Einstein para obtenção do Título de Mestre \\ em Ciências da Saúde.
}

Orientador: Prof. Dr. Lionel Fernel Gamarra 
Souza, Taylla Klei Felix

Avaliação da técnica de magneto hipertermia no tratamento de glioblastoma em modelo animal : estudo in vitro e in vivo / Taylla Klei Felix Souza. -- São Paulo, 2017.

xxiv, $143 \mathrm{f} .$, il.

Dissertação (Mestrado) - Sociedade Beneficente Israelita Brasileira Albert Einstein. Instituto Israelita de Ensino e Pesquisa Albert Einstein. Programa de Pós-Graduação em Ciências da Saúde.

Título em inglês: Evaluation of the magnetic hyperthermia technique in the treatment of glioblastoma in animal model: in vitro and in vivo study.

1. Glioblastoma. 2. Magneto hipertermia. 3. Nanopartícula de óxido de ferro. 4. Bioluminescência. 5. Citometria de fluxo. 6. Imagem por ressonância magnética.

NLM - QZ 380

Elaborada pelo Sistema Einstein Integrado de Bibliotecas 
SOCIEDADE BENEFICENTE ISRAELITA BRASILEIRA ALBERT EINSTEIN

Coordenador do Curso de Pós-Graduação: Prof. Dr. Luiz Vicente Rizzo 


\section{Taylla Klei Felix Souza}

\section{AVALIAÇÃO DA TÉCNICA DE MAGNETO HIPERTERMIA NO TRATAMENTO DE GLIOBLASTOMA EM MODELO ANIMAL: estudo in vitro e in vivo}

Presidente da banca: Prof. Dr. Lionel Fernel Gamarra

BANCA EXAMINADORA

Membros titulares:

Profa. Luciana Cavalheiro Marti

Profa. Dra. Mariana Penteado Nucci da Silva

Dra. Solange Amorim Nogueira

Membros suplentes:

Profa. Dra. Elisa Harumi Kozasa

Dra. Jessica Ruivo Maximino

Aprovada em: 06/07/2017. 


\section{Dedicatória}

Dedico este trabalho em honra a Deus, meu amor, minha família e ao meu inesquecível pai que em vida fez o possível para me dar o melhor. 


\section{Agradecimentos}

Primeiramente agradeço ao meu Deus, por me guardar no caminho e por sempre me trazer à memória aquilo que me dava esperança me fortalecendo a não desistir do alvo.

Ao amor da minha vida, Ermerson Timm, obrigado por estar sempre presente mesmo em meio a quilômetros de distância, grata por me apoiar, me fortalecer com palavras e por mostrar que eu nunca estaria sozinha nesta caminhada. Eu te amo imensuravelmente.

À minha mãe e meu irmão, por terem me apoiado na decisão de mudança de Estado para a realização deste trabalho. Amo vocês.

À Ana Claudia Camargo Miranda por ser a pessoa usada por Deus para me abençoar e ser a "ponte" para a existência desta oportunidade na minha vida. Agradeço aos professores Claudio Teixeira e Dirceu Santos por me incentivarem e me aconselharem de forma profissional a aceitar este desafio.

Agradeço muitíssimo a família Rodrigues que me acolheu com amor e hospitalidade da qual serei eternamente grata, grande valor foi a oportunidade de ter convivido com vocês. Vocês fazem parte da realização deste sonho.

Agradecimento especial ao meu orientador Dr. Lionel Fernel Gamarra, por todo o conhecimento científico repassado, pela oportunidade e confiança.

Meu eterno agradecimento aos colegas Marina Fontes de Paula Aguiar, Hélio Rodrigues da Silva e Javier Bustamante Mamani, pelas contribuições essenciais, por terem me ensinado técnicas e métodos necessários para a execução deste trabalho.

Aos colegas de trabalho, Rafael Ferreira dos Reis, Thiemy Gabriel Esichiel, Pamela Costa Carvalho, Débora Braga Vieira e Larissa Thayane Alvarim, por toda ajuda; vocês fizeram esta jornada mais alegre.

Ao Dr. Luiz Vicente Rizzo e toda a equipe do Instituto Israelita de Ensino e Pesquisa Albert Einstein (IIEPAE).

À Anna Maria Ringheim Cadete por sua atenção e disposição, além da sua simpatia que foi acolhedora. Ao Instituto do Cérebro $(\operatorname{InCe})$, ao Centro de Experimentação e Treinamento em Cirurgia (CETEC), pela infraestrutura e apoio necessário para realização deste projeto; $A$ todos os funcionários em especial à 
Laudiceia Almeida por todo auxilio e momentos de conversas esclarecedoras, aos professores do Departamento de Pós-Graduação Stricto Sensu em Ciências da Saúde da Sociedade Beneficente Israelita Brasileira Albert Einstein e ao Instituto de Física da USP de São Carlos (IFSC) pela disponibilidade do laboratório e contribuição nos estudos de ressonância magnética.

À Faculdade de Medicina Veterinária da USP (FMVZ) pelo fornecimento dos animais.

À banca de qualificação de mestrado, Luciana Cavalheiro Marti, Mariana Penteado Nucci da Silva e Solange Amorim Nogueira pelas sugestões dadas que foram de grande valia.

A todos que direta ou indiretamente contribuíram para execução deste projeto. 


\section{Agradecimentos especiais}

À CAPES pela concessão da bolsa de mestrado.

O presente trabalho foi realizado com apoio da Coordenação de Aperfeiçoamento de Pessoal de Nível Superior - Brasil (CAPES) - Código de Financiamento 001. 
"Algo só é impossível até que alguém duvide e prove o contrário." Albert Einstein 


\section{Sumário}

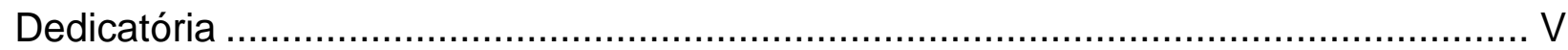

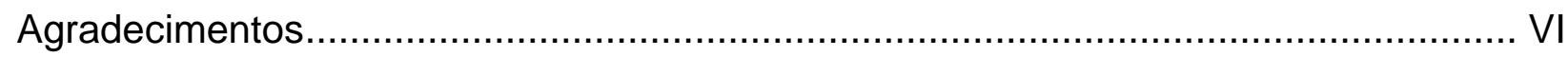

Agradecimentos especiais ........................................................................... VII

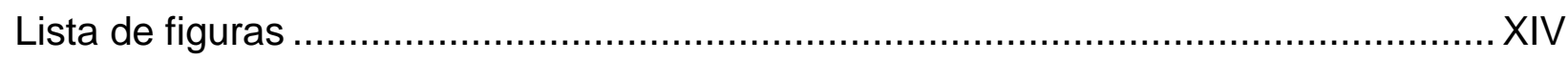

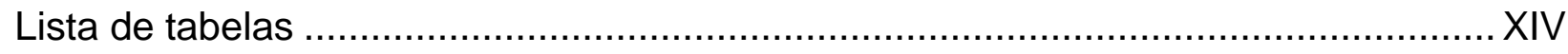

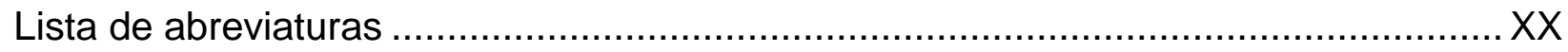

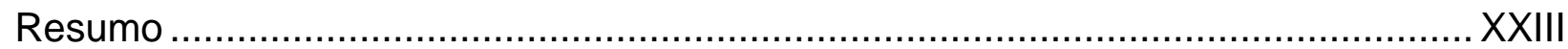

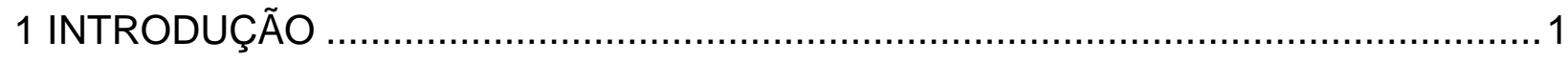

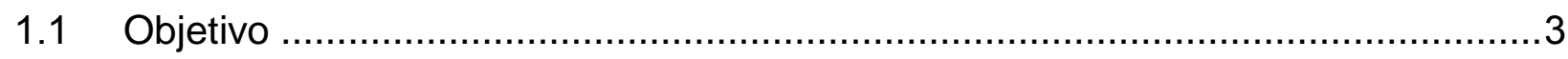

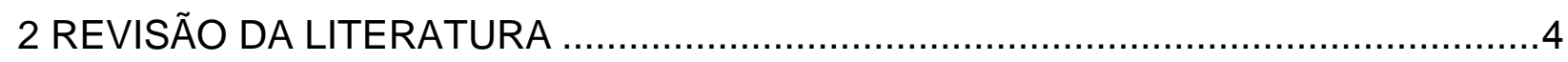

2.1 Modelos experimentais de origem glial em modelo animal ..................................

2.2 Terapias para o tratamento de glioblastoma ..............................................

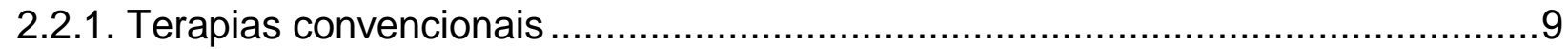

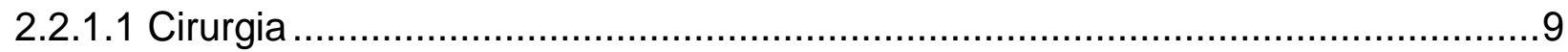

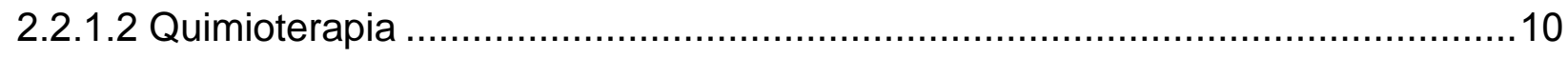

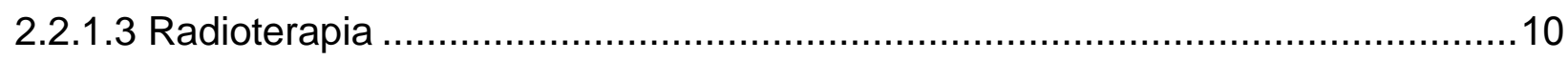

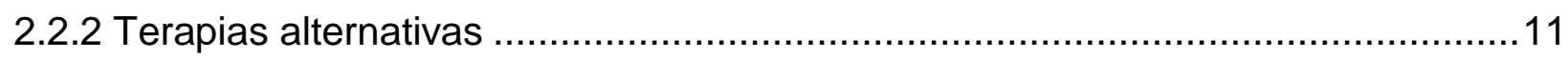

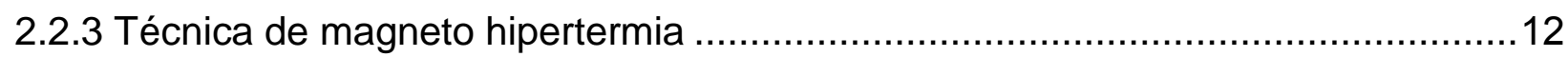

2.2.4 Nanopartículas magnéticas ................................................................. 19

2.2.5 Nanopartículas superparamagnéticas de óxido de ferro .................................21

2.2.5.1 Características físico-químicas .................................................................... 21

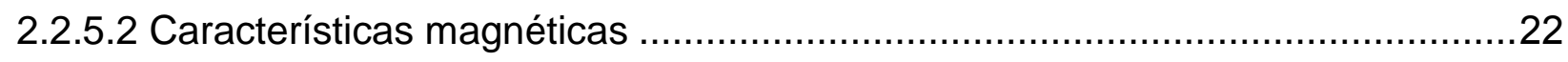

2.2.5.3 Caracterização relaxométrica ............................................................28

2.2.6 Taxa de absorção específica e perda de poder intrínseco ...............................28

2.2.7 Estudos in vitro de magneto hipertermia ................................................29

2.2.8 Estudos in vivo de magneto hipertermia......................................................... 31

2.3 Técnicas para avaliação de eficiência em magneto hipetermia.............................32

2.3.1 Imagem por ressonância magnética ..................................................... 33

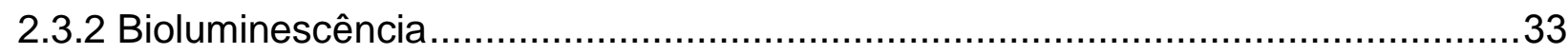

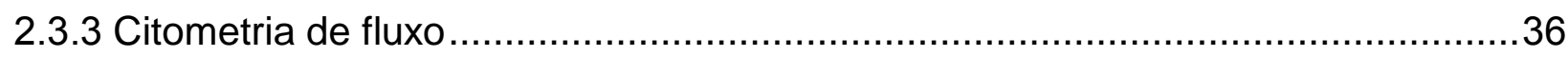

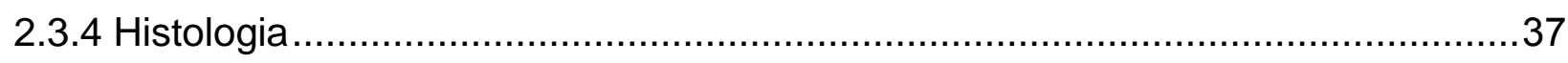

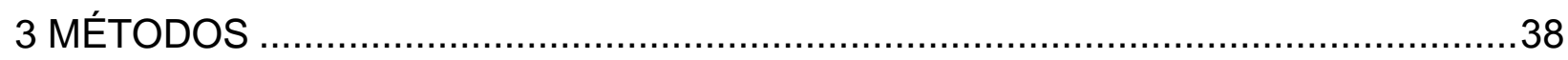


3.1 Nanopartículas superparamagnéticas de óxido de ferro com diferentes tamanhos e coberturas.

3.2 Avaliação do aquecimento das nanopartículas superparamagnéticas de óxido de ferro após aplicação do campo magnético alternado ...............................................40

3.3 Cálculo da taxa de absorção específica e da perda de poder intrínseco .................41

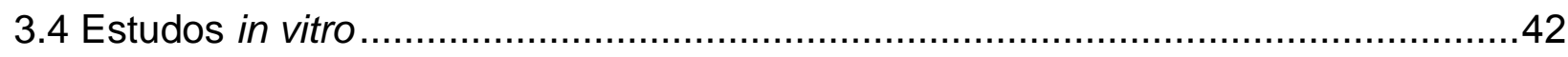

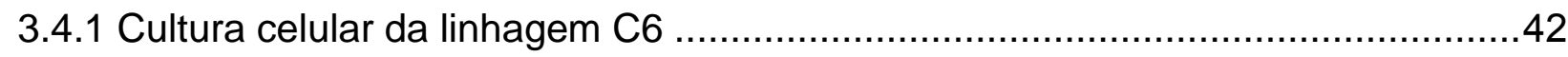

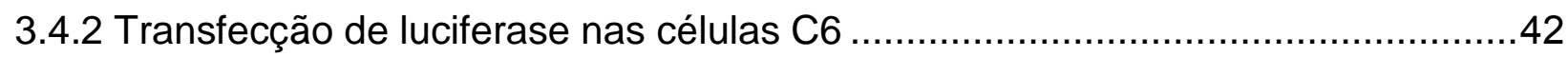

3.4.3 Cinética do sinal de bioluminescência nas C6-Luc...............................................43

3.4.4 Marcação das células C6-Luc com nanopartículas superparamagnéticas de óxido

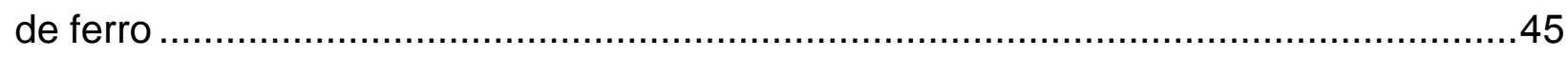

3.4.5 Visualização por azul de prússia das nanopartículas nas C6-Luc marcadas ........47

3.4.6 Configuração experimental do equipamento de magneto hipertermia ..................47

3.4.7 Aplicação de magneto hipertermia nas células C6-Luc......................................48

3.4.8 Avaliação da eficiência da técnica de magneto hipertermia ...............................49

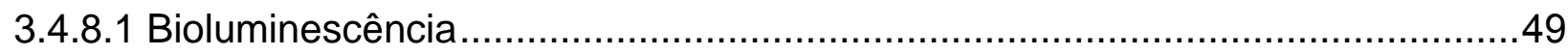

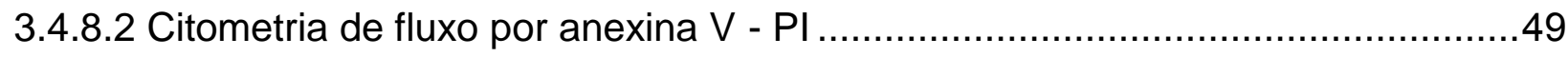

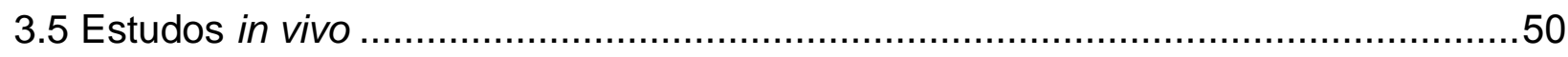

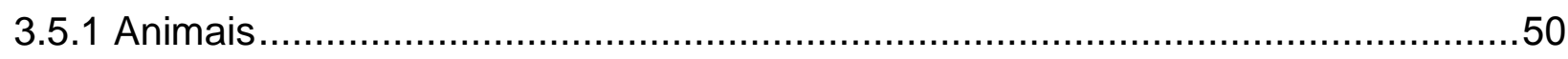

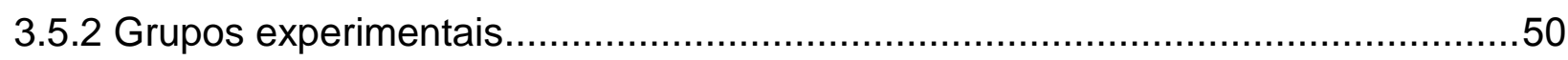

3.5.3 Indução tumoral de glioblastoma no modelo animal.........................................52

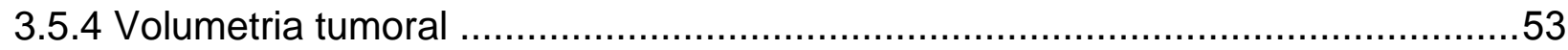

3.5.4.1 Avaliação da volumetria tumoral por imagem de ressonância magnética .........53

3.5.4.2 Avaliação da volumetria tumoral por bioluminescência ....................................54

3.5.5 Avaliação comportamental do animal após indução tumoral ................................55

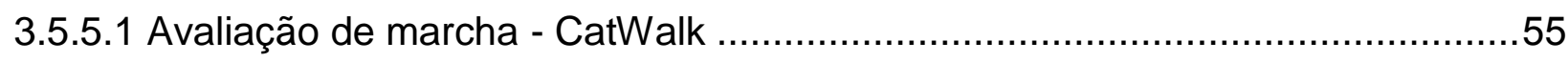

3.5.5.2 Avalição locomotora espontânea - Actômetro ...................................................59

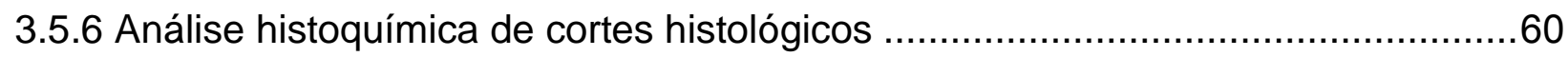

3.5.7 Ensaio do processo de magneto hipertermia no modelo animal . 613.5.8 Avaliação de eficiência terapêutica após magneto hipertermia in vivo por bioluminescência 61 
4.1 Curvas de aquecimento das nanopartículas superparamagnéticas de óxido de ferro após aplicação do campo magnético alternado.

4.2 Valores de taxa de absorção específica e perda de poder intrínseco após aplicação do campo magnético alternado .66

4.3 Estudos in vitro. .68

4.3.1 Cinética do sinal de bioluminescência nas c6-luc. 69

4.3.2 Marcação das c6-luc com nanopartículas superparamagnéticas de óxido de ferro e visualização das células marcadas .73

4.3.2.1 Sem ímã .74

4.3.2.2 Ímã estático .78

4.3.2.3 Ímã dinâmico .82

4.3.3 Aplicação da técnica de magneto hipertermia - in vitro . .87

4.3.4 Avaliação da eficiência de magneto hipertermia nas células c6-luc .88

4.3.4.1 Bioluminescência... .88

4.3.4.2 Citometria de fluxo - anexina $v$ / iodeto de propídio. .89

4.4 Estudos in vivo. .92

4.4.1 Volumetria de crescimento tumoral .92

4.4.1.1 Avaliação do crescimento tumoral por histologia e imagem por ressonância magnética . 92

4.4.1.2 Avaliação do crescimento tumoral por bioluminescência .95

4.4.2 Avaliação comportamental do animal após indução do tumor. .96

4.4.2.1 Avaliação das alterações de marcha - catwalk .97

4.4.2.1.1 Comprimento do passo. .97

4.4.2.1.2 Área máxima de contato. .98

4.4.2.1.3 Distância entre patas ipsilaterais do mesmo ciclo 100

4.4.2.1.4 Distância entre patas anteriores ou posteriores 101

4.4.2.1.5 Tempo de contato da pata 103

4.4.2.1.6 Ciclo do passo 105

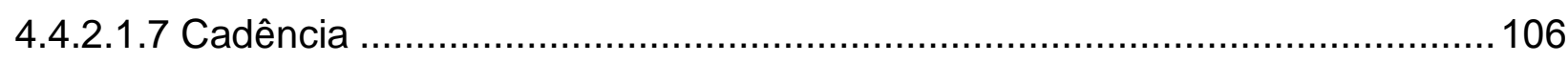

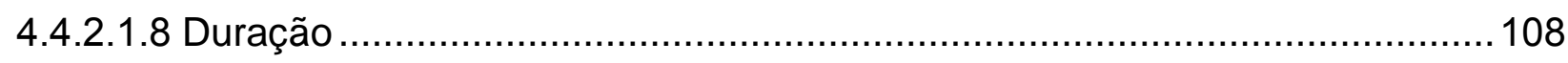

4.4.2.2 Avaliação locomotora espontânea - actômetro ............................................... 109 
4.4.2.2.1 movimento espontâneo lento do animal na plataforma (MOV-L).................109

4.4.2.2.2 Movimento espontâneo rápido do animal na plataforma (MOV-R) ..............111

4.4.2.2.3 Movimento lento da cabeça (STE-L) ............................................... 112

4.4.2.2.4 Movimento rápido da cabeça (STE-R) ............................................. 113

4.4.2.2.5 Movimento lento de erguida do animal (REA-L) ................................... 115

4.4.2.2.6 Movimento rápido de erguida do animal (REA-R) .................................116

4.4.3 Magneto hipertermia em modelo animal............................................... 118

4.4.4 Avaliação por bioluminescência da aplicação de magneto hipertermia in vivo...119

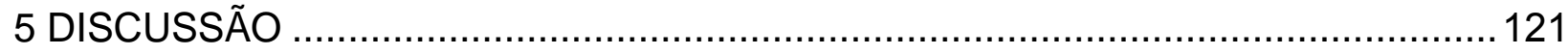

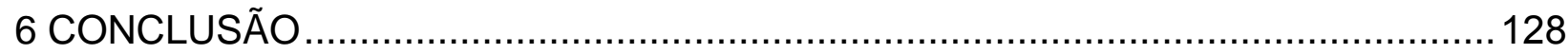

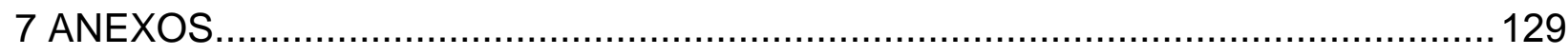

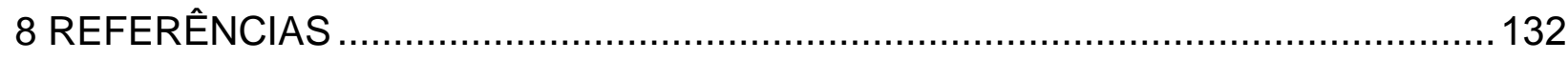

Abstract 


\section{Lista de figuras}

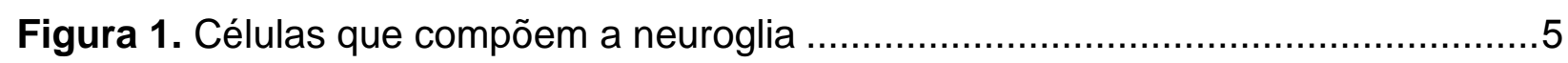

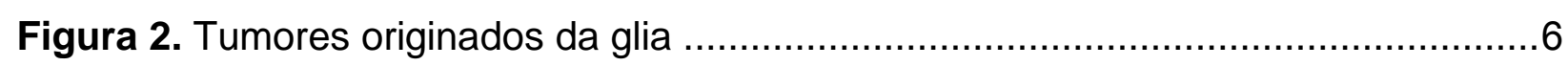

Figura 3. Imagem esquemática do processo de magneto hipertermia .........................13

Figura 4. Fases da hipertermia e a sua janela terapêutica .........................................14

Figura 5. Representação de direcionamento magnético in vivo usando nanopartículas superparamagnéticas de óxido de ferro (SPION) .................................................15

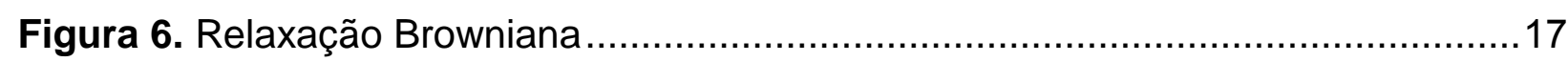

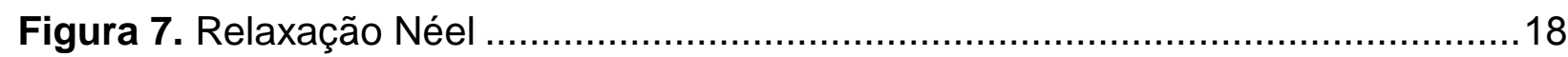

Figura 8. Imagem de distribuição de escala manométrica e de composição de

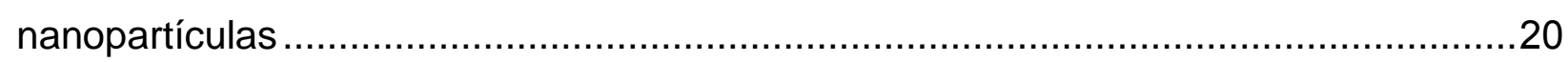

Figura 9. Nanopartículas superparamagnéticas de óxido de ferro e seu uso em

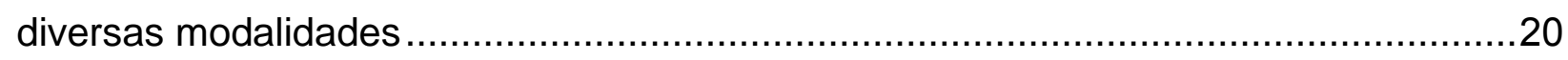

Figura 10. Estrutura de uma nanopartícula superparamagnética de óxido de ferro .....21 Figura 11. Visualização estrutural nanopartículas superparamagnéticas de óxido de

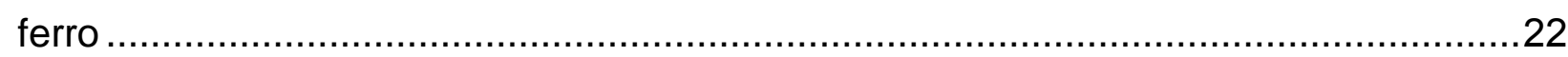

Figura 12. Interação de polos das nanopartículas superparamagnéticas de óxido de

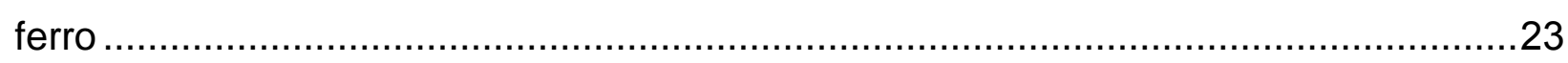

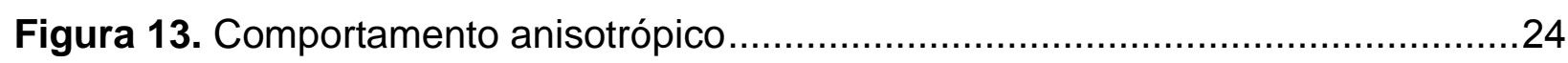

Figura 14. Característica superparamagnética das nanopartículas de óxido de ferro. .25

Figura 15. Momento magnético .25

Figura 16. Momento magnético das nanopartículas em resposta a direção de spin e ao campo magnético aplicado na geração de calor .................................................27

Figura 17. Processo de bioluminescência luciferase-luciferina.....................................35

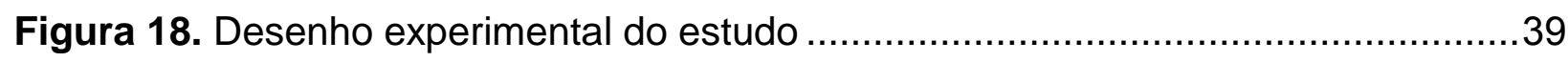

Figura 19. Parâmetros utilizados para a quantificação da taxa de absorção.................41

Figura 20. Equipamento utilizado na aquisição de imagens de bioluminescência.........44

Figura 21. Disposição das amostras na placa de 48 poços .......................................... 45

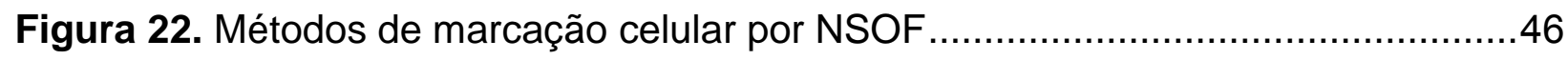

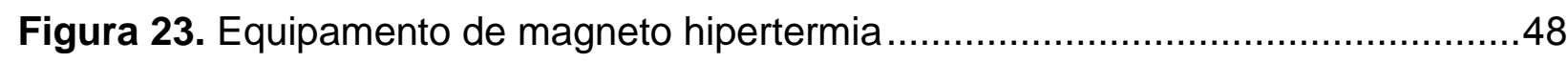

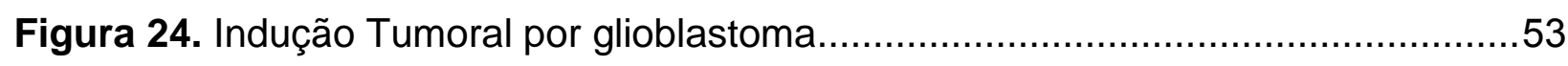

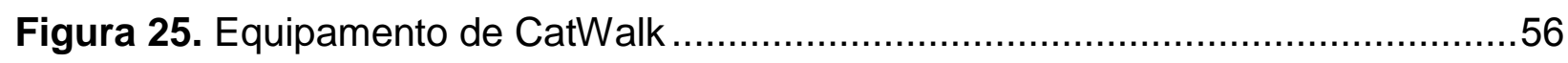


Figura 26. Sistema de CatWalk e suas variáveis envolvidas na análise do comportamento animal.

Figura 27. Equipamento Actômetro utilizado na análise comportamental exploratória espontânea.

Figura 28. Análise de resposta de aquecimento conforme campo magnético e frequência aplicada das nanopartículas recobertas com aminosilana e com dextrana .64 Figura 29. Análise de resposta de aquecimento conforme campo magnético e frequência aplicada nas nanopartícula recobertas com quitosana e com starch. .65

Figura 30. Valores de taxa de absorção específica das nanopartículas e seus respectivos tamanhos, em relação a intensidade do campo magnético e da frequência

Figura 31. Valores de taxa de absorção específica conforme os tipos de nanopartículas de $100 \mathrm{~nm}$ expostas a $300 \mathrm{gauss}$ e $551 \mathrm{kHz}$.

Figura 32. Valores de perda de poder intrínseco conforme os tipos de nanopartículas de $100 \mathrm{~nm}$ expostas a $300 \mathrm{gauss}$ e $551 \mathrm{kHz}$ .68

Figura 33. Imagens de microscopia óptica das células C6-Luc .68

Figura 34. Análise de placa de C6-Luc e sua bioluminescência

Figura 35. Imagens de bioluminescência das células C6-Luc (após adição de luciferina) no decorrer do tempo

Figura 36. Reprodutibilidade de bioluminescência das amostras em triplicata (A, B e C)

Figura 37. Análise de intensidade de bioluminescência em função da concentração celular .72

Figura 38. Análise de intensidade de sinal bioluminescente das substâncias .73

Figura 39. Marcação de C6-Luc com nanopartículas superparamagnéticas de óxido de ferro 74

Figura 40. Imagens ópticas da coloração de azul de prússia das C6-Luc com nanopartículas recobertas com aminosilana [100Fe] sem utilização de ímã .75

Figura 41. Imagens ópticas da coloração de coloração de azul de prússia das C6-Luc com nanopartículas recobertas com aminosilana [200Fe] sem utilização de ímã .76

Figura 42. Imagens ópticas da coloração de azul de prússia das C6-Luc com nanopartículas recobertas com aminosilana [300Fe] sem utilização de ímã. .77

Figura 43. Imagens ópticas da coloração de azul de prússia das C6-Luc com nanopartículas recobertas com quitosana, sem poli-lisina e sem utilização de ímã......78 
Figura 44. Imagens ópticas da coloração de azul de prússia das C6-Luc com nanopartículas recobertas com aminosilana [100Fe] com utilização de ímã estático ...79 Figura 45. Imagens ópticas da coloração de azul de prússia das C6-Luc com nanopartículas recobertas com aminosilana [200Fe] com utilização de ímã estático ...80 Figura 46. Imagens ópticas da coloração de azul de prússia das C6-Luc com nanopartículas recobertas com aminosilana [300Fe] com utilização de ímã estático ...81 Figura 47. Imagens ópticas da coloração de azul de prússia das C6-Luc com nanopartículas recobertas com quitosana, sem poli-lisina e com utilização de ímã estático

Figura 48. Imagens ópticas da coloração de azul de prússia das C6-Luc com nanopartículas recobertas com aminosilana [100Fe] com utilização de ímã dinâmico .83 Figura 49. Imagens ópticas da coloração de azul de prússia das C6-Luc com nanopartículas recobertas com aminosilana [200Fe] com utilização de ímã dinâmico .84 Figura 50. Imagens ópticas da coloração de azul de prússia das C6-Luc com nanopartículas recobertas com aminosilana [300Fe] com utilização de ímã dinâmico .85 Figura 51. Imagens ópticas da coloração de azul de prússia das C6-Luc com nanopartículas recobertas com quitosana, sem poli-lisina e com utilização de ímã dinâmico .86

Figura 52. Imagens ópticas da coloração de azul de prússia das C6-Luc com nanopartículas recobertas com aminosilana e quitosana, sem poli-lisina, com filtro na comparação de meio de marcação magnético.

Figura 53. Viabilidade celular por bioluminescência após exposição à magneto hipertermia. .89

Figura 54. Análise de viabilidade celular com Anexina $V$ e iodeto de propídio.... .91

Figura 55. Imagens por ressonância magnética ponderadas em T2 do desenvolvimento tumoral... .94

Figura 56. Volumetria tumoral por imagens de bioluminescência. .96

Figura 57. Avaliação de marcha do animal no comprimento do passo. 98

Figura 58. Avaliação de marcha do animal na área de máximo contato 100

Figura 59. Avaliação de alteração de marcha do animal na distância entre patas ipsilaterais do mesmo ciclo. 101

Figura 60. Avaliação de marcha do animal da distância entre patas anteriores ou posteriores. 102 
Figura 61. Análise da distância e contato das patas do animal detectadas pelo sistema de CatWalk. 103

Figura 62. Avaliação de marcha do animal no tempo de contato da pata na superfície 105

Figura 63. Avaliação de marcha do animal no ciclo de passo da mesma pata. Ciclo de passo da mesma pata no grupo controle (A); Ciclo de passo da mesma pata no grupo de craniotomia (B); Ciclo de passo da mesma pata no grupo tumoral (C). PAD: Pata Anterior Direita; PPD (Pata Posterior Direita); PAE (Pata Anterior Esquerda); PPE (Pata Anterior Esquerda) 106

Figura 64. Avaliação da cadência no grupo tumoral quando comparado aos demais grupos. 108

Figura 65. Avaliação da duração do percurso realizado no grupo tumoral em comparação com os demais grupos. 109

Figura 66. Avaliação do MOV-L entre o grupo de tumor e o grupo controle a partir de 21 dias 110

Figura 67. Avaliação do MOV-R entre o grupo de tumor e o grupo controle a partir de 14 dias 112

Figura 68. Alteração significativa do STE-L entre o grupo tumoral e os demais grupos a partir de 14 dias.

Figura 69. Avaliação do STE-R entre o grupo tumoral e os demais grupos a partir de 7 dias 114

Figura 70. Avaliação do REA-L entre o grupo tumoral e os demais grupos a partir de 7 dias 116

Figura 71. Avaliação do REA-R do grupo tumoral em relação aos demais grupos ....117 Figura 72. Curvas de aquecimento após magneto hipertermia em água, sangue e estes com adição de nanopartículas superparamagnéticas de óxido de ferro...... 118

Figura 73. Análise de bioluminescência in vivo após magneto hipertermia. 120

Figura 74. Diâmetro das nanopartículas magnéticas e os seus domínios magnéticos 122 


\section{Lista de tabelas}

Tabela 1. Tipos de linhagens celulares de tumores gliais e suas características .8

Tabela 2. Estudos in vitro da técnica de magneto hipertermia 30

Tabela 3. Comparação de exposição ao campo magnético alternado e resultados alcançados após magneto hipertermia em modelos in vivo 32

Tabela 4. Características das Nanopartículas superparamagnéticas de óxido de ferro utilizadas no estudo 40

Tabela 5. Médias estimadas para comprimento do passo $(\mathrm{cm})$ .97

Tabela 6. Comparações entre grupos corrigidas por Bonferroni para comprimento do passo .98

Tabela 7. Médias estimadas para área máxima de contato $(\mathrm{cm})$ 99

Tabela 8. Comparações entre grupos corrigidas por Bonferroni para Área máxima de contato 99

Tabela 9. Médias estimadas para distância entre patas ipsilaterais do mesmo ciclo (DPi) (cm) 100

Tabela 10. Comparações entre grupos corrigidas por Bonferroni para distância entre patas ipsilaterais do mesmo ciclo $(\mathrm{DPi})(\mathrm{cm})$. 101

Tabela 11. Médias estimadas para distância entre patas anteriores ou posteriores (DPA/P) (cm) 102

Tabela 12. Comparações entre grupos corrigidas por Bonferroni para distância entre patas anteriores ou posteriores (DPA/P) $(\mathrm{cm})$ 102

Tabela 13. Médias estimadas para tempo de contato (TC) (s) 104

Tabela 14. Comparações entre grupos corrigidas por Bonferroni para tempo de contato (TC) (s) 104

Tabela 15. Médias estimadas para ciclo do passo (s) 105

Tabela 16. Comparações entre grupos corrigidas por Bonferroni para ciclo do passo (s) 106

Tabela 17. Médias estimadas para Cadência (passo/segundo). 107

Tabela 18. Comparações entre grupos corrigidas por Bonferroni para Cadência (passo/segundo). 107

Tabela 19. Médias estimadas para duração (s) 108

Tabela 20. Comparações entre grupos corrigidas por Bonferroni para duração (s)....108 
Tabela 21. Médias estimadas para MOV-L 110

Tabela 22. Comparações entre grupos corrigidas por Bonferroni para MOV-L 110

Tabela 23. Médias estimadas para MOV-R 111

Tabela 24. Comparações entre grupos corrigidas por Bonferroni para MOV-R. 111

Tabela 25. Médias estimadas para STE-L 112

Tabela 26. Comparações entre grupos corrigidas por Bonferroni para STE-L 113

Tabela 27. Médias estimadas para STE-R 114

Tabela 28. Comparações entre grupos corrigidas por Bonferroni para STE-R .114

Tabela 29. Médias estimadas para REA-L. .115

Tabela 30. Comparações entre grupos corrigidas por Bonferroni para REA-L .115

Tabela 31. Médias estimadas para REA-R 116

Tabela 32. Comparações entre grupos corrigidas por Bonferroni para REA-R.. .117 


\section{Lista de abreviaturas}

5-ALA 5 Aminolevulinic Acid

AAALAC Association for Assessment and Acreditation of Laboratory Animal Care International

AC Área de Máximo Contato

AU Unidades Arbitrárias

AMP Adenosine Monophosphate

AP Azul de Prússia

ATP Adenosine Triphosphate

C6 - Luc Células C6 com gene de Luciferase

CBTRUS Central Brain Tumor Registry Of The United State

CF Citometria de Fluxo

CiP Ciclo do Passo

CMA Campo Magnético Alternado

CoP Comprimento do Passo

DLS Dynamic Light Scattering

DMEM Dulbecco's Modified Eagle Medium

DNA Deoxyribonucleic Acid

DOX Doxorrubicina

DPA/P Distância Patas Anteriores ou Posteriores

DP Distância entre Patas Posteriores

Dpi Distância entre Patas Ipsilaterais

$E_{K} \quad$ Energia de Anisotropia Magnética

ExMF External Magnetic Field

FSR Fractionated Stereotactic Radiosurgery

HE Hematoxilina e Eosina

HSP 70 Heat Shock Proteins - 70 kilodalton

ID Ímã Dinâmico

IE Ímã Estático

IGRT Image Guided Radiation Therapy

ILP Intrinsic Loss of Power

IMRT Intensity Modulated Radiation Therapy 


$\begin{array}{ll}\text { IRM } & \text { Imagem por Ressonância Magnética } \\ \text { LuC } & \text { Luciferase } \\ \text { MHT } & \text { Terapia por Magneto Hipertermia } \\ \text { MOV-L } & \text { Movimento espontâneo Lento } \\ \text { MOV-R } & \text { Movimento espontâneo Rápido } \\ \text { MSCV } & \text { Mesenchymal Stem Cell } \\ \text { NK } & \text { Células Natural Killer } \\ \text { Nm } & \text { Nanômetros } \\ \text { NSOF } & \text { Nanopartículas Superparamagnéticas de Óxido de Ferro } \\ \text { OMS } & \text { Organização mundial da saúde } \\ \text { PAD } & \text { Pata Anteior Direita } \\ \text { PAE } & \text { Pata Anterior EsquerdaPAS - Periodic Acid Schiff } \\ \text { PD's } & \text { Patas Direitas } \\ \text { PEG } & \text { Polietilenoglicol } \\ \text { PE'S } & \text { Pata Esquerdas } \\ \text { PFA } & \text { Paraformaldeído } \\ \text { PI } & \text { Propidium lodeto } \\ \text { PLL } & \text { Poly-L-Lysine } \\ \text { PPD } & \text { Pata Posterior Direita } \\ \text { PPE } & \text { Pata Posterior Esquerda } \\ \text { PPi } & \text { Pirofosfato } \\ \text { PS } & \text { Phosphatidylserine } \\ \text { PVA } & \text { Polyvinyl Alcohol } \\ \text { RARE } & \text { Rapid Acquisition with Relaxation Enhancement } \\ \text { RE } & \text { Retículo Endoplasmático } \\ \text { REA-L } & \text { Rearing - Lento } \\ \text { REA-R } & \text { Rearing - Rápido } \\ \text { RNA } & \text { Ribonucleic Acid } \\ \text { SAR } & \text { Specific Absorption Rate } \\ \text { SFB } & \text { Soro Fetal Bovino } \\ \text { SI } & \text { Sem Ímã } \\ \text { SNC } & \text { Sistema Nervoso Central } \\ \text { SPION } & \text { Superparamagnetic Iron Óxide Nanoparticles } \\ \text { SRS } & \text { Stereotactic Radiosurgery } \\ & \end{array}$


STEA-L Stereotyped Moviments - Lento

STEA-R Stereotyped Moviments - Rápido

$T_{B} \quad$ Tempo de Relaxação Browniana

TC Tempo de Contato

TE Tempo Eco

TMZ Temozolomida

$T_{N} \quad$ Tempo de Relaxação Néel

TNF-a Tumor Necrosis Factor - Alpha

TR Tempo de Repetição

TTA-TNBC Tissue Analogs-Triple negative Breast Cancer

VEGF Vascular Endothelial Growth Factor 


\section{Resumo}

Objetivos: Avaliar a eficiência da técnica de magneto hipertermia por meio da técnica de bioluminescência, no tratamento de glioblastoma em modelo animal, administrando nanopartículas superparamagnéticas de óxido de ferro para auxiliar na lise celular tumoral. Métodos: Foram obtidas curvas de potencial de aquecimento por magneto hipertermia de amostras coloidais de nanopartículas de óxido de ferro com diferentes coberturas (aminosilana, dextrana, quitosana e starch) em diferentes tamanhos (50, 100 e 200nm), expostas à três intensidades de campo magnético (50, 150 e 300 gauss) e duas frequências (305 e $551 \mathrm{kHz}$ ) para aquisição de valores da taxa de absorção específica. Após a aquisição dos valores de taxa de absorção específica, as células C6 com luciferase foram marcadas com as duas nanopartículas de óxido de ferro que obtiveram maior potencial de aquecimento sob 3 condições de marcação magnética (sem ímã, com ímã estático e dinâmico), com e sem poli-lisina para transfecção celular e filtro $0,45 \mu \mathrm{m}$. As células foram submetidas a duas condições de exposição à magneto hipertermia (44 e $48^{\circ} \mathrm{C}$ por $40 \mathrm{~min}$ ) e avaliadas por citometria de fluxo e bioluminescência para análise de eficiência terapêutica in vitro. A volumetria dos tumores induzidos por estereotaxia em ratos Wistar foi realizada mediante imagem por ressonância magnética e bioluminescência. Conjuntamente foram realizados estudos comportamentais destes animais para analisar as alterações motoras de marcha e locomoção espontânea gerada pela indução tumoral. Em seguida, os animais foram submetidos à magneto hipertermia por 40 minutos e analisados por bioluminescência. Resultados: Os melhores parâmetros técnicos para aplicação de magneto hipertermia determinados foram: intensidade de campo magnético de 300 gauss e frequência de campo de $551 \mathrm{kHz}$, com maior valor de taxa de absorção específica gerado por nanopartículas de óxido de ferro com cobertura de aminosilana e diâmetro de 100nm. Em magneto hipertermia in vitro, observou-se viabilidade celular tumoral de $31,11 \mathrm{e}$ $20,86 \%$ por bioluminescência e 65,7 e 75,2\% de morte celular analisada por citometria de fluxo após realização de magneto hipertermia por 40 minutos em 44 e $48^{\circ} \mathrm{C}$, respectivamente. Nas análises in vivo, foi observada alteração de marcha no grupo tumoral como: decaimento de comprimento de passo, área de máximo contato e distâncias entres patas, aumento do tempo de contato da pata, ciclo de passo e duração do percurso com diminuição de cadência. Houve diminuição de movimentos 
do grupo tumoral nas análises de locomoção espontânea por Actômetro. A viabilidade celular tumoral por bioluminescência após magneto hipertermia por 40 minutos foi de 67,2\%. Conclusão: A terapia por magneto hipertermia mostrou eficiência na morte de células tumorais C6-Luc tanto em estudos in vitro como in vivo. 


\section{INTRODUÇÃo}

O glioblastoma é um tumor cerebral maligno originado de célula glial e corresponde a $45,6 \%$ de todos os tumores malignos primários, ${ }^{(1)}$ acometendo em grande parte a faixa etária de 45 a 65 anos, afetando mais homens que mulheres, e uma vez em crescimento, a terapêutica deste tumor ainda representa um grande desafio, pois as células tumorais possuem crescimento rápido e agressivo e apesar dos diagnósticos e terapias existentes, seu limitado prognóstico visa retardar o processo de crescimento tumoral e melhorar a qualidade de vida do paciente, principalmente em relação às alterações neurológicas geradas pelo tumor. ${ }^{(2,3)}$

Entre as terapias convencionais utilizadas no tratamento de glioblastoma há a cirurgia, radioterapia e quimioterapia. ${ }^{(4)} \mathrm{A}$ cirurgia consiste em retirar o tumor, porém, requer bastante cautela, na delimitação da margem de segurança da ressecção da massa tumoral, devido o cérebro ser uma área em que toda a sua extensão é funcional. As cirurgias para glioblastoma são realizadas visando extrair uma maior área possível do tumor para posterior realização de radioterapia e/ou quimioterapia. ${ }^{(5)}$ A radioterapia favorece o tratamento de glioblastoma com exposição tumoral à radiação de forma local. Porém sabe-se que há a possibilidade de geração de sequelas neurocognitivas ocasionadas pela irradiação (principalmente em idosos), pois a mesma além de atingir células tumorais, lesionam células saudáveis próximas a região do tumor. ${ }^{(5)}$ Já a quimioterapia, utiliza fármacos para combater o glioblastoma de forma sistêmica, e age impedindo a replicação celular, porém seus efeitos colaterais podem ser inúmeros além de afetar as células saudáveis. ${ }^{(6)}$

A busca do desenvolvimento de terapias alternativas, minimamente invasivas, que impeçam o crescimento ou até mesmo promovam a destruição destes tumores com eficiência, principalmente com menos efeitos colaterais do que as terapias convencionais, são necessárias para o tratamento deste tipo de tumor, que possui evolução rápida e agressiva. Neste sentido, o método terapêutico de hipertermia induzida por nanopartículas superparamagnéticas de óxido de ferro (NSOF) em tecido tumoral, tem apresentado resultados promissores em diferentes estudos com modelos animais e também estudos em fase II em humanos. ${ }^{(7-10)}$

A técnica de Magneto Hipertermia (MHT) é um procedimento terapêutico que promove o aumento da temperatura de tecidos tumorais com objetivo 
de causar lise dessas células na presença de NSOF. O princípio do método de MHT compreende na administração de um fluído magnético contendo NSOF no interior do tumor para posterior aplicação de um campo magnético alternado (CMA), que promoverá o aquecimento da região tumoral, ${ }^{(11)}$ de forma localizada, pois as NSOF administradas podem ser funcionalizadas por moléculas específicas ou direcionadas de maneira efetiva por campo magnético estático externo ao tecido tumoral, com homogeneidade na distribuição da temperatura, bem como à alta taxa de transferência de calor local na região tumoral, garantindo menor dano ao tecido sadio. ${ }^{(12)} \mathrm{O}$ aumento da temperatura na região tumoral à valores acima de $41^{\circ} \mathrm{C}$, induzem a morte de células tumorais, uma vez que essas células são menos resistentes ao aumento de temperatura do que as células normais adjacentes, ${ }^{(11)}$ por possuírem heterogeneidade do suprimento de oxigênio e da demanda de nutrientes devido excessiva ramificações de vasos sinuosos e ausência de tecido linfático. ${ }^{(13)}$ Esse aumento de temperatura altera o funcionamento de muitas proteínas estruturais e enzimáticas nas células tumorais que, por sua vez, alteram a multiplicação e a diferenciação celular induzindo morte das mesmas. ${ }^{(14,15)}$

A eficiência da técnica de MHT é dependente de diferentes propriedades das NSOF, como propriedades físico-químicas, ${ }^{(16-18)}$ magnetização, taxa de absorção específica (SAR - specific absorption rate) e perda de poder intrínseco (ILP - intrinsic loss of power), assim como a intensidade do campo magnético utilizado e a frequência do mesmo. O grande interesse nesta área está em aperfeiçoar os parâmetros da técnica para cada aplicação de interesse, com o intuito de melhorar a eficiência do tratamento. Atualmente alguns estudos preliminares ${ }^{(19,20)}$ abordando o uso clínico da MHT no tratamento de glioblastoma sugerem que as NSOF possuem uma distribuição intratumoral adequada e são capazes de promover o aquecimento controlado, sem causar efeitos colaterais. Esta técnica, quando combinada com outras técnicas como radioterapia e quimioterapia, pode resultar no tratamento do glioblastoma com maior eficiência. ${ }^{(21)}$

Em estudos pré-clínicos visando a implementação da técnica de $\mathrm{MHT}$, a avaliação tem sido realizada por meio de estudos in vitro, in vivo e ex vivo. A eficácia da técnica in vitro, pode ser avaliada por diversas técnicas como ensaios histoquímicos, citometria de fluxo, bioluminescência, Imagem por Ressonância Magnética (IRM), fluorescência, entre outros. ${ }^{(22,23)}$ A IRM e a bioluminescência, permitem também a avaliação in vivo da técnica de MHT, onde a IRM tem como 
objetivo observar a localização de NSOF administradas e o volume tumoral pré e pósterapia por MHT e a bioluminescência avalia a volumetria tumoral pré e pós-MHT em decorrência da resposta das células tumorais transfectadas com gene de luciferase. ${ }^{(24,25)}$ A avaliação in vivo ou ex vivo pode ser realizada por métodos citoquímicos e imuno-histoquímicos. ${ }^{(22,23,26,27)}$

Dessa forma, o presente estudo visou avaliar a eficiência terapêutica da técnica de magneto hipertermia em células tumorais de glioblastoma e em tumores induzidos em modelo animal.

\subsection{Objetivo}

1. Avaliar a eficiência da técnica de magneto hipertermia para o tratamento de glioblastoma induzido pelas células tumorais $\mathrm{C} 6$ transfectadas com gene de Luciferase (C6-LuC) em modelo animal (in vitro, in vivo e ex vivo), utilizando as técnicas de bioluminescência e citometria de fluxo, assim como técnicas citoquímicas e histológicas. 


\section{REVISÃO DA LITERATURA}

Os tumores são uma das principais causas de mortalidade no mundo, afetando um terço dos habitantes de países desenvolvidos. ${ }^{(28)}$ A Central de Registros de Tumor Cerebral dos Estados Unidos (CBTRUS - Central Brain Tumor Registry of The United State) quantificou 326.711 tumores incidentes (112.458 malignos, 214.253 não malignos) em 2013. Aproximadamente 93\% destes, foram em indivíduos com 20 anos ou mais. ${ }^{(29)}$ Os tumores do SNC são o segundo mais comumente ocorridos na faixa etária de 20 a 24 anos, o terceiro mais comum entre os 25-29 anos de idade, o quarto entre os 30-34 e o terceiro câncer mais comumente ocorrido na faixa etária de 35-39 anos no estudo realizado pela CBTRUS em adolescentes e adultos jovens no ano de 2015 (30) $^{(30}$

Estima-se que em 2017 mais de 79.000 novos casos de tumores cerebrais primários devem ser diagnosticados. Aproximadamente um terço ou $32 \%$ dos tumores cerebrais e do SNC serão malignos, incluindo mais de 26.000 tumores malignos primários e 53.000 tumores cerebrais não malignos. ${ }^{(30)}$

O prognóstico de um paciente com câncer está relacionado com vários fatores, tais como: a idade do paciente, a localização e histologia do tumor. Em adultos, cerca da metade de todos os tumores do SNC são malignos, enquanto que em pacientes pediátricos correspondem mais que 75\%. Dos tumores primários do SNC, a grande maioria deste são meningiomas, dos quais mais de $90 \%$ são benignos. Cerca de $10 \%$ dos tumores primários do SNC são encontrados na região da sela turca. Outros sítios menos comuns de tumores primários do SNC incluem a região pineal, sistema ventricular, cerebelo, tronco cerebral, nervos cranianos e medula espinhal. ${ }^{(31)}$

A detecção da classificação histológica dos tumores malignos do SNC tem aumentado na última década, possivelmente devido ao aumento do acesso às técnicas de neuroimagem. ${ }^{(31)}$

Com origem nas células gliais, os gliomas representam mais de $36 \%$ de todos os tumores primários do SNC e consistem em tumores astrocitários, oligodendrogliais, oligoastrocísticos, gliomas mistos, e outros tumores neuroepiteliais incomuns. Os meningiomas benignos compõem 32\% dos tumores primários do SNC, seguido de tumores da bainha nervosa e tumores hipofisários. Linfoma primário, tumores embrionários e craniofaringiomas são incomuns. Os mais comuns são os 
neuroepiteliais de origem glial e estes tumores são tipicamente classificados pela Organização Mundial de Saúde (OMS) como tipos I a IV, sendo o IV o com maior grau de malignidade. O grau IV consiste no glioblastoma, neoplasia maligna de origem glial, mais comum do SNC em adultos. ${ }^{(31)}$

A maioria dos tumores malignos do SNC são de origem glial sendo designados como gliomas, ${ }^{(29)}$ sendo assim qualquer tumor que se origina a partir da estrutura glial do cérebro é chamado de glioma. A estrutura glial do SNC é formada pelos astrócitos, oligondendrócitos, células ependimais e microglia conforme mostrado na figura 1. Os gliomas fazem parte do grupo dos tumores neuroepiteliais e correspondem a mais de $36 \%$ dos todos os tumores e $80 \%$ dos tumores malignos do SNC. ${ }^{(29,31)}$

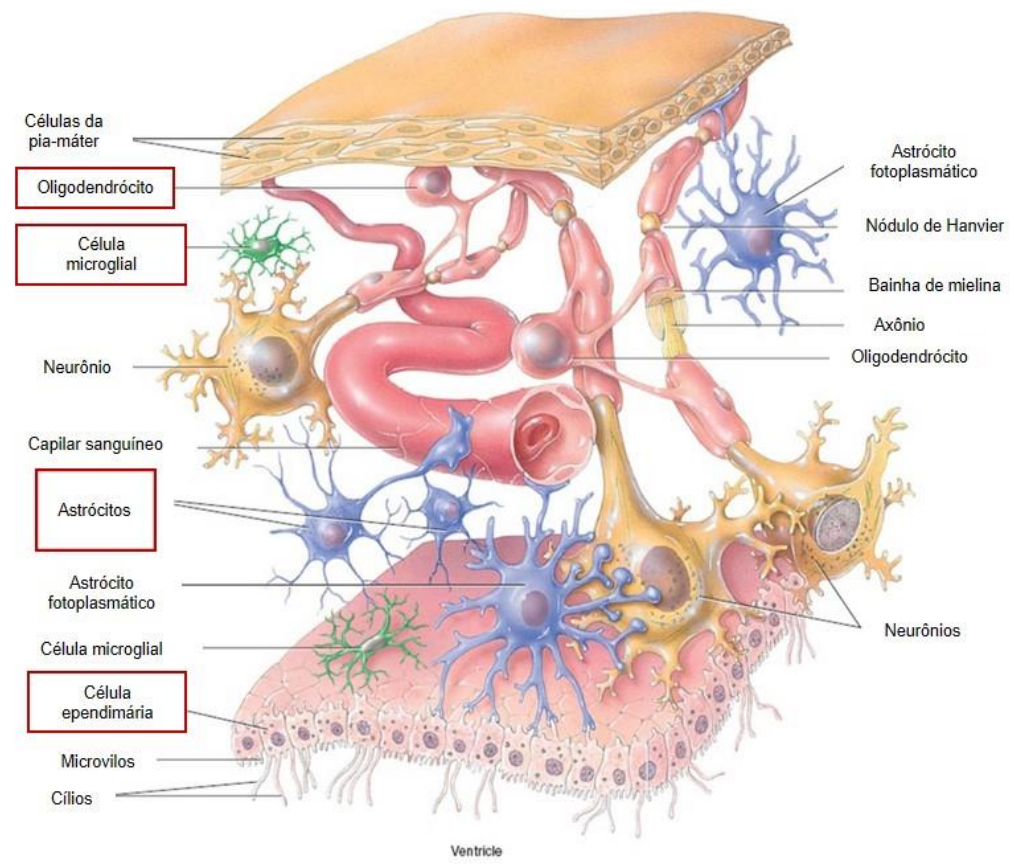

Fonte: Traduzido de Neuroglia of the central nervous system [Internet]. New York: John Wiley \& Sons; 2011 [cited 2017 Jun 13]. Available from: http://higheredbcs.wiley.com/legacy/college/tortora/0470565101 /hearthis_ill/pap13e_ch12_illustr_audio_mp3_am/simulations/h ear/neuroglia.html ${ }^{(32)}$

Figura 1. Células que compõem a neuroglia

Os gliomas são classificados conforme a severidade, malignidade, característica celular, prognóstico e são divididos em quatro graus: I e II que são de baixo grau e III e IV que são de alto grau. O de grau I é considerado benigno e sua completa excisão é curativa e são comumente diagnosticados em crianças. Os de grau 
II são considerados benignos, porém com incidência de recorrência, por isso precisam ser monitorados. O astrocitoma anaplásico é considerado o grau III, com capacidade de infiltração maligna e focal ou dispersa anaplasia. O glioblastoma é definido como o grau IV de tumores da glia, sendo o mais maligno e originado de astrócitos gliais, possuindo rápido crescimento e alta malignidade tumoral. ${ }^{(2)}$

O glioblastoma corresponde a especificamente a $54,7 \%$ dos casos de tumores originados de células da glia, como está representado na figura 2 acometendo em grande parte a faixa etária de 45 a 65 anos, afetando mais homens que mulheres, e uma vez em crescimento, este tumor é altamente difícil de tratar, devido seu crescimento rápido e agressivo. Apesar dos diagnósticos e terapias existentes, seu prognóstico visa retardar o processo de crescimento tumoral e melhorar a qualidade de vida do paciente, principalmente em relação às alterações neurológicas geradas pelo tumor. ${ }^{(2,3)}$

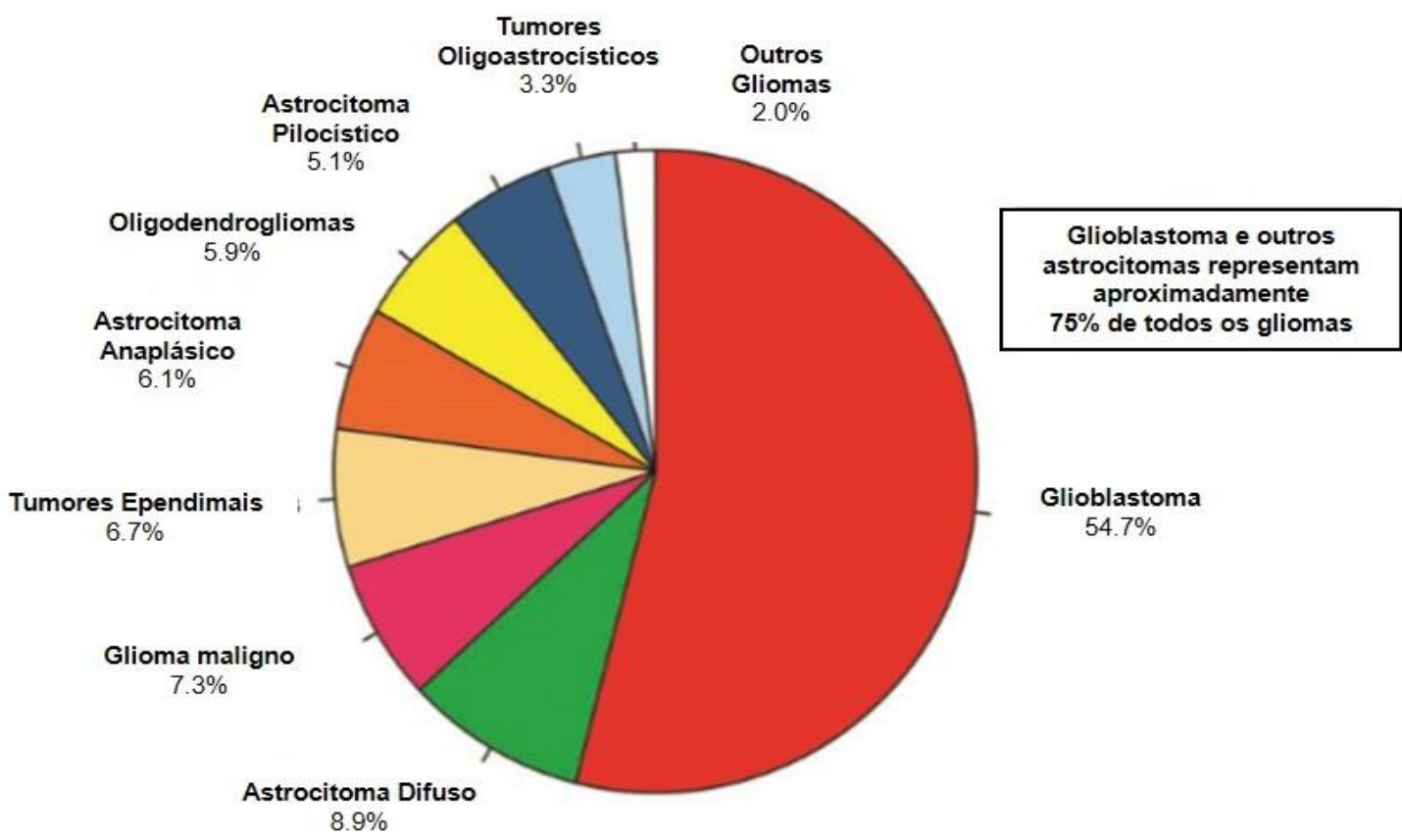

Fonte: Traduzido de Ostrom QT, Gittleman H, Liao P, Rouse C, Chen Y, Dowling J, et al. CBTRUS statistical report: primary brain and central nervous system tumors diagnosed in the United States in 2007-2011. Neuro Oncol. 2014;16 Suppl 4:iv1-63. Figure 10, Distribution of primary brain and CNS gliomas by histology subtypes $(N=96,448)$, CBTRUS statistical report: NPCR and SEER, 2007-2011; p. iv12 $2^{(1)}$

Figura 2. Tumores originados da glia

As características histológicas que distinguem o glioblastoma a partir de todas as outras classes de glioma são a presença de necrose (células mortas) e 
aumento de vasos sanguíneos em todo o tumor. Tumores de grau IV como o glioblastoma estão sempre em rápido crescimento e são altamente malignos. ${ }^{(4)}$ Essa capacidade de crescimento e malignidade pode se dar pelo fato de que os astrócitos, que são as células que originam o glioblastoma, estão em contato com os vasos sanguíneos de onde absorvem nutrientes e oxigênio, conforme observado na estrutura de neuroglia mostrada na figura 2, possuindo assim condições favoráveis para ter a capacidade de realizar angiogênese de forma rápida. ${ }^{(33)}$

A causa do glioblastoma e de outros tipos de tumores cerebrais é desconhecida. Estudos identificaram anormalidades gênicas de diversos cromossomos que podem desempenhar um papel no desenvolvimento de tumores. ${ }^{(34)}$ No entanto, o que gera essas anormalidades ainda é incerto. A maioria dos tumores cerebrais não é hereditária, porém algumas síndromes genéticas podem favorecer a formação de tumores cerebrais, tais como neurofibromatose, Li-Fraumeni, Von Hippel-Lindau, Turcot e Esclerose tuberosa, afetando apenas $5 \%$ dos pacientes. ${ }^{(3)}$

Devido às incertezas sobre a origem do câncer e da necessidade de novos métodos para diagnóstico e terapia de tumores cerebrais, se fazem necessários mais estudos sobre os mesmos.

\subsection{Modelos experimentais de origem glial em modelo animal}

Modelos pré-clínicos de tumores do SNC têm auxiliado na melhor compreensão do desenvolvimento tumoral em diferentes modelos e tipos de tumores. Com a necessidade de estratégias terapêuticas mais eficazes para tumores de células da glia, tem se desenvolvido modelos experimentais que simulam o crescimento tumoral com características específicas, pois esses modelos experimentais são induzidos com células que são imunologicamente compatíveis com o animal e com características tumorais específicas. ${ }^{(35,36)}$

Várias linhagens de células têm sido usadas em pesquisa pré-clínica para o estudo de tumores de origem glial, como: U251, U86, GL261, C6, 9L e CNS-1, além de T9, RG2, F98, BT4C, com suas respectivas características celulares conforme tabela $1 .^{(37,38)}$ 
Tabela 1. Tipos de linhagens celulares de tumores gliais e suas características

\begin{tabular}{cl} 
Linhagem celular & \multicolumn{1}{c}{ Características } \\
U251 & Padrão infiltrativo no parênquima, focos de necrose, endotélio \\
& hipertrófico, pleomorfismo celular, células gigantes multinucleadas, \\
& $\begin{array}{l}\text { atipia e focos de edema e hemorragia. Modelo usado em estudo de } \\
\text { crescimento de massa tumoral. }\end{array}$
\end{tabular}

Modelo com clara demarcação do parênquima normal sem infiltração difusa, com p53 do tipo selvagem, células atípicas,

U86 neovascularização, focos necróticos, vasos tumorais homogêneos e com maior permeabilidade. Utilizado em estudos de expressões gênicas tumorais.

Possuem células mal diferenciadas com característica invasiva, GL261 espessamento endotelial, áreas de angiogênese e hipóxia. Utilizado em estudo de terapias baseadas em imunidade.

Células pleomórficas com núcleos de forma variável e crescimento focal. Áreas de necrose e altas taxas de mitose, respostas imunogênicas e assemelha-se aos relatados em tumores cerebrais C6 humanos. Utilizado em estudos de crescimento, invasão, migração, neovascularização e regulação do fator de crescimento tumoral e avaliação de respostas terápicas em tumores cerebrais.

Gliosarcoma - Crescimento rápido, com células em forma de fuso, 9L margens delineadas com pouca invasão. Tem gene p53 mutante. Usado na avaliação de drogas, farmacocinética e resistência celular.

Padrão infiltrativo de crescimento, com disseminação periventricular e extensão do tumor para o plexo coróide. Exibem hipercelularidade, CNS-1 atipia nuclear e pleomorfismo, focos necróticos e extensa infiltração por macrófagos. Utilizado para avaliar imunidade no crescimento tumoral de gliomas.

T9 quimioterápicos.

Anaplásico ou indiferenciado, padrão invasivo de crescimento, expressam p53 de tipo selvagem. Não imunogênico em ratos Fischer

RG2 singênicos. Usados em estudos pré-clínicos para avaliar as alterações de permeabilidade vascular.

Células em forma de fuso, núcleos fusiformes, e um menor número de células poligonais com núcleos ovais. Extensa invasão formando

F98 concentrações perivasculares. Padrão invasivo e agressivo de crescimento e baixa imunogenicidade. Utilizado para avaliar eficácia de uma variedade de agentes terapêuticos experimentais.

Mistura de células achatadas com processos citoplasmáticos e células gigantes ocasionais, alta celularidade com núcleos pleomórficos e

BT4C numerosas áreas mitóticas. Os vasos são irregulares, dilatados e apresentam áreas de proliferação. Usado para testar novas estratégias de direcionamento quimioterapêutico.

Um dos modelos de glioblastoma baseia-se na administração de células C6 em ratos Wistar. A linhagem celular C6 foi desenvolvida na década de 1960 em ratos Wistar Furth. Embora originalmente desenvolvido em ratos Wistar, C6 pode 
ser implantado em ratos Long-Evans machos e Sprague-Dawley, sem rejeição. ${ }^{(37)}$ Quando as células são inoculadas no cérebro de ratos Wistar, elas exibem características de crescimento com pleomorfismos, incluindo locais de hemorragia e necrose, além de uma alta taxa de mitose, e neovascularização, características estas, que conduziram o uso da linhagem C6 para o estudo de glioblastoma. ${ }^{(35,37,39)}$

No modelo animal, o rato é o mais utilizado em estudos pré-clínicos, pois as dimensões do seu cérebro em comparação com o cérebro de camundongo são de aproximadamente de $1200 \mathrm{mg}$ versus $400 \mathrm{mg}$, o que permite a implantação de uma quantidade maior de células, utilização de um intervalo mais longo de tempo até a eutanásia, maiores análises diagnósticas e terapêuticas no animal e, além disso, possui um crânio com região óssea de maior largura o que delimita o crescimento externo à calota craniana, ${ }^{(38)}$ fator favorável no estudo de glioblastoma, devido seu crescimento rápido e agressivo.

\subsection{Terapias para o tratamento de glioblastoma}

\subsubsection{Terapias convencionais}

As terapias convencionais mais utilizadas no tratamento de glioblastoma consiste em cirurgia, quimioterapia e radioterapia. ${ }^{(4)}$

\subsubsection{Cirurgia}

A cirurgia representa o primeiro passo no tratamento de glioblastoma. Os objetivos da cirurgia são a obtenção de tecido tumoral para o planejamento diagnóstico (com biópsia) e tratamento, para realizar o máximo possível de ressecção do tumor dentro da limitação e localização possível, bem como para reduzir os sintomas causados pela presença da massa tumoral. Alguns tumores não podem ser completamente removidos devido sua localização, portanto a remoção do tumor é realizada para diminuir edemas no cérebro ou para reduzir atividades convulsivas. $^{(3)}$ 


\subsubsection{Quimioterapia}

Os fármacos antineoplásicos mais empregados incluem os alquilantes polifuncionais e os inibidores mitóticos. Os alquilantes, afetam a replicação celular em todas as fases do ciclo celular tornando-as células incapazes de se reproduzir, como por exemplo: a ciclofosfamida, ${ }^{(40)}$ a Carmustina (BCNU ou Gliadel), Lomustina (CCNU), Temozolomida (Temodal), Procarbazina, Cisplatina, Carboplatina e o Irinotecano. ${ }^{(3)}$ Os antimetabólitos inibem a biossíntese dos componentes essenciais do ácido desoxirribonucleico (DNA - Deoxyribonucleic Acid), impedindo a multiplicação da célula. Esta inibição da biossíntese pode ser dirigida às purinas (como é a ação dos quimioterápicos 6-mercaptopurina e 6-tioguanina), são particularmente ativos contra células que se encontram na fase de síntese do ciclo celular (fase S). Já os inibidores mitóticos podem paralisar a mitose na metáfase, devido à sua ação sobre a proteína tubulina, formadora dos microtúbulos que constituem o fuso espiralar, pelo qual migram os cromossomos. Deste modo, os cromossomos, durante a metáfase, ficam impedidos de migrar, ocorrendo a interrupção da divisão celular. ${ }^{(40)}$ Os tipos de antineoplásicos podem também ser combinados na quimioterapia objetivando o aumento de sua eficácia. $^{(3)}$

\subsubsection{Radioterapia}

A radioterapia focal fracionada (60 Gy, 30 - 33 frações de 1,8 - 2 Gy, ou doses / frações equivalentes) é o tratamento padrão após ressecção ou biópsia tumoral. Em pacientes idosos com glioblastoma ou pacientes com baixo desempenho cognitivo, são normalmente propostos regimes hipofracionados mais curtos (por exemplo, 40 Gy em 15 frações). ${ }^{(41)}$ Existem diferentes tipos de administração de radiação, utilizando várias doses e com diferentes escalas de tempo entre a aplicação de uma dose e outra, ${ }^{(42)}$ como:

- Radiação com fótons, também conhecida como a radioterapia de intensidade modulada (IMRT - Intensity Modulated Radiation Therapy) ou 2-D e 3-D radiação terapêutica com modulação de feixes de radiação para corresponder à forma e o tamanho do tumor; 
- Radioterapia guiada por imagem (IGRT - Image Guided Radiation Therapy), a aquisição da imagem durante o tratamento auxilia no direcionamento exato da posição do tumor;

- Radiação intersticial, que pode estar sob a forma de radiação sólida ou líquida, podendo ser implantada no interior do tumor durante a cirurgia;

- Radiocirurgia estereotáxica (SRS - Stereotactic Radiosurgery) e radiocirurgia fraccionada (FSRs - Fractionated Stereotactic Radiosurgery) que são formas especiais de radiação direcionada com aplicação de doses elevadas, distribuídas em tumores de pequenas dimensões, caracterizando como um tratamento de dose única ou de tratamento fraccionado ao longo de quatro a cinco dias. ${ }^{(5)}$

\subsubsection{Terapias alternativas}

As terapias alternativas consistem em práticas terapêuticas que não fazem parte do processo convencional de tratamento, visando auxiliar ou potencializar o mesmo, gerando assim alternativas para otimização de terapias contra o glioblastoma e outros tumores cerebrais. Vários estudos estão sendo realizados com o objetivo de tornar as células tumorais mais sensíveis à radioterapia como, por exemplo, os transportadores de fármacos radioativos, a realização de quimioterapia durante a radioterapia e o uso de fármacos que aumentam os níveis de oxigênio no cérebro. ${ }^{(3)}$ Nessa busca por terapias mais eficazes e com menos efeitos colaterais, várias vertentes terapêuticas têm surgido, como o uso de bactérias carreadoras de quimioterápicos que liberam fármaco em região tumoral de forma local, ${ }^{(43)}$ Temsirolímus (CCl-779) que é um inibidor de molécula alvo da Rapamicina (mTOR), importante via de sinalização de crescimento celular, ${ }^{(44)}$ o uso alternado de campos elétricos, com uma frequência especificamente sintonizada para penetrar as células tumorais, promovendo a parada do ciclo celular, demonstrando uma melhoria significativa na sobrevida livre de progressão tumoral em pacientes com

glioblastoma, ${ }^{(41,45)}$ terapia para tumor recorrente fazendo o uso de Bevacizumab, um anticorpo monoclonal bloqueador do fator de crescimento endotelial vascular (VEGF Vascular Endothelial Growth Factor), podendo ser administrado em combinação com Irinotecano, ${ }^{(46,47)}$ imunoterapia e formulações moleculares de controle genético, ${ }^{(48-50)}$ terapia por magneto hipertermia em que há a elevação de temperatura na área tumoral 
gerando a morte de células tumorais, além de ser utilizada para auxiliar a entrega de drogas quimioterápicas ${ }^{(51-53)}$ e estudos de proteínas de choque térmico de 70 quilodalton (HSP 70 - Heat Shock Proteins - 70 kilodalton). ${ }^{(23)}$

\subsubsection{Técnica de magneto hipertermia}

A técnica de MHT é realizada após o diagnóstico tumoral, administrando de forma intratumoral ou vascular um fluído magnético composto por NSOF como é mostrado na figura 3A. Após a administração do fluído, é realizada a aquisição de imagem por ressonância magnética para verificar localização das NSOF (Figura 3B). Posteriormente é aplicado um CMA que causará a agitação das NSOF, consequentemente gerando um aumento de temperatura local promovendo lise das células (Figura 3C) ao atingir a faixa de temperatura terapêutica (41 - 43ํㅡ) (Figura 4), possibilitando assim o tratamento do tumor (Figura 3D). ${ }^{(51,54,55)}$ 


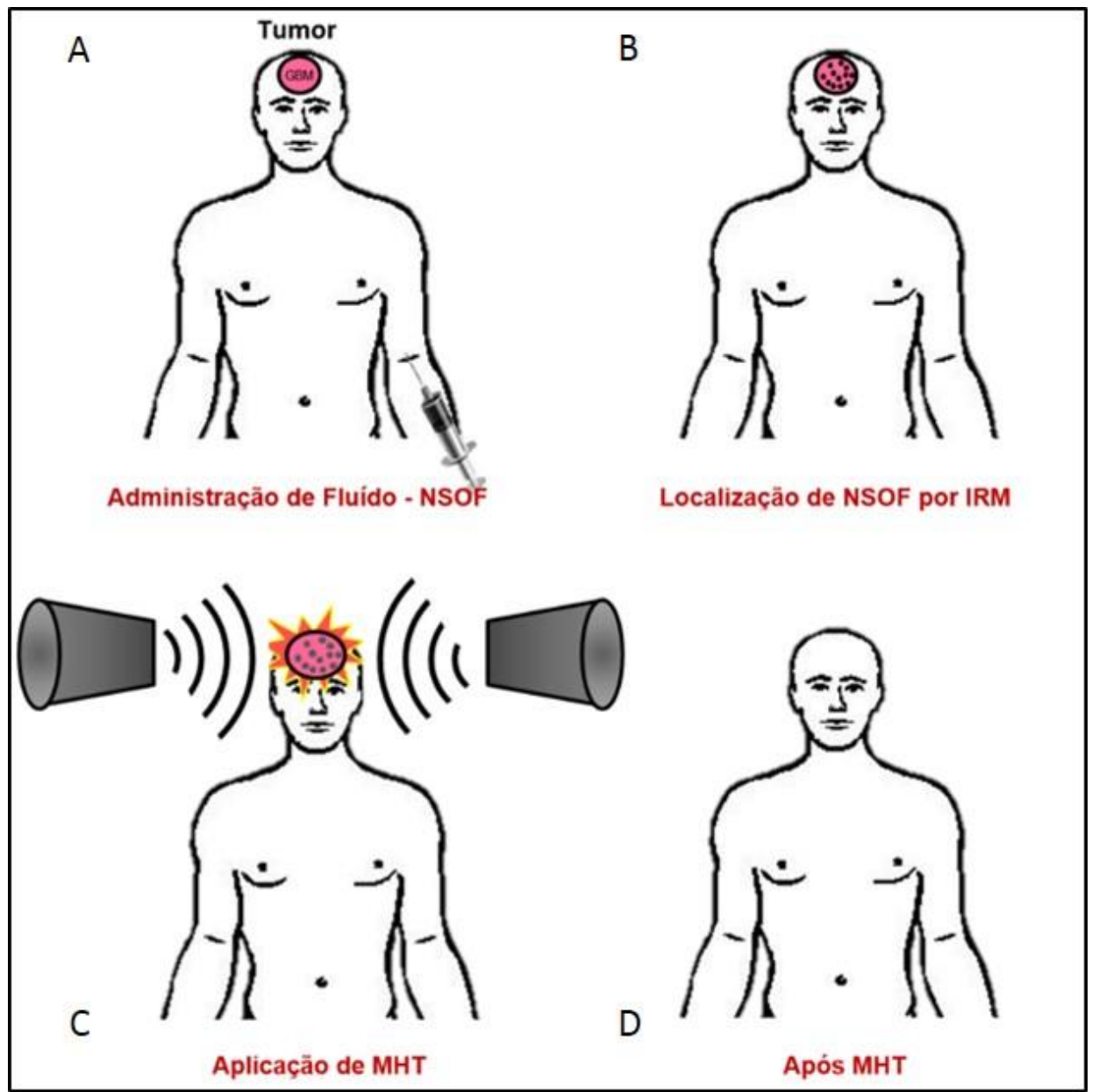

NSOF: nanopartículas superparamagnéticas de óxido de ferro; IRM: imagem por ressonância magnética; MHT: magneto hipertermia. Administração de nanopartículas superparamagnéticas de óxido de ferro (A); visualização das nanopartículas mediante imagem por ressonância magnética (B); aplicação de magneto hipertermia em região tumoral (C); tratamento realizado no tumor (D).

Figura 3. Imagem esquemática do processo de magneto hipertermia

Apesar do gráfico das fases da hipertermia determinar 41 a $43^{\circ} \mathrm{C}$ como faixa terapêutica sem gerar toxicidade às células sadias (Figura 4), vários estudos abordam faixam superiores à $43^{\circ} \mathrm{C}$; a aplicação de magneto hipertermia por 20 minutos em $46^{\circ} \mathrm{C}$; ${ }^{(56)}$ outro estudo de $\mathrm{MHT}$ com $44^{\circ} \mathrm{C}$ por 20 minutos, em que observou-se ausência de danos relevantes no tecido saudável e $20 \%$ de necrose no tecido tumoral; ${ }^{(54)} \mathrm{MHT}$ por $60^{\circ} \mathrm{C}$ com tempo de exposição de 2 minutos. ${ }^{(57)} \mathrm{Em}$ humanos, um estudo detectou que a aplicação de MHT com temperaturas entre 42 a $45^{\circ} \mathrm{C}$ foi segura. ${ }^{(52)}$ 


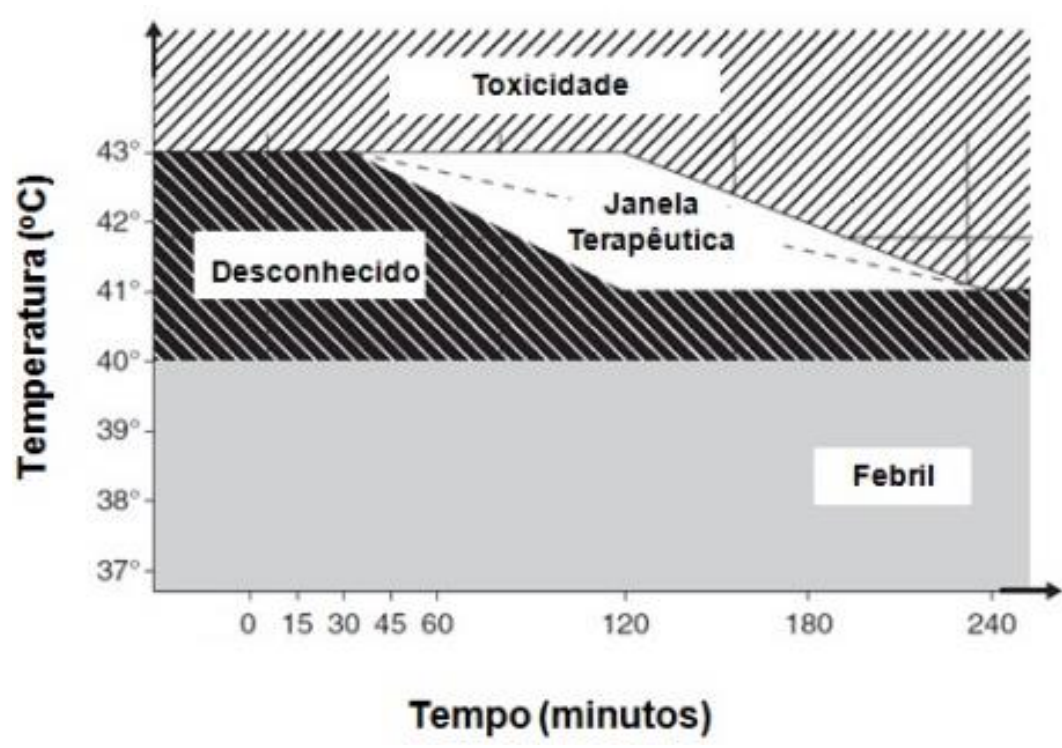

Fonte: Miotello A. Nanocápsulas contendo selol e fluído magnético: preparação, caracterização e avaliação da atividade antitumoral in vitro [dissertação]. [Ribeirão Preto]: Universidade de São Paulo, Faculdade de Ciências Farmacêuticas; 2011. Figura 8, Fases da hipertermia (Adaptado de Vertress, 1999); f. 17. ${ }^{(58)}$

Figura 4. Fases da hipertermia e a sua janela terapêutica

O fluído magnético contendo NSOF utilizado em MHT pode ser administrado: i) NSOF sem moléculas específicas de reconhecimento tumoral, ii) NSOF com acoplamento de moléculas específicas para alvejamento tumoral ou iii) utilizando um campo magnético externo de frequência constante para direcionamento das NSOF para região tumoral. ${ }^{(16,21)}$ Neste último caso, existem diversas estratégias como é mostrado na figura $5 \mathrm{~A}-\mathrm{B}$. Esta pesquisa de estratégias foi realizada como parte do presente trabalho e que resultou em um artigo científico publicado. ${ }^{(59)}$ 


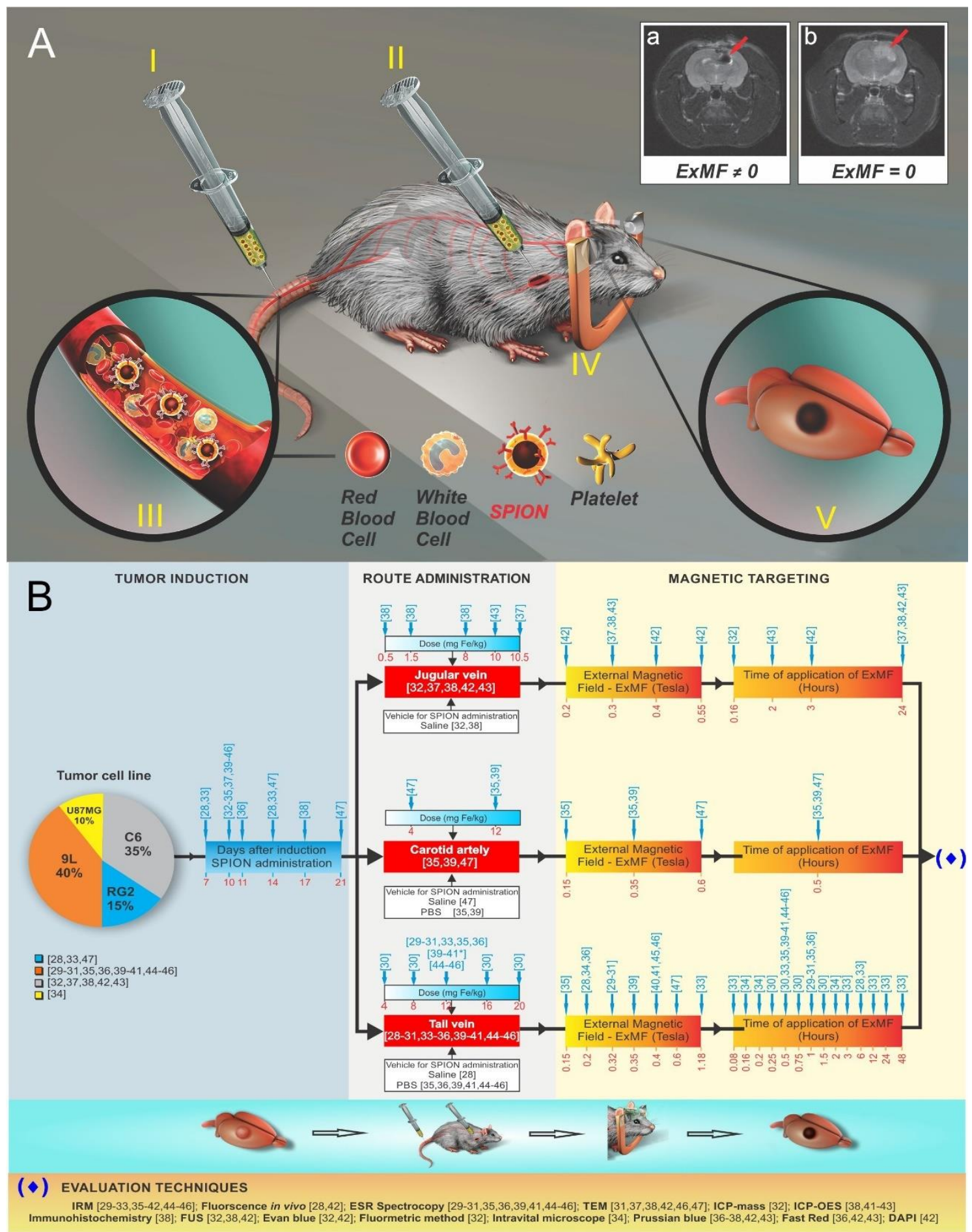

(A) Administração caudal (I) ou pela carótida (II), transporte (III). ExMF: campo magnético externo (external magnetic field) aplicado para direcionar os SPION ao tumor (IV), que são concentrados no tecido tumoral (V). Ressonância magnética mostrando acumulação SPION (Seta) no tumor com (a) e sem (b) ExMF; (B) detalhe das estratégias que são utilizados para direcionamento dos SPION ao tumor.

Fonte: Aguiar MF, Mamani JB, Felix TK, Reis RF, Silva HR, Nucci LP, et al. Magnetic targeting with superparamagnetic iron oxide nanoparticles for in vivo glioma. Nanotechnol Rev. 2017;6(5):449-72. ${ }^{(59)}$

Figura 5. Representação de direcionamento magnético in vivo usando nanopartículas superparamagnéticas de óxido de ferro (SPION) 
A característica essencial da técnica de MHT é que a energia liberada pelas NSOF transformada em calor é absorvida pelo tecido tumoral a partir da ação do CMA por meio da reversão da magnetização (quando o momento magnético da NSOF tende a se alinhar na direção do CMA) e da rotação nuclear ou total das NSOF. ${ }^{(60)}$

Quando expostas a um CMA, as NSOF geram calor por um ou mais dos seguintes mecanismos: histerese magnética, relaxação Browniana e relaxação Néel.

A histerese magnética ocorre quando ao expor uma nanopartícula magnética à um CMA, a mesma procura se alinhar ao vetor magnético, não perdendo facilmente essa magnetização quando o CMA volta ao valor zero (coercividade magnética), a não ser quando posteriormente são expostas a um CMA com sentido contrário ao sentido da magnetização, ${ }^{(17)}$ ou seja, se a relação entre a intensidade do CMA e a magnetização é conduzida para níveis crescentes de intensidade de campo, a magnetização aumentará até um ponto e, em seguida, saturará. Esta condição é chamada de saturação magnética (quando todos os momentos magnéticos estão alinhados com o campo). Se o campo magnético for agora reduzido linearmente, haverá um deslocamento da curva de magnetização chamado de 'loop', devido a magnetização remanescente. Em NSOF, não há geração de curvas de histerese magnética com valores significativos e a energia remanescente e coercividade são próximos à zero. ${ }^{(61,62)}$

A perda de energia em materiais superparamagnéticos depende do processo de relaxação dos momentos magnéticos. A relaxação é a resposta de movimento de rotações de NSOF e/ou de seus momentos magnéticos de um estado de repouso para outro estado em um período de tempo de segundos. Como citado anteriormente, essa relaxação pode ser do tipo Browniana ou de Néel. ${ }^{(63,64)}$

A relaxação Browniana $\left(T_{B}\right)$, consiste quando se tem a rotação da nanopartícula como um todo após ser exposta a um campo magnético (B) (Figura 6). Para ocorrer a relaxação Browniana, há a dependência dos seguintes fatores: viscosidade do fluxo magnético utilizado, volume hidrodinâmico da NSOF, anisotropia da mesma e da temperatura. ${ }^{(65,66)}$ 


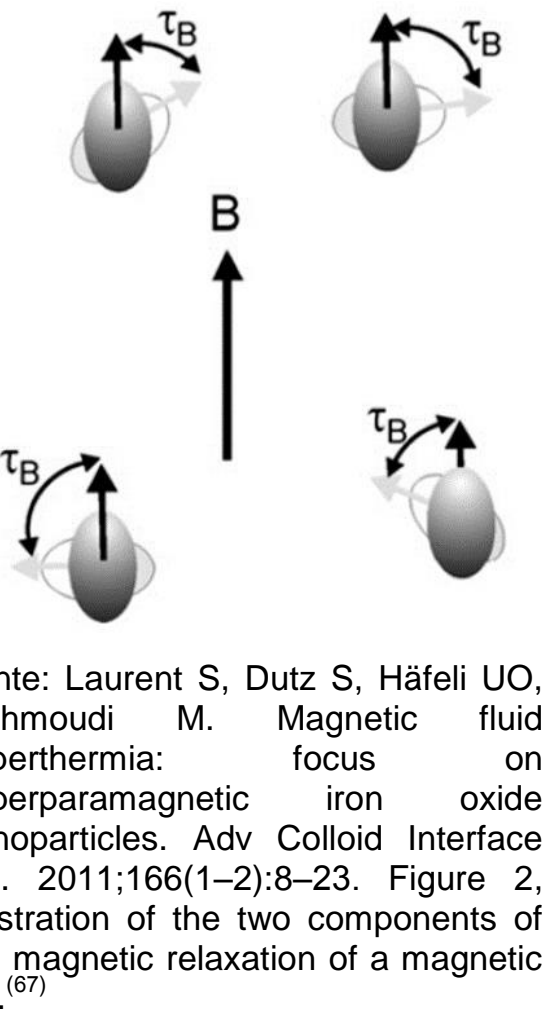

Fonte: Laurent S, Dutz S, Häfeli UO, Mahmoudi M. Magnetic fluid hyperthermia: focus on superparamagnetic iron oxide nanoparticles. Adv Colloid Interface Sci. 2011;166(1-2):8-23. Figure 2, Illustration of the two components of the magnetic relaxation of a magnetic flui. ${ }^{(67)}$

Figura 6. Relaxação Browniana

A forma funcional para a relaxação Browniana é mostrada na equação 2.1:

$$
T_{B}=\frac{3 \eta V_{H}}{\mathrm{kT}}
$$

Onde $T_{B}$ é o tempo de relaxação Browniana, $\eta$ a viscosidade do fluido e $V_{H}$ é o volume hidrodinâmico, $k$ constante de Boltzmann e $T$ a temperatura.

A relaxação Néel $\left(T_{N}\right)$, consiste quando há somente a rotação nuclear (momento magnético) da nanopartículas magnética após ser exposta a um CMA (Figura 7). Para ocorrer a relaxação Néel, há a dependência dos seguintes fatores: constante de Boltzmann, volume do núcleo da NSOF, da relaxação Néel inicial, da anisotropia da NSOF e da temperatura. ${ }^{(65)}$ 


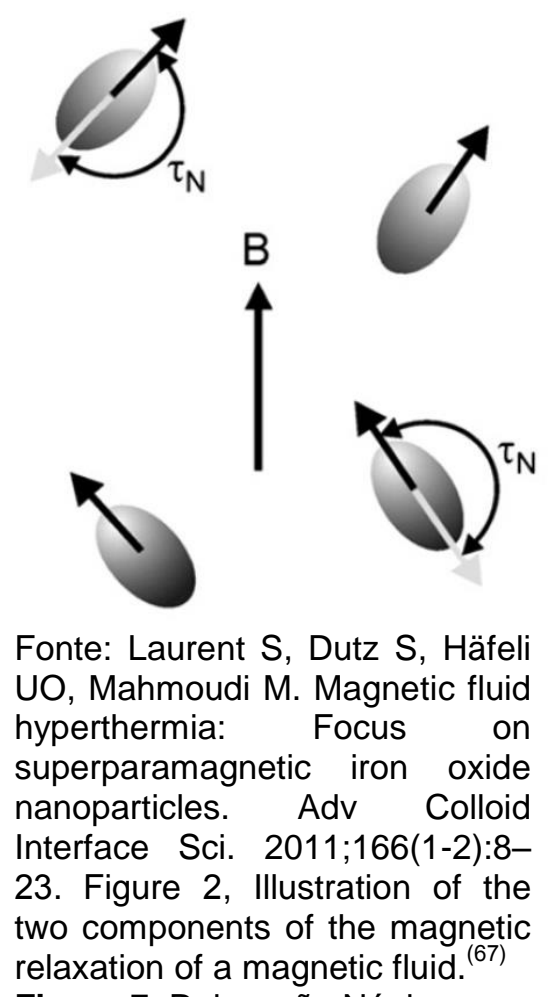

Figura 7. Relaxação Néel

A forma funcional para a relaxação Néel é mostrada na equação 2.2:

$$
T_{N}=T_{0} e^{\frac{K V_{M}}{k T}}
$$

Onde $T_{N}$ é o tempo de relaxação Néel, $T_{0}$ tempo inicial de relaxação, $\mathrm{K}$ constante de anisotropia, $\mathrm{V}_{\mathrm{M}}$ é o volume da nanopartícula, $\mathrm{k}$ a anisotropia e $\mathrm{T}$ a temperatura.

Verifica-se que a relaxação $T_{B}$ e $T_{N}$ são inversas, ou seja, quando há predominância de relaxação Browniana a relaxação Néel encontra-se diminuída. ${ }^{(68)}$ Então considera-se a equação 2.3 no processo de relaxação efetiva total,

$$
T=\frac{T_{B} T_{N}}{T_{B}+T_{N}}
$$

Onde $T$ é a relaxação efetiva total, $T_{B}$ a relaxação Browniana e $T_{N} a$ relaxação Néel. 
Nas agitações das NSOF deve ser levado em consideração o tipo de nanopartícula quando se fala de fator volume, pois as mesmas podem ser: monodomínio ou multi-domínios. ${ }^{(68)}$ Domínios são regiões das NSOF em que os spins dos átomos que compõem essas nanopartículas, se alinham a um CMA passando a ter uma mesma orientação. Sabe-se que ao reduzir o diâmetro das NSOF, chega-se a um momento crítico (dependente da magnetização de saturação, anisotropia e energia de troca entre os átomos), em que o material passa a ser constituído de apenas um domínio magnético (mono-domínio). Conforme aumento do diâmetro as NSOF há a formação de várias áreas de domínios magnéticos na estrutura (multi-domínios), e estes domínios se unem para formar um momento magnético total na NSOF. ${ }^{(69)} \mathrm{O}$ tipo de domínio magnético é um fator importante na geração de agitação das NSOF, pois a resposta magnética das nanopartículas se altera conforme suas características de domínio. ${ }^{(70)}$

\subsubsection{Nanopartículas magnéticas}

A nanotecnologia é a ciência que abrange a matéria na escala de 1 bilionésimo de um medidor (isto é, $10^{-9} \mathrm{~m}=1 \mathrm{~nm}$ ), e é também o estudo da manipulação da matéria na escala atômica e molecular. Uma nanopartícula é o componente fundamental de uma nanoestrutura, ${ }^{(71)}$ os quais são menores ou comparáveis ao

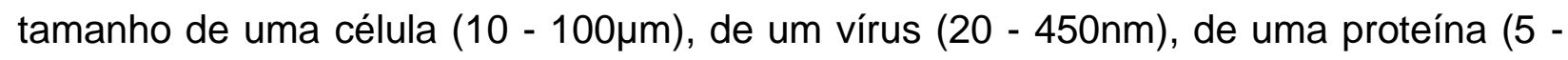
$50 \mathrm{~nm})$ ou de um gene (2nm de largura e 10 - 100nm de comprimento). ${ }^{(72)}$ Isto significa que as nanopartículas podem ser empregadas como uma entidade biológica, porém é maior do que um átomo ou uma molécula simples. Em geral, o tamanho de uma nanopartícula abrange a gama entre 1 e $100 \mathrm{~nm} .{ }^{(71)}$ Muitos autores limitam o tamanho de nanomateriais a $50 \mathrm{~nm}$ ou $100 \mathrm{~nm}$. No entanto, este limite de tamanho varia de acordo com o tipo de material e não pode ser a base para uma determinada classificação. A definição estende esse limite de tamanho superior a 1 micron sendo definidas como nano e são em geral classificadas com base na sua dimensionalidade, morfologia, composição, uniformidade e aglomeração ${ }^{(73)}$ (Figura 8). 


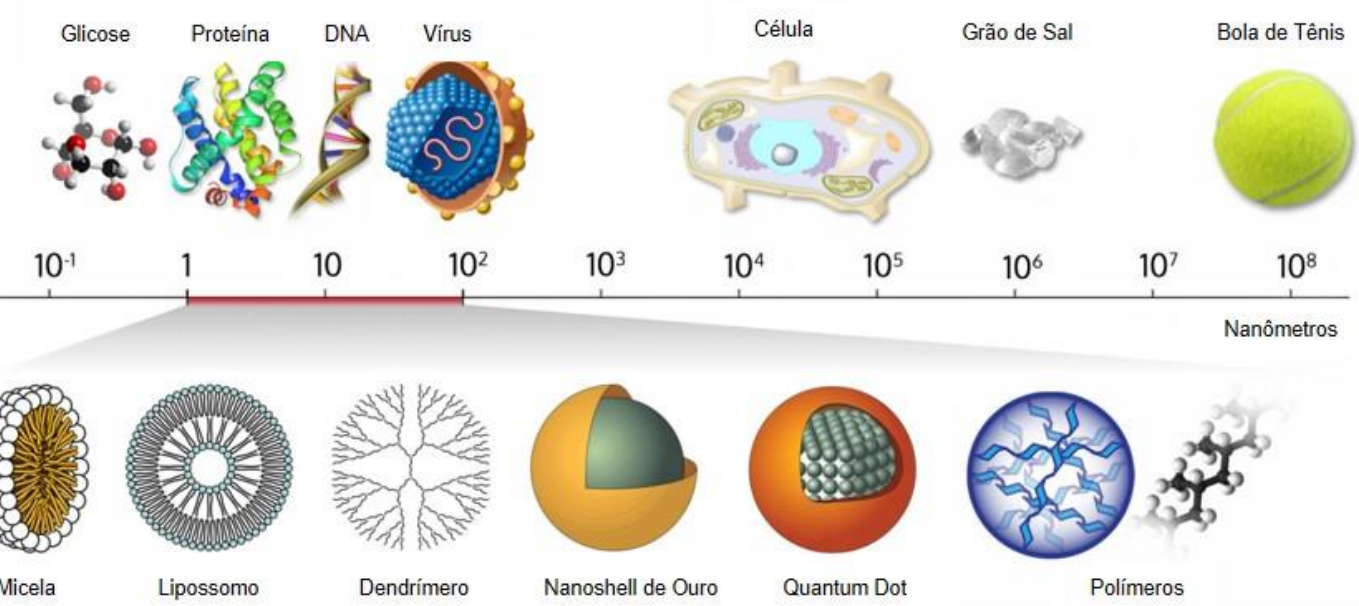

Fonte: Traduzido de University of New South Wales. School of Chemical Engineering. WichLab [Internet]. Sydney: University of New South Wales; 2017 [cited 2017 Feb 8]. Available from: http://www.wichlab.com/research/(74)

Figura 8. Imagem de distribuição de escala manométrica e de composição de nanopartículas

As nanopartículas magnéticas possuem aplicações potenciais na biomedicina dentro da área diagnóstica, terapêutica e como contraste em IRM, bem como para marcação celular, para aquisição de imagens multimodais, entrega de drogas, entrega gênica e sondas ativadas ${ }^{(75)}$ (Figura 9).

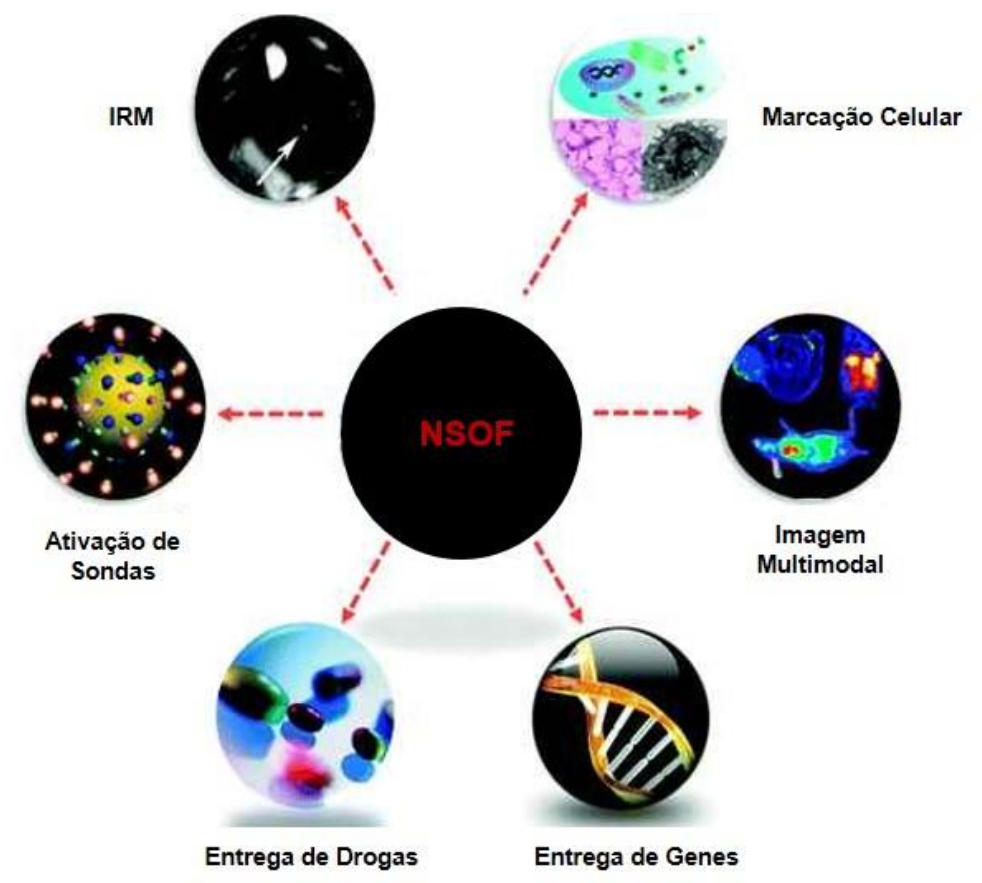

Fonte: Traduzido e adaptado de Jin Xie, Gang Liu, Henry S. Eden HA and XC. Surface-engineered magnetic nanoparticle platforms for cancer imaging and therap. Acc Chem Res. $2011 ; 44(10): 883-92$. $^{(76)}$

Figura 9. Nanopartículas superparamagnéticas de óxido de ferro e seu uso em diversas modalidades 


\subsubsection{Nanopartículas superparamagnéticas de óxido de ferro}

As NSOF podem ser usadas em caráter diagnóstico ou terapêutico. Existem diversos óxidos de ferro, entre eles os mais utilizados na área nanomédica são: hematita $\left(\alpha-\mathrm{Fe}_{2} \mathrm{O}_{3}\right)$, magnetita $\left(\mathrm{Fe}_{3} \mathrm{O}_{4}\right)$ e maghemita $\left(\mathrm{\gamma}-\mathrm{Fe}_{2} \mathrm{O}_{3}\right)$. Cada um desses óxidos de ferro têm característica físico-químicas, magnéticas e catalíticas particulares que proporcionam diversas aplicações. ${ }^{(77)}$

Estas nanopartículas recebem atenção considerável por oferecer vantagens em relação a outros materiais, pois são fisicamente e quimicamente estáveis, além de serem biocompatível e ambientalmente seguras. ${ }^{(78)}$

\subsubsection{Características físico-químicas}

As NSOF possuem um núcleo de óxido de ferro e uma camada estabilizante (cobertura) composta de polímero hidrófilo, solúvel em água e biocompatível (Figura 10). As coberturas mais usadas são polietilenoglicol (PEG), quitosana, dextrana, starch, aminosilana, polyvinyl alcohol (PVA) entre outras. ${ }^{(21,79)}$

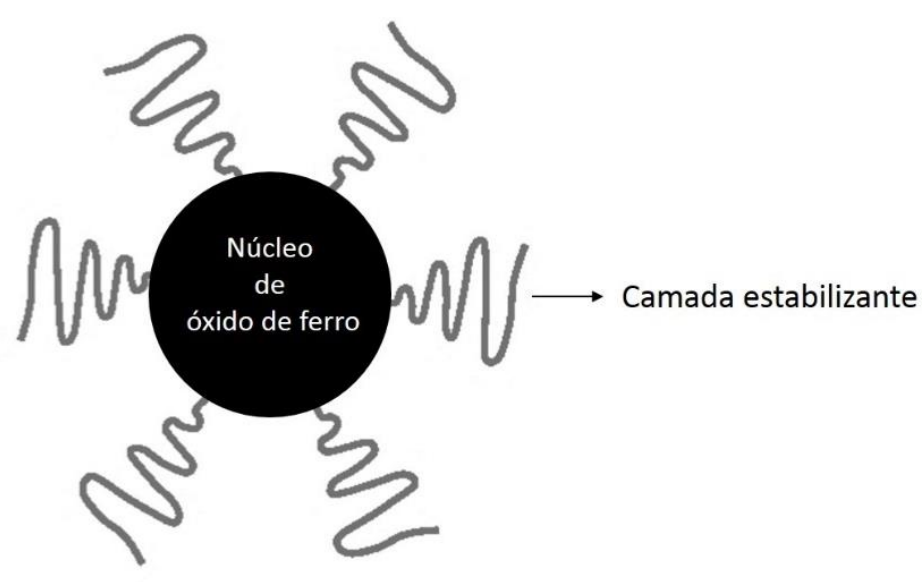

Figura 10. Estrutura de uma nanopartícula superparamagnética de óxido de ferro

A magnetita e maghemita são minerais magnéticos isoestruturados com vacâncias catiônicas, gerada pelo deslocamento de um cátion do seu sítio. As propriedades físico-químicas destas NSOF são bastante semelhantes, o que torna 
difícil distinguir uma da outra, porém, a magnetita tem a particularidade de conter os íons $\mathrm{Fe}^{2+}$ e $\mathrm{Fe}^{3+}$, dentro de uma estrutura de espinela inversa. Trinta e dois ânions de oxigênio que formam uma estrutura unitária cúbica, com um comprimento de aresta =0,839nm, os íons de ferro estão localizados em 8 locais tetraédricos (rodeados por quatro íons de oxigênio) e 16 sítios octaédricos (rodeados por 8 íons de oxigênio). Os sítios tetraédricos são ocupados exclusivamente por íons $\mathrm{Fe}^{3+}$, enquanto os íons $\mathrm{Fe}^{2+} \mathrm{e}$ $\mathrm{Fe}^{3+}$ ocupam, alternadamente, sítios octaédricos (Figura 11A). Esta organização é por vezes expressa nas fórmulas químicas: Magnetita $\mathrm{Fe}^{3+}\left[\mathrm{Fe}^{2+} \mathrm{Fe}^{3+}\right] \mathrm{O}_{4}$ e maghemita $\mathrm{Fe}^{3+}\left[\mathrm{Fe}^{3+}{ }_{5 / 3} \mathrm{~V}_{1 / 3}\right] \mathrm{O}_{4}$ em que $\mathrm{V}$ representa a vacância catiônica). ${ }^{\left({ }^{80,81)} \text { conforme }\right.}$ mostrado na figura $11 \mathrm{~B}$

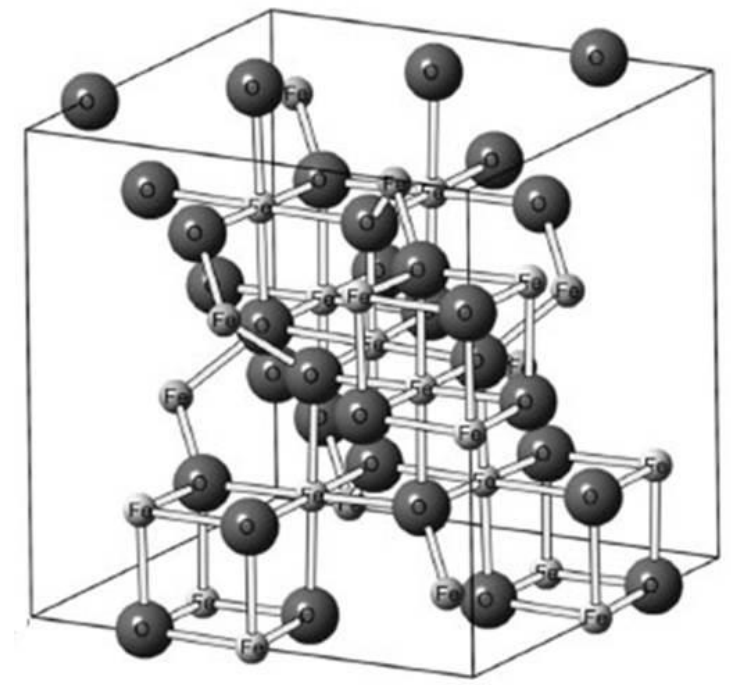

A Magnetita

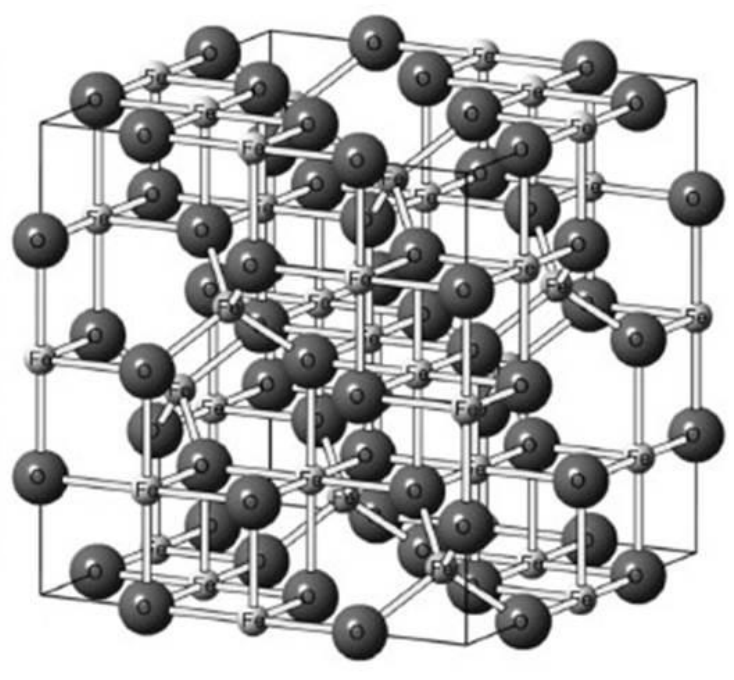

B Maghemita

Fonte: Oliveira LC, Fabris JD, Pereira MC. Óxidos de ferro e suas aplicações em processos catalíticos: uma revisão. Quim Nova. 2013;36(1):123-30. Figura 3. Estrutura cristalina da magnetita. Figura 4. Estrutura cristalina da maghemita Magnetita (A); maghemita (B). ${ }^{(81)}$

Figura 11. Visualização estrutural nanopartículas superparamagnéticas de óxido de ferro

\subsubsection{Características magnéticas}

Existem características magnéticas que proporcionam a possibilidade dessas nanopartículas gerarem elevação de temperatura na região as quais estão inseridas, devido à liberação de calor pelas mesmas e assim serem eficientes no uso de MHT. Essas características abrangem o fato destas nanopartículas serem dipolares, superparamagnéticas, possuírem anisotropia e momento magnético. ${ }^{(22,60)}$ 
A dipolaridade magnética das NSOF é a característica de se possuir dois pólos magnéticos opostos que proporcionam a interação entre as NSOF gerando resposta magnética local (Figura 12). ${ }^{(82,83)}$

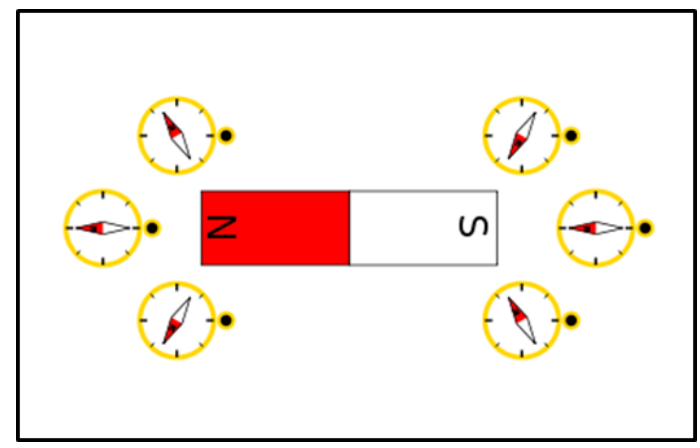

Fonte: Wikiwand. Força magnética [Internet]. 2017 [citado 2017 Fev 11]. [S.I.]: Wikiwand; Available from: http://www.wikiwand.com/pt/For\%C3\%A7a_ magn\%C3\%A9tica ${ }^{(84)}$

Figura 12. Interação de polos das nanopartículas superparamagnéticas de óxido de ferro

A composição nuclear cristalina das NSOF permite que estas gerem respostas em diferentes direções ao serem expostas à um CMA. Possuindo a capacidade de responder a este campo conforme o eixo de magnetização determinado pela interação de prótons e elétrons dispostos no átomo, da intensidade dos momentos magnéticos associados aos átomos ou íons vizinhos no momento de exposição ao CMA, da distância entre os íons vizinhos e da simetria da composição cristalina, a isto, definimos como anisotropia ou eixo de fácil magnetização. ${ }^{(85)}$ Portanto a anisotropia é a energia de magnetização do material a partir de uma determinada direção em relação à sua estrutura física. A energia de anisotropia magnética $\left(E_{K}\right)$ refere-se à barreira de energia associada à rotação do momento magnético de uma NSOF contrário ao eixo de anisotropia. ${ }^{(17,86)}$

A anisotropia (eixo de fácil magnetização) pode ser uniaxial (duas direções antiparalelas entre si separadas pela barreira de $E_{K}$ ) ou multi-axial (várias direções). Para a magnetita ou maghemita, devido à sua simetria cúbica, existem oito eixos de anisotropia (ao longo das diagonais da estrutura). No entanto, a anisotropia de NSOF de magnetita é frequentemente assumida como uniaxial. ${ }^{(80)} \mathrm{Na}$ anisotropia uniaxial, a energia magnética depende do ângulo entre o momento magnético e o eixo de anisotropia. Quando o ângulo é igual a $0^{\circ}$ ou $180^{\circ}$, há a probabilidade de 
alinhamento do momento magnético ao longo do eixo de anisotropia, ${ }^{(80)}$ conforme mostrado na figura 13 .

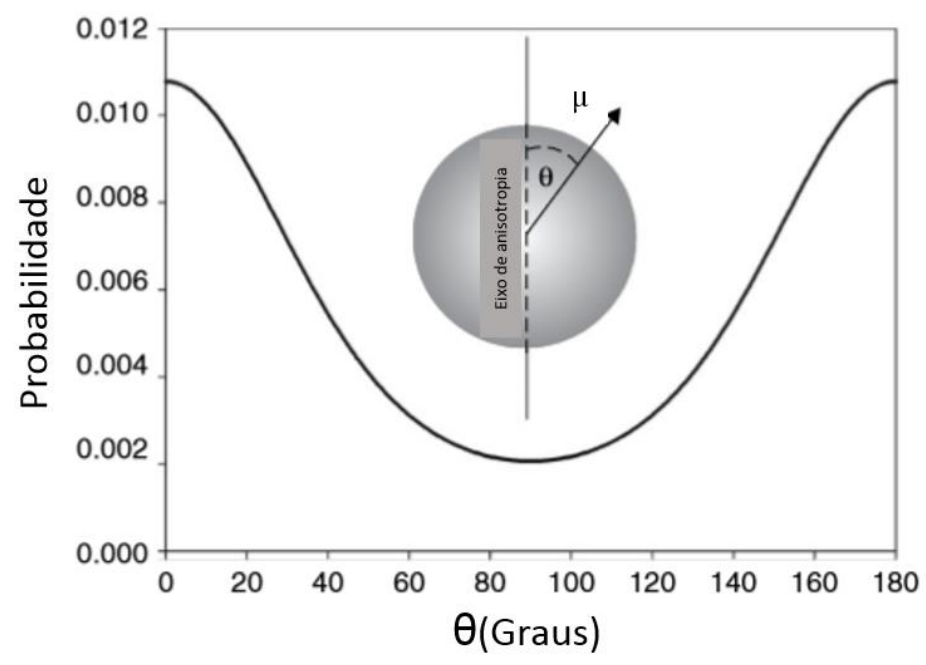

$\mu$ : permeabilidade magnética, $\theta$ : ângulo de magnetização. Fonte: Traduzido de Gossuin Y, Gillis P, Hocq A, Vuong $\mathrm{QL}$, Roch A. Magnetic resonance relaxation properties of superparamagnetic particles. Wiley Interdiscip Rev Nanomedicine Nanobiotechnology. 2009;1(3):299-310. ${ }^{(80)}$ Figure 2. Model of uniaxial anisotropy for a magnetite (or maghemite) nanoparticle. The graph shows the probability of alignment of the magnetic moment in one direction with respect to the angle between this direction and the anisotropy axis (for a sphere with a radius $\mathrm{R}=5 \mathrm{~nm}$ and an anisotropy constant $\mathrm{K}=13,500 \mathrm{Jm}-3$ ).

Figura 13. Comportamento anisotrópico

A característica de superparamagnetismo das NSOF procede do fato de que ao serem expostas à um CMA, estas nanopartículas respondem a este campo de forma nuclear gerando uma direção magnética em resposta ao do CMA se alinhando na direção do mesmo e ao ser retirado o campo, as NSOF voltam a sua direção magnética de repouso de forma não alinhada ${ }^{(17,83)}$ (Figura 14). 


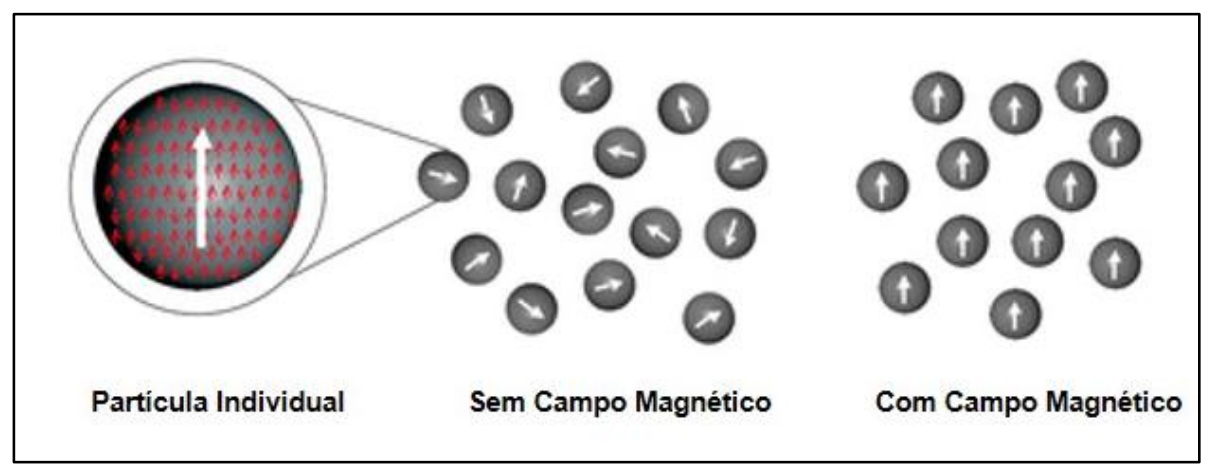

Fonte: Traduzido de Colombo M, Carregal-Romero S, Casula MF, Gutiérrez L, Morales MP, Böhm IB, et al. Biological applications of magnetic nanoparticles. Chem Soc Rev. 2012;41(11):4306-34. ${ }^{(87)}$

Figura 14. Característica superparamagnética das nanopartículas de óxido de ferro

O momento magnético consiste em uma medida da tendência das NSOF para se alinhar com um CMA. É uma grandeza vetorial, com o sentido positivo onde as nanopartículas magnéticas tendem a alinhar-se de modo que o seu spin esteja em paralelo com as linhas do CMA. ${ }^{(16)}$ (Figura 15).

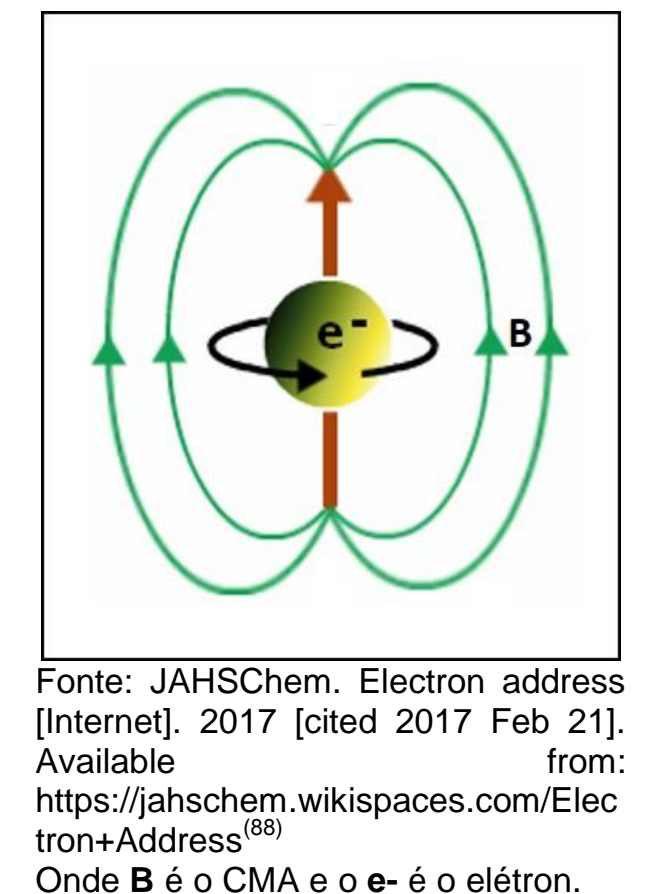

Figura 15. Momento magnético

O momento magnético individual do material determinado pela anisotropia contribui para a geração de resposta de aumento de temperatura. Há uma relação da anisotropia de uma NSOF e a direção do vetor de magnetização do CMA na geração de magnetização e calor. Quando a direção de anisotropia possui a mesma 
direção que a do CMA, a energia anisotrópica é baixa, gerando baixa magnetização do material e consequentemente o calor gerado também será baixo ${ }^{(85)}$ (Figura 16A). Já quando a direção de anisotropia é contrária à direção do CMA, se faz necessário ultrapassar a barreira de $E_{K}$ para alterar o momento magnético da NSOF em alinhamento com o do CMA aumentando a interação entre as NSOF, gerando assim alta magnetização de resposta e consequentemente maior geração de calor ${ }^{(62)}$ (Figura 16B). A mudança na direção do momento magnético das NSOF gera liberação de energia a cada ângulo alcançado na direção do vetor magnético. Quanto maior a angulação referente ao estado anterior de repouso, maior a magnetização gerada, pois a energia aumenta conforme o ângulo entre o eixo do CMA e o de anisotropia ${ }^{(16,62)}$ (Figura 16C). Porém, se o valor de anisotropia é muito alto, o momento magnético da NSOF permanecerá bloqueado no eixo de fácil magnetização, gerando um dipolo rígido com resistência de reposta magnética ${ }^{(62)}$ para pular a barreira de $E_{K}$ e colocar o momento magnético em alinhamento com o CMA conforme mostrado na figura 16D. 


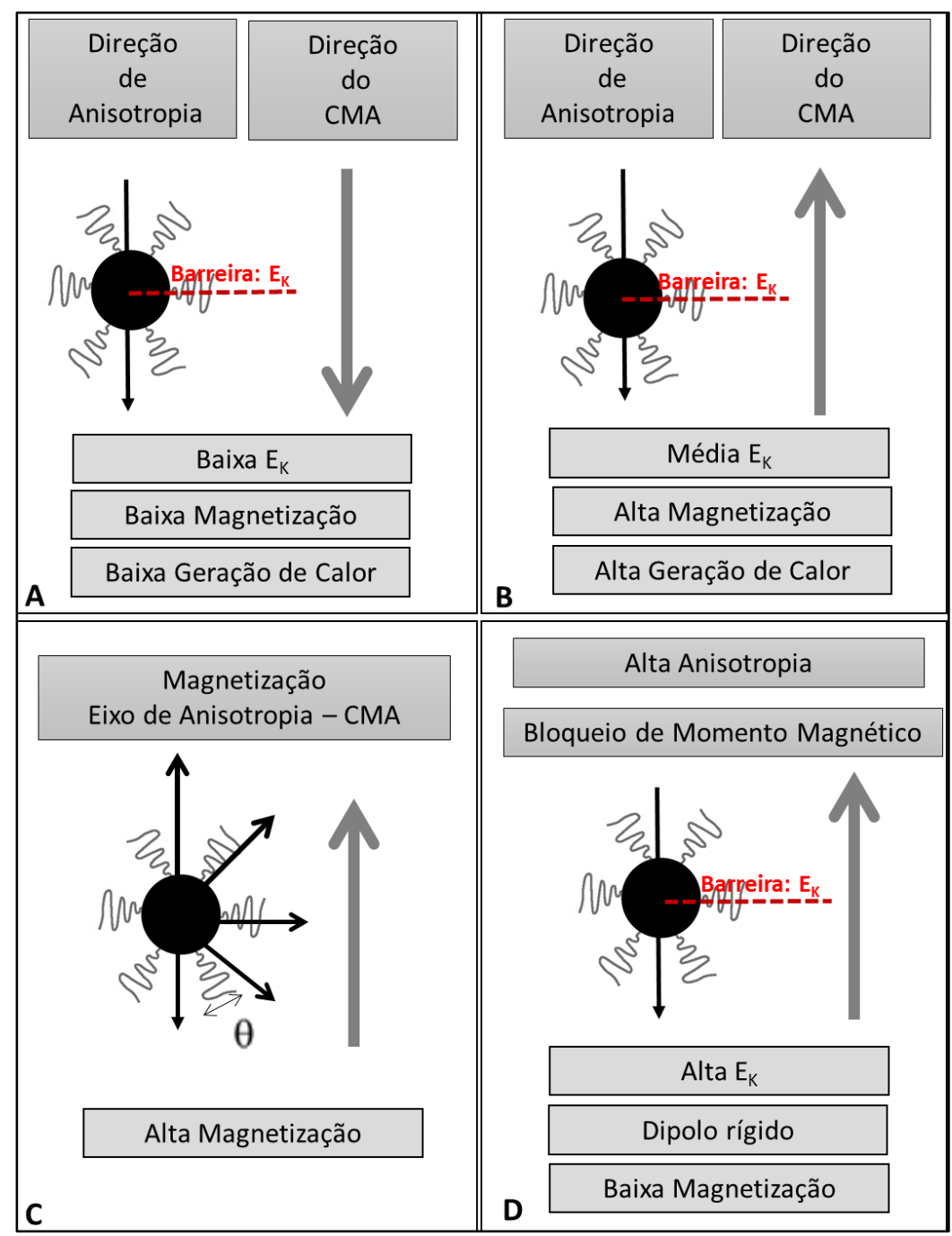

Processo de baixa geração de calor (A); Processo de alta geração de calor (B); Angulação em decorrência do processo de magnetização $(C)$, onde $\theta$ é o ângulo de magnetização gerado; Bloqueio de magnetização (D).

Figura 16. Momento magnético das nanopartículas em resposta a direção de spin e ao campo magnético aplicado na geração de calor

A anisotropia varia com a temperatura. A energia térmica induz 0 momento magnético a superar a barreira $E_{K}$, ocasionando relaxação de NSOF e alinhamento do momento magnético da mesma com o CMA. Porém, com o tempo, a energia térmica gera direção aleatória dos momentos magnéticos, resultando em decaimento da magnetização. ${ }^{(62,85)}$ 


\subsubsection{Caracterização relaxométrica}

A relaxação se dá conforme informado no item 2.2.3, e como visto anteriormente, é a resposta de movimento de rotações de NSOF e/ou de seus momentos magnéticos de um estado de repouso para outro estado em um período de tempo (s), podendo ser do tipo Browniana (rotação da nanopartícula como um todo após ser exposta a um campo magnético) ou de Néel (somente a rotação nuclear da nanopartícula) e é caracterizado por tempos de relaxação (tempo médio para uma NSOF reverter seu momento magnético de um estado de repouso para outro) influenciando os valores de SAR. ${ }^{(63,64)}$

\subsubsection{Taxa de absorção específica e perda de poder intrínseco}

A taxa de absorção específica (SAR - Specific Absorption Rate) é um parâmetro que determina principalmente as dosagens de NSOF que devem ser administradas, a fim de alcançar morte celular de forma eficaz resultante do aumento de temperatura local onde foi administrado as NSOF. O SAR é definido pela quantidade de calor emitida por unidade de massa das NSOF, como consequência da exposição das NSOF a um CMA e do tempo resultante da curva de temperatura da amostra coloidal. ${ }^{(21,89,90)}$

O SAR deve ser tão grande quanto possível no caso de aplicação de $\mathrm{MHT}$, pois, quanto maior o SAR, maior o potencial de aquecimento local gerado pelas NSOF, onde esse potencial é dependente de alguns fatores ${ }^{(60,90)}$ como:

- Amplitude magnética do campo $(\mathrm{H})$;

- Frequência (f);

- Permeabilidade $(\mu)$;

- Tamanho e forma das NSOF.

No cálculo do SAR participam a massa da NSOF que é administrada assim como o calor específico das NSOF e do líquido no qual as nanopartículas estão suspensas. Outro fator que participa no cálculo é o valor absoluto da variação da temperatura por unidade de tempo. Assim teremos o valor do SAR, ${ }^{(91)}$ conforme a equação 2.4 


$$
\operatorname{SAR}(W / g)=\frac{m_{N P} c_{N P}+m_{1} c_{1}}{m_{N P}}\left(\frac{d T}{d t}\right) \max
$$

Onde $\mathrm{m}_{\mathrm{NP}}$ : massa da nanopartícula $[\mathrm{kg}]$, $\mathrm{c}_{\mathrm{NP}}$ : calor específico da nanopartícula $[\mathrm{J} /(\mathrm{kg} . \mathrm{K})], \mathrm{m}_{1}$ : massa do líquido $[\mathrm{kg}], \mathrm{c}_{1}$ : calor específico do líquido [J/(kg.K)], e (dT / dt) max: gradiente máximo da curva de temperatura da amostra coloidal submetida a um teste de $\mathrm{InH}[\mathrm{K} / \mathrm{s}] .^{(92)}$

O SAR tem relação com a densidade do material magnético, com o CMA e com a frequência utilizada. Devido a isso introduziu-se o perda de poder intrínseco (ILP - Intrinsic Loss Power) no processo. O ILP é definindo conforme a equação $2.5,{ }^{(93)}$

$$
\mathrm{ILP}=\frac{\mathrm{SAR}}{\mathrm{fH}_{\mathrm{o}}^{2}}
$$

Onde o valor de SAR é caracterizado em valores de Watts por kilograma no potencial da curva $[\mathrm{W} / \mathrm{Kg}]$, f frequência do campo em $\mathrm{kHz}$ e $\mathrm{H}_{0}$ intensidade inicial do CMA. Onde a energia gerada por escalas de MHT com a frequência, de forma quadrática com o CMA, permite que sejam feitas comparações entre as medições realizadas em diferentes condições de frequência e campo magnético. ${ }^{(94)}$

\subsubsection{Estudos in vitro de magneto hipertermia}

Para analisar o processo de MHT, estudos in vitro têm sido realizados para obter respostas de potencial de aquecimento das NSOF, e as derivações deste potencial em relação às propriedades das NSOF como: cobertura, núcleo (composição e análise em mono-domínio e multi-domínio), diâmetro, funcionalização e o meio em que estão inseridas as amostras (como por exemplo: fluído aquoso, agarose, PVA e outros). ${ }^{(95)}$ As propriedades das NSOF bem como o SAR, influenciam na eficiência de MHT, portanto, são parâmetros que devem ser 
analisados afim de se obter a NSOF com maior valor de SAR para gerar melhor resposta terapêutica. ${ }^{(91,96)}$

Em um estudo, NSOF foram utilizadas para realizar MHT em três linhagens celulares cancerígenas (DA3, MCF-7 e linhagem de células HeLa). Os resultados experimentais mostraram que houve elevação de temperatura nos níveis de $42^{\circ} \mathrm{C}$ em menos de 200 segundos, minimizando a duração de exposição das células ao CMA e promovendo morte celular de células tumorais. ${ }^{(97)}$ Em um outro estudo utilizando células Hela, observou-se porcentagem de viabilidade celular tumoral igual à 80\% após 15 minutos de exposição ao CMA, 20\% após 30 minutos e 0\% após 60 minutos de exposição. ${ }^{(98)}$

Estudos recentes demonstram a eficiência de MHT com a utilização de NSOF in vitro em diversas linhagens com e sem terapia combinada, como mostrado na tabela 2.

Tabela 2. Estudos in vitro da técnica de magneto hipertermia

\begin{tabular}{|c|c|c|c|}
\hline Estudo & Linhagem & $\begin{array}{c}\text { Terapia } \\
\text { combinada } \\
\end{array}$ & Resultados \\
\hline Zamora-Mora et al. ${ }^{(99)}$ & A-172 & Quimioterapia & $\begin{array}{l}\text { Apoptose celular significativa } \\
\text { de A-172 }\end{array}$ \\
\hline Stocke et al. ${ }^{(100)}$ & TTA-TNBC & Não & $\begin{array}{l}\text { Aumento significativo na } \\
\text { morte celular tumoral }\end{array}$ \\
\hline Sanz et al. ${ }^{(101)}$ & SH-SY5Y & Não & $\begin{array}{l}\text { Destruição celular tumoral } \\
\text { desencadeada por } \\
\text { nanopartículas magnéticas. }\end{array}$ \\
\hline Sharifabad et al. ${ }^{(102)}$ & MCF7 e U87 & DOX & $\begin{array}{l}\text { Redução de viabilidade } \\
\text { celular em } 20 \% \text { em MCF7 e } \\
\text { de } 20 \% \text { na linhagem U87 }\end{array}$ \\
\hline Yunok et al. ${ }^{(103)}$ & MDA-MB-231 & Não & $\begin{array}{l}\text { Morte celular por indução de } \\
\text { apoptose com elevação de } \\
\text { temperatura à } 42^{\circ}\end{array}$ \\
\hline
\end{tabular}

A-172 e U87: linhagem humana de glioblastoma; TTA-TNBC: análogo de tecido tumoral de câncer de mama triplo negativo (tumor tissue analogs- triple negative breast cancer); MCF7: linhagem humana de carcinoma de mama; DOX: doxorrubicina; SH-SY5Y: linhagem de neuroblastoma humano; MDA-MB-231: linhagem humana de adenocarcinoma de mama.

Para analisar a eficiência terapêutica por MHT medindo a porcentagem de células mortas por elevação de temperatura, é crucial que os testes de viabilidade sejam iniciados imediatamente após a terapia, para evitar a exposição das células à vários fatores externos e que influenciem nos resultados da eficiência da técnica de MHT. ${ }^{(97)}$ 


\subsubsection{Estudos in vivo de magneto hipertermia}

Observou-se análise mais fidedigna aos danos gerados pelo calor em tumores in vivo do que nas células tumorais in vitro, com diferença significativa na imunidade de modelos in vivo, por conta da heterogeneidade da rede vascular dentro do tumor, além da presença de áreas com diferença de $\mathrm{pH}$, bem como a diminuição da disponibilidade de oxigênio. ${ }^{(52)}$

Em um estudo de MHT com câncer de mama em camundongo, observou-se redução de massa tumoral e endocitose de NSOF pelas células endoteliais após aplicação terápica, ${ }^{(104)}$ eficiência observada também em um estudo com carcinoma epidermóide de cabeça e pescoço tratados por MHT, em que foram detectados graus variados de ulceração e inflamação da parede do tumor em comparação com animais controles (não tratados). Estes tumores tratados tinham abundante ferro livre em região intracelular (citoplasma e núcleo), células necróticas e presença de fibroblastos em torno do tumor. ${ }^{(105)}$

Foi estudada a eficácia terapêutica in vivo da técnica de MHT utilizando NSOF e observou-se a eliminação tumoral 18 dias após a aplicação da terapia. ${ }^{(106)}$ Ao combinar MHT e quimioterapia para o tratamento de mieloma múltiplo, com uso de nanopartículas magnéticas para liberação de doxorrubicina, células tumorais foram totalmente eliminadas sem a recorrência do tumor. ${ }^{(54)}$

Em um estudo com humanos, detectou-se que a aplicação de MHT com temperaturas entre $42^{\circ} \mathrm{C}$ a $45^{\circ} \mathrm{C}$ foi segura e causou poucos efeitos secundários para os pacientes, além de ser observado que as NSOF administradas ficaram retidas dentro do tecido tumoral. ${ }^{(52)}$

Em um estudo neuropatológico pós-morte de três pacientes com glioblastoma submetidos a $\mathrm{MHT}$, detectou-se a presença de nanopartículas na região do tumor, macrófagos e uma área necrótica no tumor. $\mathrm{Na}$ análise histológica destes pacientes, as nanopartículas injetadas estavam dispersas em forma de aglomerados e as regiões necróticas estavam confinadas ao local de NSOF, com ativação de fagócitos. ${ }^{(23)}$

A trajetória e a eliminação das NSOF no organismo é um fator importante para análise de eficiência terapêutica e de toxicidade destas nanopartículas magnéticas. ${ }^{(16)}$ Em um estudo in vivo, NSOF foram seletivamente absorvidas pela rede 
celular que reveste os vasos sanguíneos e posteriormente detectadas no baço e fígado. ${ }^{(16)}$ Devido a absorção celular, à ação terapêutica e eliminação das NSOF no organismo, é fundamental a realização de estudos in vivo, para observação destes processos. $^{(16,52)}$

Estudos recentes demonstraram a eficiência de MHT com a utilização de NSOF in vivo, expostas a diversos tempos de exposição ao CMA, com e sem terapia combinada, como mostrado na tabela 3.

Tabela 3. Comparação de exposição ao campo magnético alternado e resultados alcançados após magneto hipertermia em modelos in vivo

\begin{tabular}{|c|c|c|c|c|}
\hline Estudo & $\begin{array}{c}\text { Tempo } \\
\text { de exposição } \\
\text { (min) }\end{array}$ & $\begin{array}{l}\text { Temperatura } \\
\left({ }^{\circ} \mathrm{C}\right)\end{array}$ & $\begin{array}{l}\text { Terapia } \\
\text { combinada }\end{array}$ & Resultados \\
\hline Arriortua et al. ${ }^{(107)}$ & 21 & 43 & RGD & $\begin{array}{l}\text { Ausência de danos } \\
\text { relevantes no tecido saudável } \\
\text { e } 20 \% \text { de necrose no tecido } \\
\text { tumoral }\end{array}$ \\
\hline Di Corato et al..$^{(108)}$ & 30 & 40 & PDT & $\begin{array}{c}\text { Completa erradicação } \\
\text { tumoral }\end{array}$ \\
\hline Kossatz et al. ${ }^{(109)}$ & 60 & 43 & DOX & $\begin{array}{l}\text { Observou-se uma inibição de } \\
\text { proliferação tumoral em } 40 \%\end{array}$ \\
\hline Hayashi et al. ${ }^{(54)}$ & 20 & 44 & DOX & $\begin{array}{l}\text { Na } 8^{a} \text { semana após terapia, o } \\
\text { tecido tumoral foi erradicado }\end{array}$ \\
\hline Jeon et al..$^{(110)}$ & 20 & 42 & DOX & $\begin{array}{c}\text { Tumor com completa } \\
\text { eliminação sem rescindiva } \\
\text { após } 14 \text { dias }\end{array}$ \\
\hline Liu et al. ${ }^{(56)}$ & 10 & 46 & Não & $\begin{array}{l}\text { Aumento na sobrevida do } \\
\text { animal, presença de necrose } \\
\text { celular tumoral }\end{array}$ \\
\hline Huang et al. ${ }^{(57)}$ & 2 & 60 & Não & $\begin{array}{c}\text { Após } 160 \text { dias, } 78 \% \text { dos } \\
\text { animais tiveram tumor } \\
\text { eliminado }\end{array}$ \\
\hline
\end{tabular}

\subsection{Técnicas para avaliação de eficiência em magneto hipetermia}

$\mathrm{Na}$ implementação da técnica de MHT em estudos pré-clínicos a avaliação pode ser realizada mediante as técnicas de IRM, bioluminescência, citometria de fluxo, histologia entre outras. ${ }^{(111,112)}$ 


\subsubsection{Imagem por ressonância magnética}

A imagem por ressonância magnética (IRM) é uma das técnicas utilizadas no diagnóstico de glioblastoma ${ }^{(3)}$ e permite avaliar a regressão do tecido tumoral após aplicação da técnica de MHT. Mediante esta técnica de IRM é possível determinar no processo terapêutico a distribuição das nanopartículas magnéticas utilizando imagens hipointensas ponderadas em T2.

A aquisição de imagens é realizada por um campo magnético constante conjuntamente com gradientes de campo magnético em três direções e que na presença de pulsos de radiofrequência permite adquirir imagens mapeando a posição de prótons, que existem em diferentes densidades nos tecidos. ${ }^{(113)}$

A IRM reconstrói imagens a partir dos sinais eletromagnéticos gerados pela estimulação e relaxamento de hidrogênio. ${ }^{(75)}$ Devido à alta resolução espacial, estabilidade e a capacidade das NSOF de realizar interações à nível atômico e molecular, influenciando o tempo de relaxamento de prótons de hidrogênio contidos em moléculas de água, as mesmas estão sendo usadas em IRM em diversas modalidades como: agente de acompanhamento de migração celular por monitoramento in vivo e de diferenciação celular com marcação molecular, ${ }^{(114)}$ agente de contraste, gerando efeitos de realce, como uma diminuição de sinal (negativo), aparecendo em tumores cerebrais como um sinal de hipointensidade em imagem ponderadas em T2. ${ }^{(75,115)}$

\subsubsection{Bioluminescência}

A bioluminescência é uma técnica não invasiva que permite avaliar a viabilidade das células tumorais.

Bioluminescência é a geração de emissão de luz resultante da reação da luciferina sob condições fisiológicas no interior ou em associação com um organismo vivo quando os mesmos contem luciferase (Luc). ${ }^{(24)} \mathrm{A}$ luciferase proveniente do vagalume Photinus pyralis é encontrada na região emissora de luz contida no interior de seu abdômen. Em seu estado natural, após a emissão de um flash de luz, a bioluminescência rapidamente decai para um nível mais baixo de emissão. ${ }^{(116)}$ Assim, no processo gerador de reação de emissão de luz bioluminescente, a luciferina é 
considerada o substrato reator e a luciferase fator enzimático importante na reação. Em uma reação bioluminescente ou quimioluminescente, forma-se um produto (emissor) no estado excitado. O retorno do emissor para o estado de menor energia é acompanhado pela emissão de luz. A formação do emissor no estado excitado é catalisada pela luciferase. Com isso torna-se possível a realização de estudos de bioluminescência, pois para rastrear células em ensaios in vitro e in vivo por bioluminescência, estas células de interesse precisam ser geneticamente modificadas para expressar luciferase. ${ }^{(117,118)}$

Essa modificação genética é realizada através da transfecção celular do gene da luciferase que foi isolado e colocado em um pequeno pedaço de DNA - um plasmídeo. O plasmídeo consiste em uma sequência promotora (sequência de DNA que regula a expressão do gene de luciferase nas células vivas) e numa sequência repórter do gene da luciferase direcionado para o citoplasma e núcleo celular (o gene repórter é um marcador de sequência promotora e são utilizados para estudar promotores, fatores de transcrição e transdução de sinal). Após a transfecção do plasmídeo na célula, realiza-se o processo de transcrição que se dá com o reconhecimento da região promotora do gene pela RNA-Polimerase (Ribonucleic Acid), destacando um filamento de mRNA (RNA mensageiro) que ao ser traduzido sintetiza uma proteína Luc ${ }^{(117)}$ (Figura 17A).

As células transfectadas com Luc são transplantadas no animal, que após a administração de luciferina irá promover a expressão do gene repórter de Luc induzindo o processo de emissão de luz na presença de oxigênio, magnésio $\left(\mathrm{Mg}^{2+}\right)$, trifosfato de adenosina (ATP - adenosine triphosphate), e de um substrato (luciferina) para gerar $\mathrm{CO}_{2}$, monosfato de adenosina (AMP - adenosine monophosphate), pirofosfato (PPi) e oxiluciferina. A proteína Luc catalisa a conversão de luciferina para oxiluciferina, acompanhada pela emissão de luz na faixa de 400-620nm, com um pico máximo de $562 \mathrm{~nm}^{(119,120)}$ (Figura 17B), a luz é então detectada e quantificada, sendo posteriormente visualizada como diversos sinais luminosos captando assim a localização interna das células com luciferase no corpo do animal ${ }^{(24)}$ (Figura 17C). 


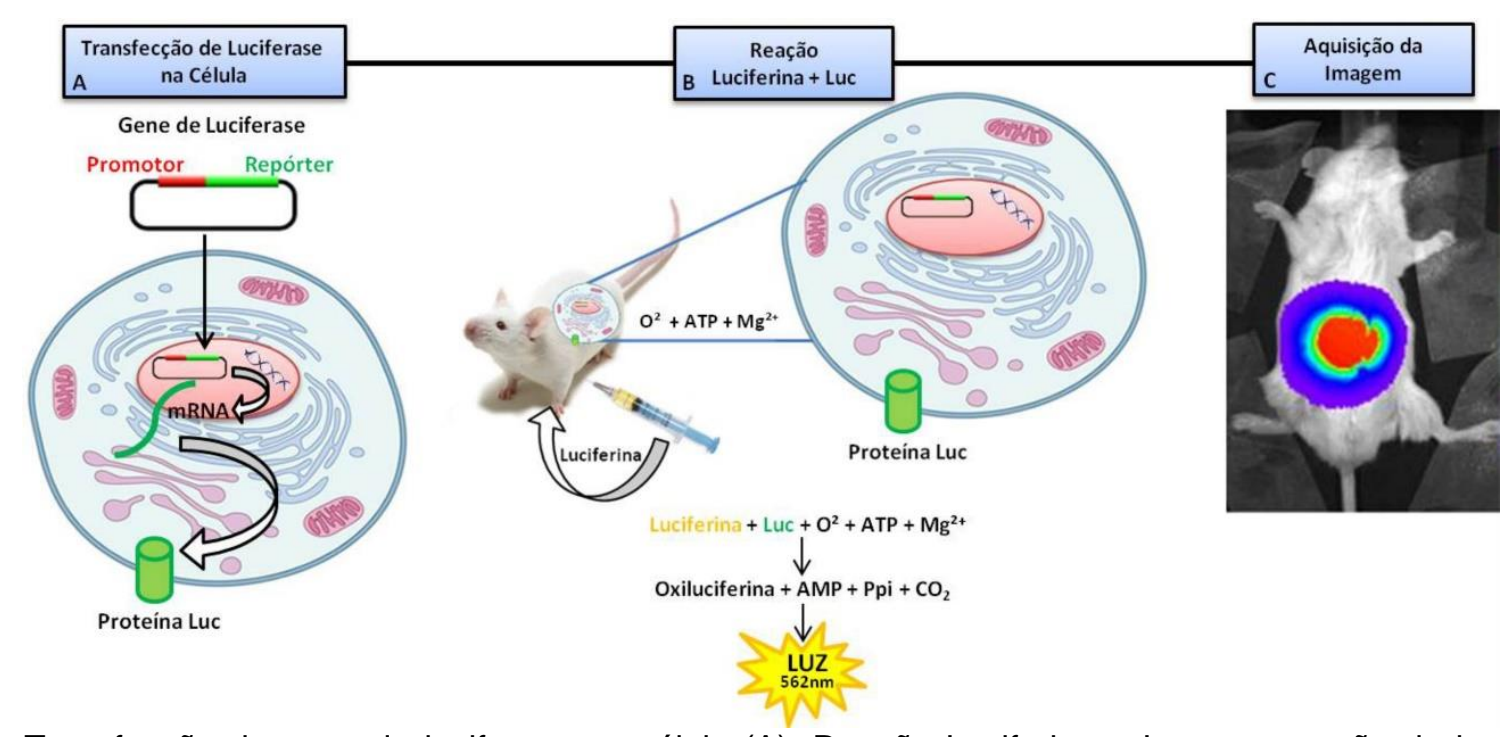

Transfecção do gene de luciferase na célula (A); Reação Luciferina e Luc na geração de luz (B); Aquisição de imagem de bioluminescência em modelo animal (C). mRNA: RNA mensageiro, Luc: Luciferase; $\mathrm{O}^{2}$ : Oxigênio, ATP: Adenosine triphosphate), $\mathrm{CO}_{2}$ : Dióxido de carbono, AMP: Monosfato de adenosina, PPi: Pirofosfato, $\mathrm{Mg}^{2+}$ : Magnésio.

Figura 17. Processo de bioluminescência luciferase-luciferina

A técnica de bioluminescência tem sido utilizada em vários campos de estudos biológicos, tais como expressão gênica, modificação pós-translacional e interação proteína-proteína in vitro e in vivo, ${ }^{(25)}$ avaliação de enxertos ${ }^{(121)}$ e outros como monitoração de células troncos em Parkinson ${ }^{(122)}$ e progressão de infecções quantificando colônias de micro-organismos em vários pontos de tempo. ${ }^{(123)}$ As nanopartículas magnéticas têm sido empregadas em diversos estudos de bioluminescência como: detecção e rastreamento celular de espermatozoide ${ }^{(124)}$ e de células dendríticas, ${ }^{(87)}$ mapeamento e diagnóstico de câncer de próstata, ${ }^{(125)}$ administração intracelular de enzima encapsulada e de DNA plasmídico com microcápsulas magnéticas, ${ }^{(126)} \mathrm{MHT}{ }^{(110)}$ entre outras. ${ }^{(127,128)}$

$\mathrm{Na}$ realização da técnica de $\mathrm{MHT}$, a bioluminescência é utilizada para marcação e visualização das células tumorais viáveis. Proteínas como a luciferase são utilizadas para a visualização de tumores e obtenção de informações sobre aspectos celulares e moleculares do tecido neoplásico in vitro e in vivo, entre eles o monitoramento em ciclos de tempo do crescimento e da regressão de tumores após terapias possuindo baixos níveis de toxicidade e rápida eliminação pelo organismo. ${ }^{(25,129-131)}$ 


\subsubsection{Citometria de fluxo}

A citometria de fluxo (CF) é utilizada para a análise de células em suspensão, promovendo a identificação e a quantificação de células pelo tamanho, granulosidade e intensidade de fluorescência das células, ${ }^{(132)}$ como também permite a análise de morte celular por apoptose e necrose, além de análise do volume celular e da granulosidade das células avaliadas a partir de modificações nos padrões FSC (foward scatter) e SSC (side scatter) de dispersão da luz, respectivamente. ${ }^{(133,134)}$ Para a realização destas análises, vários fluoróforos (marcadores celulares) são usados, como: DAPI (marcadores de DNA e RNA, que se liga na sequência de bases A-T), lodeto de Propídio (PI - Propidium lodide), Anexina V- FITC e brometo de etídio para avaliação de morte celular, entre outros. ${ }^{(135)}$

$A$ anexina $V$ realiza detecção de apoptose em vários tipos celulares, pela dosagem de fosfatidilserina (PS - phosphatidylserine) que é predominantemente observada na superfície interna da bicamada lipídica, voltada para o citosol. Em apoptose inicial, onde a membrana celular permanece intacta mas sofre uma desorganização, a PS é translocada para a superfície exterior da bicamada. A presença de PS na superfície externa faz com que a Anexina $V$ se ligue a PS na presença íons de cálcio. Porém, a anexina $\mathrm{V}$ pode ainda permear a célula quando a mesma possui poros na sua membrana se ligando a PS quando a mesma está localizada na camada interna da membrana. ${ }^{(136)}$

O PI é amplamente utilizado em conjunto com Anexina V para determinar a viabilidade celular quanto aos processos de apoptose e necrose, através de diferenças na integridade e na permeabilidade da membrana plasmática, baseandose no princípio de que o PI é capaz de se ligar ao DNA marcando células, quando estas possuem fragmentação de seu DNA. ${ }^{(137)}$ A capacidade de PI de internalizar uma célula depende da permeabilidade da membrana; o fluoróforo PI não marca células viáveis ou em apoptose precoce devido à presença de uma membrana plasmática intacta. Nas células necróticas, a integridade da membrana plasmática é prejudicada, fazendo com que o PI transponha a mesma. ${ }^{(138)}$

A CF é um dos métodos para análise de morte celular gerada pela aplicação de terapia por MHT, quando a mesma pela elevação de temperatura nas células tumorais, efeitos sobre a distribuição de proteínas de membrana, perturbação 
de potencial mitocondrial, alteração do estado homeostático celular, além de alterar a replicação do DNA, ${ }^{(27,139)}$ apoptose, desordem mitótica secundária e alterações nas proteínas e necrose. ${ }^{(139,140)}$ Com isso, torna-se possível avaliar por CF os efeitos gerados pela técnica de MHT em células tumorais, destacando os métodos de análise de desequilíbrio e morte celular após a aplicação da terapia.

\subsubsection{Histologia}

A eficácia na análise de tecidos biológicos, desde sua estrutura ao seu funcionamento, fez da histologia um método amplamente utilizado em estudos ex vivo.

Várias técnicas citoquímicas e histoquímicas são utilizadas em estudos histológicos para a coloração de componentes específicos da célula, como por exemplo: a coloração com Sudan Black B para corar lipídios, Hematoxilina e Eosina (HE) para diferenciação de partes basófilas (hematoxilina) e acidófilas (eosina), azul de metileno e fucsina (corantes para marcação bacteriológica), o ácido periódico-Schiff (PAS - Periodic Acid-Schiff) que é utilizado para corar carboidratos, como o glicogênio e as glicoproteínas, ${ }^{(141)}$ azul de prússia (AP) e Fast Red que são bastante empregadas em estudos de marcação com NSOF (o grau de coloração está relacionado a quantidade de ferro presente na amostra exposta ao AP), ${ }^{(23)}$ além da marcação com Tricrômico de Masson que coram queratina, fibras musculares, colágeno e tecido ósseo, citoplasma e núcleos das células ${ }^{(108)}$ entre outras técnicas. ${ }^{(110,142)}$

A análise por histologia tem sido bastante utilizada na verificação de morte celular, além da realização de estudos de expressão de moléculas através de diversas marcações histoquímicas. ${ }^{(143-145)} \mathrm{O}$ estudo de morte celular por histologia é importante em estudos terapêuticos como o de $\mathrm{MHT}$, pois permite analisar os efeitos gerados pela terapia no tecido tumoral e nos tecidos circunvizinhos, como já mostrado, com detecção de áreas necróticas em região tumoral após 24 horas da exposição à $\mathrm{MHT}$, e também regiões de células morfologicamente viáveis perto do limite tumoral. ${ }^{(22)}$ 


\section{MÉTODOS}

A metodologia foi dividida em 3 etapas: (i) Análise físico-química das nanopartículas magnéticas, (ii) estudo in vitro de MHT e (iii) estudo in vivo.

Foi realizada a exposição das NSOF à MHT para obtenção das curvas de aquecimento e cálculo de SAR e ILP, conforme mostrado na figura 18.

O estudo in vitro, foi realizado utilizando células C6 transfectadas com Luc marcadas com NSOF. As C6-Luc marcadas com NSOF foram submetidas a MHT. Após aplicação de MHT, foi realizada a análise de viabilidade das células C6-Luc com NSOF através de bioluminescência e de citometria de fluxo para avaliação de eficiência terapêutica (Figura 18).

O estudo in vivo, foi realizada a indução tumoral de células C6-Luc em ratos Wistar para avaliação volumétrica e comportamental. Após 21 dias de evolução tumoral o animal foi submetido à MHT com aquisição de imagens por bioluminescência (Figura 18). 


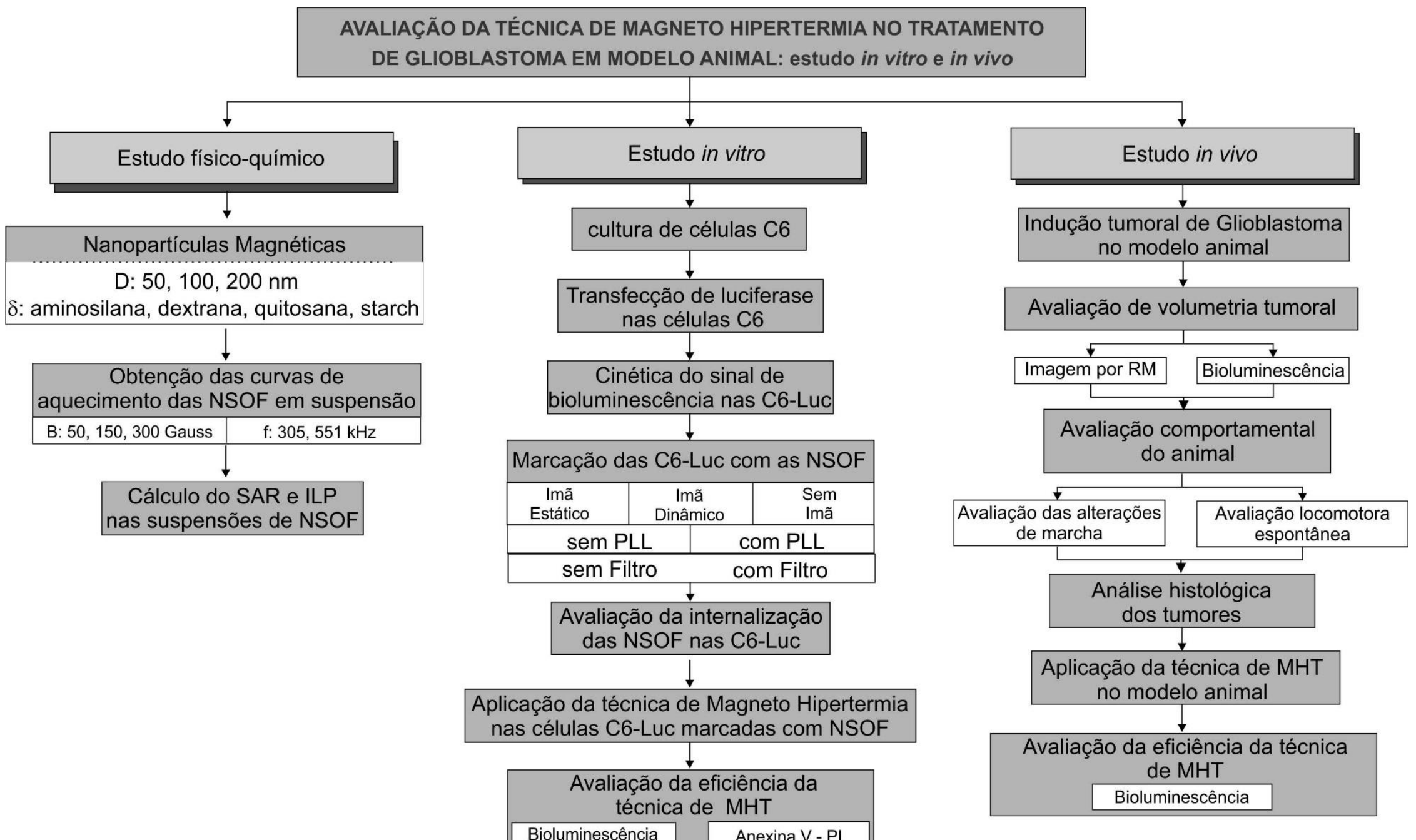

Quadro branco: subdivisões.

Figura 18. Desenho experimental do estudo 


\subsection{Nanopartículas superparamagnéticas de óxido de ferro com diferentes tamanhos e coberturas}

Com o objetivo de observar a resposta de NSOF na aplicação de MHT, foram utilizadas nanopartículas com três diâmetros e com quatro coberturas diferentes para cada um dos grupos do estudo.

As características das NSOF (Chemicell $\mathrm{GmbH}$, Berlin-Germany) estão descritas na tabela 4. A concentração da suspensão coloidal corresponde a $25 \mathrm{mgFe} / \mathrm{mL}$ em água bidestilada.

Tabela 4. Características das Nanopartículas superparamagnéticas de óxido de ferro utilizadas no estudo

\begin{tabular}{ccccccc}
\hline NSOF & Núcleo & Cobertura & $\begin{array}{c}\text { Diâmetro } \\
\text { Hidrodinâmico } \\
\text { (nm) }\end{array}$ & $\begin{array}{c}\text { No } \\
\text { Partículas/g }\end{array}$ & $\begin{array}{c}\text { Densidade } \\
\mathbf{g} / \mathbf{c m}^{3}\end{array}$ & $\begin{array}{c}\text { Grupo } \\
\text { funcional }\end{array}$ \\
\hline fluidMAG & $\mathrm{Fe}_{3} \mathrm{O}_{4}$ & Aminosilana & 100 & $\sim 1,3 \times 10^{15}$ & $\sim 1,25$ & Amino $-\mathrm{NH}_{2}$ \\
-Amino & & 200 & $\sim 2,2 \times 10^{14}$ & & \\
& & 50 & $\sim 1,3 \times 10^{16}$ & & \\
fluidMAG & $\mathrm{Y}-\mathrm{Fe}_{2} \mathrm{O}_{3}$ & Dextrana & 100 & $\sim 1,8 \times 10^{15}$ & $\sim 1,25$ & Grupo \\
-DX & & & 200 & $\sim 2,2 \times 10^{14}$ & & Hidroxila \\
fluidMAG & $\mathrm{Fe}_{3} \mathrm{O}_{4}$ & Quitosana & 100 & $\sim 2,2 \times 10^{14}$ & $\sim 1,25$ & Amino $-\mathrm{NH}_{2}$ \\
- & & & 200 & $\sim 2.2 \times 10^{14}$ & &
\end{tabular}

Chitosan

\begin{tabular}{ccccccc} 
fluidMAG & & 50 & $\sim 1,3 \times 10^{16}$ & & \\
-D & $\mathrm{Fe}_{3} \mathrm{O}_{4}$ & Starch & 100 & $\sim 1,8 \times 10^{15}$ & $\sim 1,25$ & Grupo \\
\hline & & 200 & $\sim 2,2 \times 10^{14}$ & & Hidroxila
\end{tabular}

NSOF: nanopartícula superparamagnética de óxido de ferro; nm: nanômetros; Quitosana: polissacarídeo, linear, D-glucosamina ligada ao B- (1-4) e N-acetil-D-glucosamina.

\subsection{Avaliação do aquecimento das nanopartículas superparamagnéticas de óxido de ferro após aplicação do campo magnético alternado}

Para adquirir as curvas de aquecimento gerada pelas NSOF após exposição ao CMA, foi utilizado $1 \mathrm{~mL}$ de cada amostra de NSOF com concentração de $25 \mathrm{mg} / \mathrm{mL}$ de Ferro, em uma porta amostra de acrílico. As amostras foram submetidas a análise primeiramente fixando frequências e posteriormente fixando campo magnético. 
As curvas geradas destas análises foram usadas para calcular os valores de SAR e ILP e para análise em relação ao diâmetro e a cobertura da NSOF.

\subsection{Cálculo da taxa de absorção específica e da perda de poder intrínseco}

O cálculo de SAR e ILP foi realizado por meio do software Zar v1.0 desenvolvido pela nanoScale Biomagnetics, baseado nas equações de 2.4 e 2.5 citadas no item 2.2.6. O SAR e o ILP foram calculados em dependência da distribuição do tamanho e da cobertura das NSOF em função da frequência e da intensidade do campo magnético.

Para a realização do processo de quantificação de SAR, foram analisadas: 4 tipos de NSOF com 3 tamanhos de núcleo de magnetita e maghemita, sob 3 campos magnéticos diferentes e 2 frequências distintas como está mostrado na figura 19.

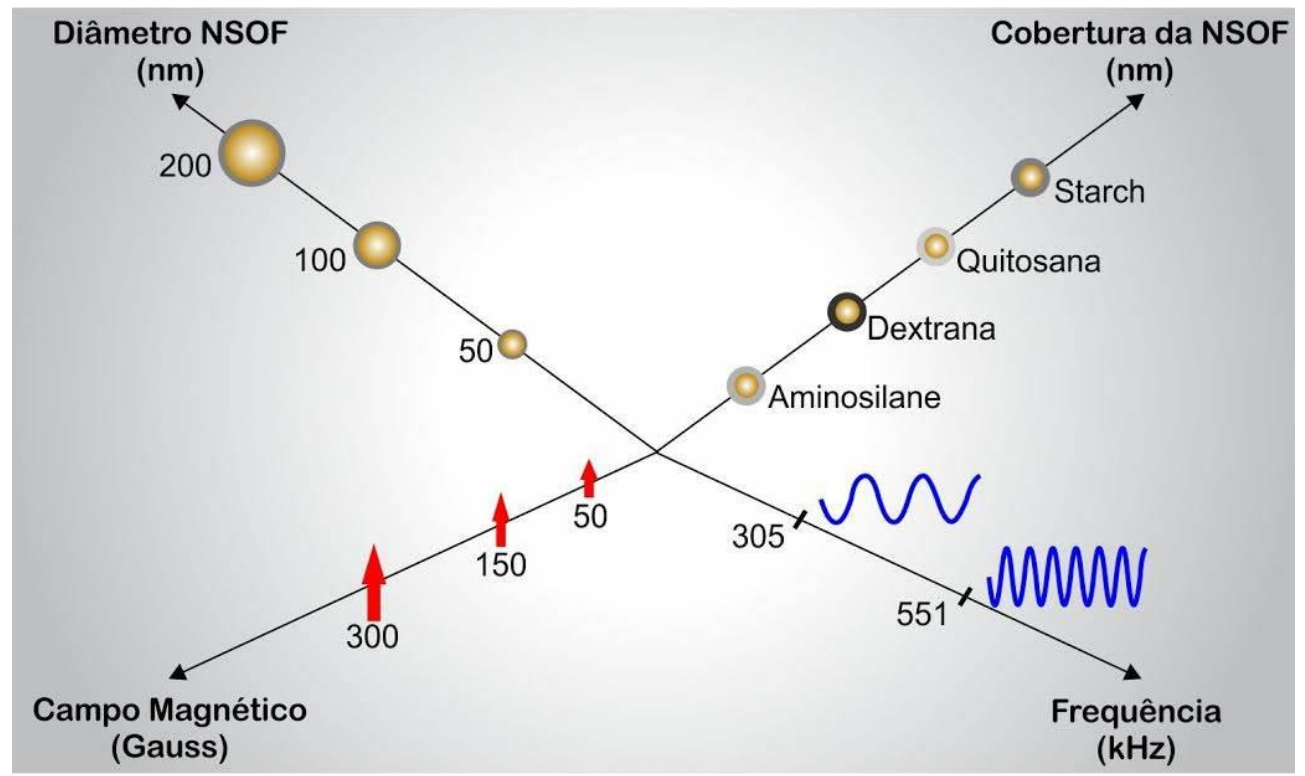

Figura 19. Parâmetros utilizados para a quantificação da taxa de absorção específica e perda de poder intrínseco 


\subsection{Estudos in vitro}

Para a análise da eficiência de $\mathrm{MHT}$, foi realizado o estudo in vitro utilizando células tumorais C6-Luc. Foram selecionadas NSOF, frequência e campo magnético após o melhor SAR obtido conforme descrito no item 3.3.

\subsubsection{Cultura celular da linhagem C6}

Foram utilizadas linhagem celular C6 provenientes do Banco de Células do Rio de Janeiro (BCRJ). As células foram cultivadas em garrafas de cultura de $75 \mathrm{~cm}^{2}$ (Corning, USA) em meio de crescimento essencial DMEM (Dulbecco's Modified Eagle Medium, GIBCO ${ }^{\circledR}$ Invitrogen Corporation, CA, USA) suplementado com $10 \%$ de soro fetal bovino (SFB) $\left(\right.$ GIBCO $^{\circledR}$ Invitrogen Corporation, CA, USA), com 1\% de penicilina-estreptomicina $\left(\right.$ GIBCO $^{\circledR}$ Invitrogen Corporation, CA, USA) e 1\% de L-glutamina (GIBCO ${ }^{\circledR}$ Invitrogen Corporation, CA, USA). Além disso, foram deixadas na estufa (Thermo Fisher Scientific Inc 3110, Waltham, MA), que proporcionou uma atmosfera de $5 \%$ de $\mathrm{CO}_{2}$ e $95 \%$ de ar a uma temperatura de $37^{\circ} \mathrm{C}$, condições essenciais para o crescimento das células, onde alcançaram a confluência de 75\%.

O meio foi removido, as células foram lavadas com PBS (tampão fosfato-salino) e posteriormente, foram liberadas para incubação com tripsina $(0,04 \%$ de tripsina / EDTA). Após desativação de tripsina com meio DMEM, as células foram centrifugadas a 1500 rpm por 5 minutos em $21^{\circ} \mathrm{C}$. Após centrifugação o pelete celular foi ressuspendido em meio DMEM para o uso no experimento.

\subsubsection{Transfecção de luciferase nas células C6}

A transfecção de luciferase nas células C6 (C6-Luc) foi realizada em parceria com a Universidade de São Paulo (USP), campus de Ribeirão Preto.

As células C6 foram transduzidas com vírions carreando o vetor lentiviral pMSCV_Luc2_T2A_puro. Este vetor codifica a proteína bioluminescente luciferase 2 e a proteína puromicina $\mathrm{N}$-acetil-transferase, a qual confere resistência ao antibiótico puromicina. 
Para a produção dos vírions, células HEK 293FT foram transfectadas simultaneamente com os vetores pMSCV_Luc2_T2A_puro, pCMV_dr8.91 (que codifica o capsídeo do HIV e os componentes enzimáticos dos vírions) e pMD2.G (que codifica o envelope do VSV-G). A transfecção foi realizada com politilenimina (PEI) linear de $25 \mathrm{kda}$ utilizando uma taxa de nitrogênio/fósforo de 50 . Dois dias após a transfecção, o sobrenadante contendo os vírions foi coletado, concentrado por ultracentrifugação e o título viral foi calculado por PCR quantitativo (qPCR) em tempo real.

Para a transdução lentiviral, os vírions foram adicionados às células C6 a uma multiplicidade de infecção de 3 na presença de $8 \mu \mathrm{g} / \mathrm{mL}$ de polibreno. O meio foi substituído após 18 horas e as células $\mathrm{C} 6$ foram cultivadas por mais 48 horas. Por fim, as células foram incubadas com puromicina durante 6 dias para a eliminação de células que não foram transduzidas, resultando na obtenção de uma população de células $\mathrm{C} 6$ expressando luciferase.

\subsubsection{Cinética do sinal de bioluminescência nas C6-Luc}

A análise da cinética do sinal de bioluminescência nas células C6Luc é fundamental para não se obter viés de resposta das células após MHT e assim captar com fidelidade o decaimento condizente com morte celular devido aplicação da terapia e não o decaimento natural de sinal bioluminescente da célula em decorrência do tempo. Portanto, após a transfecção de luciferase as células C6, as células C6-Luc foram submetidas a análise da bioluminescência para avaliação da cinética de sinal bioluminescente nas mesmas.

Para analisar a cinética do sinal, as células C6-Luc sem marcação com NSOF foram analisadas primordialmente sem adição de luciferina e posteriormente, após adição de luciferina, para quantificação de sinal bioluminescente e viabilidade celular por meio do equipamento IVIS ${ }^{\circledR}$ Lumina LT Series III (PerkinElmer USA) (Figura 20). 


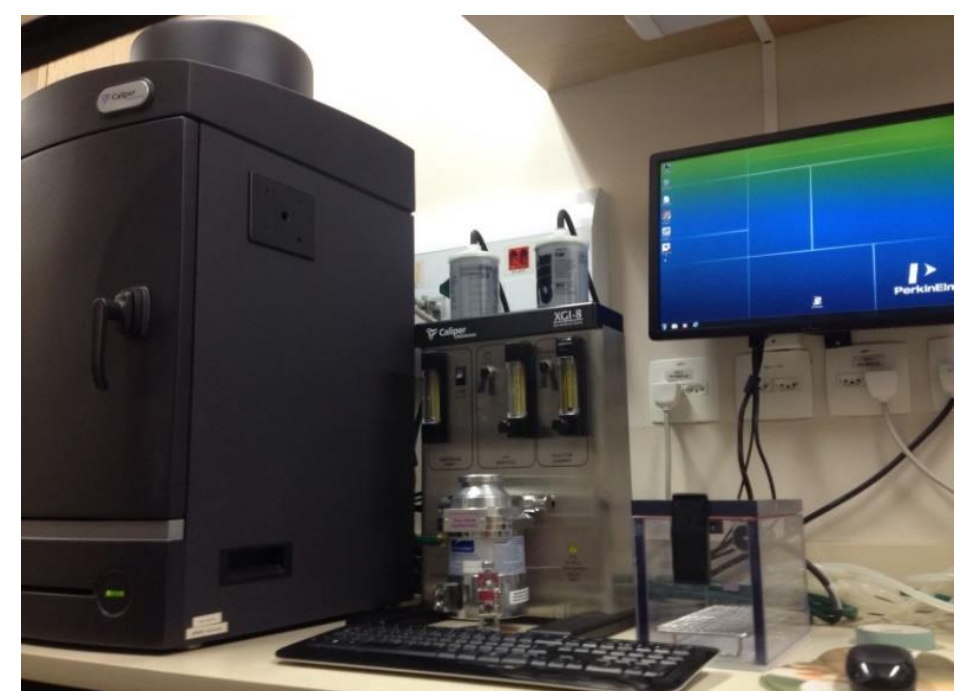

Figura 20. Equipamento utilizado na aquisição de imagens de bioluminescência

Para obtenção das imagens de bioluminescência, as células foram plaqueadas em poços de 48, distribuídas em concentrações celulares como é mostrada na figura 21. A placa sem adição de luciferina foi submetida a análise de bioluminescência para se obter respostas controle das concentrações celulares. Após a análise do sinal controle, foram adicionados 100uL de luciferina nos poços contendo as células e imediatamente foi adquirido o sinal de bioluminescência, devido a reação luciferase+luciferina. A análise da cinética do sinal bioluminescente foi avaliada temporalmente durante 24 horas. 


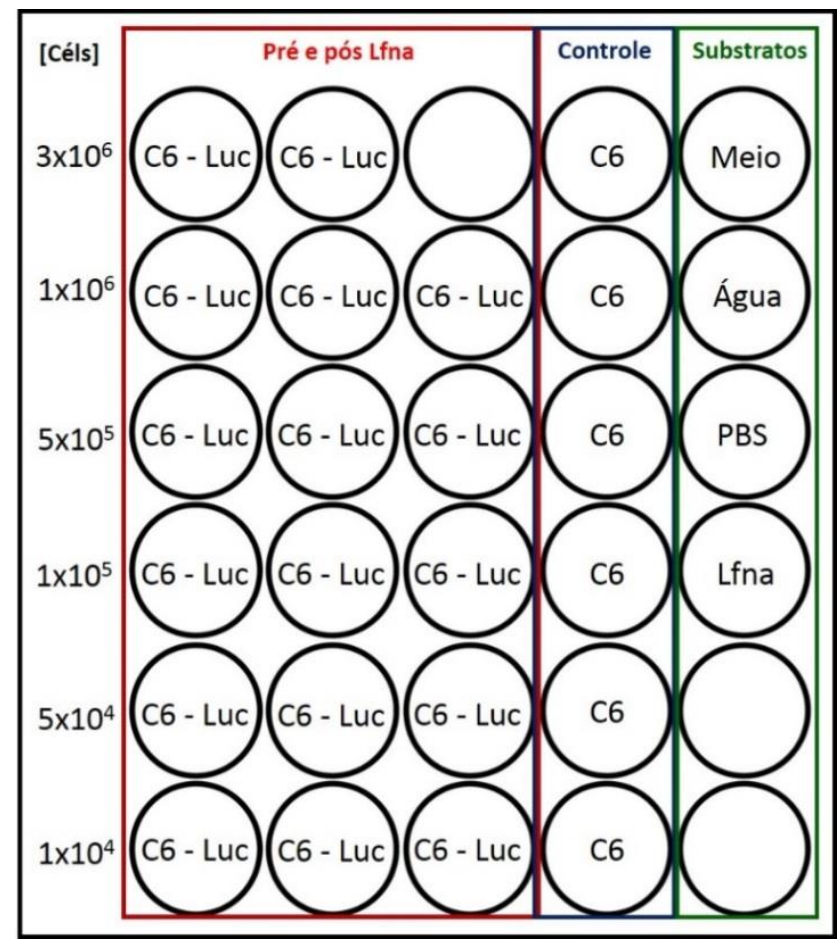

C6 - Luc: Células C6 com trasnfecção de luciferase; C6: Células C6 sem Luciferase; Meio: DMEM-LOW; PBS: tampão fosfato-salino; Lfna: Luciferina.

Figura 21. Disposição das amostras na placa de 48 poços

\subsubsection{Marcação das células C6-Luc com nanopartículas superparamagnéticas de óxido de ferro}

Para a marcação com NSOF, as células C6-Luc foram plaqueadas em poços de 24 em concentração de $10^{6}$ de células/poço, com meio RPMI (GIBCO ${ }^{\circledR}$ Invitrogen Corporation, CA, USA), suplementado com $10 \%$ de SFB $\left(\mathrm{GIBCO}^{\circledR}\right.$ Invitrogen Corporation, CA, USA). Após 3 horas em estufa, as células contendo $2 \mathrm{~mL}$ de meio, foram marcadas com as NSOF que obtiveram maiores valores de SAR.

As células C6-Luc foram marcadas com as duas melhores NSOF que obtiveram maiores valores de SAR (Figura 22A). A marcação foi realizada em três condições magnéticas: sem ímã (Figura 22B), IE (Figura 22C-D) e ímã dinâmico com execução à $0.25 \mathrm{kHz}$ (Figura 23E-G), em duas condições de filtração: com e sem filtro $0.45 \mu \mathrm{m}$ (SARSTEDT, Alemanha) (Figura 22A), com duas condições de agente de transfecção celular: com e sem agente de transfecção de Poli-L-Lisina (PLL - Poly-LLysine - Sigma-Aldrich Chemie GmbH, Germany) (Figura 22A) e em três 
concentrações de NSOF: 100, 200 e 300mg/mL, conforme figura 22A. A marcação das C6-Luc com as NSOF foi realizada por um período de 18 horas.

A visualização da marcação foi realizada por azul de Prússia.

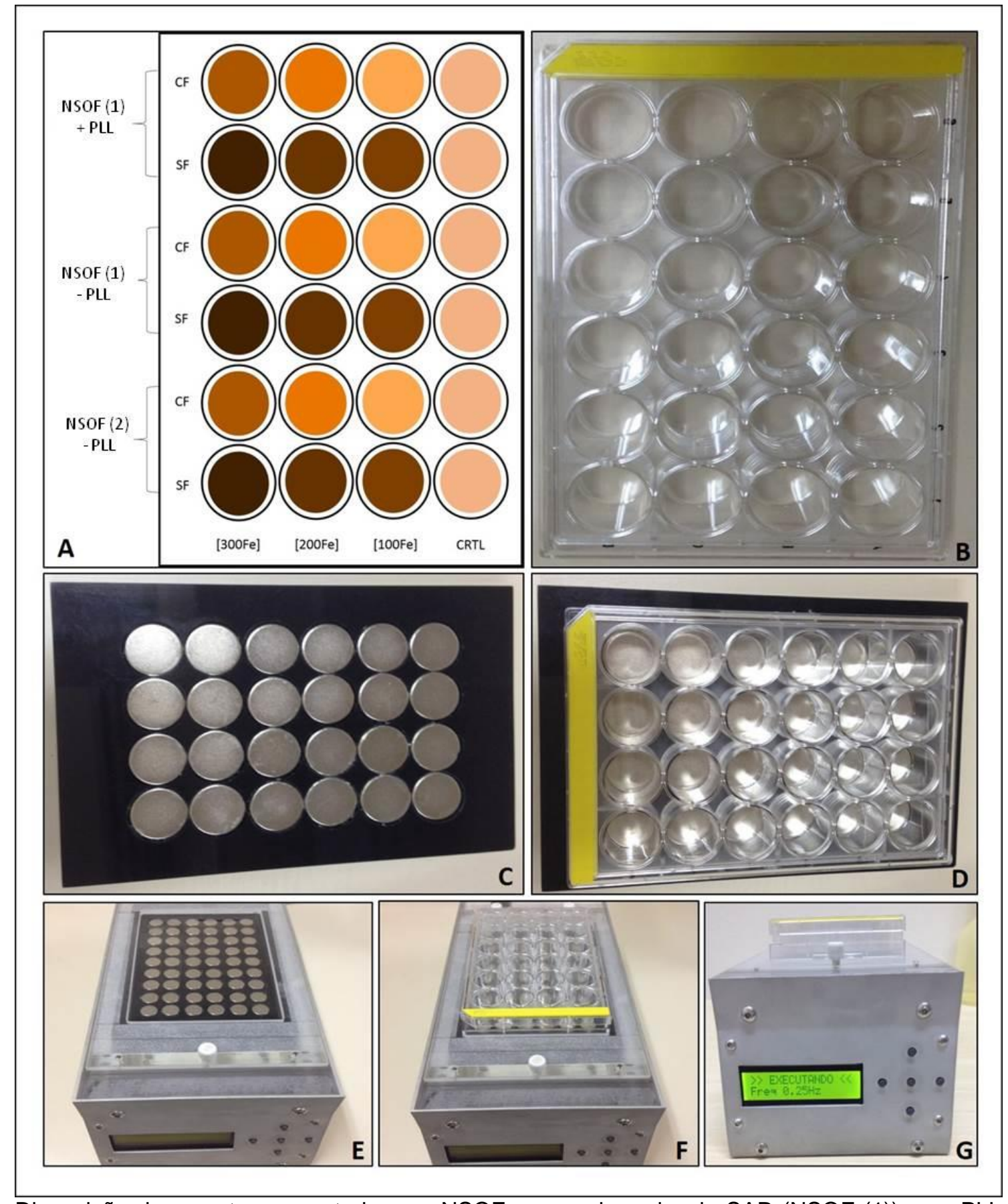

Disposição de amostras no estudo com NSOF com maior valor de SAR (NSOF (1)) com PLL (+), sem PLL(-) e com NSOF com segundo maior valor de SAR. (A); Placa de 24 sem ímã (B); ímã estático (C); Placa de 24 sobre ímã estático (D); Ímã dinâmico (E); Placa de 24 sobre ímã dinâmico (F); Îma dinâmico movimentado a 0,25 kHz (G). CF: Com filtro; SF: Sem filtro; PLL: Poly-L-lysina.

Figura 22. Métodos de marcação celular por NSOF 


\subsubsection{Visualização por azul de prússia das nanopartículas nas C6-Luc marcadas}

Para confirmar a marcação intracelular de NSOF nas C6-Luc, foi realizada a coloração por AP, para identificação de ferro na célula na forma de ferritina ou hemossiderina. A reação é gerada na interação de íons de ferrocianeto com íons férricos no interior celular, produzindo um precipitado de cor azul-esverdeado chamado ferrocianeto férrico:

$$
\mathrm{K}^{+}+\mathrm{Fe}^{3+}+\mathrm{Fe}(\mathrm{CN}) 6^{4-} \leftrightarrow \mathrm{KFe}[\mathrm{Fe}(\mathrm{CN}) 6]
$$

Onde o núcleo de óxido de ferro reage com a solução, e assim indica a presença das NSOF nas células C6-Luc marcando as mesmas em coloração azul. A solução de AP foi obtida a partir de $\mathrm{HCL}$ a $5 \%$ e com $\mathrm{K}_{4} \mathrm{Fe}(\mathrm{CN})_{6}$ resultando em uma solução final $\mathrm{K}_{4} \mathrm{Fe}(\mathrm{CN})_{6} \mathrm{HCl} 5 \%$.

Portanto, após marcação das células C6-Luc com NSOF, os poços das placas foram lavadas duas vezes com PBS e fixadas com 600uL de paraformol (PFA 4\%, Sigma-Aldrich, USA) por duas horas, para posterior marcação por azul de prússia. Após este período, os poços foram lavados duas vezes com PBS e posteriormente foram adicionados $600 \mathrm{uL}$ da solução de $\mathrm{K} 4 \mathrm{Fe}(\mathrm{CN}) 6 \mathrm{HCl} 5 \%$ em cada poço.

Após 5-6 minutos com a solução de azul de prússia em temperatura ambiente e protegidas da luz, os poços foram lavados com PBS para posterior registro das imagens no microscópio FSX-100 OLYMPUS.

\subsubsection{Configuração experimental do equipamento de magneto hipertermia}

O equipamento gerador de CMA a ser utilizado para aplicação de $\mathrm{MH}$, aquisição de curvas de aquecimento e cálculos de SAR e ILP é o MANIAC v1.0 com DM100/ Modelo DMC1 (nanoScale Biomagnetics) conforme mostrado na figura 23. O equipamento possui três sensores de temperatura de fibra óptica de alta resolução condicionada com uma faixa de medição de $-10^{\circ} \mathrm{C}$ a $120^{\circ} \mathrm{C}$ e com precisão: \pm $0,2^{\circ} \mathrm{C}$, com controle de temperatura da bobina. Opera em diferentes intensidades de campo magnético sinusoidal na faixa de 48 a 300 Gauss e frequência de 247 a 867 
$\mathrm{kHz}$. O resfriamento do sistema é realizado com o minichiller MCA-5-RI (Mecalor, Brasil) ajustado para uma vazão de agua $2 \mathrm{~m}^{3} / \mathrm{h}$ com uma pressão de 2,8 bar, mantendo a agua a uma temperatura de $12^{\circ} \mathrm{C}$.

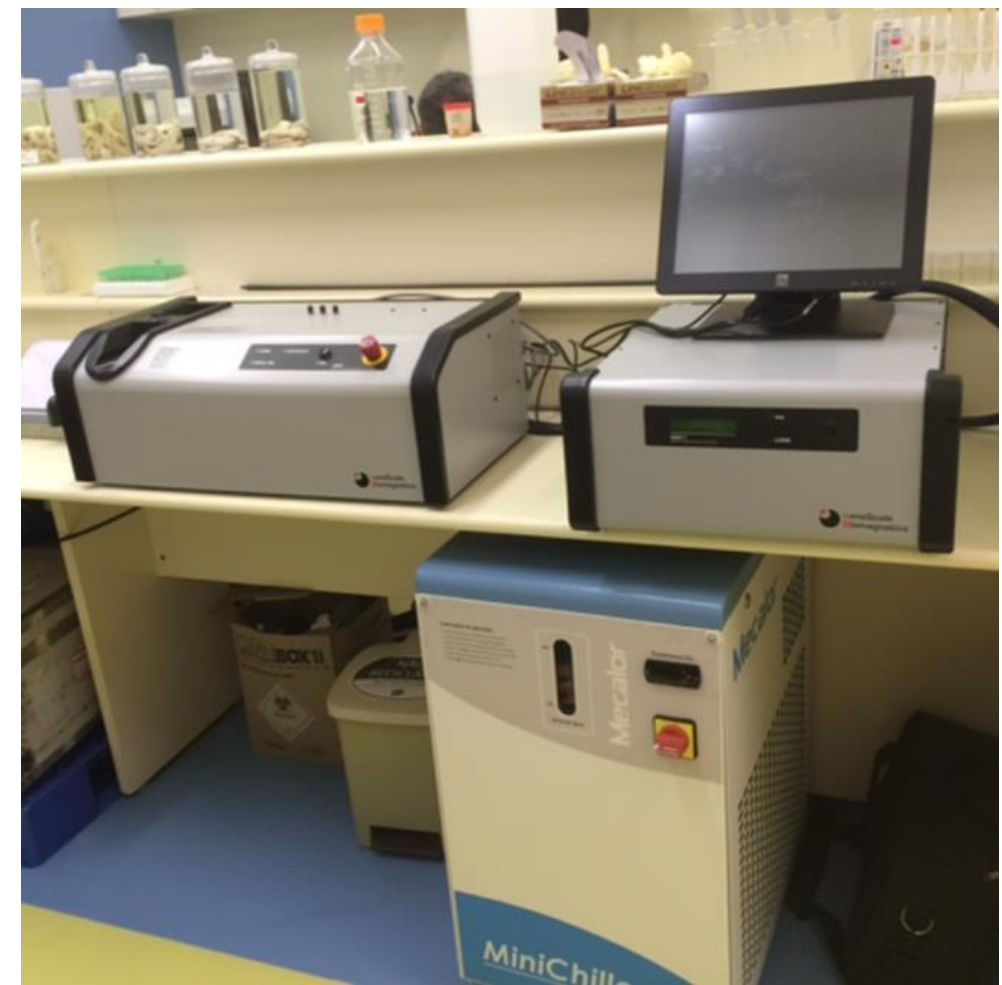

Figura 23. Equipamento de magneto hipertermia

\subsubsection{Aplicação de magneto hipertermia nas células C6-Luc}

Após realização da marcação, as células C6-Luc $\left(10^{6}\right)$ marcadas com a NSOF que obteve maior valor de SAR, foram ressuspendidas em 100uL de meio e colocadas em um porta amostra, para serem expostas à uma temperatura de $44^{\circ} \mathrm{C}$ por 10 e 40 minutos e por $48^{\circ} \mathrm{C}$ por 40 minutos à aplicação de CMA para gerar aquecimento das NSOF e posterior lise das células tumorais as quais as nanopartículas magnéticas estão internalizadas. A elevação de temperatura foi captada por um dos sensores de temperatura de fibra óptica. 


\subsubsection{Avaliação da eficiência da técnica de magneto hipertermia}

A avaliação da viabilidade celular após a aplicação de MHT é fundamental para análise de eficiência da técnica. Essa avaliação foi realizada comparando a viabilidade das células C6-Luc sem marcação com NSOF e sem exposição à MHT; C6-Luc não marcadas com NSOF e expostas à MHT; C6-Luc marcadas com NSOF e não expostas à MHT e C6-Luc marcadas com NSOF e expostas à MHT.

\subsubsection{Bioluminescência}

A bioluminescência das células C6-Luc marcadas com a NSOF com maior valor de SAR submetidas à MHT foi realizada após a aplicação da terapia de acordo com tempo e temperatura, portanto, após a realização de terapia por magneto hipertermia, foram adicionados $100 \mathrm{uL}$ de luciferina nas amostras contendo as células e imediatamente foi adquirido o sinal de bioluminescência.

As imagens após adição de luciferina foram captadas por 40 minutos e por 24 horas com intervalo de 2 min entre cada aquisição, das amostras de células marcadas com SPION sem MHT, para análise de viabilidade de marcação ao longo do tempo.

\subsubsection{Citometria de fluxo por anexina V - PI}

A análise da viabilidade das células marcadas com NSOF foi realizada por meio de ensaios de anexina $V$ - FITC/PI utilizando citometria de fluxo (BD LSRFortessa, Estados Unidos), para a análise do processo de célula viável/morte celular (necrose/apoptose). Após a aplicação de MHT, as células C6-Luc (10 ${ }^{6}$ células) foram centrifugadas e lavadas com wash buffer e posteriormente marcadas com iodeto de propídio $(5 \mu \mathrm{L})$ e anexina V-FITC $(5 \mu \mathrm{L})$, e após 20 minutos, a marcação foi bloqueada para análise, conforme protocolo já estabelecido. ${ }^{(146)}$ 


\subsection{Estudos in vivo}

Foi realizado o estudo in vivo no modelo animal de glioblastoma com o objetivo de analisar a eficiência da técnica de MHT em modelo animal.

\subsubsection{Animais}

Foram utilizados animais Wistar da linhagem Rattus norvegicus, machos, pesando entre 290 e $350 \mathrm{~g}$ no início do experimento. Os animais foram aclimatados no Biotério do Centro de Experimentação e Treinamento em Cirurgia (CETEC) /Instituto do Cérebro do Hospital Israelita Albert Einstein, onde permaneceram alojados com ração e água (ad libitum) em gaiolas de polipropileno apropriadas, forradas com serragem autoclavada, com tampa tipo grade em aço inoxidável e divisões para ração balanceada e água, tendo livre acesso à água e ração. Durante todo o período de realização dos experimentos, esses animais ficaram alojados em caixas de polipropileno individuais. O biotério é acreditado pela AAALAC, obedecendo a um ciclo claro-escuro de 12 horas (7 a 19 horas), com temperatura ambiente constante de $(21 \pm 2)^{\circ} \mathrm{C}$, conforme especificações internacionais.

\subsubsection{Grupos experimentais}

Os grupos foram definidos prevendo o uso de 38 animais distribuídos nos seguintes grupos:

\section{G0: Estudo de volumetria tumoral}

Estudo para aquisição de volumetria tumoral por IRM $\operatorname{com} 10^{4}, 10^{5} \mathrm{e}$ $10^{6}$ de células em $10 \mu \mathrm{L}$ de meio de cultura, avaliar a cinética do crescimento tumoral.

- Grupo Controle ( $n=03)$ : Animais sem nenhuma intervenção;

- Grupo $10^{4}$ ( $\left.n=03\right)$ : Administração de $10^{4}$ células C6-Luc;

- Grupo $10^{5}$ ( $\mathrm{n}=03$ ): Administração de $10^{5}$ células C6-Luc; 
- Grupo $10^{6}$ ( $n=03$ ): Administração de $10^{6}$ células C6-Luc.

\section{G1: Estudo comportamental}

Estudo para aquisição de resposta comportamental padrão de glioblastoma.

- Grupo Controle $(n=04)$ : Animais sem nenhuma intervenção;

- Grupo Craniotomia ( $n=04)$ : Craniotomia com administração de10 $\mu \mathrm{L}$ meio de cultura;

- Grupo Tumoral ( $n=04)$ : Indução tumoral de glioblastoma.

A avaliação comportamental foi realizada em 0, 7, 14, 21 e 28 dias. Nestes períodos foram obtidas imagens de IRM. Após cada etapa de crescimento tumoral obteve-se cortes histológicos do cérebro dos animais.

\section{G2: Estudo de volumetria por bioluminescência}

Estudo para aquisição de padrão de volumetria tumoral adquirida por técnica de bioluminescência.

- Grupo Tumoral ( $n=08)$ : Indução tumoral por glioblastoma.

A avaliação temporal foi realizada nos mesmo períodos de tempo do estudo de volumetria por IRM na análise comportamental.

\section{G3: Estudo de eficiência de MHT}

Estudo para avaliar eficiência terápica, após aplicação de MHT.

- Grupo Controle ( $n=03)$ : Animais sem nenhuma intervenção;

- Grupo Tumoral ( $n=03)$ : Com NSOF e com aplicação de MHT.

O grupo tumoral foi submetido à MHT no $21^{\circ}$ dia de crescimento tumoral. Os grupos foram mapeados por bioluminescência pré e após-MHT. 


\subsubsection{Indução tumoral de glioblastoma no modelo animal}

Os animais foram anestesiados com ketamina $(90 \mathrm{mg} / \mathrm{Kg})$ e xilasina $(12 \mathrm{mg} / \mathrm{Kg})$. O anestésico foi administrado por via intramuscular na dose de $4 \mathrm{~mL} / \mathrm{Kg}$ do peso do animal. Os animais foram posicionados em um aparelho de estereotaxia (51603, Harvard Apparatus ${ }^{\circledR}$, USA), com região superior da cabeça alinhada e fixada por barras intra-auriculares e por pressão de dentes incisivos superiores (Figura 24A). Após a incisão da pele na região dorsal do crânio e a remoção do periósteo (Figura 24B) foi efetuada a trepanação da calota óssea, por meio de uma broca dentária 50000 RPM (TECH 2000 CE, USA) (Figura 24C), para a introdução da agulha de uma seringa hamington de $10 \mu \mathrm{L}$ para o implante de células C6-Luc no córtex parietal direito (Figura 24D).

A implantação das células C6-Luc foi determinada e marcada sobre a tábua óssea seguindo as orientações do Atlas estereotáxico. ${ }^{(147)}$ A administração das células foi realizada no córtex parietal direito com as seguintes coordenadas: ânteroposterior $=2,0$, látero-lateral $=2,0$, profundidade $=2,5$. Em seguida, o plano ósseo foi recomposto com resina acrílica odontológica (Figura 24E) e a pele suturada com fio de algodão (Figura 24F). 


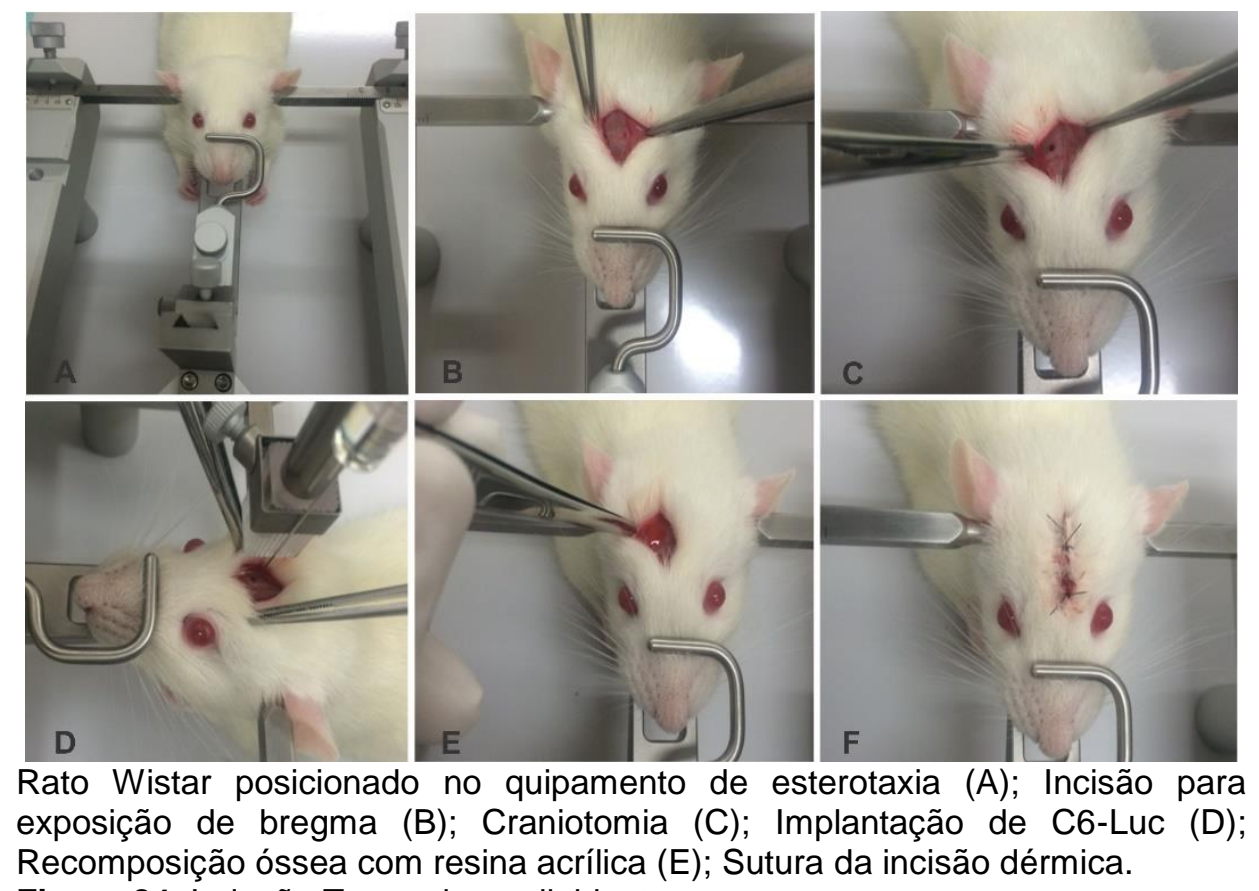

Figura 24. Indução Tumoral por glioblastoma

\subsubsection{Volumetria tumoral}

Foi avaliado o crescimento do tecido tumoral por IRM e bioluminescência para definir melhor quantidade de células para indução e posteriormente a visualização de resposta de crescimento tumoral após terapia por MHT.

\subsubsection{Avaliação da volumetria tumoral por imagem de ressonância magnética}

Foram adquiridas imagens por RM dos animais nos dias 7, 14, $21 \mathrm{e}$ 28 dias após indução de glioblastoma com diversas concentrações celulares de C6Luc. Antes de iniciar as sessões de IRM, os animais foram anestesiados com uma mistura de ketamina $(90 \mathrm{mg} / \mathrm{Kg})$ e xilasina $(12 \mathrm{mg} / \mathrm{Kg})$, por via intramuscular na dose de $4 \mathrm{~mL} / \mathrm{Kg}$ do peso do animal, para evitar movimentos voluntários.

As IRM foram adquiridas utilizando um magneto supercondutor horizontal com campo 2T da Oxford Instruments (modelo 65310HR), que opera em conjunto com um espectrômetro Bruker ${ }^{\circledR}$. A sequência utilizada para a aquisição das imagens ponderada em T2 foi a RARE, com os parâmetros: TR=4,000ms, TE=67,1ms, rare factor $=6$, 18 médias e comprimento de banda de $12,5 \mathrm{KHz}$, resultando em um 
tempo de aquisição de cerca de 50 minutos por animal. O campo de visão utilizado foi de $35 \times 35 \mathrm{~mm}^{3}$, com uma matriz de $192 \times 192$ pontos, produzindo uma resolução espacial de $182 \times 182 \mathrm{~mm}$. Foram utilizadas 26 fatias de $0,5 \mathrm{~mm}$ de espessura sem espaçamentos entre elas. Para cada sessão de imagens em cada ponto temporal, dos 26 cortes adquiridos, foram selecionados os cortes de melhor visualização tumoral para realização de ROls com a ajuda do software Paravision $5^{\circledR}$. Foi obtida a área tumoral em cada corte, que, somada e multiplicada pela espessura da fatia, forneceu o volume do tumor.

\subsubsection{Avaliação da volumetria tumoral por bioluminescência}

Após indução tumoral por glioblastoma os animais foram monitorados nos dias 7, 14, 21 e 28 para análise de volumetria tumoral por bioluminescência.

Para realização de bioluminescência os animais foram anestesiados com isoflurano. O equipamento IVIS, dispõe de um sistema (XGI-8 - Gas Anesthesia System - Perkin Elmer ${ }^{\circledR}$ ) para indução e manutenção de anestesia inalatória, que possibilita uma rápida indução de anestesia e manutenção de forma segura. Para a indução anestésica, o animal foi acondicionado em uma caixa de acrílico, acoplada ao sistema de anestesia. Em seguida, foi liberado para a caixa, o fluxo de 2,5L/min de $\mathrm{O}_{2}$, com saturação de $2,5 \%$ de Isoflurano. Após a indução de imobilidade e perda dos reflexos de endireitamento (cerca de 3 minutos) o animal foi transferido para o interior do equipamento, que dispõe de cânulas de acrílico (que funcionam com respirador acoplado ao sistema de anestesia) e controle preciso da vaporização, que permitiram a manutenção da anestesia durante o procedimento.

A recuperação anestésica ocorreu com a redução da saturação do anestésico e aumento da saturação de $\mathrm{O}_{2}$. A indução do sinal de bioluminescência foi realizada pela adição de $100 \mu \mathrm{L}$ de solução de luciferina (1mM em PBS) utilizando um período de leitura de 1 segundo através de um sistema de imagem de bioluminescência (IVIS System III, Xenogen Corp. CA, EUA). As imagens por bioluminescência foram detectadas em 5 minutos após administração de luciferina e assim o sinal de bioluminescência proveniente das células C6-Luc pôde ser detectado 
após a exposição das células transfectadas a solução de luciferina, utilizando uma câmera CCD ultrassensível para o imageamento e quantificação da intensidade da luz.

\subsubsection{Avaliação comportamental do animal após indução tumoral}

A análise de comportamento animal foi realizada com objetivo de se ter respostas motoras e de comportamento exploratório gerado pelo crescimento do tumor em comparação com animal controle e posteriormente com grupo apósaplicação de MHT.

\subsubsection{Avaliação de marcha - CatWalk}

A marcha do animal foi analisada usando um aparelho CatWalk (Noldus Information Technology®, Holanda), que consiste em uma plataforma de vidro de $1,3 m$ de comprimento iluminada por luzes fluorescentes que são refletidas para baixo quando se aplica pressão na plataforma. Debaixo da plataforma de vidro uma câmera foi montada para gravar o animal em locomoção. A passagem foi fixada a $250 \mathrm{~mm}$ de largura. A câmera foi posicionada a $70 \mathrm{~cm}$ abaixo da plataforma e as configurações de detecção automática foram aplicadas. Um limite de intensidade foi ajustado para 0,10 e o ganho da câmera foi ajustado para 9Db (Figura 25A-B). Um ensaio foi considerado como bem-sucedido quando o animal não obteve uma variação de velocidade máxima superior a $60 \%$, duração mínima de corrida de 0,5 segundo, duração máxima de corrida de 30 segundos e não parasse na plataforma. Repetiu-se qualquer tentativa sem êxito até se obter o número necessário de 3 ensaios bemsucedidos. Os ratos foram submetidos à avaliação da marcha no dia 0 (linha de base) e nos dias 7, 14, 21 e 28 dias após a indução tumoral ou cirurgia simulada (animais de craniotomia). 


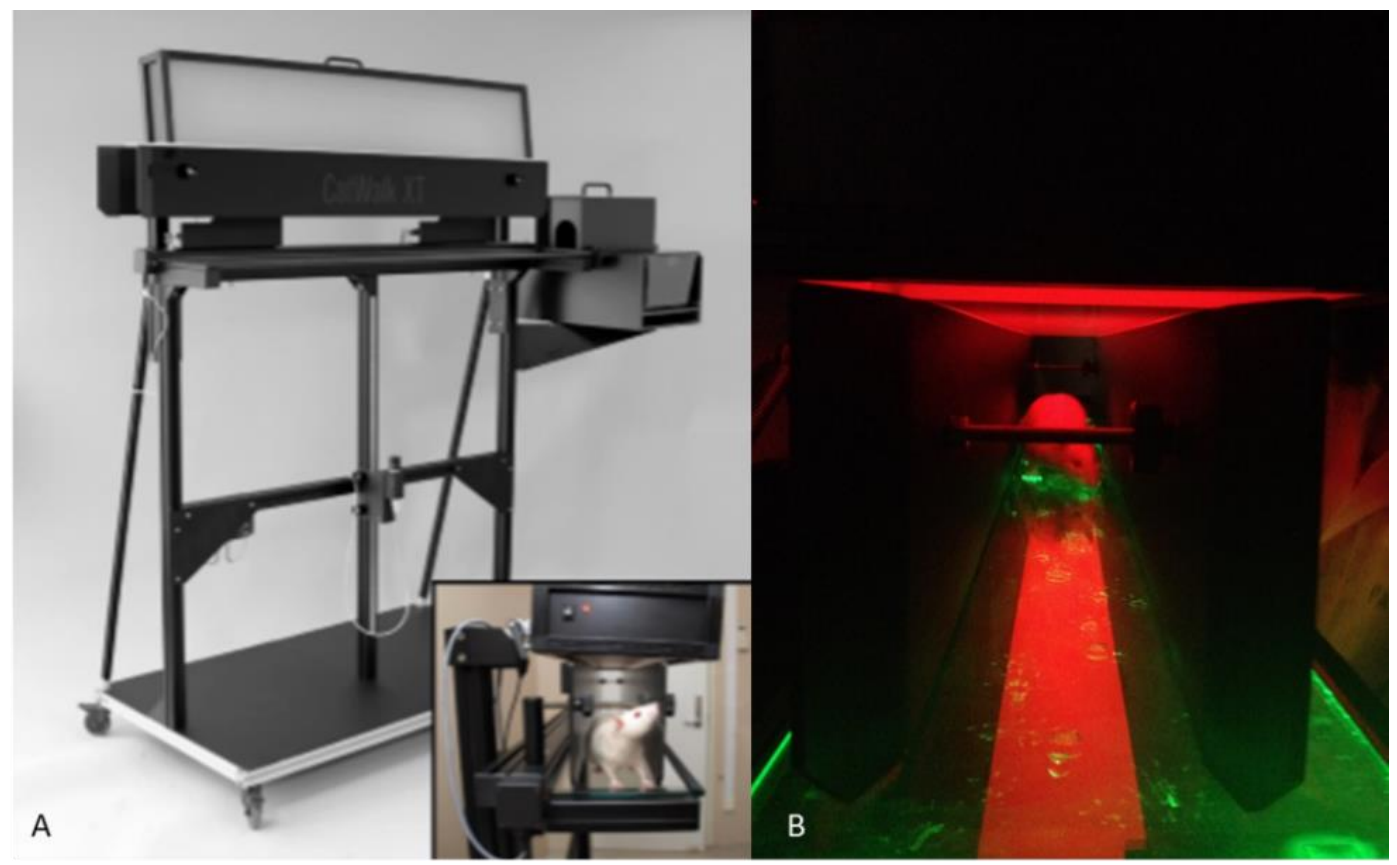

Estrutura do equipamento e plataforma (A); Animal posicionado no equipamento para análise de marcha (B). A- imagem do manual.

Figura 25. Equipamento de CatWalk

A avaliação consistiu primariamente na identificação correta das patas: patas posteriores direita e esquerda (PPD, PPE), e patas anteriores direita e esquerda (PAD, PAE) (Figura 26A). Após a identificação das patas, os passos gerados pelo animal foram analisados conforme a classificação padrão do sistema, mostrado na figura 26E. Durante a análise dos dados, uma análise visual foi realizada para identificação correta das patas e remoção de classificações errôneas causadas pela cauda e bigodes. Após a identificação de pegadas individuais, realizou-se uma análise automatizada de uma ampla gama de parâmetros. Os dados foram classificados da seguinte forma:

(i) parâmetros espaciais: comprimento do passo (CoP) em centímetros, entre duas pegadas consecutivas da mesma pata, conforme mostrado na figura 26B; área de máximo contato (AC), é a maior área de contato de uma pata durante toda a corrida em centímetros quadrados (Figura 26F); distância entre patas ipsilateraisDPi do mesmo ciclo (DPi) em centímetros, conforme mostrado na figura 26A; distância entre patas anteriores ou posteriores (DP) em centímetros, entre patas da parte frontal ou traseira (Figura 26A).

(ii) parâmetros temporais: tempo de contato (TC) da pata na superfície em segundos, no qual a pata fica em contato com a plataforma durante uma pegada (Figura 26C); ciclo do passo (CiP) da mesma pata em segundos, tempo entre o 
contato inicial de uma pegada e o contato inicial da pegada consecutiva (Figura 26C); cadência, passos por segundo e a duração do ciclo, que é a duração do tempo de toda a corrida.

No final da sessão, os animais foram devolvidos à sua gaiola e a plataforma de vidro (CatWalk) foi limpa com álcool a 5\% para evitar perturbação do olfato do animal, evitando assim um viés de comportamento que alterasse a aquisição de marcha do animal. 


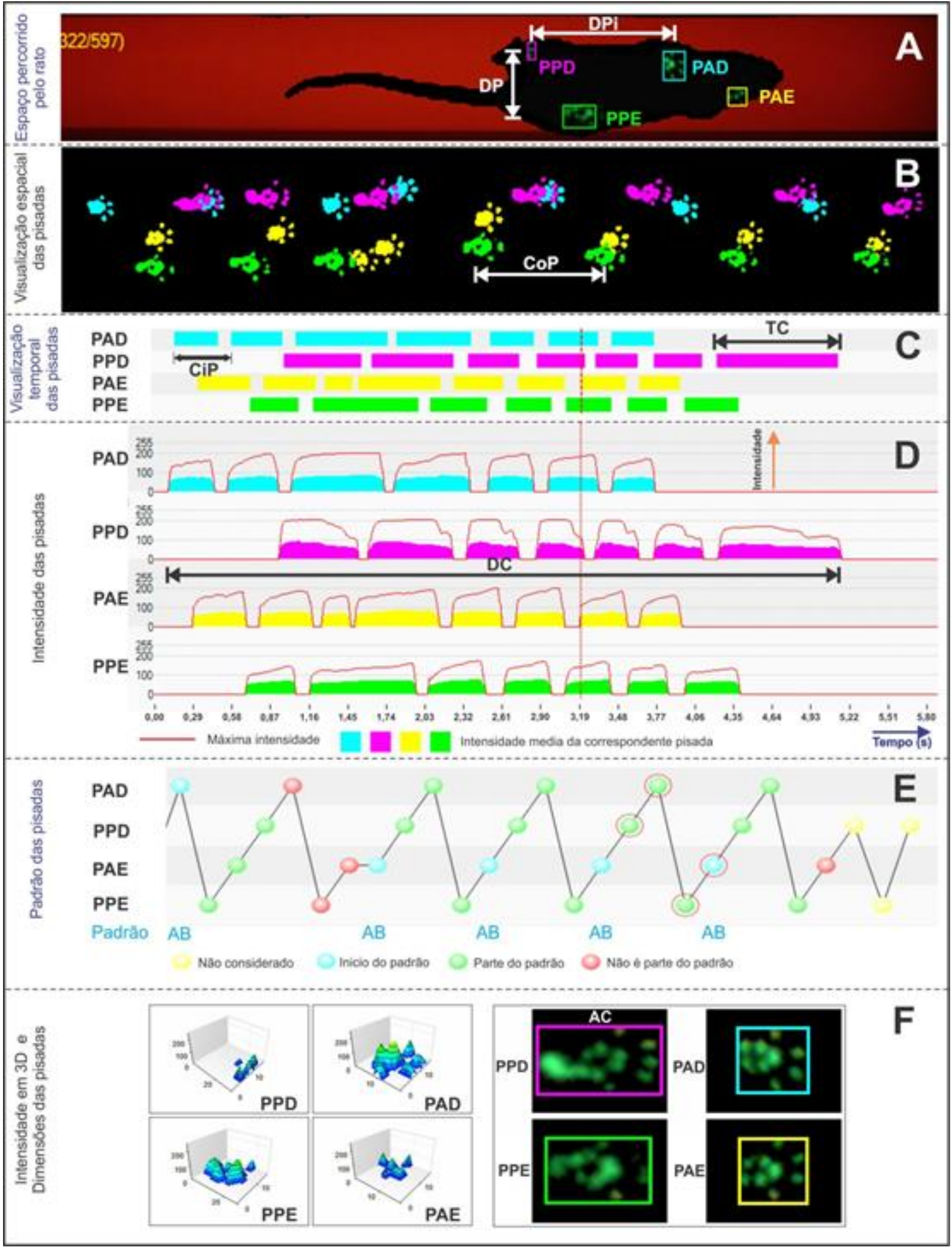

PPD: pata posterior direita; PPE: pata posterior esquerda; PAD: pata anterior direita; PAE: pata anterior esquerda; CoP: comprimento do passo; CiP: ciclo do passo; TC: tempo de contato; DPi: distância entre patas ipsilaterais do mesmo ciclo; AC: área de máximo contato; CiP: Ciclo do passo. Figura 26. Sistema de CatWalk e suas variáveis envolvidas na análise do comportamento animal 


\subsubsection{Avalição locomotora espontânea - Actômetro}

A atividade locomotora espontânea global foi quantificada utilizando o sistema Infrared (IR) Actimeter LE 8825 (Actitrack, Panlab Harvard Apparatus, Barcelona, Espanha). O sistema é composto por uma superfície quadrada bidimensional (eixos $\mathrm{X}$ e $\mathrm{Y}$ ), um suporte de quadro e uma unidade de controle. Cada frame conta com 16x16 feixes infravermelhos para a detecção de sujeitos, usados para avaliação de atividade geral locomotora, movimentos estereotipados ou exploração (detecção de raio-nariz na opção hole-board). O aparelho é constituído por um quadro quadrado de $450 \times 450 \mathrm{~mm}^{2}$, rodeado por paredes transparentes de $30 \mathrm{~cm}$ de altura. A atividade locomotora espontânea foi quantificada utilizando gaiolas de atividade equipadas com dois feixes infravermelhos horizontais localizados um acima do outro, 4 e $8 \mathrm{~cm}$ acima do piso da gaiola. Cada animal foi colocado no centro do quadrado e o comportamento espontâneo foi rastreado durante 5 minutos (Figura 27).

Durante o ensaio, a atividade locomotora horizontal (movimentos ou estereótipos) foi determinada por rupturas em fotossensores sensíveis a movimentos que foram então convertidos em contagens de atividade locomotora e atividade vertical (número de episódios de criação quebrando os feixes de fotocélula da estrutura superior). O limiar programado para a moldura superior foi de 10 segundos e o frame inferior foi de 5 segundos para a velocidade de movimento (lenta ou rápida).

Movimentos espontâneo lento (MOV-L) e rápido (MOV-R), respectivamente, representam o número de deslocamentos abaixo ou acima do limiar; o movimento de cabeça ou movimentos estereotipados Rápidos (STE-R - Stereotyped Moviments) e Lentos (STE-L), representa o número de movimentos sem deslocamento acima ou abaixo do limiar; movimentos de erguidas lentos (REA-L - Rearing) e rápidos (REA-R), respectivamente, representa o número de vezes que o animal se levanta abaixo ou acima do limiar. Os dados descritos acima foram processados usando 0 software SEDACOM v2.0.

Ao final da sessão, os animais foram devolvidos à sua gaiola e a superfície do equipamento foi limpa com álcool (5\%) a cada mudança de animal para evitar perturbação do olfato do animal. 


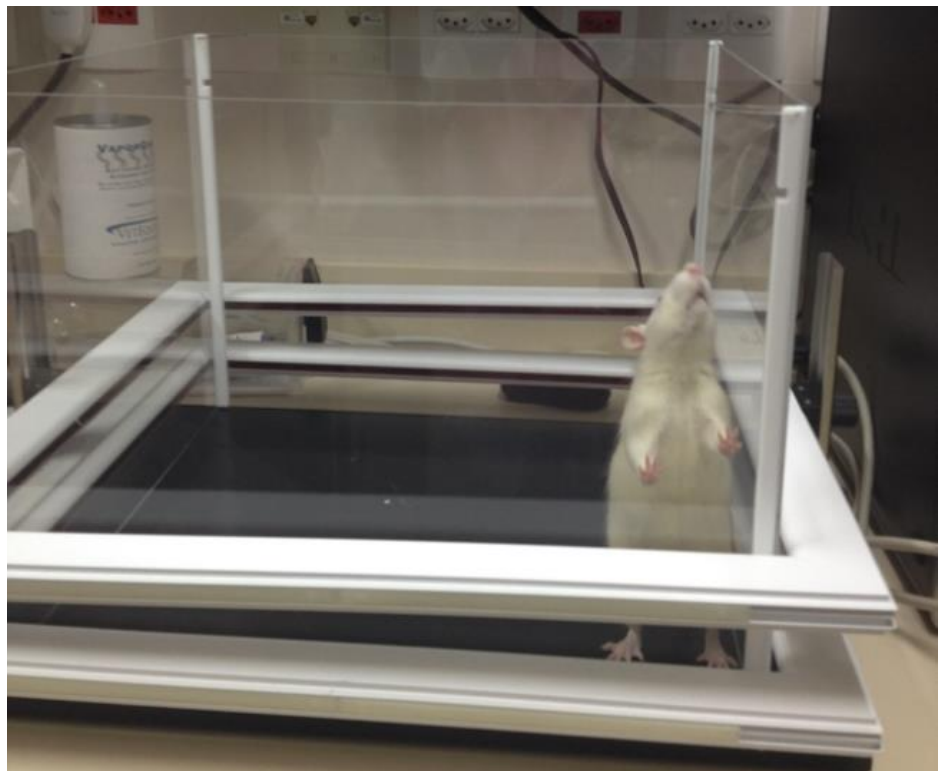

Figura 27. Equipamento Actômetro utilizado na análise comportamental exploratória espontânea

\subsubsection{Análise histoquímica de cortes histológicos}

A avaliação histoquímica do cérebro foi realizada após 7, 14, 21 e 28 dias da indução do tumor de glioblastoma. Nos períodos citados os animais foram eutanasiados e os cérebros retirados para análise histológica tumoral. A anestesia para a eutanásia do animal foi realizada administrando ketamina $(90 \mathrm{mg} / \mathrm{Kg})$ e xilasina $(12 \mathrm{mg} / \mathrm{Kg})$. Com o animal já eutanasiado, foi realizada a excisão do cérebro do animal para posterior preservação tecidual com PFA a 4\% por 24 horas, em solução contendo sacarose a $30 \%$ por 24 horas, criopreservação do tecido por metilbutano e imediata alocação em refrigeração $-80^{\circ} \mathrm{C}$. Para realização de corte histológico no criostato Leica (CM 1860, Alemanha), primeiramente se extraiu o cerebelo da composição cerebral, e em seguida foi estimada a localização e o tamanho do tumor para realização dos cortes histológicos e sua fixação na lâmina.

Os cortes cerebrais foram corados com Hematoxilina-Eosina (HE) para análise de tecido tumoral e as imagens histológicas foram registradas pelo microscópio Nikon Eclipse -TI-FL (Nikon, Japão). 


\subsubsection{Ensaio do processo de magneto hipertermia no modelo animal}

Foi realizada aquisição de volumetria tumoral por bioluminescência três dias antes da aplicação da técnica de MHT para averiguação de localização de tumor e administração de NSOF. O animal foi anestesiado com ketamina $(90 \mathrm{mg} / \mathrm{Kg})$ e xilasina $(12 \mathrm{mg} / \mathrm{Kg})$ para evitar movimentações ao ser submetido à $\mathrm{MHT}$. Foi administrado no total de $100 \mu \mathrm{L}$ fluído da NSOF com maior valor de SAR calculado, em 4 regiões diferentes circudante da massa tumoral $(25 \mu \mathrm{L}$ cada região) com acesso pela mesma via de indução tumoral.

Em seguida o animal foi disposto dentro da bobina do equipamento de MHT de tal modo que o volume tumoral fosse posicionado no centro da mesma. Assim, foi aplicado um CMA, com frequência e duração em escala de tempos de $10 \mathrm{e}$ 40 minutos.

O mapeamento da temperatura foi adquirido mediante o uso de um termômetro de fibra óptica (Luxtron 3204) com sondas de temperatura (diâmetro de $0,55 \mathrm{~mm}$ ) permitindo a leitura instantânea da temperatura no local do tumor e do reto durante todo o procedimento.

\subsubsection{Avaliação de eficiência terapêutica após magneto hipertermia in vivo por bioluminescência}

A análise de bioluminescência foi realizada conforme descrito no item 3.5.4.2, para detectar a resposta de sinal bioluminescente do tumor após aplicação de MHT e assim verificar a porcentagem de lise celular tumoral.

\subsection{Análises estatísticas}

Os resultados das curvas de aquecimento das NSOF submetidas ao CMA foram caracterizados calculando a média e o desvio padrão obtidos.

Para as variáves da avaliação comportamental do CatWalk, devido ao número de observações para cada combinação de grupo e momento, não foi 
investigado a priori a distribuição amostral dos dados e os valores foram descritos por médias e desvios padrão.

Para as comparações foram utilizados modelos mistos generalizados e modelos de equações de estimação generalizadas. Os resultados foram apresentados por valores ajustados pelos modelos e intervalos de confiança de $95 \%$, e as comparações múltiplas foram corrigidas pelo método de Bonferroni.

Para as variáveis do Actômetro, a melhor estrutura de covariância foi a autorregressiva de primeira ordem e a distribuição considerada foi a Poisson, com função de ligação log. Para as demais variáveis, foi considerada a distribuição Gamma e a estrutura de correlação foi a de simetria composta.

As análises foram realizadas com o auxílio do pacote SPSS e considerando nível de significância 5\%.

\subsection{Aspectos éticos}

O trabalho foi desenvolvido de acordo com as Normas do Comitê de Ética em Pesquisa Animal do Hospital Israelita Albert Einstein (HIAE). 


\section{RESULTADOS}

4.1 Curvas de aquecimento das nanopartículas superparamagnéticas de óxido de ferro após aplicação do campo magnético alternado

As nanopartículas recobertas com aminosilana (NSOF-Amino), dextrana (NSOF-Dex), quitosana (NSOF-Quit) e starch (NSOF-Starch) foram submetidas ao CMA em diferentes intensidades de campo e em diferentes frequências conforme figuras 28 e 29, para obtenção de curvas de aquecimento e quantificação de SAR e ILP, para se obter a melhor NSOF, melhor frequência e melhor campo magnético para aplicação de MHT.

As figuras 28A-C correspondem aos três tamanhos $(50,100$ e 200nm) da NSOF-Amino e as curvas de resposta que foram adquiridas. As figuras 28D-F, correspondem as curvas obtidas pelas NSOF-Dex. Em um determinado tempo (800 segundos) as curvas de resposta da amostra de NSOF-Dex de 50 e 100nm permanecem constante após alcançar o pico de temperatura máxima, exceto, as amostras que foram submetidas ao campo de 300 gauss e a $551 \mathrm{kHz}$ (inset, Figura 28D) e da curva de 300 gauss com 305 e $551 \mathrm{kHz}$ (inset, Figura 28E). 

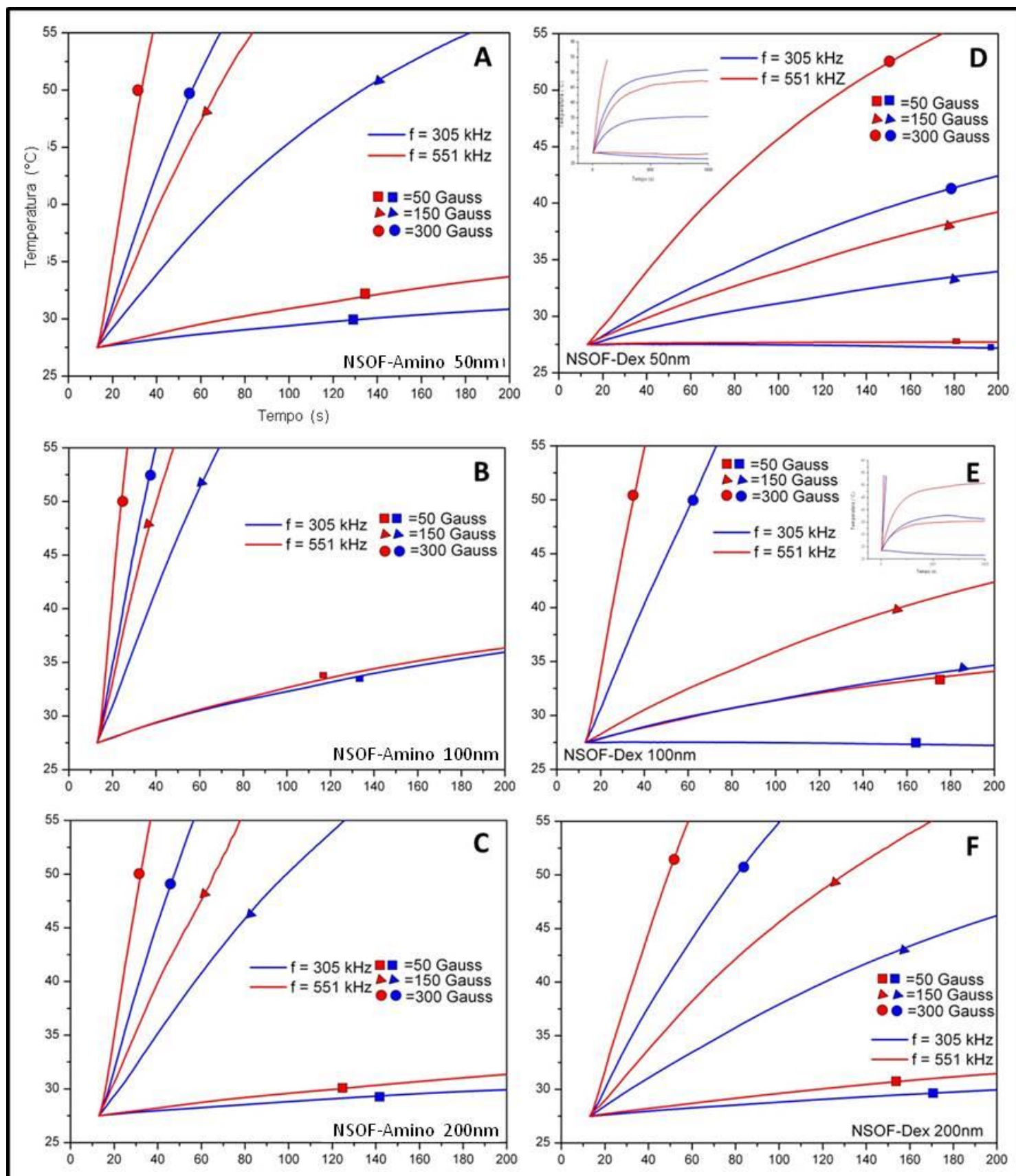

Inset D-E: Platô da curva após o alcance do máximo de temperatura máxima em aproximados 800 segundos.

Figura 28. Análise de resposta de aquecimento conforme campo magnético e frequência aplicada das nanopartículas recobertas com aminosilana e com dextrana

As figuras 29A-C correspondem às curvas de aquecimento da NSOF-Quit em seus respectivos tamanhos. As figuras 29D-F correspondem às curvas obtidas pelo aquecimento das NSOF recobertas com starch (NSOF-Stach). Observa-se que em aproximadamente 800 segundos as curvas das amostras de NSOF-Quit de 50, 100 e 200nm e NSOF-Starch de 100 e 200nm em 50gauss, alcançam o valor máximo 
de aquecimento e permanecem nessa temperatura ao longo do tempo (inset, Figuras 29A-C e 29E).

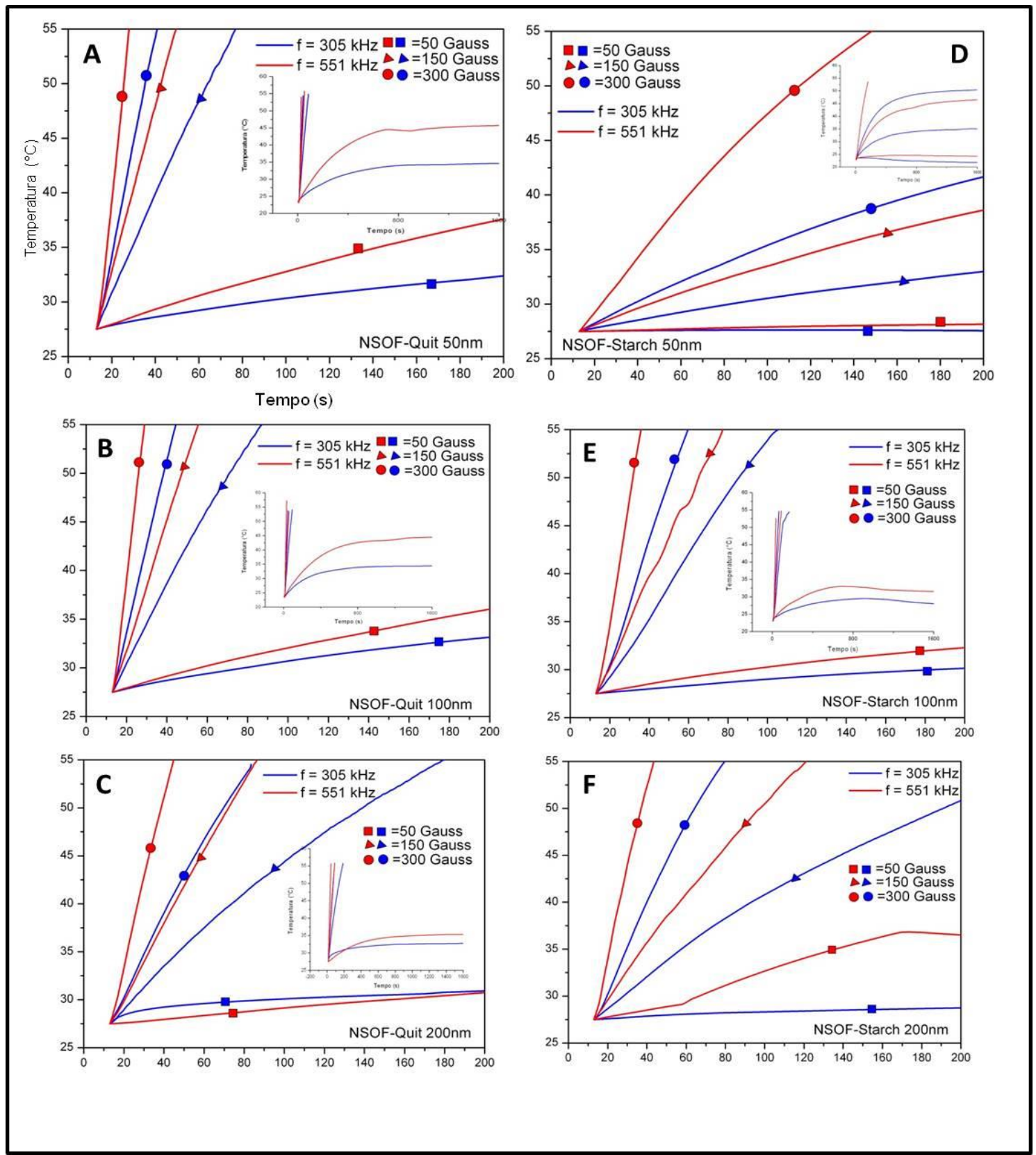

Inset A-C e E: Platô das curvas de 50 gauss em aproximados 800 (s). Inset D: Platô de todas as curvas após 800 (s), com exceção da curva de 300 gauss e $551 \mathrm{kHz}$.

Figura 29. Análise de resposta de aquecimento conforme campo magnético e frequência aplicada nas nanopartícula recobertas com quitosana e com starch

Constatou-se um potencial de aquecimento maior, quando as NSOF foram submetidas ao campo magnético de 300 gauss e sob exposição de frequência de $551 \mathrm{kHz}$ em todas as curvas de respostas de aquecimento, pois estas curvas alcançaram uma temperatura de aproximadamente $55^{\circ} \mathrm{C}$ num intervalo mais curto, 
quando comparadas as NSOF expostas com outras intensidades de campo e de frequência.

\subsection{Valores de taxa de absorção específica e perda de poder intrínseco após aplicação do campo magnético alternado}

Após a obtenção das curvas de aquecimento com a aplicação do CMA, as mesmas foram utilizadas para realização do cálculo do SAR e ILP das NSOF. Os valores de SAR mostrados na figura $30 A-D$, conforme os valores de SAR obtidos de cada NSOF e seus respectivos diâmetros, após serem expostas CMA com diferentes intensidades de campo e frequências.

Ao analisar a figura 30A-D, observa-se que as NSOF de $100 \mathrm{~nm}$ exposta a intensidade de campo de 300 gauss e frequência de $551 \mathrm{kHz}$ obteve os maiores valores de SAR quando comparadas com as NSOF de 50 e 200nm e expostas nas outras condições de intensidade de campo e frequência.
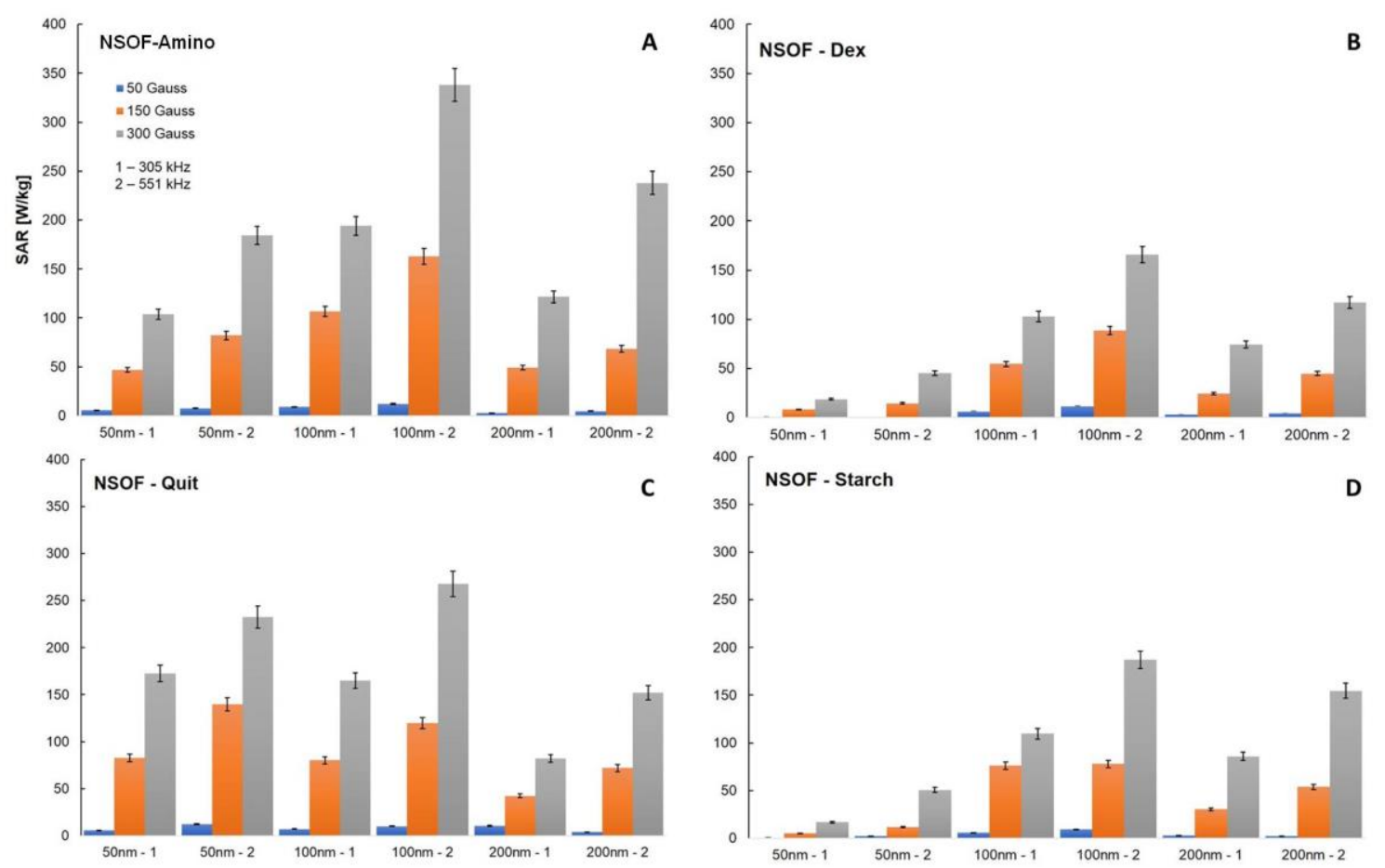

SAR das NSOF-Amino (A); SAR das NSOF-Dex (B); SAR das NSOF-Quit (C); SAR das NSOFStarch (D). $1-305 \mathrm{kHz}$ de frequência; $2-551 \mathrm{kHz}$.

Figura 30. Valores de taxa de absorção específica das nanopartículas e seus respectivos tamanhos, em relação a intensidade do campo magnético e da frequência 
Ao comparar os valores do SAR das NSOF de $100 \mathrm{~nm}$ que foram adquiridas a 300 gauss e $551 \mathrm{kHz}$, verificou-se que a NSOF-Amino de $100 \mathrm{~nm}$ alcançou o maior valor no estudo seguido pelas NSOF-Quit (Figura 31).

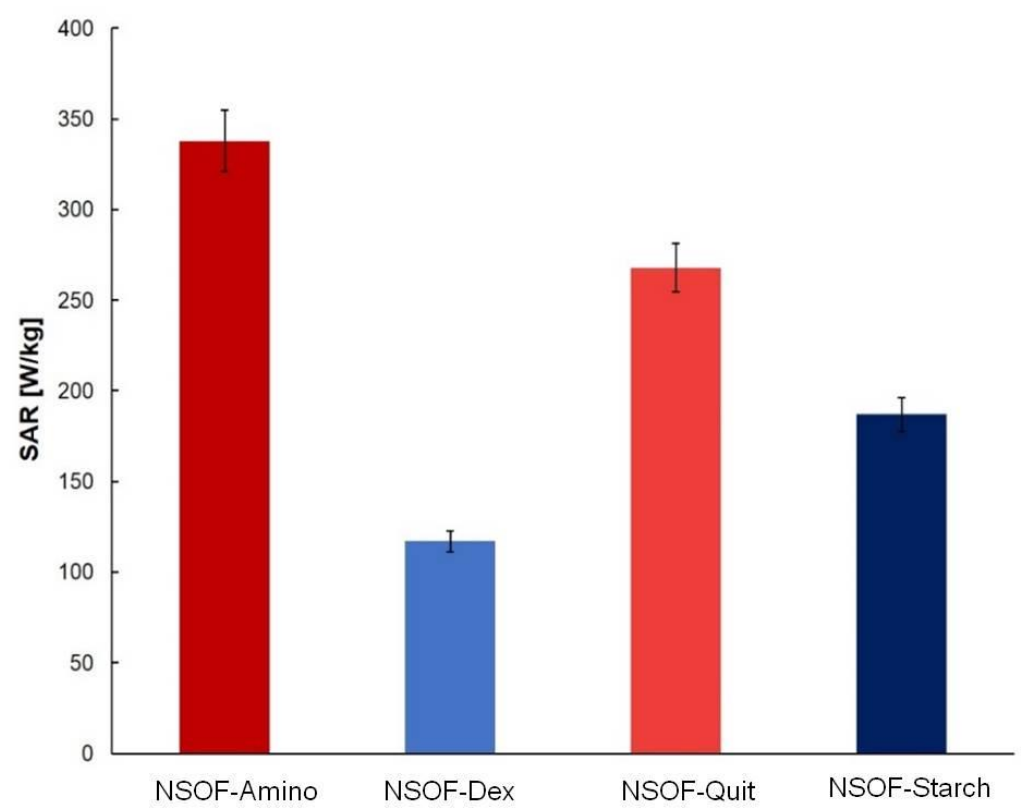

Figura 31. Valores de taxa de absorção específica conforme os tipos de nanopartículas de $100 \mathrm{~nm}$ expostas a 300 gauss e $551 \mathrm{kHz}$

Ao analisar os valores de ILP das amostras de NSOF que atingiram maiores valores de SAR exposta na figura 32, observou-se que a NSOF-Amino de $100 \mathrm{~nm}$ obteve o maior valor de ILP conforme visualizado na figura 32 . 


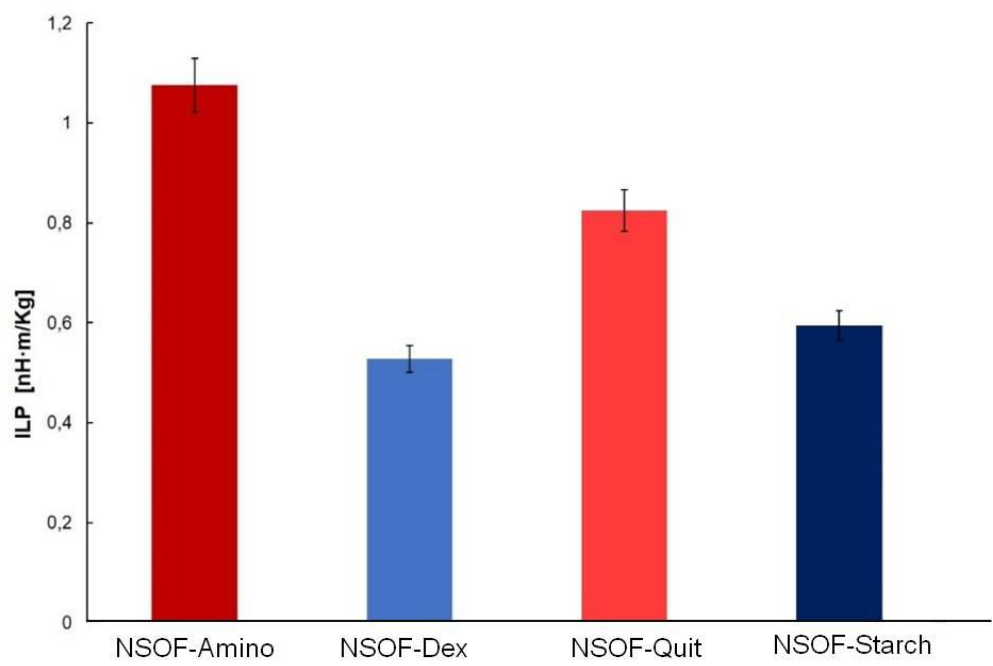

Figura 32. Valores de perda de poder intrínseco conforme os tipos de nanopartículas de $100 \mathrm{~nm}$ expostas a 300 gauss e $551 \mathrm{kHz}$

\subsection{Estudos in vitro}

Os estudos in vitro foram realizados utilizando células C6-Luc (Figuras 33A-D).
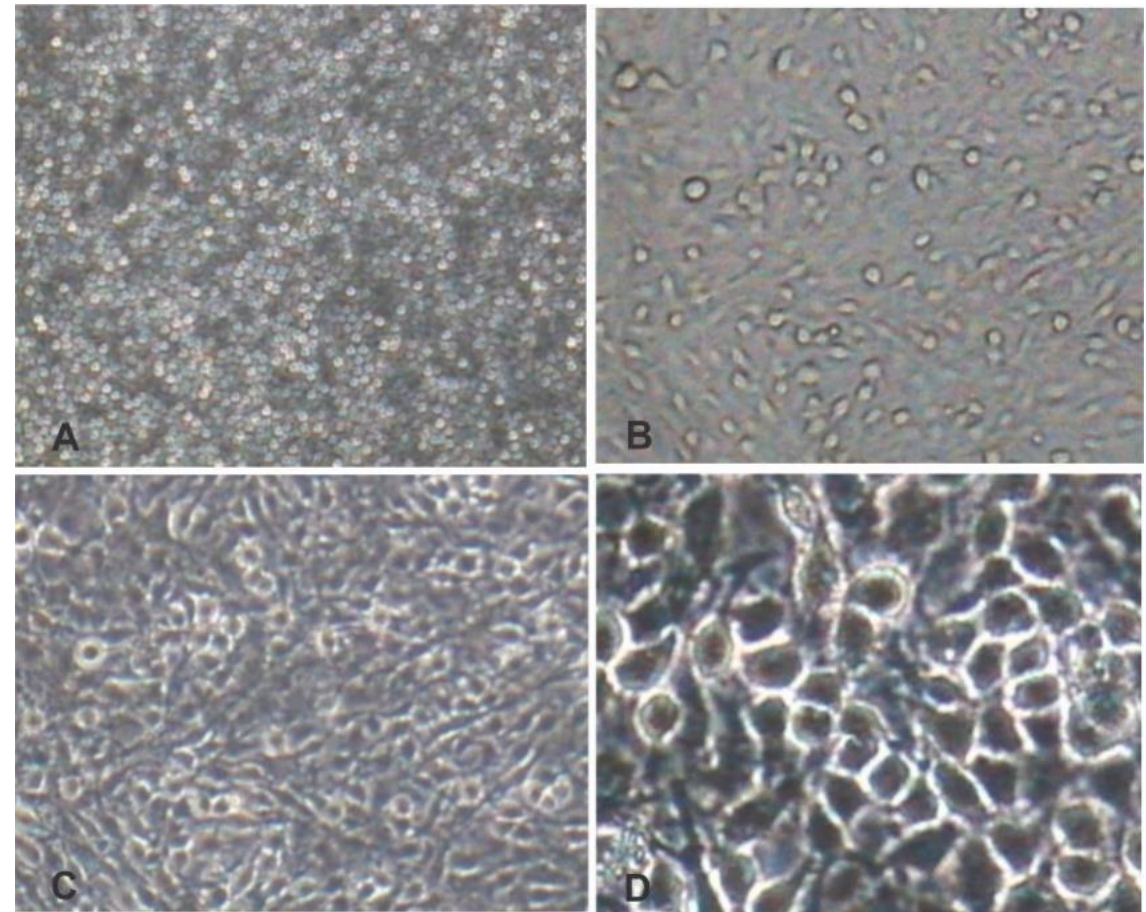

C6-Luc a 5x (A); C6-Luc a 10x (B); C6-Luc em maior confluência a 10x (C); C6-Luc a 20x (D).

Figura 33. Imagens de microscopia óptica das células C6-Luc 


\subsubsection{Cinética do sinal de bioluminescência nas C6-Luc}

As células C6 transfectadas com luciferase foram avaliadas para entender a cinética de sinal bioluminescente das mesmas.

Observou-se alteração de cor no conteúdo dos poços das placas, após a adição de luciferina (Figura 34A-B). As placas sem adição de luciferina submetidas à análise por bioluminescência, não mostrou nenhuma intensidade de sinal bioluminescente (Figura 34C), porém após a adição de luciferina nos poços da placa a aquisição de imagem mostrou intensidades de sinais de bioluminescência (Figura 34D).

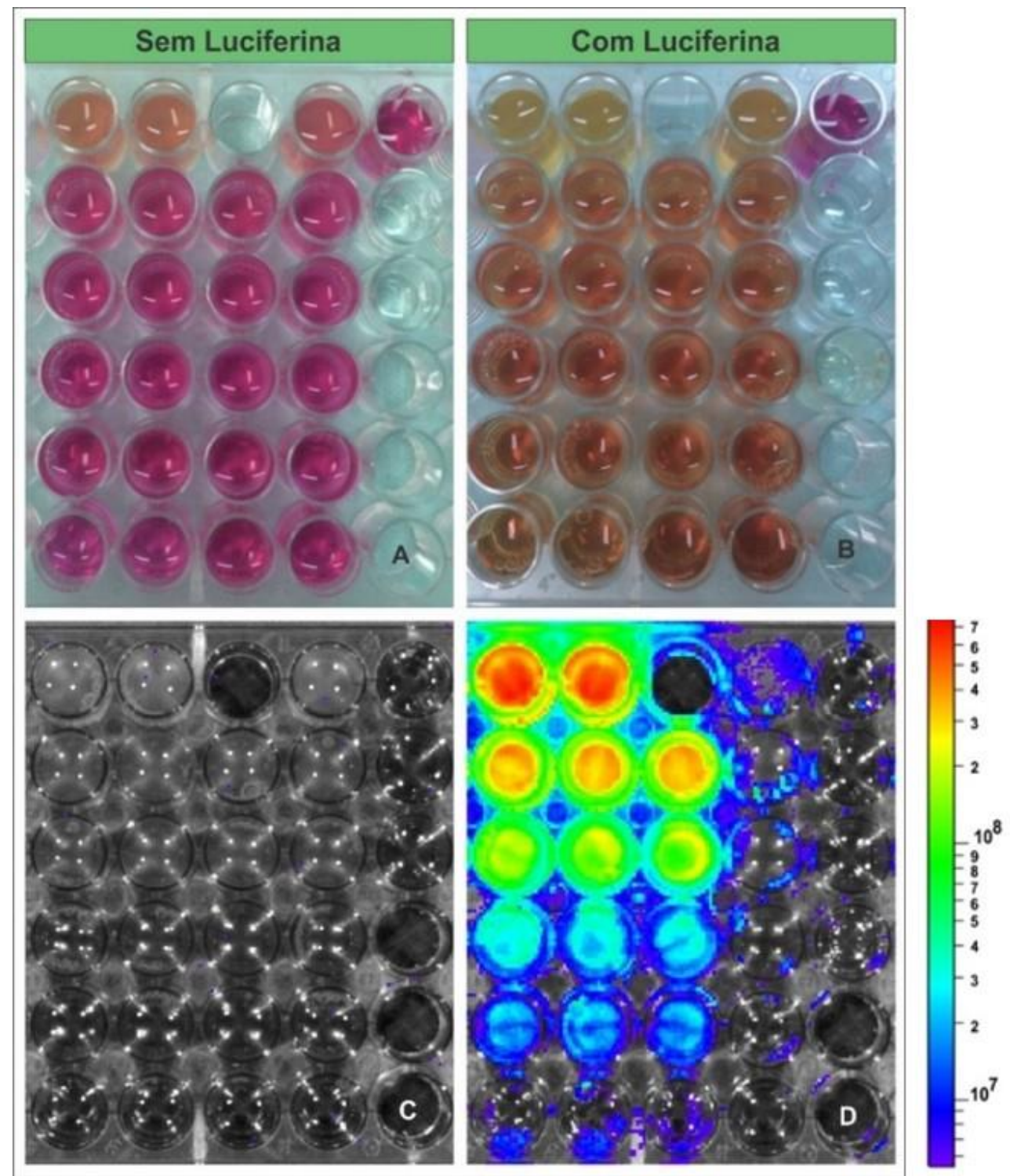

Anterior à aplicação de luciferina (A) e após - aplicação de luciferina (B); Imagem obtida pelo ilumina IVIS, da placa sem luciferina $(C)$ e após adição de luciferina (D).

Figura 34. Análise de placa de C6-Luc e sua bioluminescência 
$\mathrm{Na}$ análise das imagens de bioluminescência que foram adquiridas, foi observada a atividade da luciferase ao longo do tempo usando a região de interesse (ROI) das imagens, a partir de células tumorais induzidas para expressar luciferase após adição de luciferina. Observa-se decaimento de sinal bioluminescente das células (demonstrada pela diminuição da intensidade de cores dos poços) conforme a evolução temporal (Figura $35 \mathrm{~A}-\mathrm{F}$ ). As imagens de acompanhamento total do decaimento de sinal bioluminescente ao longo do tempo, estão expostas em anexo 1.

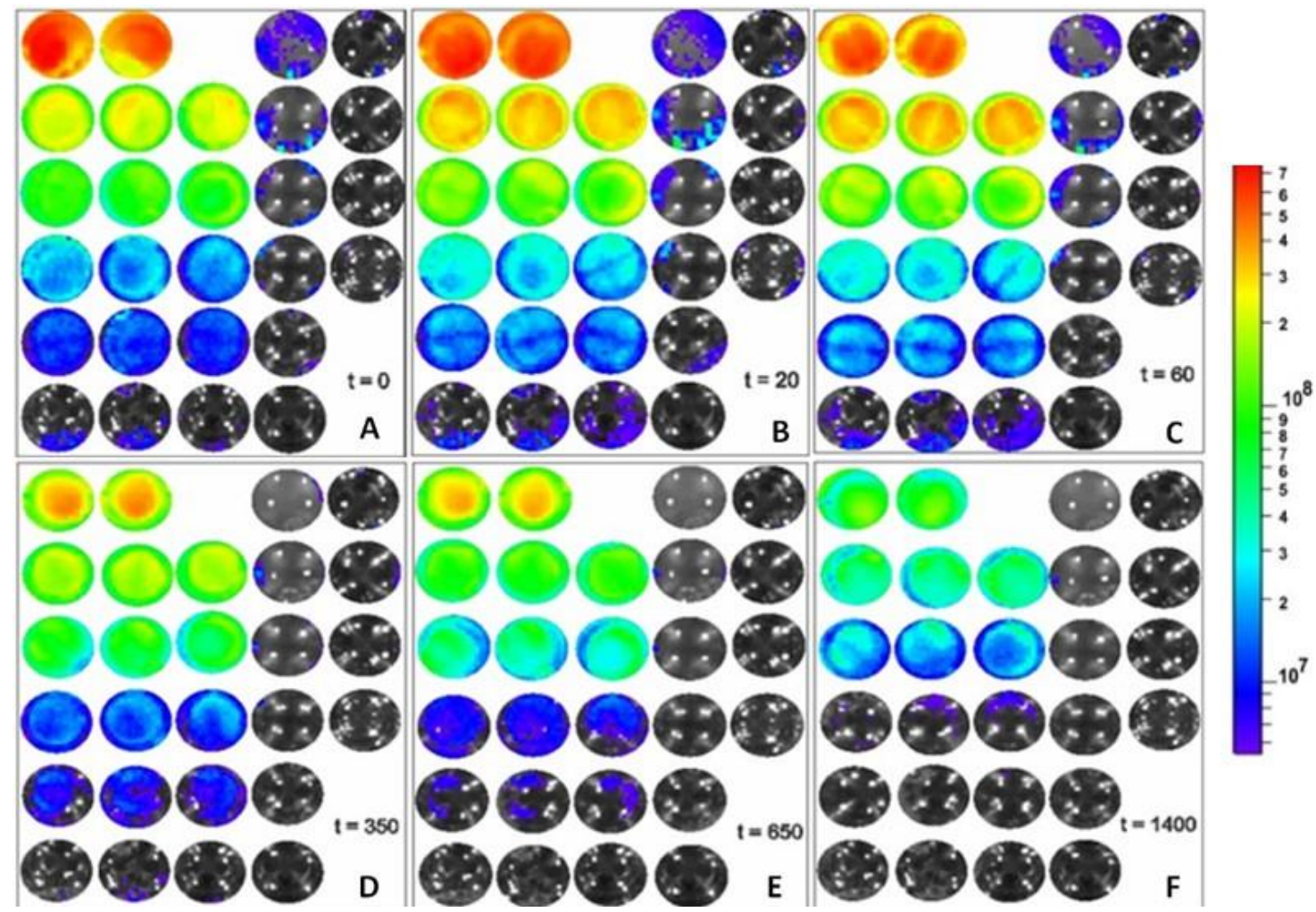

Imagens dos poços no tempo inicial (A); Bioluminescência dos poços com células-C6-Luc no tempo de $20 \mathrm{~min}(\mathrm{~B})$; Poços após 60min (C); Imagens dos poços após $350 \mathrm{~min}(\mathrm{D})$; Poços após 650 min (E); Imagens dos poços após 1400 min (F). (t: min).

Figura 35. Imagens de bioluminescência das células C6-Luc (após adição de luciferina) no decorrer do tempo

Foi realizada análise de reprodutibilidade com estudo da sensibilidade nas diferentes concentrações celulares mediante a técnica de bioluminescência, conforme mostrado na figura 36 (A, B e C são as mesmas amostras para cada condição experimental). Observou-se a confirmação de reprodutibilidade das amostras, quando os mesmos tipos de amostras obtiveram sinal bioluminescente semelhante em cada ponto de aquisição ao longo do tempo. Os valores de intensidade de sinal nas curvas mostraram uma intensidade de sinal proporcional à quantidade 
celular, com picos de intensidade de sinal seguidos de um decaimento progressivo. 0 inset da figura 36, indica que o pico de intensidade de sinal bioluminescente ocorreu na faixa de 0 e 50 minutos, mais precisamente na terceira aquisição de sinal (terceiro ponto na curva) o que equivaleu a 20 minutos (Anexo 1).

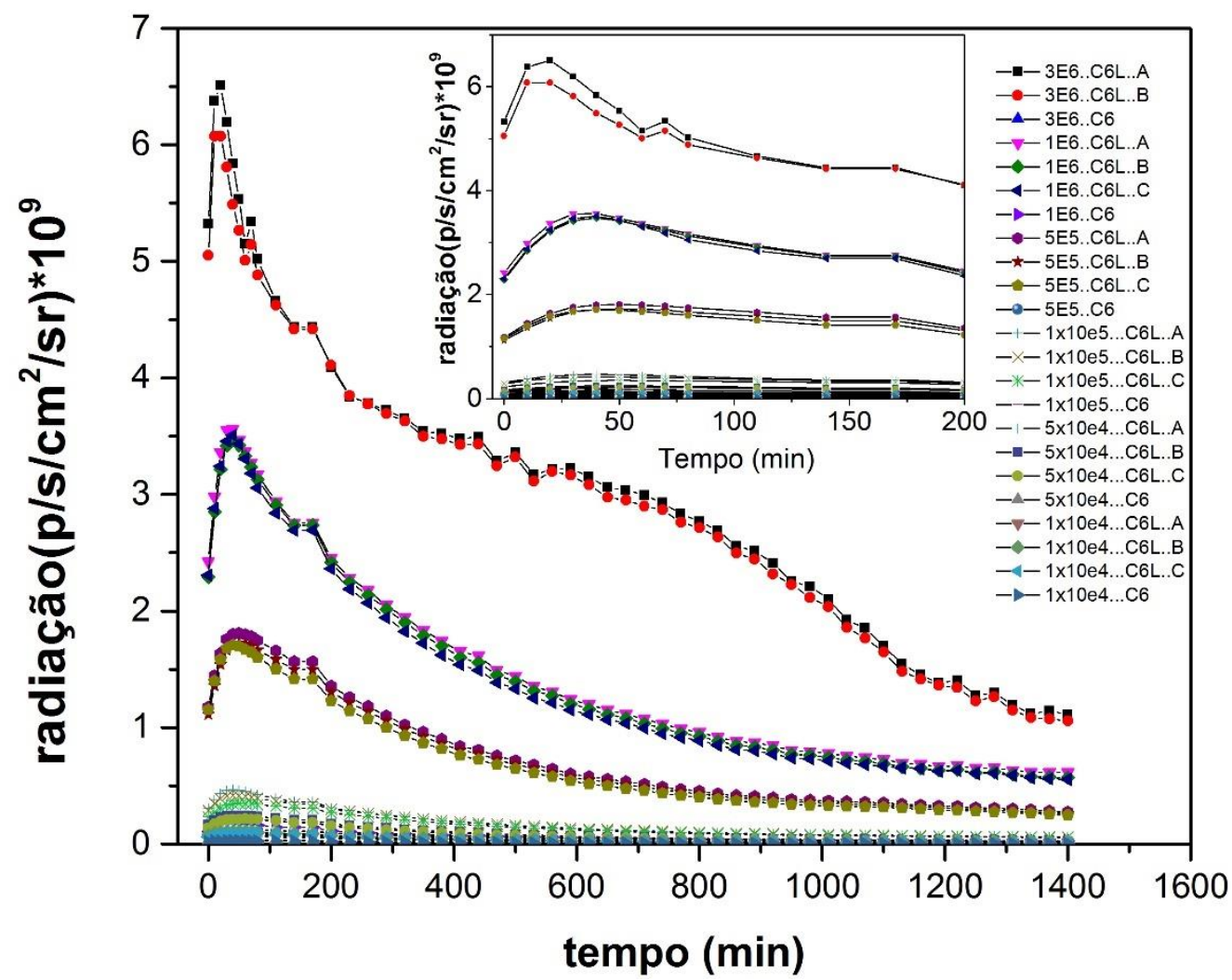

Inset, faixa de tempo do pico de intensidade de sinal bioluminescente, com melhor visualização do comportamento da curva nos primeiros $200 \mathrm{~min}$ de aquisição do sinal.

Figura 36. Reprodutibilidade de bioluminescência das amostras em triplicata (A, B e C)

A intensidade de sinal bioluminescente se diferenciou conforme as concentrações celulares estudadas. Observou-se que quanto maior a concentração celular maior o sinal bioluminescente gerado após a adição de luciferina nas amostras.

A figura 37 mostra as curvas de intensidade de cada concentração celular $\left(3 \times 10^{6}, 10^{6}, \quad 0,5 \times 10^{6}, 0,1 \times 10^{6}, 0,05 \times 10^{6}\right.$ e $\left.0,01 \times \times 10^{6}\right)$ e a imagem bioluminescente representativa num ponto de aquisição das diferentes concentrações celulares. O maior sinal bioluminescente resultou da concentração de $3 \times 10^{6}$ de células com intensidade de $6,5 \times 10^{9} \mathrm{p} / \mathrm{s} / \mathrm{cm}^{2} / \mathrm{sr}$ após 20 minutos do início da aquisição e o menor sinal foi proveniente da concentração de $0,01 \times 10^{6}$ de células com intensidade na faixa de $0,05-0,10 \times 10^{9} \mathrm{p} / \mathrm{s} / \mathrm{cm}^{2} / \mathrm{sr}$ após $40 \mathrm{~min}$ (Figura 37 ). $\mathrm{O}$ inset da figura 37 exibe 
as curvas das amostras celulares com sinal bioluminescente inferior a $0,20 \times 10^{9}$ $\mathrm{p} / \mathrm{s} / \mathrm{cm}^{2} / \mathrm{sr}$, mostrando que ainda com sinal pequeno é possível observar a diferença entre as concentrações celulares menores.

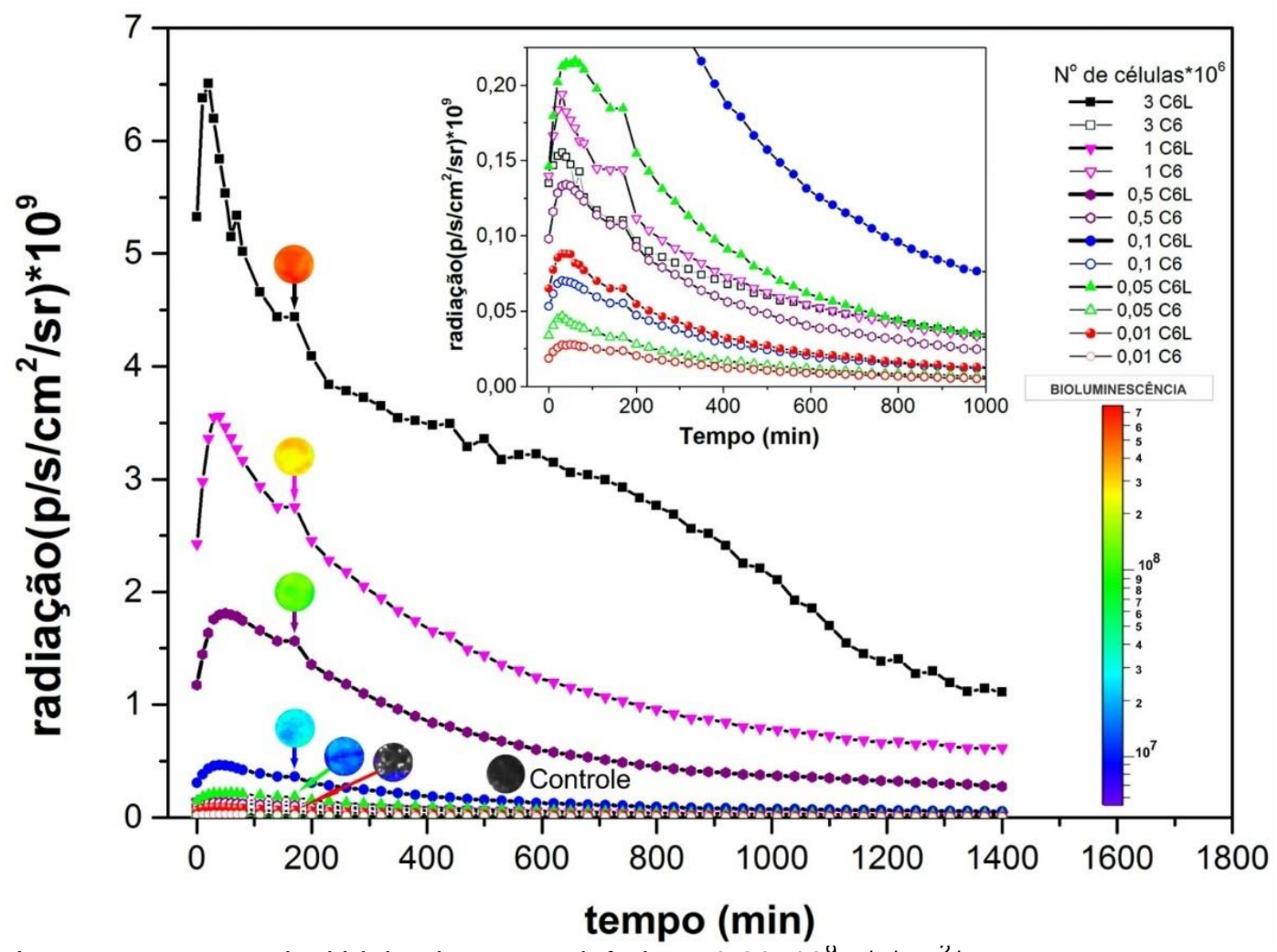

Inset, curvas com sinal bioluminescente inferior a $0,20 \times 10^{9} \mathrm{p} / \mathrm{s} / \mathrm{cm}^{2} / \mathrm{sr}$.

Figura 37. Análise de intensidade de bioluminescência em função da concentração celular

Com o objetivo de descartar nos experimentos in vitro, algum sinal bioluminescente dos substratos com o sistema de captura das imagens de bioluminescência, foram adquiridas imagens de DMEM-LG, Agua, PBS e Luciferina (Figura 38). Foi observado que a intensidade do sinal obtido é baixa e que não influencia no sinal quando comparado com da figura 37. 


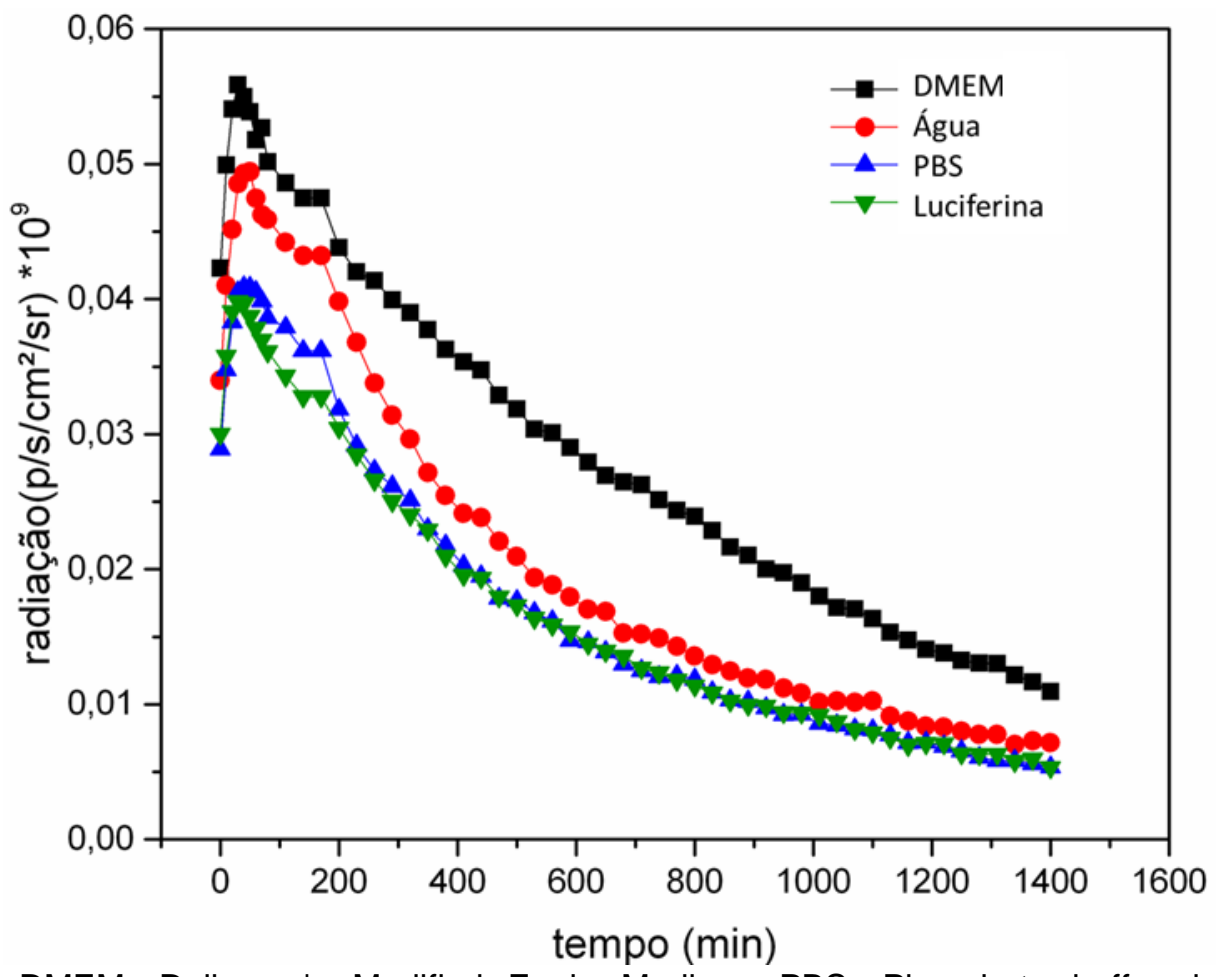

DMEM: Dulbecco's Modified Eagle Medium; PBS: Phosphate buffered saline.

Figura 38. Análise de intensidade de sinal bioluminescente das substâncias

\subsubsection{Marcação das C6-Luc com nanopartículas superparamagnéticas de óxido de} ferro e visualização das células marcadas

A marcação da C6-Luc foi realizada com as NSOF-Amino e NSOFQuit de 100nm, sendo estas duas NSOF escolhidas para a marcação por apresentarem o melhor SAR e ILP (Figuras 28 e 29). A visualização da NSOF nas células C6-Luc foi realizada por meio da coloração de AP, para avaliar marcação celular em três condições de marcação magnética, conforme mostrado na figura 39A-M. 


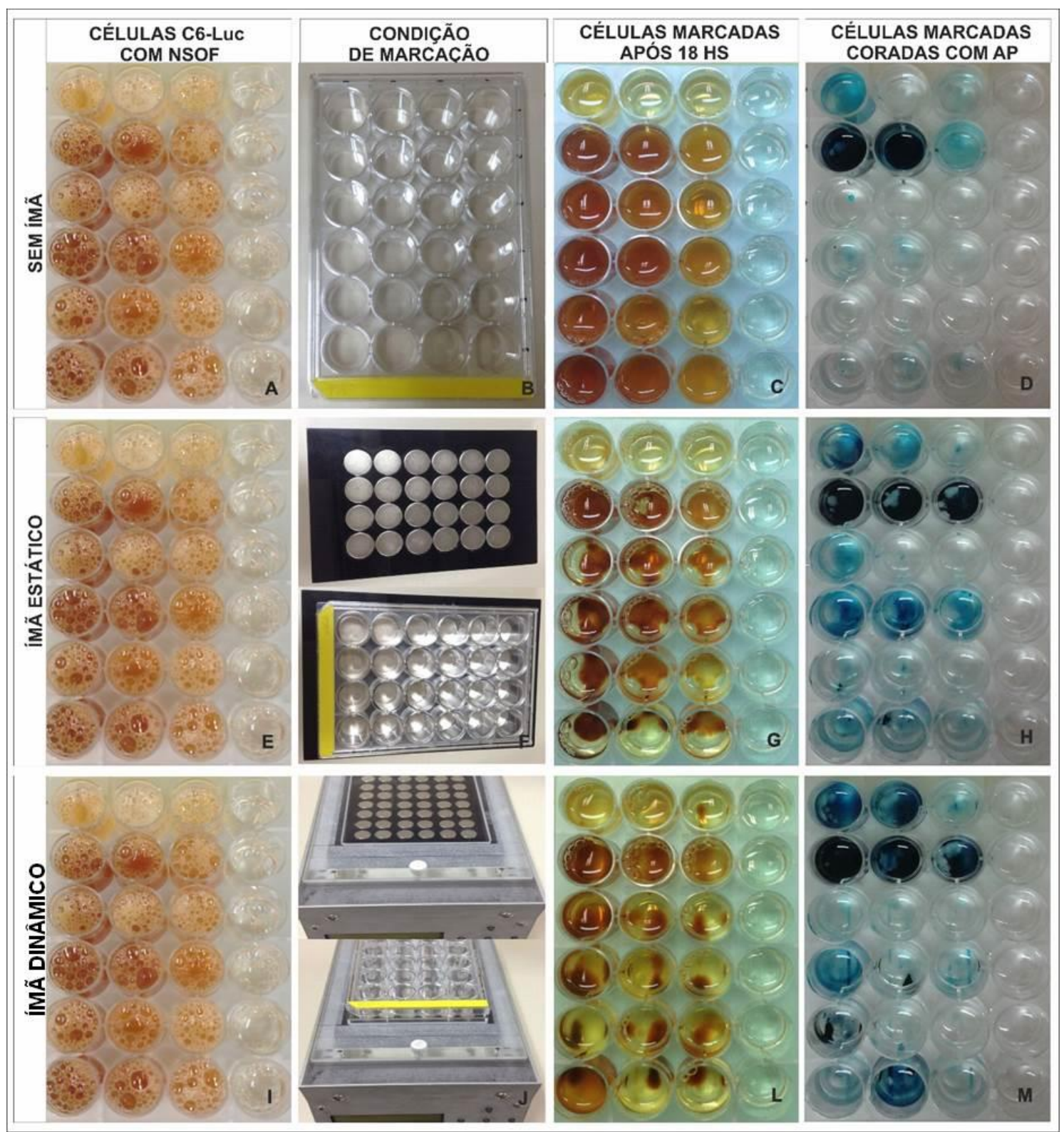

Células marcadas sem imã, visualização após 18hs de marcação e após coloração com AP (Linha A-D); Células marcadas com ímã estático, visualização após 18hs de marcação e após coloração com AP (Linha E-H); Células marcadas com ímã dinâmico, visualização após 18hs de marcação e após coloração com AP (Linha I-M). AP: Azul de prússia.

Figura 39. Marcação de C6-Luc com nanopartículas superparamagnéticas de óxido de ferro

\subsubsection{Sem ímã}

Ao analisar a marcação das células com NSOF-Amino com uma concentração de $100 \mu \mathrm{g} \mathrm{NSOF/mL} \mathrm{(Amino} \mathrm{[100Fe]),} \mathrm{200 \mu g} \mathrm{NSOF/mL} \mathrm{(Amino} \mathrm{[200Fe])}$ e 300 $\mathrm{g}$ NSOF/mL (Amino [300Fe]) sem utilizar ímã na sua encubação, observa-se que as amostras com filtro possuem marcação adequada e efetiva em comparação com células marcadas sem filtro. As células marcadas com PLL obtiveram maior 
internalização celular nesta condição em comparação com as células marcadas sem PLL. (Figura 40). Já na marcação com concentrações de $200 \mu \mathrm{g}$ NSOF/mL (Amino [200Fe]) e 300 $\mathrm{g}$ NSOF/mL (amino [300Fe]), observa-se que as células marcadas sem PLL obtiveram internalização celular com nível adequado em comparação com as células marcadas sem PLL (Figura 41 e 42).

Ao analisar a marcação das células com NSOF-Quit, observa-se que as amostras com filtro possuem marcação adequada e efetiva em comparação com células marcadas sem filtro e que a concentração de [200Fe] foi mais eficiente pois gerou marcação que acompanhou a morfologia celular (Figura 43).

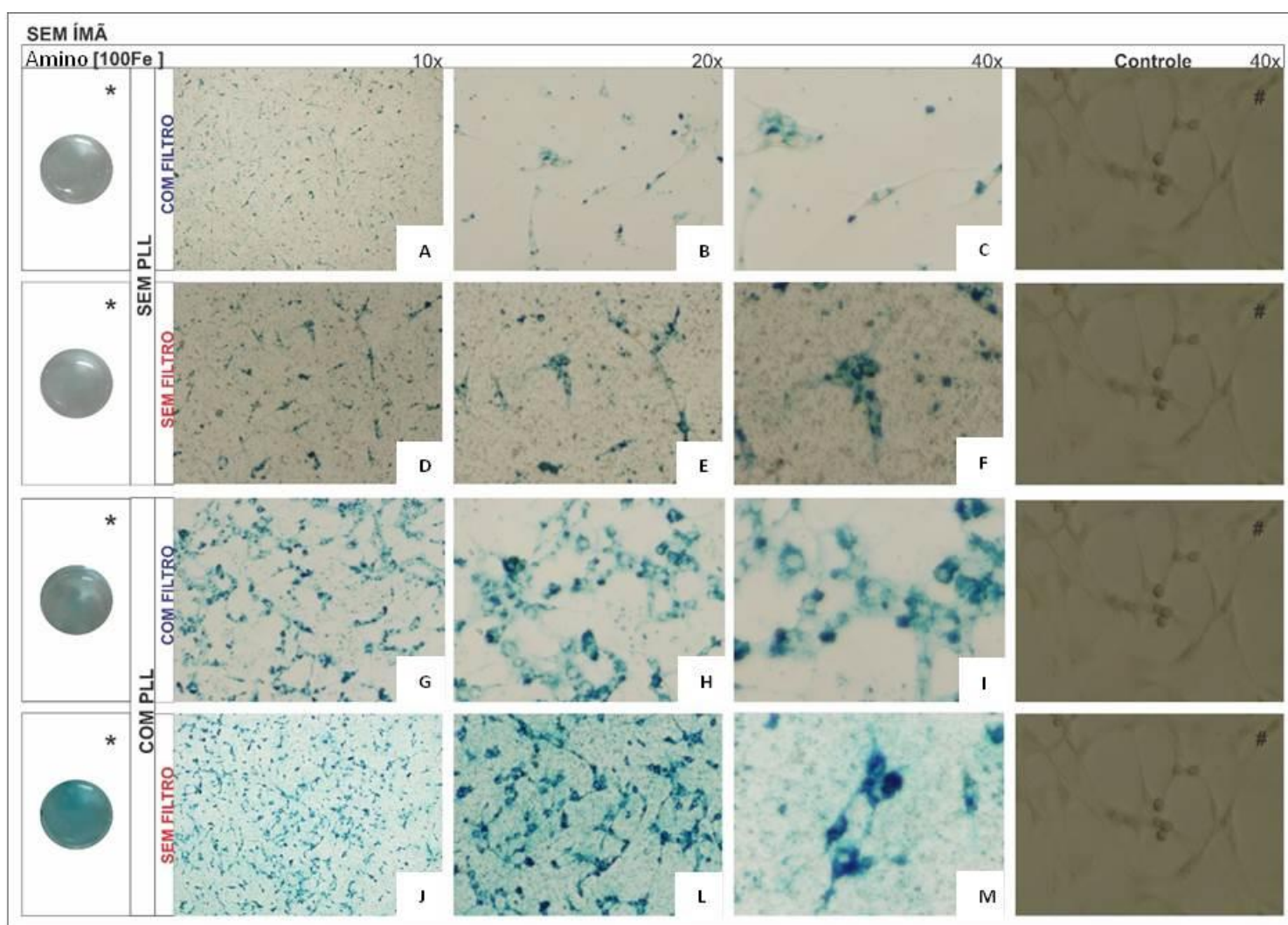

Células marcadas sem PLL (A-F) e com PLL (G-M); Com Filtro (A-C) e de (G-I); Sem filtro (D-F) e de (J-M). *: imagem macroscópica do poço referente das imagens em disposição linha; \#: Controle.

Figura 40. Imagens ópticas da coloração de azul de prússia das C6-Luc com nanopartículas recobertas com aminosilana [100Fe] sem utilização de ímã 


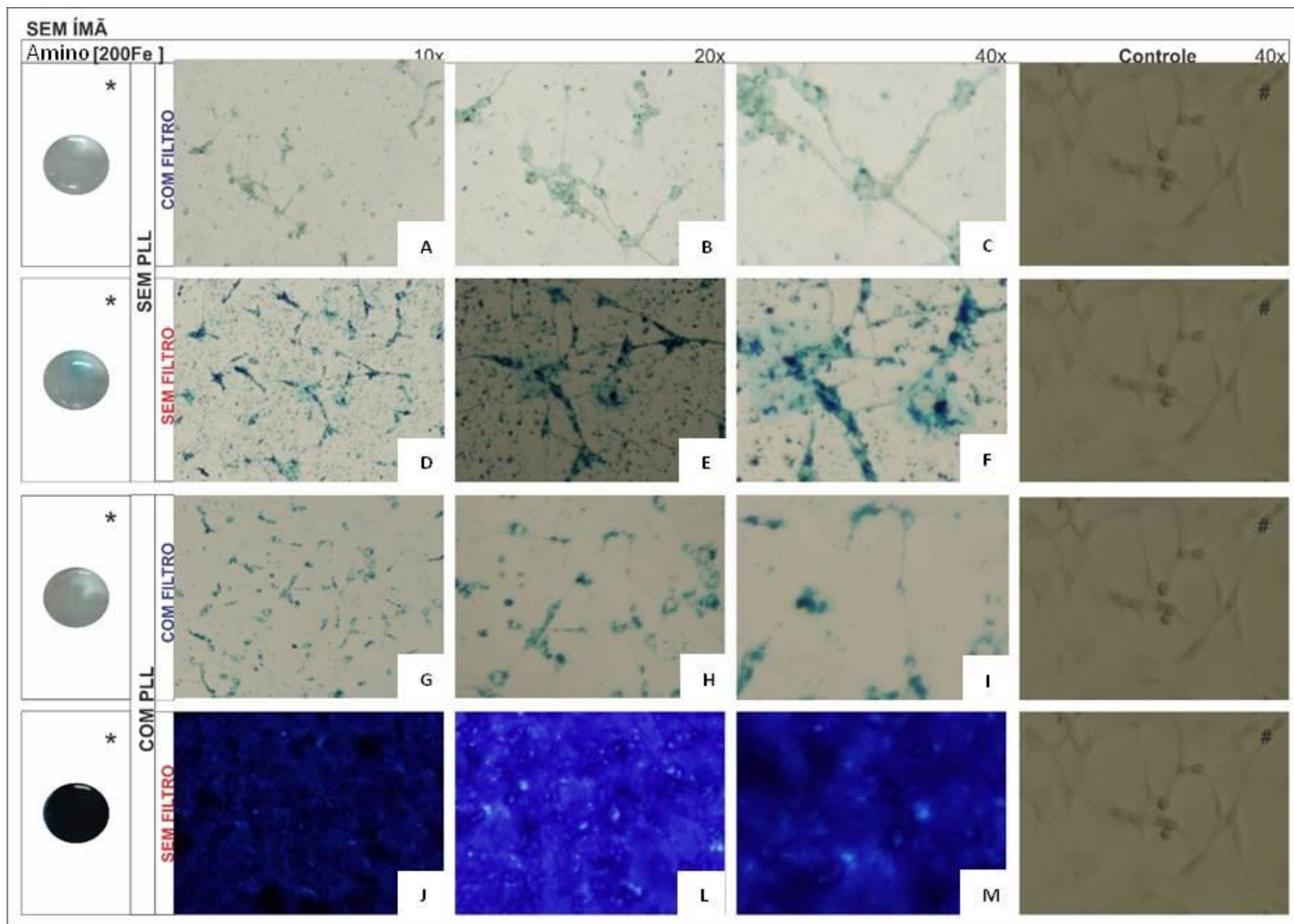

Células marcadas sem PLL (A-F) e com PLL (G-M); Com Filtro (A-C) e de (G-I); Sem filtro (D-F) e de (J-M).*: imagem macroscópica do poço referente, das imagens em disposição linha; \#: Controle.

Figura 41. Imagens ópticas da coloração de coloração de azul de prússia das C6-Luc com nanopartículas recobertas com aminosilana [200Fe] sem utilização de ímã 


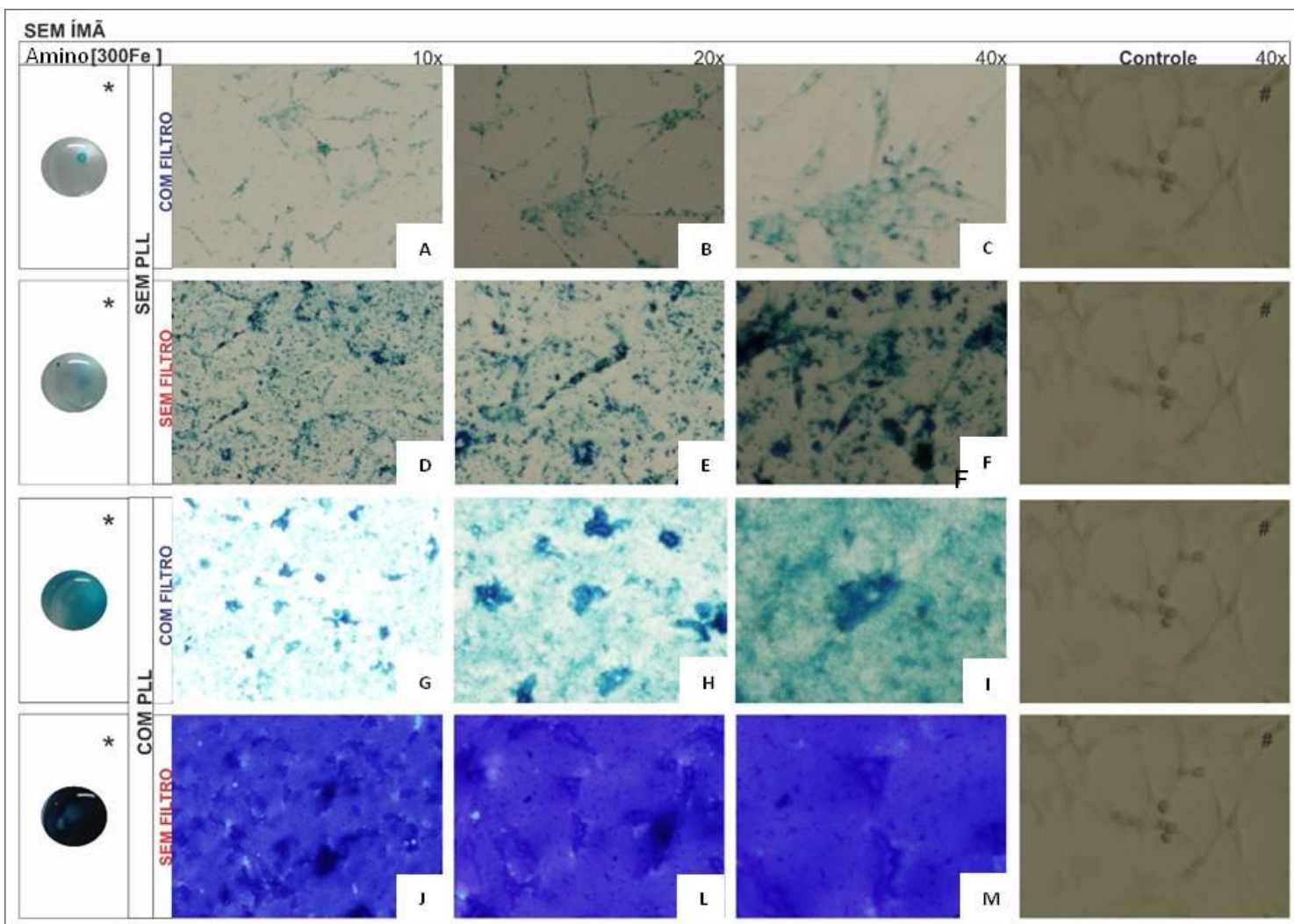

Células marcadas sem PLL (A-F) e com PLL (G-M); Com Filtro (A-C) e de (G-I); Sem filtro (D-F) e de (J-M).*: imagem macroscópica do poço referente, das imagens em disposição linha; \#: Controle.

Figura 42. Imagens ópticas da coloração de azul de prússia das C6-Luc com nanopartículas recobertas com aminosilana [300Fe] sem utilização de ímã 


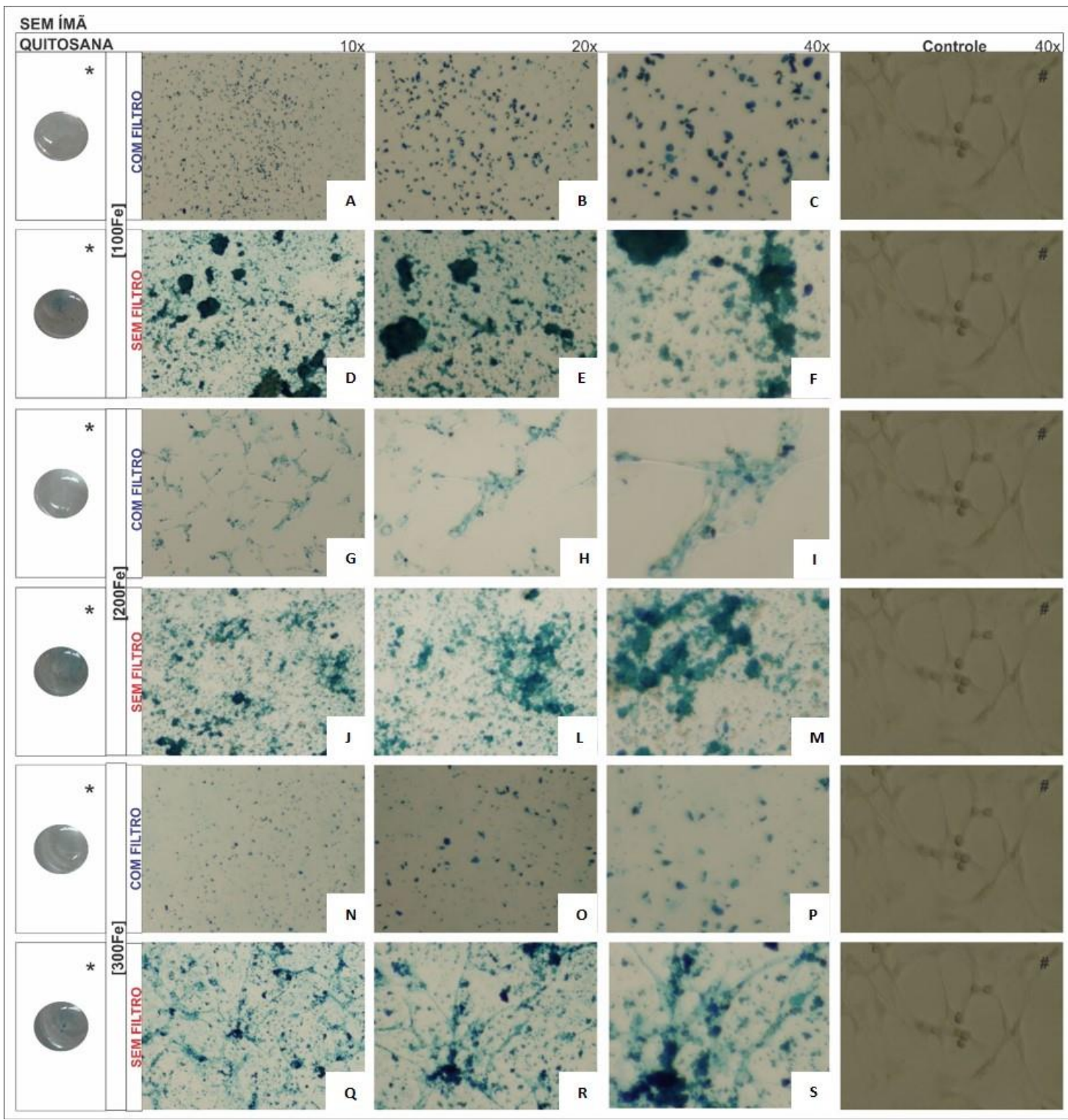

Células marcadas com [100Fe] (A-F), [200Fe] (G-M) e [300Fe] (N-S); Com Filtro (A-C), de (G-I) e de (N-P); Sem filtro (D-F), de (J-M) e de (Q-S). *: imagem macroscópica do poço referente, das imagens em disposição linha; \#: Controle.

Figura 43. Imagens ópticas da coloração de azul de prússia das C6-Luc com nanopartículas recobertas com quitosana, sem poli-lisina e sem utilização de ímã

\subsubsection{2 Ímã estático}

Ao analisar a marcação das células com NSOF-Amino [100Fe], [200Fe] e [300Fe] com utilização de IE na sua encubação, observa-se que as amostras com filtro possuem marcação adequada e efetiva em comparação com células marcadas sem filtro. As células marcadas sem PLL obtiveram internalização celular mais favorável acompanhando a morfologia celular sem gerar formação de 
aglomeração de nanopartículas em comparação com as células marcadas sem PLL (Figuras 44, 45 e 46).

Ao analisar a marcação das células com NSOF-Quit, utilizando IE na sua encubação, observou-se que as amostras com filtro possuem marcação adequada e efetiva em comparação com células marcadas sem filtro e que a concentração de [100 Fe] e [200Fe] foi mais eficiente em comparação a de [300Fe] que marcou a célula gerando aglomeração de nanopartículas além de não acompanhar a morfologia celular (Figura 47).

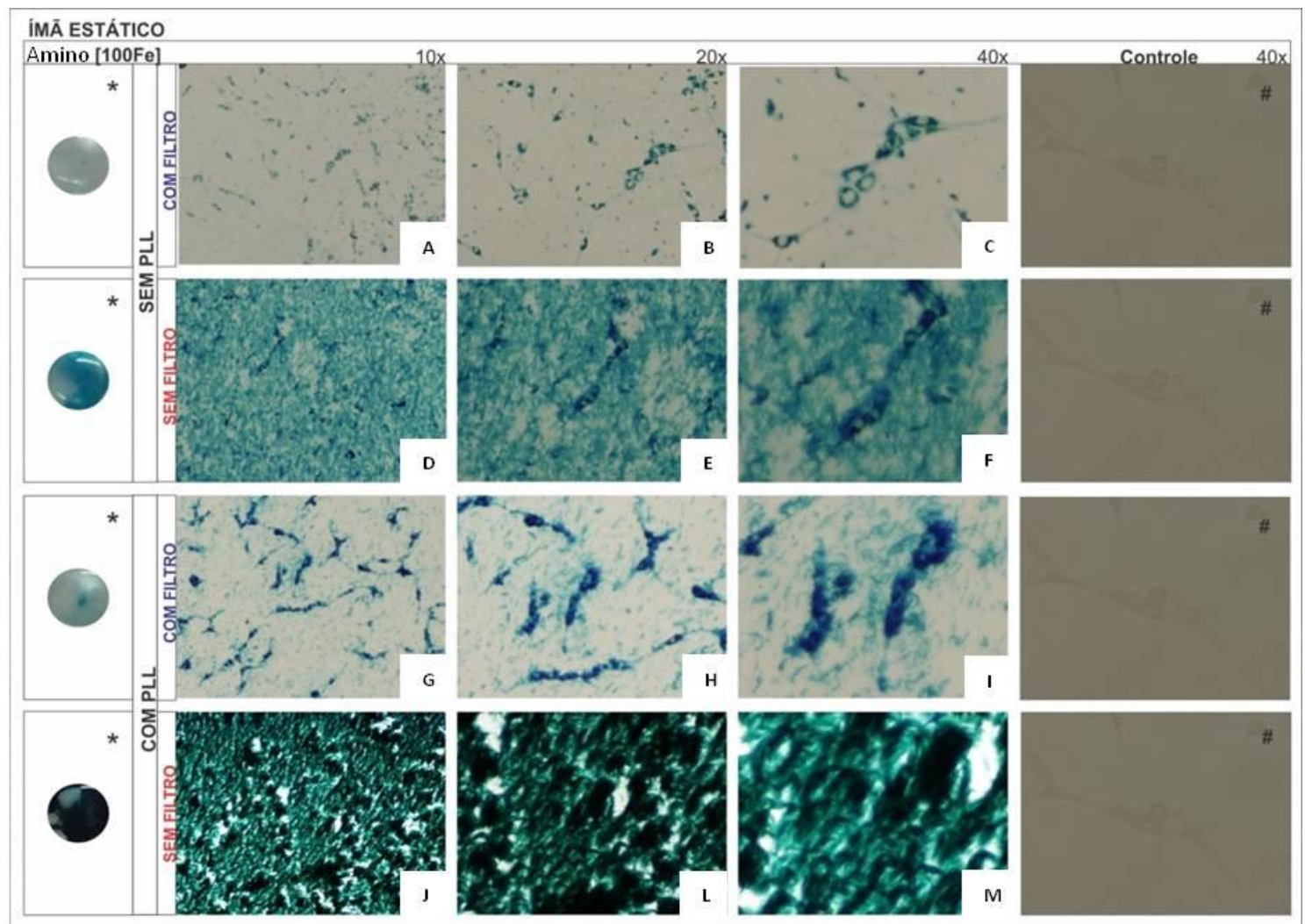

Células marcadas sem PLL (A-F) e com PLL (G-M); Com Filtro (A-C) e de (G-I); Sem filtro (D-F) e de (J-M). *: imagem macroscópica do poço referente, das imagens em disposição linha; \#: Controle.

Figura 44. Imagens ópticas da coloração de azul de prússia das C6-Luc com nanopartículas recobertas com aminosilana [100Fe] com utilização de ímã estático 


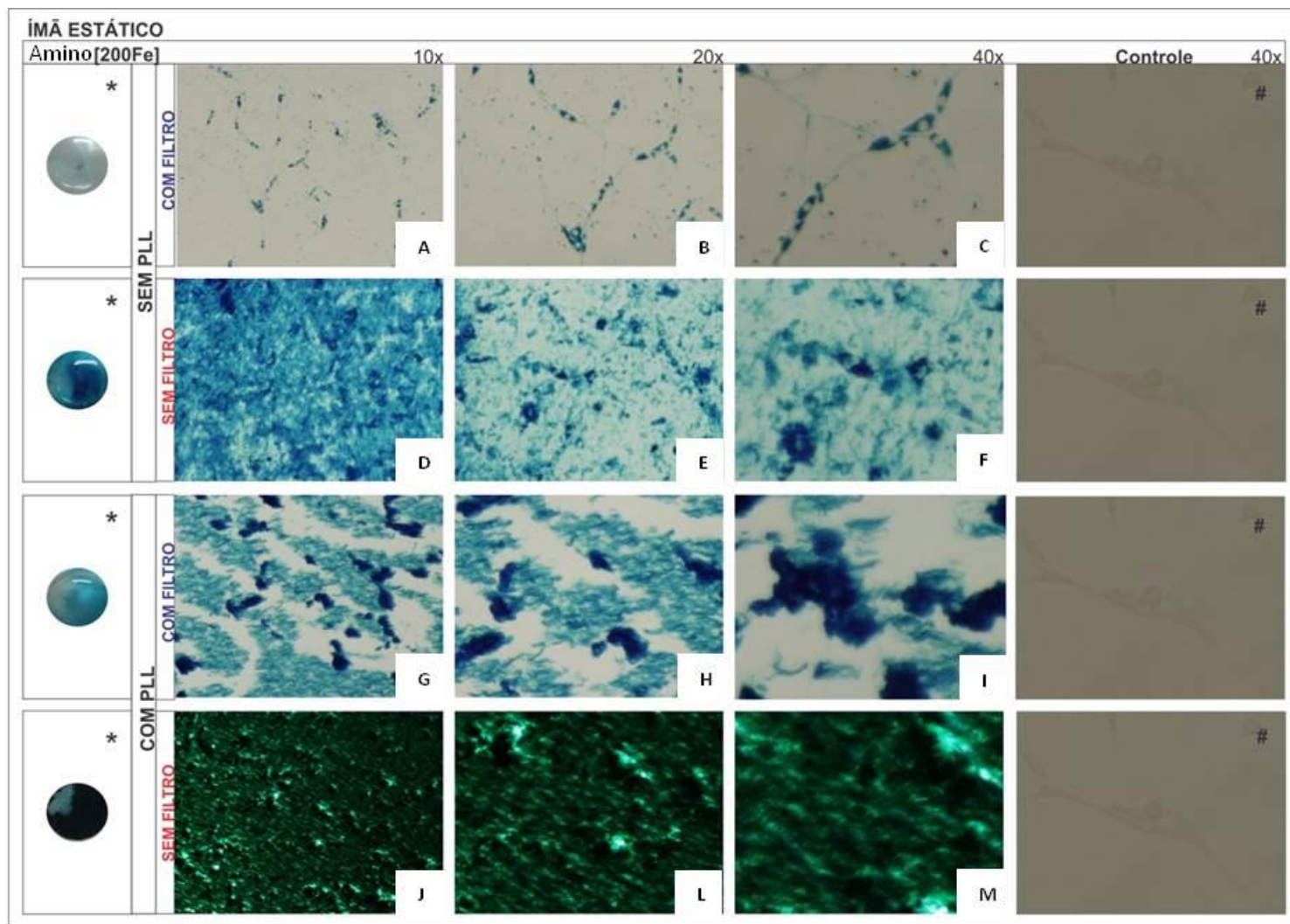

Células marcadas sem PLL (A-F) e com PLL (G-M); Com Filtro (A-C) e de (G-I); Sem filtro (D-F) e de (J-M). *: imagem macroscópica do poço referente, das imagens em disposição linha; \#: Controle.

Figura 45. Imagens ópticas da coloração de azul de prússia das C6-Luc com nanopartículas recobertas com aminosilana [200Fe] com utilização de ímã estático 


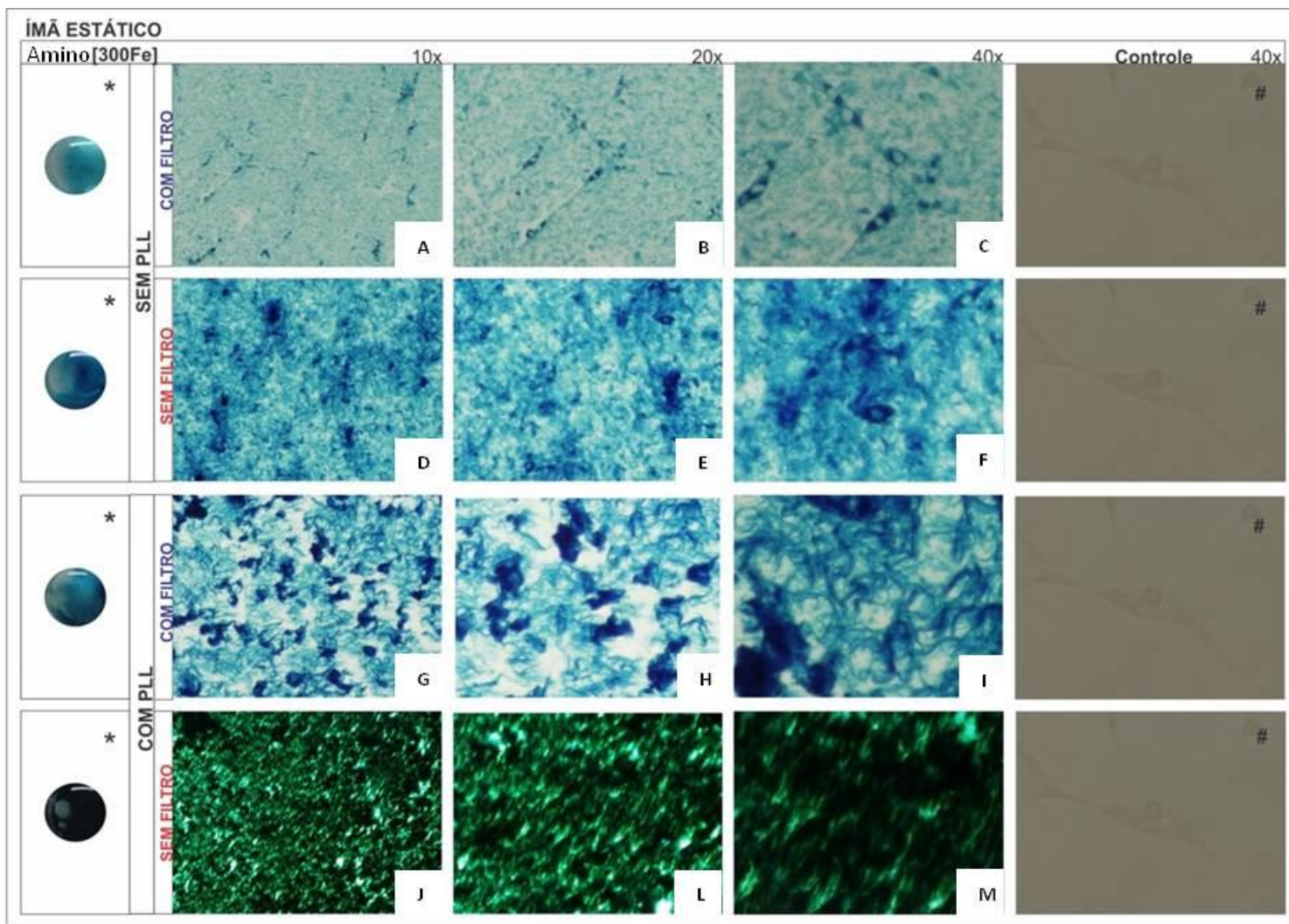

Células marcadas sem PLL (A-F) e com PLL (G-M); Com Filtro (A-C) e de (G-I); Sem filtro (D-F) e de (J-M). *: imagem macroscópica do poço referente, das imagens em disposição linha; \#: Controle.

Figura 46. Imagens ópticas da coloração de azul de prússia das C6-Luc com nanopartículas recobertas com aminosilana [300Fe] com utilização de ímã estático 


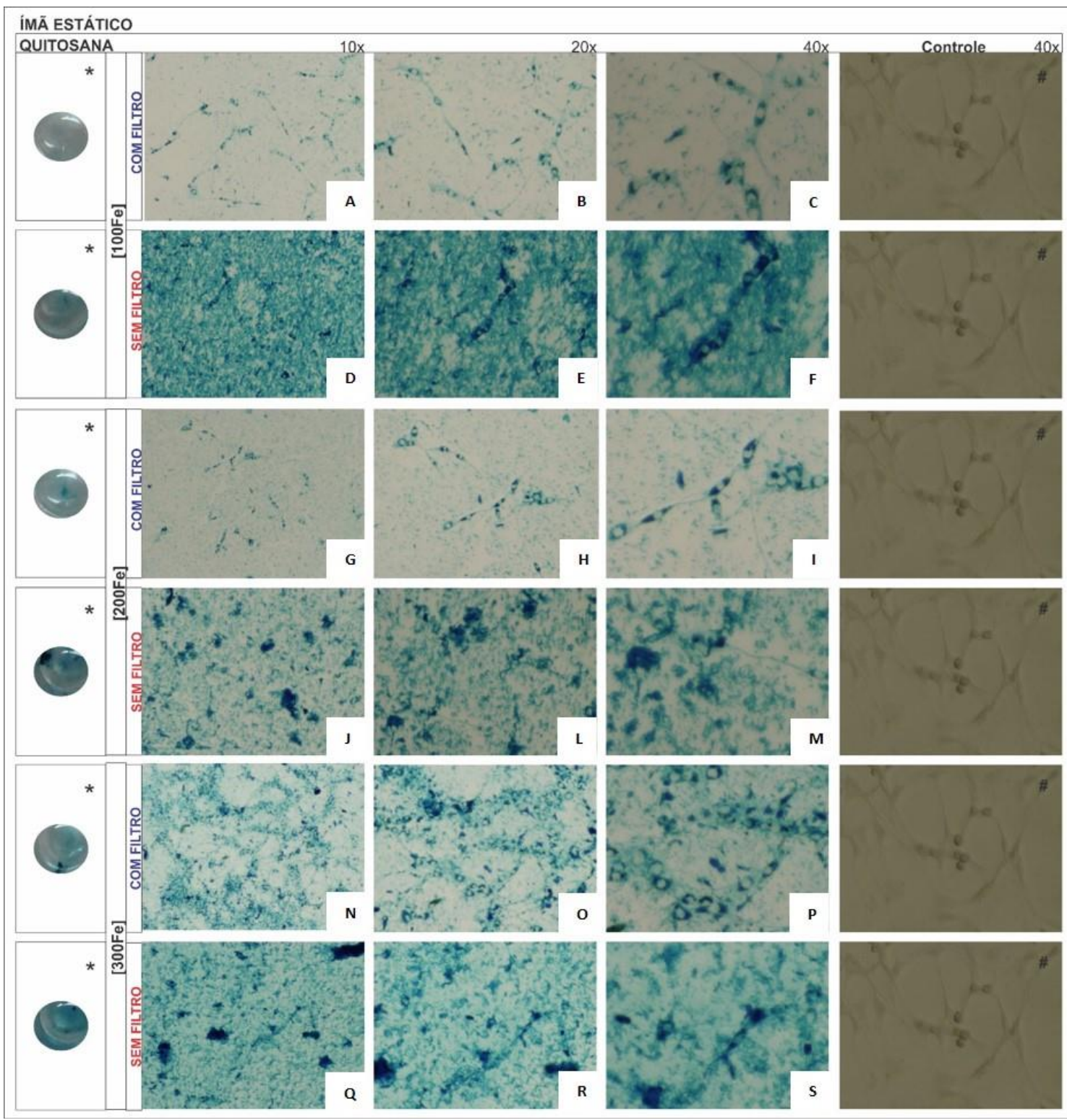

Células marcadas com [100Fe] (A-F), [200Fe] (G-M) e [300Fe] (N-S); Com Filtro (A-C), de (G-I) e de (N-P); Sem filtro (D-F), de (J-M) e de (Q-S). *: imagem macroscópica do poço referente, das imagens em disposição linha imagem macroscópica do poço referente, das imagens em disposição linha; \#: Controle.

Figura 47. Imagens ópticas da coloração de azul de prússia das C6-Luc com nanopartículas recobertas com quitosana, sem poli-lisina e com utilização de ímã estático

\subsubsection{3 Ímã dinâmico}

Ao analisar a marcação das células com NSOF-Amino [100Fe], [200Fe] e [300Fe] com utilização de ímã dinâmico na sua encubação, observa-se que as amostras com filtro possuem marcação adequada e efetiva em comparação com células marcadas sem filtro. As células marcadas sem PLL obtiveram internalização 
celular de forma não exagerada em comparação com as células marcadas com PLL (Figuras 48, 49 e 50).

Ao analisar a marcação das células com NSOF-Quit, utilizando ímã dinâmico na sua encubação, observou-se que as amostras sem filtro na concentração de [100Fe] possuem marcação adequada e efetiva em comparação com células marcadas sem filtro, porém na concentração de [200Fe] e [300Fe] o uso de filtro foi mais eficiente (Figura 51).

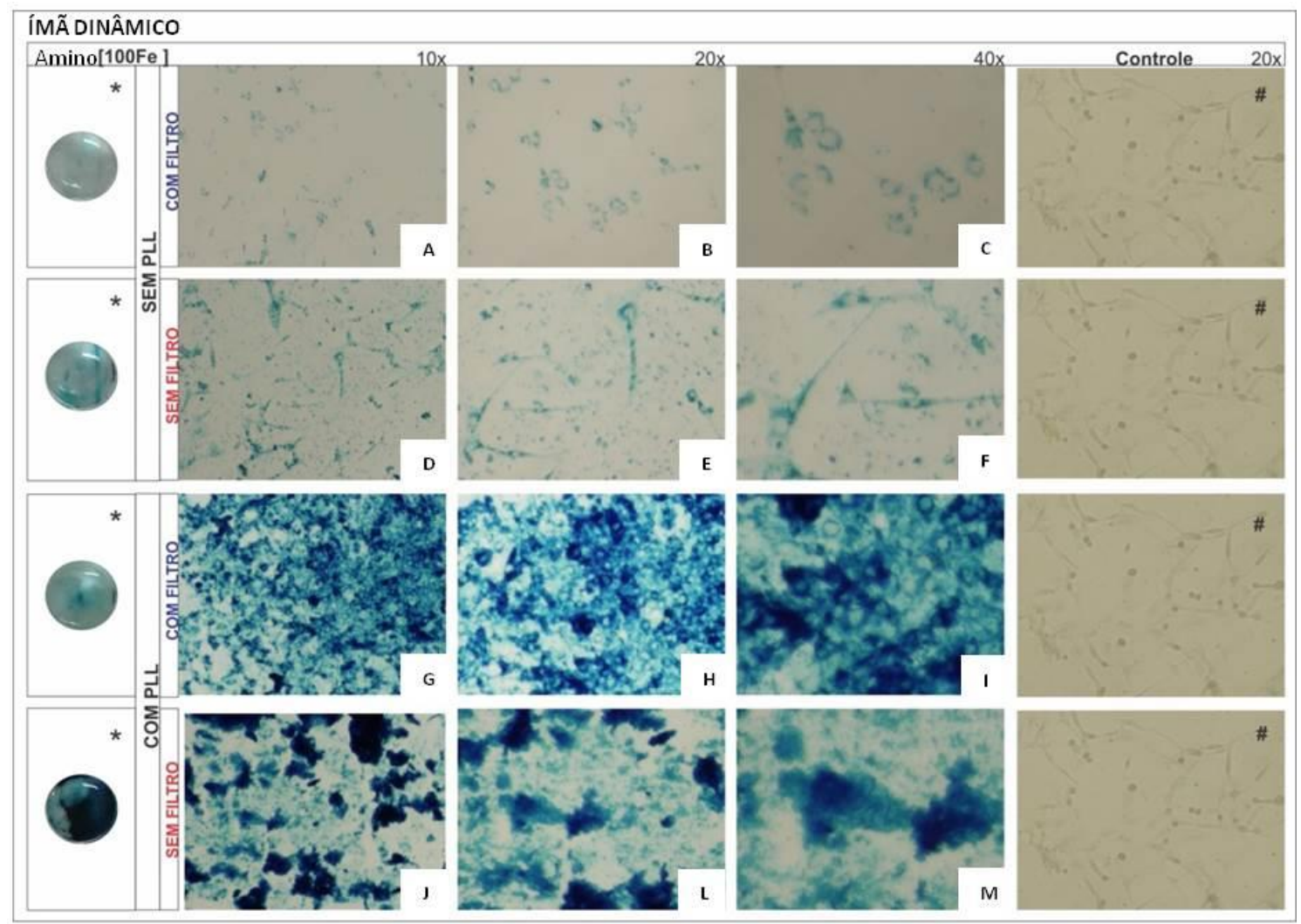

Células marcadas sem PLL (A-F) e com PLL (G-M); Com Filtro (A-C) e de (G-I); Sem filtro (D-F) e de (J-M). *: imagem macroscópica do poço referente, das imagens em disposição linha; \#: Controle.

Figura 48. Imagens ópticas da coloração de azul de prússia das C6-Luc com nanopartículas recobertas com aminosilana [100Fe] com utilização de ímã dinâmico 


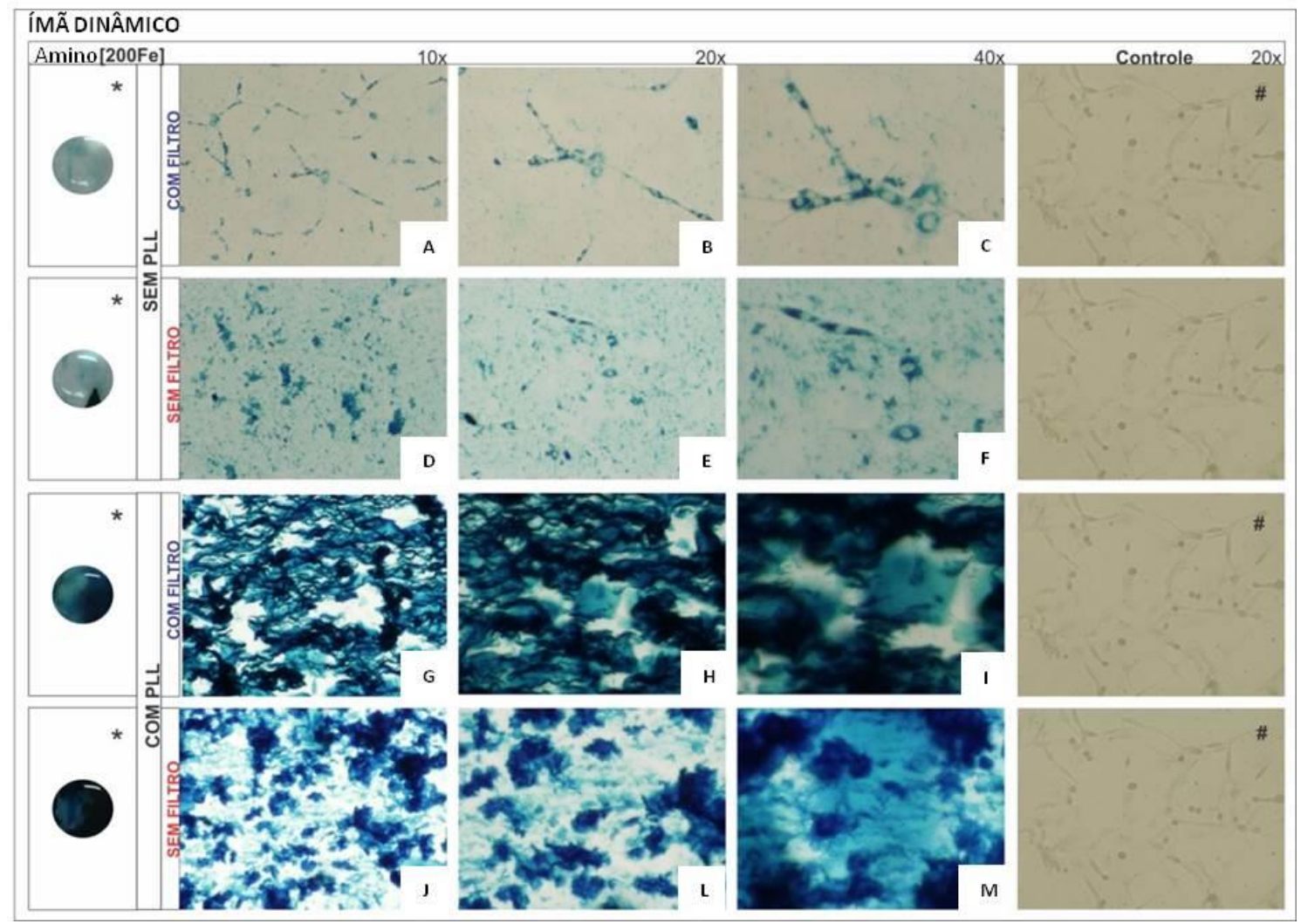

Células marcadas sem PLL (A-F) e com PLL (G-M); Com Filtro (A-C) e de (G-I); Sem filtro (D-F) e de (J-M). *: imagem macroscópica do poço referente, das imagens em disposição linha; \#: Controle.

Figura 49. Imagens ópticas da coloração de azul de prússia das C6-Luc com nanopartículas recobertas com aminosilana [200Fe] com utilização de ímã dinâmico 


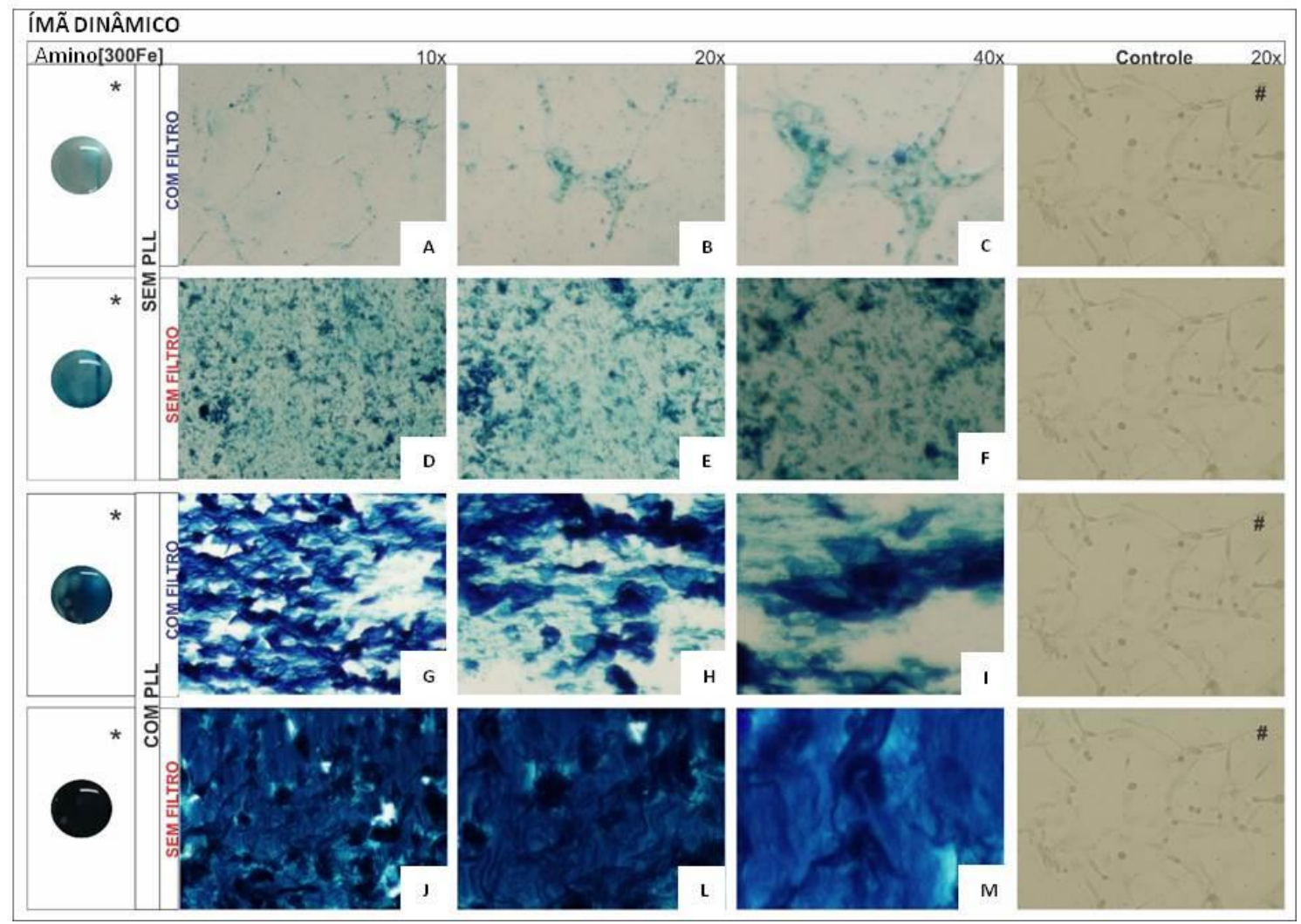

Células marcadas sem PLL (A-F) e com PLL (G-M); Com Filtro (A-C) e de (G-I); Sem filtro (D-F) e de (J-M). *: imagem macroscópica do poço referente, das imagens em disposição linha; \#: Controle.

Figura 50. Imagens ópticas da coloração de azul de prússia das C6-Luc com nanopartículas recobertas com aminosilana [300Fe] com utilização de ímã dinâmico 


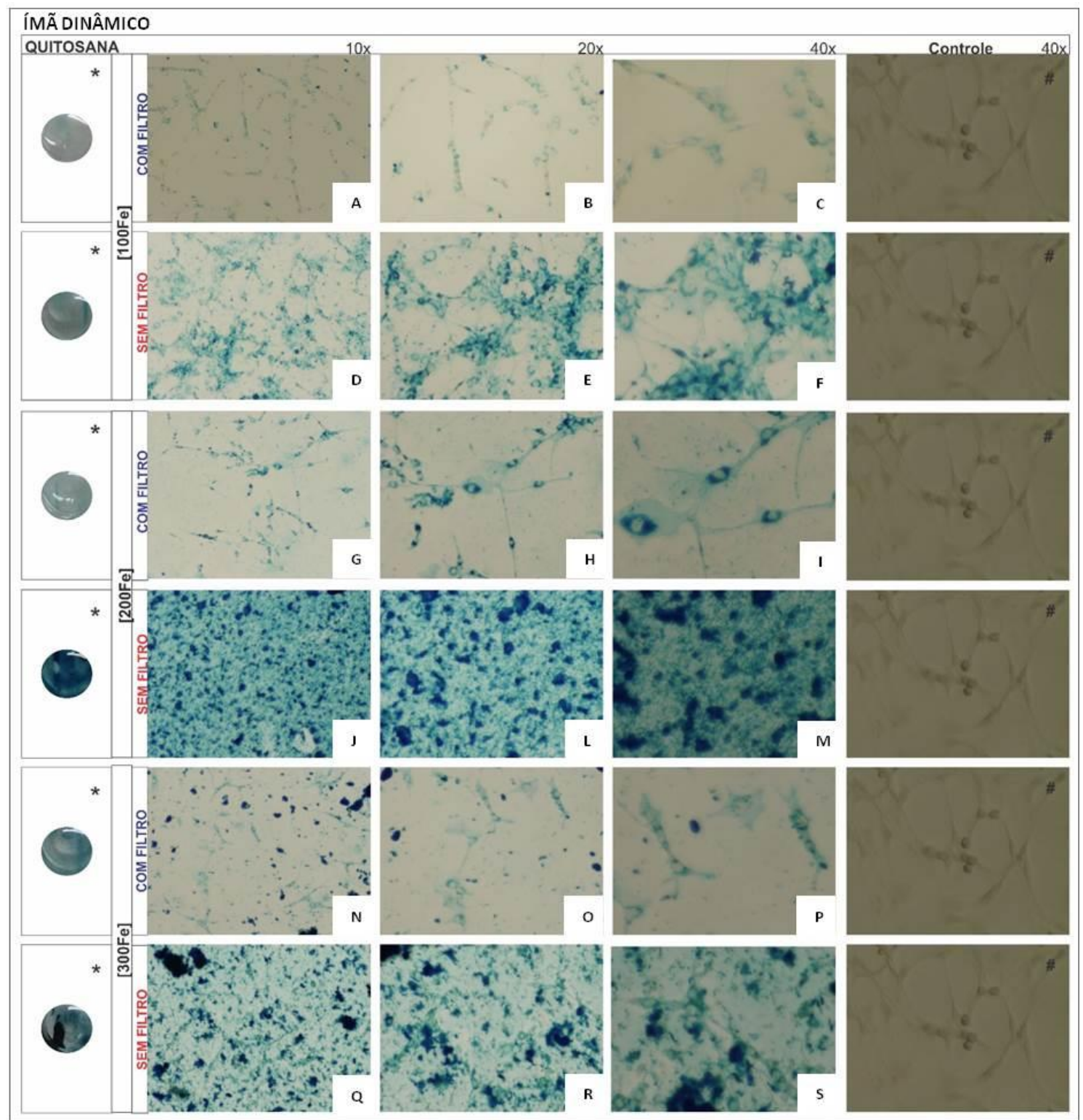

Células marcadas com [100Fe] (A-F), [200Fe] (G-M) e [300Fe] (N-S); Com Filtro (A-C), de (G-I) e de (N-P); Sem filtro (D-F), de (J-M) e de (Q-S). *: imagem macroscópica do poço referente, das imagens em disposição linha; \#: Controle.

Figura 51. Imagens ópticas da coloração de azul de prússia das C6-Luc com nanopartículas recobertas com quitosana, sem poli-lisina e com utilização de ímã dinâmico

Ao analisar as melhores condições de marcação decorrentes, observa-se que a melhor marcação magnética celular por NSOF-Amino e NSOF-Quit, foi com uso de IE. Ao analisar a melhor concentração observa-se que a de [300Fe] possuiu marcação inadequada, impregnando com NSOF a célula e o campo em que ela está. As concentrações de [100Fe] e [200Fe], foram as que possuíram maior eficiência sem impregnar de forma inadequada as células com as nanopartículas, acompanhando a morfologia da célula (Figura 52). 

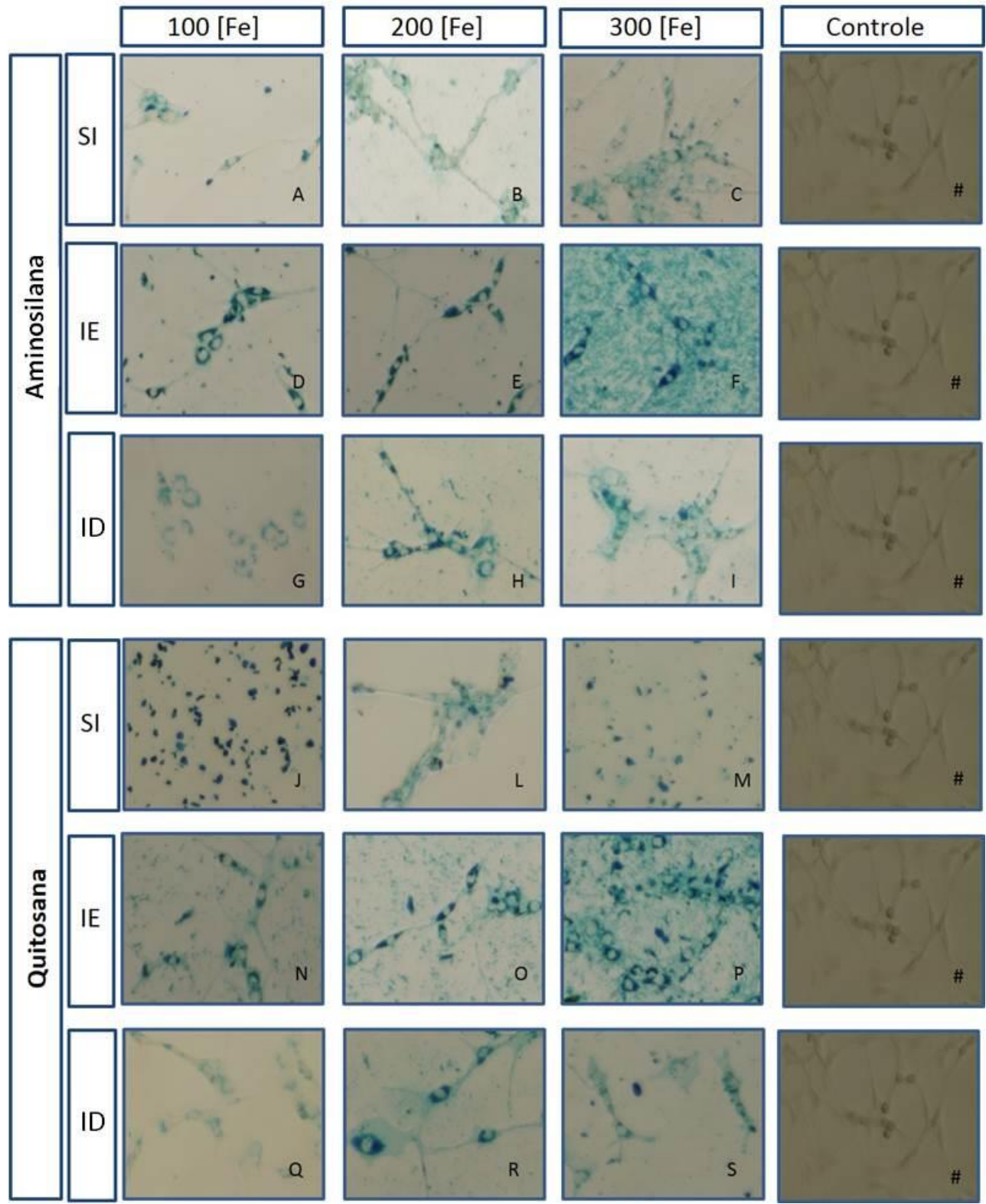

Células marcadas com NSOF-Amino [100-200-300Fe] (A-I); sem ímã (A-C), com ímã estático (D-F) e ímã dinâmico (G-I); Células marcadas com NSOF-Quit [100200-300Fe] (J-S); sem ímã (J-M), ímã estático (N-P) e Ímã dinâmico (Q-S). \#: Controle. SI: Sem Î́mã; IE: Ímã Estático e ID: Ímã Dinâmico.

Figura 52. Imagens ópticas da coloração de azul de prússia das C6-Luc com nanopartículas recobertas com aminosilana e quitosana, sem poli-lisina, com filtro na comparação de meio de marcação magnético

\subsubsection{Aplicação da técnica de magneto hipertermia - In vitro}

Foi realizada aplicação de MHT nas células C6-Luc marcadas com NSOF-Amino de 100nm aplicando uma intensidade de campo magnético de 300 gauss e uma frequência de $551 \mathrm{kHz}$ por 40 minutos à temperatura de $44^{\circ} \mathrm{C}$ e $48^{\circ} \mathrm{C}$. 


\subsubsection{Avaliação da eficiência de magneto hipertermia nas células C6-Luc}

A viabilidade das células após a aplicação de MHT foi obtida por imagens de bioluminescência e citometria de fluxo com marcação de anexina $\mathrm{V}$ e PI.

\subsubsection{Bioluminescência}

Com a aquisição das imagens de bioluminescência após a realização de MHT, verificou-se que as células C6-Luc sem marcação com NSOFAmino e sem MHT, com MHT e com NSOF-Amino sem MHT não alcançaram a temperatura programada de $44^{\circ} \mathrm{C}$, mantendo uma temperatura inferior a $30^{\circ} \mathrm{C} \mathrm{em}$ decorrência do tempo (Figura 53A-B), com curvas de campo magnético e frequência constante (Figura $53 \mathrm{C}-\mathrm{D}$ ), obtendo intensidade de sinal bioluminescente semelhante $\left(4,79 \times 10^{9}, 4,74 \times 10^{9}\right.$ e $4,41 \times 10^{9}$ fotons $\left./ \mathrm{s} / \mathrm{cm}^{2} / \mathrm{sr}\right)$.

Ao submeter às células C6-Luc marcadas com NSOF-Amino à MHT por 40 minutos em 44 e $48^{\circ} \mathrm{C}$ observou-se que houve elevação de temperatura das amostras na temperatura programa, permanecendo constante durante o tempo de realização da terapia (Figura 53E-F), devido alternância do campo magnético (Figura $53 \mathrm{G}$ ), permanecendo com frequência constante em $557 \mathrm{kHz}$ (Figura $53 \mathrm{H}$ ), obtendo diminuição de intensidade de sinal bioluminescente das células após realização da terapia com $44^{\circ} \mathrm{C}\left(1,49 \times 10^{9}\right.$ fotons $\left./ \mathrm{s} / \mathrm{cm}^{2} / \mathrm{sr}\right)$ e $48^{\circ} \mathrm{C}\left(9,98 \times 10^{8}\right.$ fotons $\left./ \mathrm{s} / \mathrm{cm}^{2} / \mathrm{sr}\right)$ comparadas as células marcadas com NSOF-Amino sem MHT $\left(4,41 \times 10^{9}\right.$ fotons $/ \mathrm{s} / \mathrm{cm}^{2} / \mathrm{sr}$ ).

Verificou-se que a curva de viabilidade analisada ao longo do tempo, de C6-luc marcadas com NSOF-Amino foi semelhante a curva de C6-luc não marcadas (figura 53I). Observou-se que houve diminuição da viabilidade celular das células C6Luc marcadas com NSOF-Amino submetidas à MHT de 44 e $48^{\circ} \mathrm{C}$ em 31,11 e 20,86\% respectivamente (Figura 53J). 

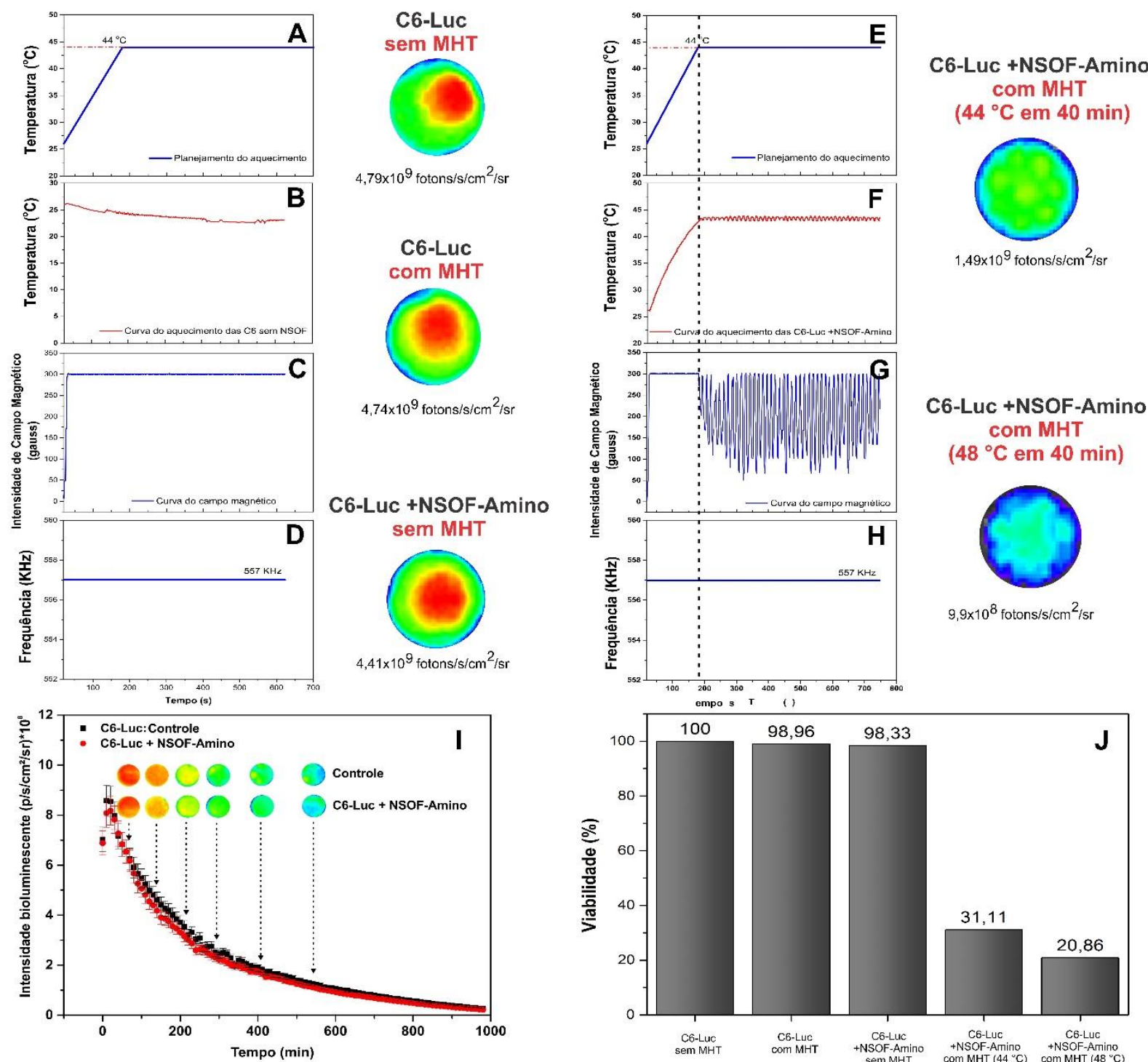

C6-Luc +NSOF-Amino com MHT $\left(48^{\circ} \mathrm{C} \mathrm{em} 40 \mathrm{~min}\right)$

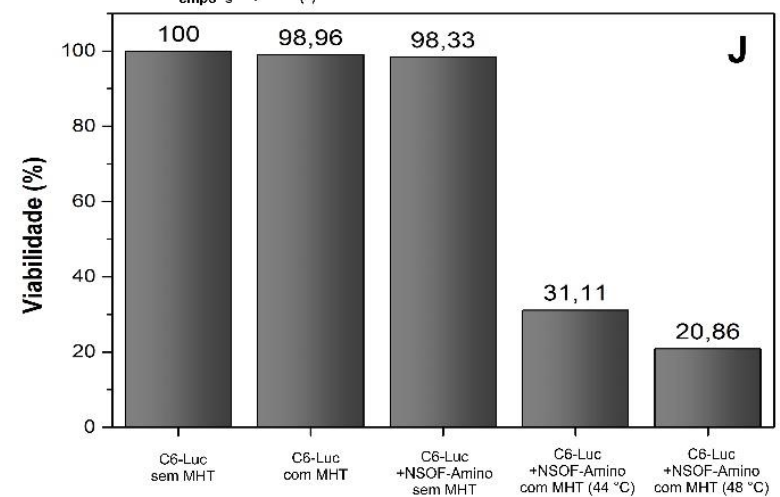

Curva de aquecimento programada em $44^{\circ} \mathrm{C}(\mathrm{A})$; Curva de aquecimento gerada pelas amostras controles (C6-Luc sem MHT, C6-Luc sem NSOF com MHT e C6-Luc com NSOF e sem MHT) (B); Curva da intensidade do campo magnético das amostras controles (C); Curva de frequência de campo das amostras controles (D); Curva de temperatura programada para MHT (E); Curva de aquecimento da amostra de $\mathrm{MHT} 44^{\circ} \mathrm{C}(\mathrm{E})$; Oscilação da curva do campo magnético das amostras submetidas a terapia(G); Curva de frequência de campo das amostras submetidas a terapia por MHT (H); Curva de viabilidade de marcação de C6-Luc com NSOF-Amino ao longo do tempo (I); Gráfico de viabilidade dos grupos de estudo (J).

Figura 53. Viabilidade celular por bioluminescência após exposição à magneto hipertermia

\subsubsection{Citometria de fluxo - Anexina V / lodeto de Propídio}

Os ensaios por Anexina V e PI permitiram a análise de viabilidade celular conforme a descriminação de que células viáveis são negativas para anexina e para PI (-Anexina/-PI), células em início de apoptose são positivas para anexina e negativas para $\mathrm{PI}$ (+Anexina/-PI) e células tardiamente apoptóticas ou necróticas são 
positivas para anexina e para $\mathrm{PI}(+$ Anexina/+PI). Portanto, ao submeter às células C6Luc marcadas com NSOF à análise de viabilidade por anexina $\mathrm{V}$ e $\mathrm{PI}$, determinou a proporção positiva para anexina $\mathrm{V}$ e PI (Q2) de células C6-Luc sem NSOF e sem aplicação de CMA em 0,28\%, de C6-Luc com aplicação de CMA em 1,04\%, C6-Luc marcadas com NSOF-Amino sem aplicação de CMA em 0,06\%, C6-Luc após MHT de $44^{\circ} \mathrm{C}$ por 40 minutos em $65,7 \%$ e com $48^{\circ} \mathrm{C}$ em $75,2 \%$ (Figura $54 \mathrm{~A}-\mathrm{E}$ ). Foi observado, portanto, redução da viabilidade celular nos grupos após MHT em 30,8 e 21,7\%, com $9,1 \%$ de redução de viabilidade do grupo em que foi aplicado $\mathrm{MHT}$ à $48^{\circ} \mathrm{C}$ quando comparado ao de $44^{\circ} \mathrm{C}$ (Figura 54F). 


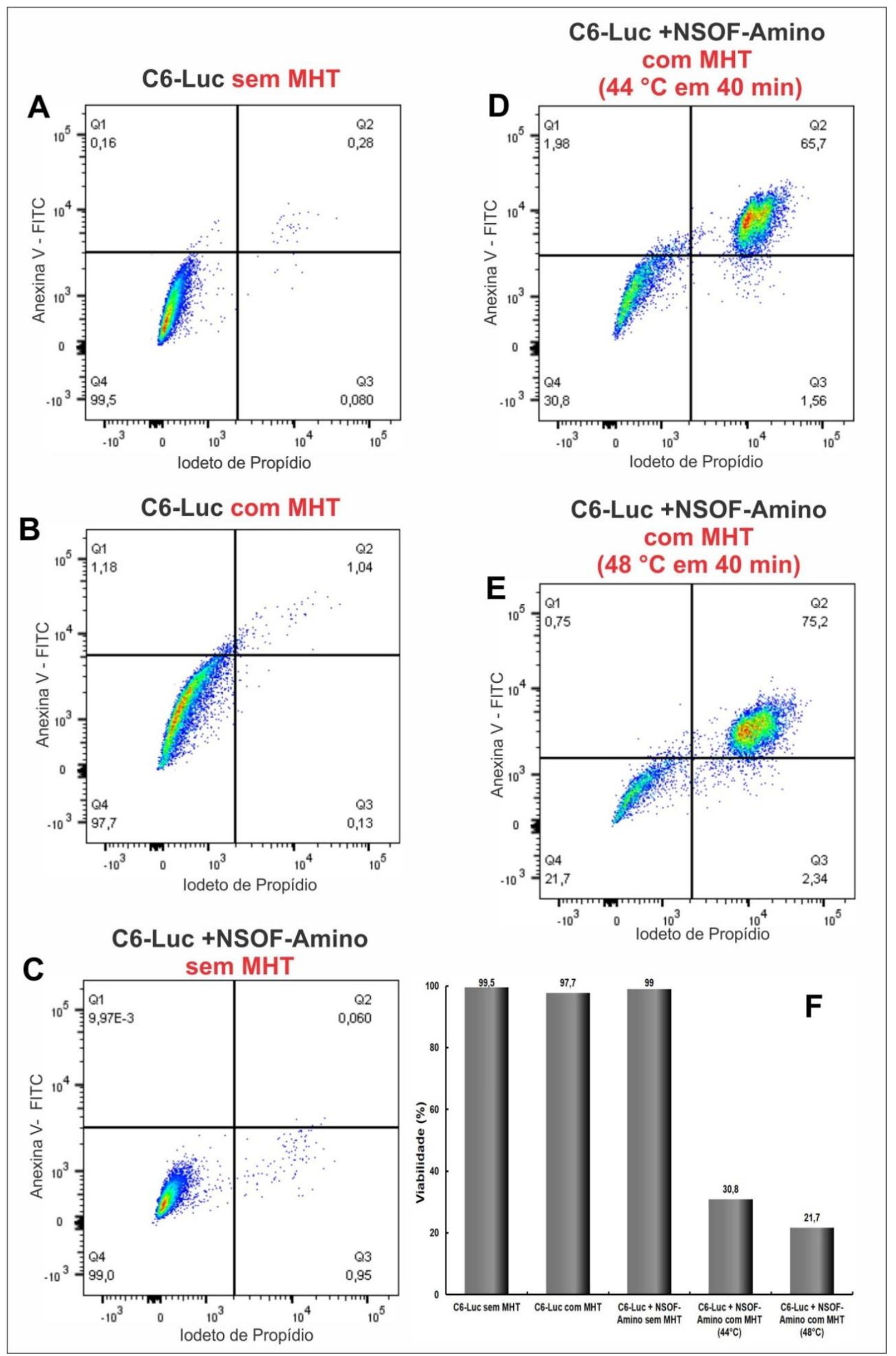

C6-Luc sem marcação com NSOF e sem exposição ao campo magnético (A); C6-Luc sem marcação com NSOF após exposição ao campo magnético (B); C6-Luc marcadas com NSOF sem exposição ao campo magnético (C); C6-Luc marcadas com NSOF-Amino após exposição à MHT em $44^{\circ} \mathrm{C}$ por 40 min (D); C6-Luc com NSOF-Amino após MHT por 40 min na temperatura de $48^{\circ} \mathrm{C}(\mathrm{E})$; Viabilidade celular (\%) de cada grupo (F).

Figura 54. Análise de viabilidade celular com Anexina $V$ e iodeto de propídio 


\subsection{Estudos in vivo}

No estudo in vivo foi realizada a indução de glioblastoma em ratos Wistar com posterior avaliação de volumetria tumoral bem como avaliação comportamental em decorrência do crescimento tumoral. E por fim, foi realizada aplicação de MHT no animal e avaliação por bioluminescência da eficiência da terapia.

\subsubsection{Volumetria de crescimento tumoral}

Foram realizadas análises de volumetria tumoral por IRM e por bioluminescência, para determinar qual seria o melhor tempo para ser aplicada a técnica de MHT e seja possível observar os efeitos terapêuticos.

\subsubsection{Avaliação do crescimento tumoral por histologia e imagem por ressonância magnética}

Para averiguação de posterior alteração comportamental, a análise de volumetria tumoral foi estendida para 28 dias, com $10^{6}$ células na indução tumoral.

As imagens por ressonância magnética do tumor induzido com $10^{6}$ células são mostradas na figura 55 C-J. A figura 55B indica o local da aplicação das células C6-Luc para indução de glioblastoma $(2,0 ; 2 ; 0 ; 2,5)$ tendo como ponto referencial o bregma. Imagens macroscópicas e imagens histológicas estão inseridas na figura 55 G-J.

Como mostradas nas figuras 55C-E, os tumores cerebrais induzidos com C6-Luc são visíveis para imagens obtidas nos períodos de 7, 14, 21 e 28 dias (Figuras 55C-F) e do animal controle (Figura 55A) ponderadas nos tempos de relaxação T2. As imagens obtidas após implantação das células C6 com 7, 14, 21 e 28 dias apresentaram uma região de crescimento de massa mal delimitada com contornos irregulares apresentando sinal heterogêneo de iso, hipo e hipersinal devido à consistência de áreas com sinais variados evidente no $28^{\circ}$ dia, indicando presença e crescimento de tecido tumoral expressivo gerando deslocamentos de córtex cerebral e de estruturas da linha média, além de expansão tumoral para calota óssea quando 
comparadas com a imagem de animal controle (Figura 55A). As imagens histológicas e macroscópicas ex vivo (Figuras 55G-J), corroboram com as imagens visualizadas por IRM do animal controle e da do animal com massa tumoral de 28 dias.

Após a seleção dos cortes de melhor visualização tumoral para realização de ROls pelo software Paravision $5 \Theta$, foi obtida a área tumoral em cada corte que, somada e multiplicada pela espessura da fatia, forneceu o volume do tumoral. Com isso, observou-se aumento do volume tumoral conforme evolução temporal mostrada na figura $55 \mathrm{~K}$. 


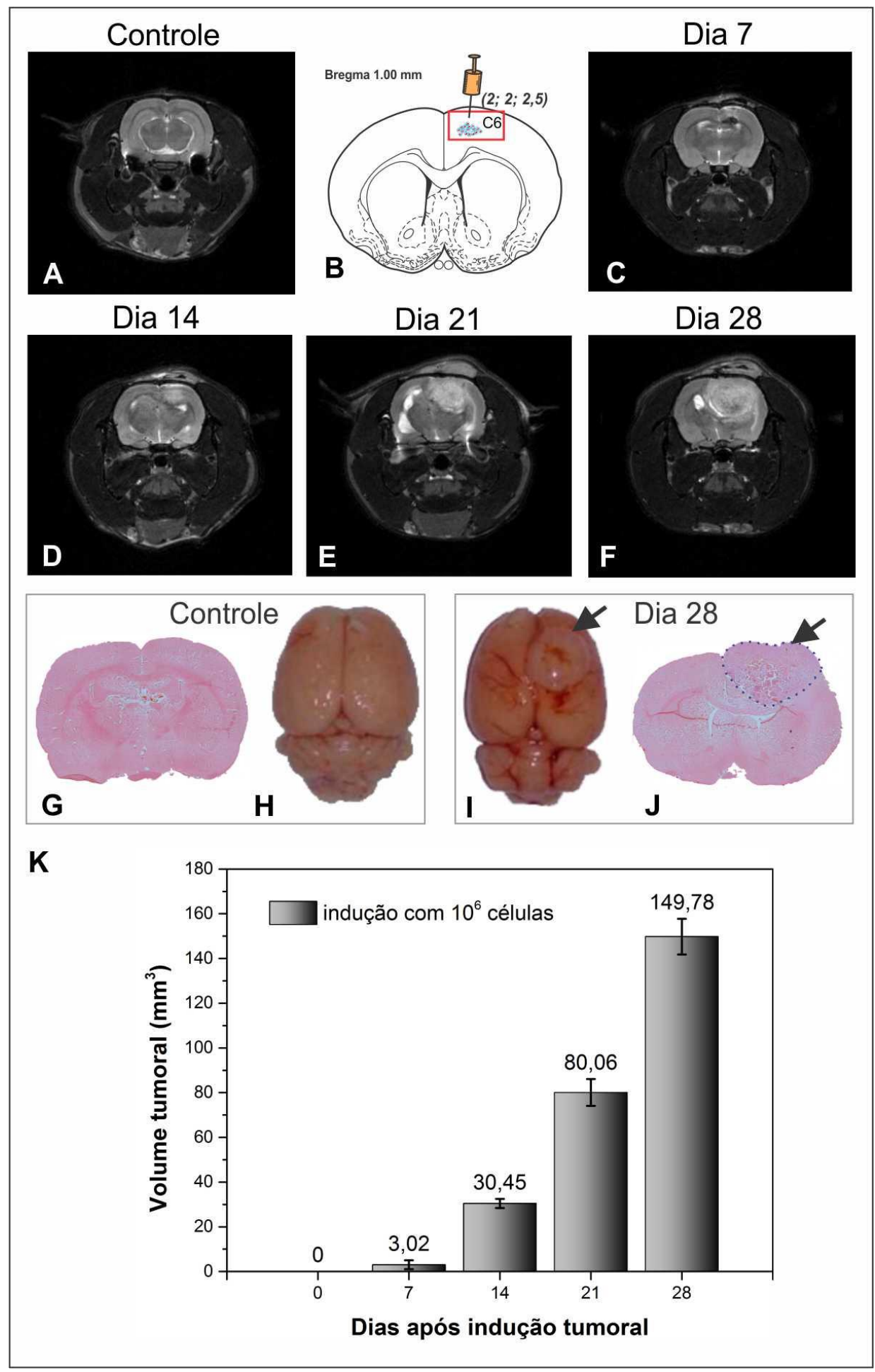

Imagens obtidas nos períodos $0,7,14,21$ e 28 dias (A, C-F). Aplicação das células C6 nas coordenadas $(2,0 ; 2 ; 0 ; 2,5)$ mostrada na figura 1B. Imagem histológica de cérebro controle (G); Imagem macroscópica do cérebro controle $(\mathrm{H})$; Imagem macroscópica de cérebro tumoral após 28 dias de indução (I); Imagem histológica de cérebro com 28 dias de indução tumoral (J); Gráfico de barras do volume do tumor em $\mathrm{mm}^{3}(\mathrm{~K})$.

Figura 55. Imagens por ressonância magnética ponderadas em T2 do desenvolvimento tumoral 


\subsubsection{Avaliação do crescimento tumoral por bioluminescência}

Observa-se que a aquisição de imagem sem administração de luciferina não possui sinal bioluminescente gerado, conforme visualizado nas imagens controle, necessitando assim da luciferina para geração de sinal por reação luciferaseluciferina, conforme visualizado na figura 56.

Após administração de luciferina detectou-se 0 sinal de bioluminescência e que a intensidade do sinal aumentou conforme crescimento do tumor (por conta do aumento do número de células) na evolução temporal como observado na figura 56.

As imagens ex vivo dos cérebros adquiridas 10 minutos após extração cerebral, confirmam os resultados in vivo.

Com estes resultados observa-se que a análise de volumetria tumoral por bioluminescência deve ser caracterizada primordialmente pela análise de intensidade de sinal bioluminescente e posteriormente pela extensão tumoral observada. 


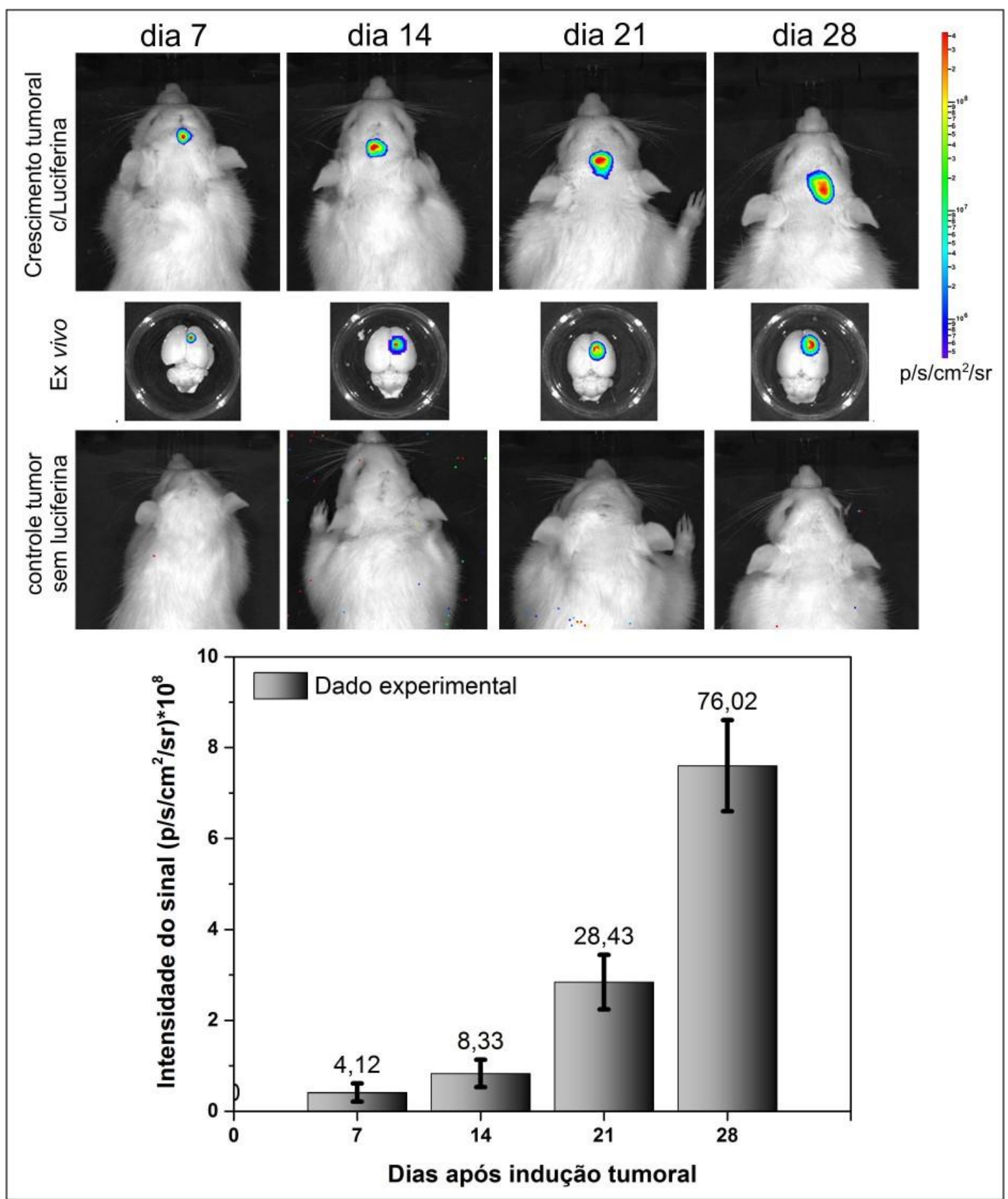

Figura 56. Volumetria tumoral por imagens de bioluminescência

\subsubsection{Avaliação comportamental do animal após indução do tumor}

Foram realizadas análises comportamentais do animal para a avaliação das alterações de marcha e atividade locomotora espontânea. As avaliações foram realizadas nos períodos $0,7,14,21$ e 28 dias após a indução tumoral. 


\subsubsection{Avaliação das alterações de marcha - CatWalk}

Foram avaliados os parâmetros espaciais utilizados na avaliação da marcha: CoP, AC, DPi e distância entre as patas anteriores ou posteriores (DPA/P).

\subsection{Comprimento do passo}

As médias estimadas (Tabela 5) e as comparações entre grupos corrigidas por Bonferroni (Tabela 6) mostram que há evidências de alterações ao longo do tempo principalmente para os grupos Craniotomia e tumor e de diferenças entre os grupos de forma não similar entre as patas e momentos.

Tabela 5. Médias estimadas para comprimento do passo $(\mathrm{cm})$

\begin{tabular}{|c|c|c|c|c|c|c|}
\hline \multirow{2}{*}{ Pata } & \multirow{2}{*}{ Grupo } & \multicolumn{5}{|c|}{ Momento } \\
\hline & & Basal & 7 dias & 14 dias & 21 dias & 28 dias \\
\hline \multirow{3}{*}{ PE } & Tumor & $\begin{array}{c}10,94 \\
(10,63 ; 11,26)\end{array}$ & $\begin{array}{c}9,92 \\
(9,50 ; 10,35)\end{array}$ & $\begin{array}{c}9,09 \\
(8,71 ; 9,49)\end{array}$ & $\begin{array}{c}8,70 \\
(8,27 ; 9,15)\end{array}$ & $\begin{array}{c}6,95 \\
(6,40 ; 7,56)\end{array}$ \\
\hline & Craniotomia & $\begin{array}{c}10,06 \\
(9.62: 10,53)\end{array}$ & $\begin{array}{c}10,35 \\
(10,07 ; 10,65)\end{array}$ & $\begin{array}{c}10,39 \\
(9,86 ; 10,94)\end{array}$ & $\begin{array}{c}9,82 \\
(9,17 ; 10,52)\end{array}$ & $\begin{array}{c}11,16 \\
(10,69 ; 11,65)\end{array}$ \\
\hline & Controle & $\begin{array}{c}11,29 \\
(10,85 ; 11,75)\end{array}$ & $\begin{array}{c}11,65 \\
(11,29 ; 12,03)\end{array}$ & $\begin{array}{c}10,40 \\
(9,86 ; 10,97)\end{array}$ & $\begin{array}{c}11,04 \\
(10,39 ; 11,72)\end{array}$ & $\begin{array}{c}12,24 \\
(11,60 ; 12,91)\end{array}$ \\
\hline \multirow{3}{*}{ PD } & Tumor & $\begin{array}{c}11,32 \\
(10,96 ; 11,69)\end{array}$ & $\begin{array}{c}9,96 \\
(9,45 ; 10,49)\end{array}$ & $\begin{array}{c}9,26 \\
(8,75 ; 9,81)\end{array}$ & $\begin{array}{c}8,92 \\
(8,36 ; 9,51)\end{array}$ & $\begin{array}{c}6,79 \\
(6,20 ; 7,44)\end{array}$ \\
\hline & Craniotomia & $\begin{array}{c}10,38 \\
(9,87 ; 10,92)\end{array}$ & $\begin{array}{c}10,36 \\
(9,92 ; 10,82)\end{array}$ & $\begin{array}{c}10,55 \\
(10,08 ; 11,05)\end{array}$ & $\begin{array}{c}10,04 \\
(9,45 ; 10,66)\end{array}$ & $\begin{array}{c}10,87 \\
(10,31 ; 11,45)\end{array}$ \\
\hline & Controle & $\begin{array}{c}11,43 \\
(10,96 ; 11,92)\end{array}$ & $\begin{array}{c}11,45 \\
(11,06 ; 11,85)\end{array}$ & $\begin{array}{c}10,37 \\
(10,07 ; 10,68)\end{array}$ & $\begin{array}{c}11,07 \\
(10,49 ; 11,69)\end{array}$ & $\begin{array}{c}11,69 \\
(11,15 ; 12,26)\end{array}$ \\
\hline \multirow{3}{*}{$A E$} & Tumor & $\begin{array}{c}10,01 \\
(9,68 ; 10,36)\end{array}$ & $\begin{array}{c}8,77 \\
(8,42 ; 9,14)\end{array}$ & $\begin{array}{c}8,67 \\
(8,12 ; 9,26)\end{array}$ & $\begin{array}{c}8,14 \\
(7,61 ; 8,72)\end{array}$ & $\begin{array}{c}6,25 \\
(5,86 ; 6,67)\end{array}$ \\
\hline & Craniotomia & $\begin{array}{c}9,50 \\
(8,88 ; 10,16)\end{array}$ & $\begin{array}{c}9,45 \\
(9,03 ; 9,88)\end{array}$ & $\begin{array}{c}10,21 \\
(9,72 ; 10,73)\end{array}$ & $\begin{array}{c}9,48 \\
(8,95 ; 10,05)\end{array}$ & $\begin{array}{c}10,35 \\
(9,59 ; 11,18)\end{array}$ \\
\hline & Controle & $\begin{array}{c}10,49 \\
(9,88 ; 11,15)\end{array}$ & $\begin{array}{c}10,47 \\
(10,04 ; 10,91)\end{array}$ & $\begin{array}{c}10,07 \\
(9,74 ; 10,41)\end{array}$ & $\begin{array}{c}10,49 \\
(9,95 ; 11,06)\end{array}$ & $\begin{array}{c}11,17 \\
(10,37 ; 12,04)\end{array}$ \\
\hline \multirow{3}{*}{$A D$} & Tumor & $\begin{array}{c}9,91 \\
(9,49 ; 10,34)\end{array}$ & $\begin{array}{c}9,30 \\
(8,89 ; 9,73)\end{array}$ & $\begin{array}{c}8,84 \\
(8,41 ; 9,30)\end{array}$ & $\begin{array}{c}8,09 \\
(7,64 ; 8,56)\end{array}$ & $\begin{array}{c}6,04 \\
(5,50 ; 6,64)\end{array}$ \\
\hline & Craniotomia & $\begin{array}{c}9,68 \\
(9,35: 10.02)\end{array}$ & $\begin{array}{c}10,31 \\
(9.95: 10.69)\end{array}$ & $\begin{array}{c}10,73 \\
(10.25: 11.23)\end{array}$ & $\begin{array}{c}9,70 \\
(9.02: 10,42)\end{array}$ & $\begin{array}{c}10,30 \\
(9.84: 10.78)\end{array}$ \\
\hline & Controle & $\begin{array}{c}10,14 \\
(9,68 ; 10,63)\end{array}$ & $\begin{array}{c}10,84 \\
(10,36 ; 11,35)\end{array}$ & $\begin{array}{c}10,04 \\
(9,69 ; 10,40)\end{array}$ & $\begin{array}{c}10,18 \\
(9,48 ; 10,92)\end{array}$ & $\begin{array}{c}10,55 \\
(10,02 ; 11,10)\end{array}$ \\
\hline
\end{tabular}

PE: pata posterior esquerda; PD: pata posterior direita; AE: pata anterior esquerda; AD: pata anterior direita. 
Tabela 6. Comparações entre grupos corrigidas por Bonferroni para comprimento do passo

\begin{tabular}{ccccccc}
\hline Pata & Contraste & \multicolumn{5}{c}{ Momento } \\
\cline { 3 - 7 } & Basal & 7 dias & 14 dias & 21 dias & 28 dias \\
\hline \multirow{2}{*}{ PE } & Tumor - Craniotomia & $<0,001$ & $>0,99$ & $<0,001$ & $<0,001$ & $<0,001$ \\
& Tumor - Controle & $>0,99$ & $<0,001$ & $<0,001$ & $<0,001$ & $<0,001$ \\
& Craniotomia - Controle & $<0,001$ & $<0,001$ & $>0,99$ & $<0,001$ & $<0,001$ \\
& & & & & & \\
\multirow{2}{*}{ PD } & Tumor - Craniotomia & 0,092 & $>0,99$ & $<0,001$ & 0,002 & $<0,001$ \\
& Tumor - Controle & $>0,99$ & 0,002 & $<0,001$ & $<0,001$ & $<0,001$ \\
& Craniotomia - Controle & 0,011 & 0,015 & $>0,99$ & 0,016 & $>0,99$ \\
& & & & & & \\
\multirow{2}{*}{ AE } & Tumor - Craniotomia & $>0,99$ & $>0,99$ & 0,004 & $<0,001$ & $<0,001$ \\
& Tumor - Controle & $>0,99$ & $<0,001$ & 0,004 & $<0,001$ & $<0,001$ \\
& Craniotomia - Controle & 0,019 & 0,097 & $>0,99$ & 0,030 & 0,022 \\
& & & & & & \\
& Tumor - Craniotomia & $>0,99$ & 0,029 & $<0,001$ & $<0,001$ & $<0,001$ \\
AD & Tumor - Controle & $>0,99$ & $<0,001$ & $<0,001$ & $<0,001$ & $<0,001$ \\
& Craniotomia - Controle & $>0,99$ & $>0,99$ & $<0,001$ & $>0,99$ & $>0,99$ \\
\hline
\end{tabular}

PE: pata posterior esquerda; PD: pata posterior direita; AE: pata anterior esquerda; AD: pata anterior direita.

As figuras $57 \mathrm{~A}-\mathrm{C}$ demonstram as análises referentes ao CoP do animal, com decaimento contínuo do comprimento de passos no grupo tumor na evolução do tempo.

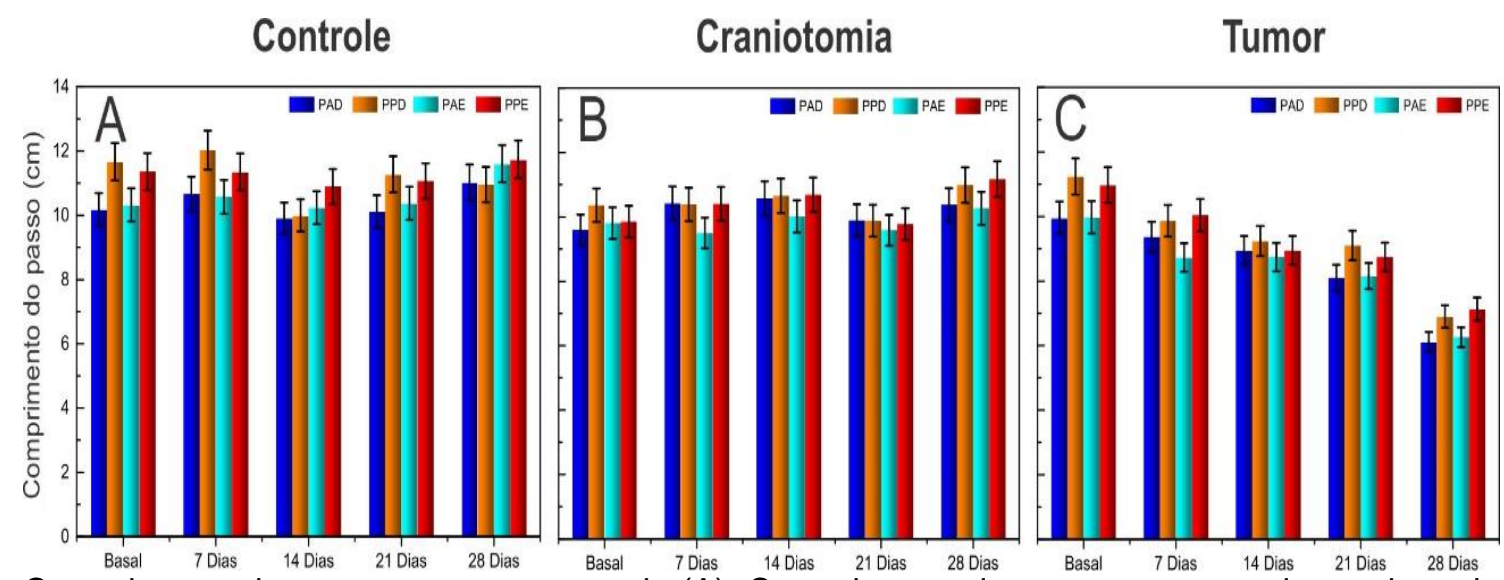

Comprimento do passo no grupo controle (A); Comprimento do passo no grupo de craniotomia (B); Comprimento do passo no grupo tumoral (C). PAD: Pata Anterior Direita; PPD (Pata Posterior Direita); PAE (Pata Anterior Esquerda); PPE (Pata Anterior Esquerda).

Figura 57. Avaliação de marcha do animal no comprimento do passo

\subsubsection{2 Área máxima de contato}

As médias estimadas (Tabela 7) e as comparações entre grupos feitas separadamente por momento (Tabela 8) mostram que há alteração das medidas 
ao longo do tempo principalmente para o grupo tumor e evidências de diferenças entre os grupos tumor e controle a partir de 21 dias, entre tumor e craniotomia ou craniotomia e tumor as diferenças dependem da pata e momento considerados. Os valores-p obtidos com as comparações múltiplas foram corrigidos pelo método de Bonferroni.

Tabela 7. Médias estimadas para área máxima de contato $(\mathrm{cm})$

\begin{tabular}{|c|c|c|c|c|c|c|}
\hline \multirow{2}{*}{ Pata } & \multirow{2}{*}{ Grupo } & \multicolumn{5}{|c|}{ Momento } \\
\hline & & Basal & 7 dias & 14 dias & 21 dias & 28 dias \\
\hline \multirow{3}{*}{ PE } & Tumor & $1,90(1,81 ; 2,00)$ & $1,95(1,86 ; 2,05)$ & $2,33(2,14 ; 2,54)$ & $2,11(1,95 ; 2,28)$ & $1,61(1,46 ; 1,76)$ \\
\hline & Craniotomia & $1,80(1,72 ; 1,89)$ & $2,05(1,97 ; 2,13)$ & $2,33(2,25 ; 2,41)$ & $2,37(2,26 ; 2,50)$ & $2,45(2,34 ; 2,56)$ \\
\hline & Controle & $1,94(1,89 ; 1,99)$ & $2,06(1,96 ; 2,16)$ & $2,23(2,14 ; 2,34)$ & $2,49(2,40 ; 2,59)$ & $2,42(2,28 ; 2,57)$ \\
\hline \multirow{3}{*}{ PD } & Tumor & $2,14(2,03 ; 2,25)$ & $2,19(2,06 ; 2,33)$ & $2,44(2,27 ; 2,62)$ & $2,10(1,96 ; 2,26)$ & $1,63(1,46 ; 1,82)$ \\
\hline & Craniotomia & $1,93(1,85 ; 2,02)$ & $2,20(2,12 ; 2,27)$ & $2,33(2,24 ; 2,44)$ & $2,27(2,13 ; 2,42)$ & $2,38(2,20 ; 2,58)$ \\
\hline & Controle & $2,09(1,99 ; 2,18)$ & $2,21(2,14 ; 2,28)$ & $2,24(2,13 ; 2,35)$ & $2,38(2,25 ; 2,53)$ & $2,35(2,18 ; 2,54)$ \\
\hline \multirow{3}{*}{$\mathrm{AE}$} & Tumor & $1,54(1,50 ; 1,58)$ & $1,54(1,46 ; 1,61)$ & $1,74(1,63 ; 1,85)$ & $1,45(1,36 ; 1,54)$ & $0,93(0,84 ; 1,03)$ \\
\hline & Craniotomia & $1,52(1,44 ; 1,60)$ & $1,68(1,62 ; 1,75)$ & $1,81(1,70 ; 1,93)$ & $1,70(1,60 ; 1,82)$ & $1,48(1,36 ; 1,62)$ \\
\hline & Controle & $1,61(1,53 ; 1,70)$ & $1,66(1,60 ; 1,72)$ & $1,70(1,61 ; 1,80)$ & $1,76(1,65 ; 1,88)$ & $1,44(1,32 ; 1,57)$ \\
\hline \multirow{3}{*}{$A D$} & Tumor & $1,63(1,56 ; 1,71)$ & $1,71(1,63 ; 1,80)$ & $1,93(1,81 ; 2,06)$ & $1,53(1,45 ; 1,61)$ & $1,06(0,98 ; 1,15)$ \\
\hline & Craniotomia & $1,46(1,41 ; 1,51)$ & $1,69(1,65 ; 1,74)$ & $1,82(1,74 ; 1,90)$ & $1,63(1,51 ; 1,75)$ & $1,53(1,41 ; 1,66)$ \\
\hline & Controle & $1,59(1,54 ; 1,65)$ & $1,72(1,65 ; 1,80)$ & $1,76(1,70 ; 1,83)$ & $1,72(1,62 ; 1,84)$ & $1,53(1,41 ; 1,65)$ \\
\hline
\end{tabular}

Tabela 8. Comparações entre grupos corrigidas por Bonferroni para Área máxima de contato

\begin{tabular}{|c|c|c|c|c|c|c|}
\hline \multirow{2}{*}{ Pata } & \multirow{2}{*}{ Contraste } & \multicolumn{5}{|c|}{ Momento } \\
\hline & & Basal & 7 dias & 14 dias & 21 dias & 28 dias \\
\hline \multirow{3}{*}{ PE } & Tumor - Craniotomia & $>0,99$ & $>0,99$ & $>0,99$ & 0,170 & $<0,001$ \\
\hline & Tumor - Controle & $>0,99$ & $>0,99$ & $>0,99$ & $<0,001$ & $<0,001$ \\
\hline & Craniotomia - Controle & 0,281 & $>0,99$ & $>0,99$ & $>0,99$ & $>0,99$ \\
\hline \multirow{3}{*}{ PD } & Tumor - Craniotomia & 0,872 & $>0,99$ & $>0,99$ & 0,956 & $<0,001$ \\
\hline & Tumor - Controle & $>0,99$ & $>0,99$ & $>0,99$ & 0,003 & $<0,001$ \\
\hline & Craniotomia - Controle & $>0,99$ & $>0,99$ & $>0,99$ & $>0,99$ & $>0,99$ \\
\hline \multirow{3}{*}{$\mathrm{AE}$} & Tumor - Craniotomia & $>0,99$ & 0,580 & $>0,99$ & $<0,001$ & $<0,001$ \\
\hline & Tumor - Controle & $>0,99$ & $>0,99$ & $>0,99$ & $<0,001$ & $<0,001$ \\
\hline & Craniotomia - Controle & $>0,99$ & $>0,99$ & 0,119 & $>0,99$ & $>0,99$ \\
\hline \multirow{3}{*}{$A D$} & Tumor - Craniotomia & $<0,001$ & $>0,99$ & $>0,99$ & $>0,99$ & $<0,001$ \\
\hline & Tumor - Controle & $>0,99$ & $>0,99$ & 0,156 & $<0,001$ & $<0,001$ \\
\hline & Craniotomia - Controle & $<0,001$ & $>0,99$ & $>0,99$ & $>0,99$ & $>0,99$ \\
\hline
\end{tabular}

PE: pata posterior esquerda; PD: pata posterior direita; AE: pata anterior esquerda; AD: pata anterior direita. 
A figura $58 \mathrm{~A}-\mathrm{C}$ representa as alterações referentes à área de máximo contato das patas do animal, com diminuição do contato em $\mathrm{cm}^{2}$ das patas anteriores do grupo tumoral a partir do $21^{\circ}$ dia, seguida de discreta diminuição das patas posteriores.

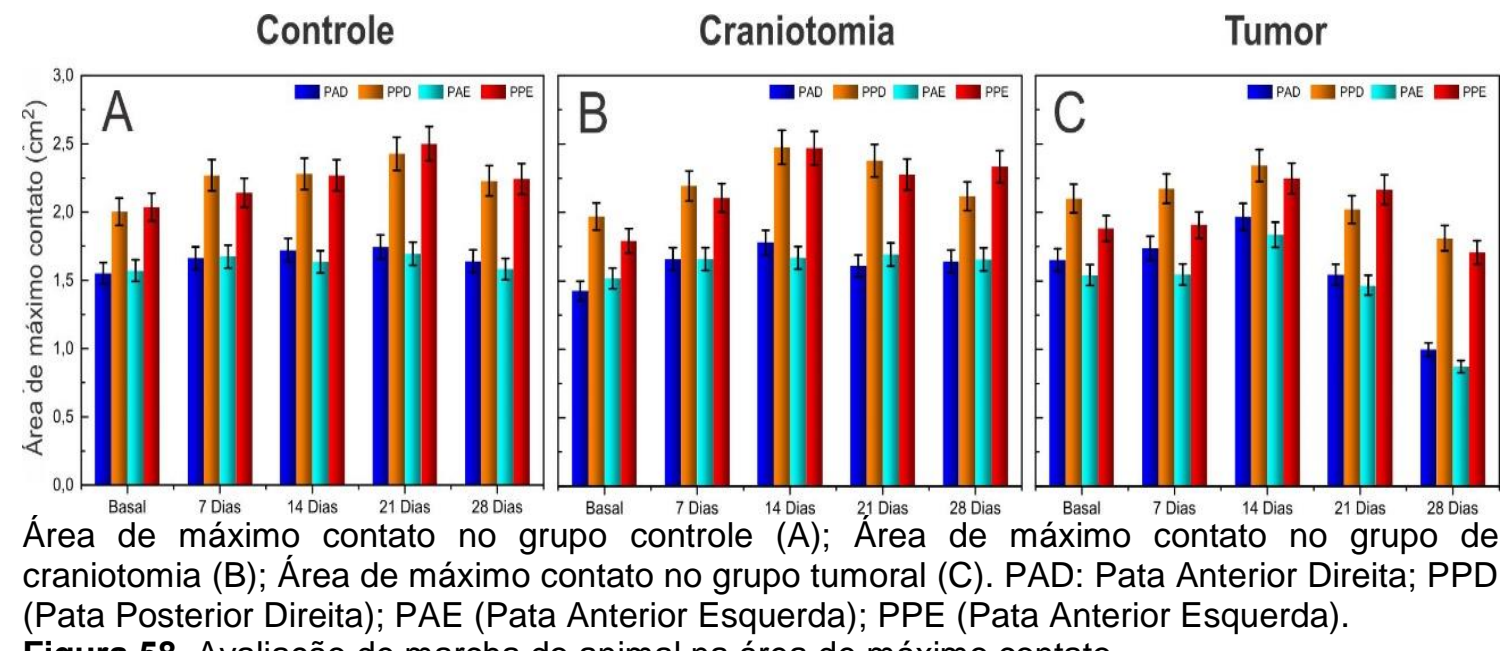

Figura 58. Avaliação de marcha do animal na área de máximo contato

\subsection{Distância entre patas ipsilaterais do mesmo ciclo}

As médias estimadas (Tabela 9) e as comparações entre grupos feitas separadamente por momento (Tabela 10) mostram que há alteração das medidas ao longo do tempo de forma não uniforme entre grupos e patas. Os valores-p obtidos com as comparações múltiplas foram corrigidos pelo método de Bonferroni e mostram que as alterações ao longo do tempo são mais frequentes para o grupo tumor e as diferenças entre grupos são principalmente entre o grupo tumor e demais grupos.

Tabela 9. Médias estimadas para distância entre patas ipsilaterais do mesmo ciclo (DPi) (cm)

\begin{tabular}{lcccccc}
\hline \multirow{2}{*}{ Pata } & \multirow{2}{*}{ Grupo } & \multicolumn{5}{c}{ Momento } \\
\cline { 3 - 7 } & & Basal & $\mathbf{7}$ dias & $\mathbf{1 4}$ dias & $\mathbf{2 1}$ dias & $\mathbf{2 8}$ dias \\
\hline \multirow{3}{*}{ Esquerda } & Cumor & $1,86(1,78 ; 1,94)$ & $1,51(1,46 ; 1,57)$ & $1,72(1,59 ; 1,86)$ & $1,23(1,13 ; 1,33)$ & $0,39(0,36 ; 0,43)$ \\
& Craniotomia & $2,05(1,95 ; 2,15)$ & $1,87(1,81 ; 1,94)$ & $2,09(1,98 ; 2,20)$ & $2,11(1,98 ; 2,25)$ & $1,88(1,69 ; 2,08)$ \\
& Controle & $2,16(2,05 ; 2,28)$ & $1,96(1,84 ; 2,10)$ & $2,26(2,16 ; 2,38)$ & $1,95(1,86 ; 2,05)$ & $1,84(1,69 ; 2,02)$ \\
& & & & & & \\
\multirow{2}{*}{ Direita } & Tumor & $2,08(1,98 ; 2,18)$ & $1,82(1,74 ; 1,90)$ & $1,89(1,77 ; 2,03)$ & $1,40(1,31 ; 1,50)$ & $0,55(0,49 ; 0,61)$ \\
& Craniotomia & $1,97(1,88 ; 2,07)$ & $1,95(1,89 ; 2,01)$ & $1,99(1,89 ; 2,09)$ & $2,08(1,96 ; 2,21)$ & $2,26(2,06 ; 2,48)$ \\
& Controle & $1,97(1,86 ; 2,09)$ & $1,93(1,84 ; 2,03)$ & $2,04(1,95 ; 2,13)$ & $1,82(1,73 ; 1,92)$ & $2,10(1,90 ; 2,32)$ \\
\hline
\end{tabular}


Tabela 10. Comparações entre grupos corrigidas por Bonferroni para distância entre patas ipsilaterais do mesmo ciclo (DPi) (cm)

\begin{tabular}{lcccccc}
\hline \multirow{2}{*}{ Patas } & Contraste & \multicolumn{5}{c}{ Momento } \\
\cline { 3 - 6 } & Tumor - Craneotomia & 0,017 & $<0,001$ & $<0,001$ & $<0,001$ & $<0,001$ \\
\multirow{3}{*}{ Esquerda } & Tumor - Controle & $<0,001$ & $<0,001$ & $<0,001$ & $<0,001$ & $<0,001$ \\
& Craniotomia - Controle & $>0,99$ & $>0,99$ & 0,087 & 0,513 & $>0,99$ \\
& & & & & \\
& & & & & \\
\multirow{2}{*}{ Direita } & Tumor - Craneotomia & $>0,99$ & 0,173 & $>0,99$ & $<0,001$ & $<0,001$ \\
& Tumor - Controle & $>0,99$ & $>0,99$ & 0,966 & $<0,001$ & $<0,001$ \\
& Craniotomia - Controle & $>0,99$ & $>0,99$ & $>0,99$ & $<0,001$ & $>0,99$ \\
\hline
\end{tabular}

A distância entre as patas do mesmo lado do animal foi estudada, conforme mostra a figura 59A-C, em que se observa uma alta diminuição da distância entre as patas no grupo tumoral comparado aos outros grupos a partir do $21^{\circ}$ dia.

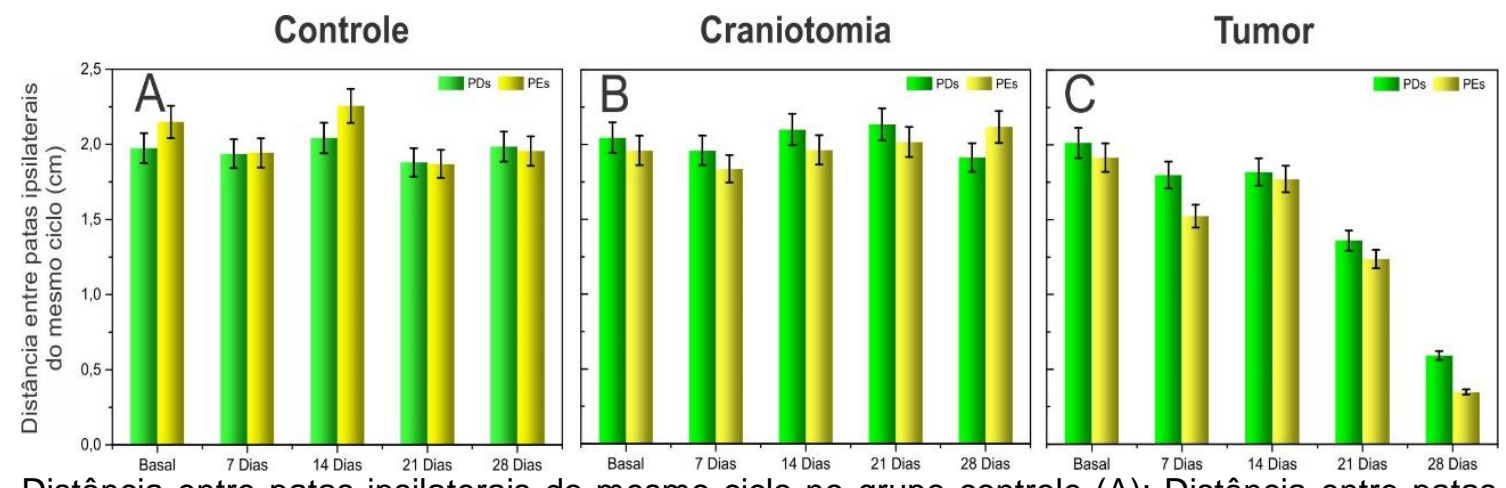

Distância entre patas ipsilaterais do mesmo ciclo no grupo controle (A); Distância entre patas ipsilaterais do mesmo ciclo no grupo de craniotomia (B); Distância entre patas ipsilaterais do mesmo ciclo no grupo de tumor (C). PDs (Patas direitas); PEs (Patas Esquerdas).

Figura 59. Avaliação de alteração de marcha do animal na distância entre patas ipsilaterais do mesmo ciclo

\subsection{Distância entre patas anteriores ou posteriores}

As médias estimadas (Tabela 11) e as comparações múltiplas corrigidas por Bonferroni (Tabela 12) mostram evidências de alterações ao longo do tempo principalmente para o grupo tumor e de diferenças entre o grupo tumor e os demais em 28 dias, além de diferença entre grupos tumor e controle no momento inicial para posteriores e entre tumor e controle em 14 e 21 dias para anteriores. 
Tabela 11. Médias estimadas para distância entre patas anteriores ou posteriores (DPA/P) (cm)

\begin{tabular}{|c|c|c|c|c|c|c|}
\hline \multirow{2}{*}{ Pata } & \multirow{2}{*}{ Grupo } & \multicolumn{5}{|c|}{ Momento } \\
\hline & & Basal & 7 dias & 14 dias & 21 dias & 28 dias \\
\hline \multirow{5}{*}{ Posteriores } & \multirow[t]{2}{*}{ Tumor } & $\begin{array}{c}4,60 \\
(42 \cdot 479)\end{array}$ & $\begin{array}{c}4,18 \\
(398 \cdot 439)\end{array}$ & $\begin{array}{c}4,09 \\
(380 \cdot 442)\end{array}$ & $\begin{array}{c}3,75 \\
(38 \cdot 416)\end{array}$ & $\begin{array}{c}3,13 \\
(287 \cdot 342)\end{array}$ \\
\hline & & 4,11 & $\begin{array}{c}(3,90,4,39) \\
4,25\end{array}$ & $\begin{array}{c}(3,80,4,42) \\
4,47\end{array}$ & $\begin{array}{c}(3,38 ; 4,16) \\
4,20\end{array}$ & $\begin{array}{c}(2,8 / ; 3,42) \\
4,75\end{array}$ \\
\hline & Craniotomia & $(3,88 ; 4,35)$ & $(4,04 ; 4,47)$ & $(4,28 ; 4,67)$ & $(4,03 ; 4,37)$ & $(4,49 ; 5,03)$ \\
\hline & \multirow{2}{*}{ Controle } & 4,21 & 4,25 & 4,47 & 4,24 & 4,51 \\
\hline & & $(4,06 ; 4,38)$ & $(4,02 ; 4,49)$ & $(4,27 ; 4,69)$ & $(4,07 ; 4,41)$ & $(4,24 ; 4,80)$ \\
\hline \multirow{6}{*}{ Anteriores } & \multirow{2}{*}{ Tumor } & 2,85 & 2,60 & 2,55 & 2,24 & 1,66 \\
\hline & & $(2,71 ; 2,99)$ & $(2,44 ; 2,78)$ & $(2,37 ; 2,74)$ & $(2,03 ; 2,47)$ & $(1,51 ; 1,81)$ \\
\hline & \multirow{2}{*}{ Craniotomia } & 2,65 & 2,75 & 2,89 & 2,61 & 2,61 \\
\hline & & $(2,52 ; 2,78)$ & $(2,60 ; 2,92)$ & $(2,79 ; 3,00)$ & $(2,51 ; 2,71)$ & $(2,46 ; 2,77)$ \\
\hline & \multirow{2}{*}{ Controle } & 2,74 & 2,78 & 2,92 & 2,66 & 2,51 \\
\hline & & $(2,54 ; 2,96)$ & $(2,58 ; 2,99)$ & $(2,82 ; 3,04)$ & $(2,56 ; 2,76)$ & $(2,36 ; 2,65)$ \\
\hline
\end{tabular}

Tabela 12. Comparações entre grupos corrigidas por Bonferroni para distância entre patas anteriores ou posteriores (DPA/P) $(\mathrm{cm})$

\begin{tabular}{lcccccc}
\hline \multirow{2}{*}{ Pata } & Contraste & \multicolumn{5}{c}{ Momento } \\
\cline { 3 - 6 } & & Basal & 7 dias & 14 dias & 21 dias & 28 dias \\
\hline \multirow{2}{*}{ Posteriores } & Tumor - Craniotomia & 0,062 & $>0,99$ & $>0,99$ & $>0,99$ & $<0,001$ \\
& Tumor - Controle & 0,018 & $>0,99$ & $>0,99$ & $>0,99$ & $<0,001$ \\
& Craniotomia - Controle & $>0,99$ & $>0,99$ & $>0,99$ & $>0,99$ & $>0,99$ \\
\multirow{4}{*}{ Anteriores } & Tumor - Craniotomia & $>0,99$ & $>0,99$ & 0,065 & 0,150 & $<0,001$ \\
& Tumor - Controle & $>0,99$ & $>0,99$ & 0,020 & 0,020 & $<0,001$ \\
& Craniotomia - Controle & $>0,99$ & $>0,99$ & $>0,99$ & $>0,99$ & $>0,99$ \\
\hline
\end{tabular}

$\mathrm{Na}$ figura $60 \mathrm{~A}-\mathrm{C}$, pode-se analisar a distância entre as patas anteriores e posteriores do animal do mesmo lado do corpo. Observa-se um aumento da distância entre as patas conforme tabela 18, no $28^{\circ}$ dia no grupo com tumor quando comparado aos demais grupos.

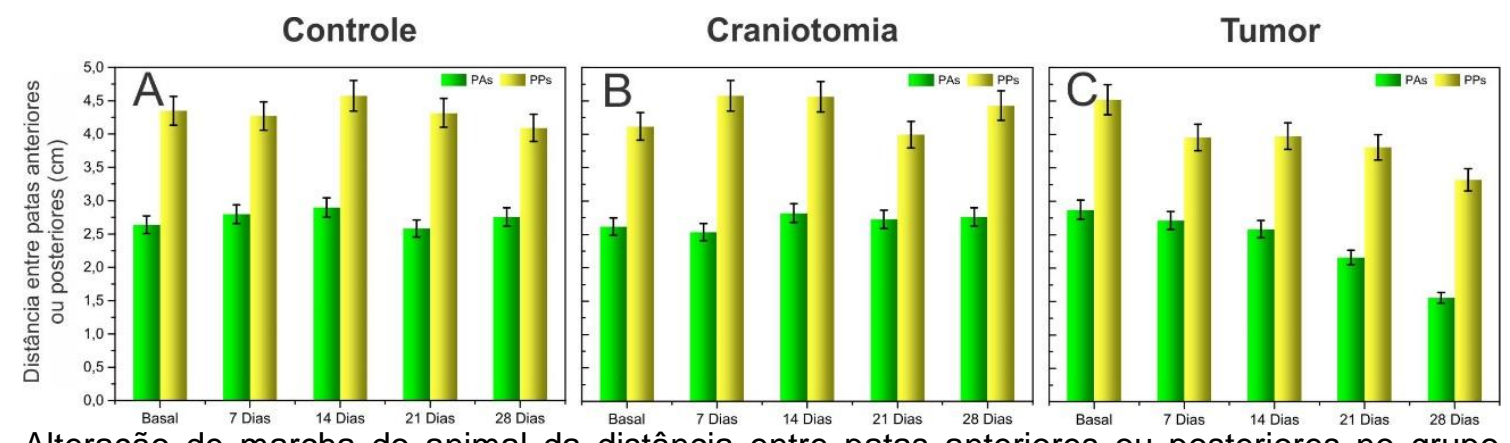

Alteração de marcha do animal da distância entre patas anteriores ou posteriores no grupo controle (A); Alteração de marcha do animal da distância entre patas anteriores ou posteriores no grupo de craniotomia (B); Alteração de marcha do animal da distância entre patas anteriores ou posteriores no grupo de tumor (C). PDs (Patas direitas); PEs (Patas Esquerdas).

Figura 60. Avaliação de marcha do animal da distância entre patas anteriores ou posteriores 
Portanto, ao analisar as imagens obtidas através da câmera do sistema representadas na figura 61, é possível observar as alterações decorrentes da presença do tumor no $2^{\circ}$ dia, comparados à análise basal (tempo 0 de crescimento tumoral) do animal. É possível visualizar a diminuição da DPi do mesmo ciclo, diminuição da AC e da distância entre patas anteriores ou posteriores (DPA/P).

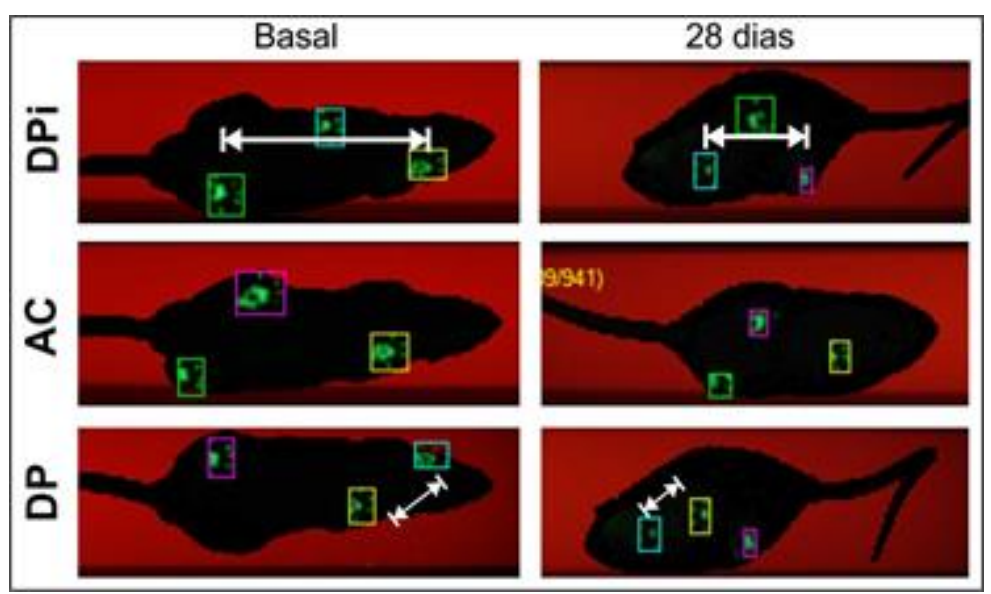

Comparação entre animal controle e tumoral. Distância entre patas ipsilaterais do mesmo ciclo (DPi); Área de máximo contato (AC); Distância entre patas anteriores (DP).

Figura 61. Análise da distância e contato das patas do animal detectadas pelo sistema de CatWalk

Dentre os parâmetros temporais utilizados na avaliação da marcha, tempo de contato da pata no solo, ciclo do passo, cadência e duração, verificou-se uma diminuição gradual de cada variável analisada ao longo do tempo. Portanto com a evolução do tumor, o animal se tornou mais lento durante a análise da marcha.

\subsection{Tempo de contato da pata}

As médias estimadas (Tabela 13) e as comparações entre grupos separadamente por momento (Tabela 14) mostram que há alteração das medidas ao longo do tempo, sendo essa alteração não uniforme nos três grupos e nas diferentes patas. Os valores-p obtidos com as comparações múltiplas foram corrigidos pelo método de Bonferroni e mostram que há mais alterações ao longo do tempo para o grupo do tumor e diferenças entre o grupo do tumor e os demais a partir de 14 dias. 
Tabela 13. Médias estimadas para tempo de contato (TC) (s)

\begin{tabular}{|c|c|c|c|c|c|c|}
\hline \multirow{2}{*}{ Pata } & \multirow{2}{*}{ Grupo } & \multicolumn{5}{|c|}{ Momento } \\
\hline & & Basal & 7 dias & 14 dias & 21 dias & 28 dias \\
\hline \multirow{3}{*}{ PE } & Tumor & $0,46(0,44 ; 0,48)$ & $0,50(0,48 ; 0,52)$ & $0,57(0,53 ; 0,60)$ & $0,70(0,65 ; 0,77)$ & $0,89(0,81 ; 0,98)$ \\
\hline & Craniotomia & $0,43(0,41 ; 0,44)$ & $0,46(0,44 ; 0,49)$ & $0,45(0,43 ; 0,47)$ & $0,47(0,44 ; 0,50)$ & $0,46(0,43 ; 0,49)$ \\
\hline & Controle & $0,43(0,42 ; 0,44)$ & $0,48(0,46 ; 0,50)$ & $0,47(0,46 ; 0,49)$ & $0,49(0,47 ; 0,51)$ & $0,47(0,45 ; 0,50)$ \\
\hline \multirow{3}{*}{ PD } & Tumor & $0,43(0,42 ; 0,45)$ & $0,47(0,44 ; 0,50)$ & $0,53(0,50 ; 0,57)$ & $0,65(0,59 ; 0,71)$ & $0,82(0,75 ; 0,91)$ \\
\hline & Craniotomia & $0,44(0,42 ; 0,46)$ & $0,47(0,44 ; 0,51)$ & $0,46(0,44 ; 0,48)$ & $0,47(0,46 ; 0,49)$ & $0,46(0,44 ; 0,48)$ \\
\hline & Controle & $0,44(0,43 ; 0,46)$ & $0,49(0,46 ; 0,52)$ & $0,48(0,45 ; 0,51)$ & $0,49(0,48 ; 0,50)$ & $0,47(0,45 ; 0,50)$ \\
\hline \multirow{3}{*}{$\mathrm{AE}$} & Tumor & $0,33(0,31 ; 0,34)$ & $0,38(0,37 ; 0,40)$ & $0,44(0,41 ; 0,47)$ & $0,56(0,52 ; 0,60)$ & $0,70(0,65 ; 0,75)$ \\
\hline & Craniotomia & $0,30(0,29 ; 0,31)$ & $0,35(0,33 ; 0,37)$ & $0,34(0,33 ; 0,36)$ & $0,36(0,35 ; 0,38)$ & $0,35(0,32 ; 0,38)$ \\
\hline & Controle & $0,29(0,28 ; 0,31)$ & $0,36(0,34 ; 0,37)$ & $0,35(0,33 ; 0,38)$ & $0,37(0,35 ; 0,39)$ & $0,35(0,33 ; 0,38)$ \\
\hline \multirow{3}{*}{$A D$} & Tumor & $0,31(0,29 ; 0,33)$ & $0,35(0,33 ; 0,37)$ & $0,44(0,42 ; 0,46)$ & $0,50(0,45 ; 0,56)$ & $0,63(0,57 ; 0,70)$ \\
\hline & Craniotomia & $0,31(0,30 ; 0,32)$ & $0,35(0,33 ; 0,37)$ & $0,38(0,36 ; 0,39)$ & $0,36(0,35 ; 0,37)$ & $0,35(0,33 ; 0,37)$ \\
\hline & Controle & $0,29(0,28 ; 0,30)$ & $0,34(0,32 ; 0,36)$ & $0,37(0,36 ; 0,39)$ & $0,35(0,34 ; 0,37)$ & $0,34(0,32 ; 0,36)$ \\
\hline
\end{tabular}

PE: pata posterior esquerda; PD: pata posterior direita; $A E$ : pata anterior esquerda; $A D$ : pata anterior direita.

Tabela 14. Comparações entre grupos corrigidas por Bonferroni para tempo de contato (TC) (s)

\begin{tabular}{|c|c|c|c|c|c|c|}
\hline \multirow{2}{*}{ Pata } & \multirow{2}{*}{ Contraste } & \multicolumn{5}{|c|}{ Momento } \\
\hline & & Basal & 7 dias & 14 dias & 21 dias & 28 dias \\
\hline \multirow{3}{*}{ PE } & Tumor - Craniotomia & 0,596 & $>0,99$ & $<0,001$ & $<0,001$ & $<0,001$ \\
\hline & Tumor - Controle & 0,741 & $>0,99$ & $<0,001$ & $<0,001$ & $<0,001$ \\
\hline & Craniotomia - Controle & $>0,99$ & $>0,99$ & $>0,99$ & $>0,99$ & $>0,99$ \\
\hline \multirow{3}{*}{ PD } & Tumor - Craniotomia & $>0,99$ & $>0,99$ & $<0,001$ & $<0,001$ & $<0,001$ \\
\hline & Tumor - Controle & $>0,99$ & $>0,99$ & 0,389 & $<0,001$ & $<0,001$ \\
\hline & Craniotomia - Controle & $>0,99$ & $>0,99$ & $>0,99$ & $>0,99$ & $>0,99$ \\
\hline \multirow{3}{*}{$\mathrm{AE}$} & Tumor - Craniotomia & $<0,001$ & 0,189 & $<0,001$ & $<0,001$ & $<0,001$ \\
\hline & Tumor - Controle & $<0,001$ & 0,051 & $<0,001$ & $<0,001$ & $<0,001$ \\
\hline & Craniotomia - Controle & $>0,99$ & $>0,99$ & $>0,99$ & $>0,99$ & $>0,99$ \\
\hline \multirow{3}{*}{$A D$} & Tumor - Craniotomia & $>0,99$ & $>0,99$ & $<0,001$ & $<0,001$ & $<0,001$ \\
\hline & Tumor - Controle & $>0,99$ & $>0,99$ & $<0,001$ & $<0,001$ & $<0,001$ \\
\hline & Craniotomia - Controle & $<0,001$ & $>0,99$ & $>0,99$ & $>0,99$ & $>0,99$ \\
\hline
\end{tabular}

PE: pata posterior esquerda; PD: pata posterior direita; $A E$ : pata anterior esquerda; AD: pata anterior direita.

A figura $62 \mathrm{~A}-\mathrm{C}$ representa os gráficos resultantes do tempo de contato da pata do animal com a plataforma nos diferentes grupos. Observou-se um aumento do tempo de contato da pata do grupo tumoral a partir do $14^{\circ}$ dia quando comparado com o grupo controle e de craniotomia. 


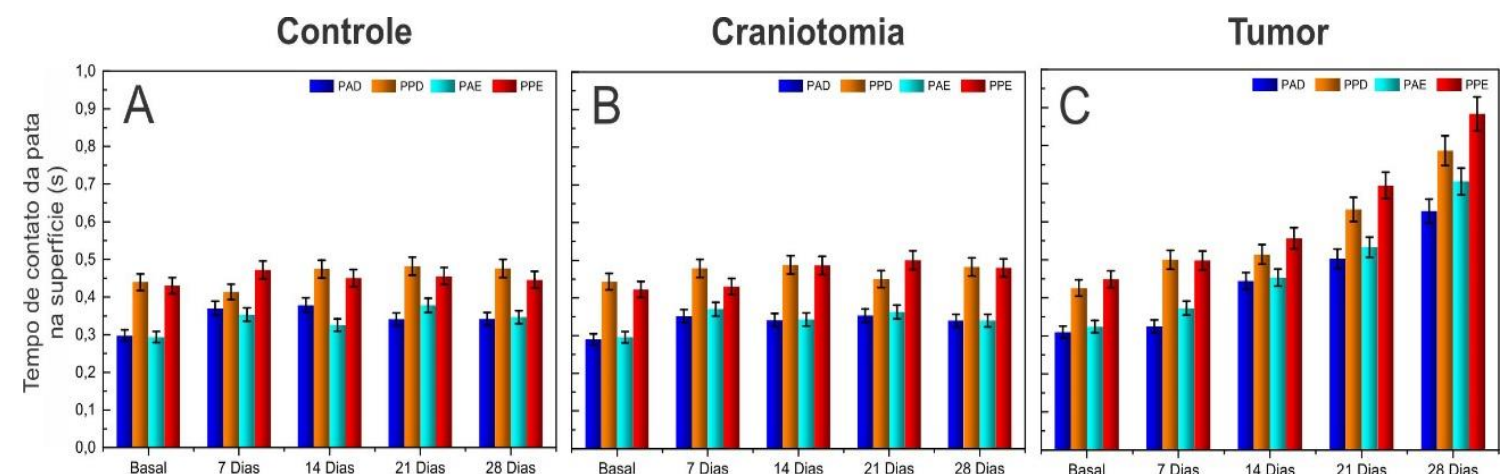

Tempo de contato da pata na superfície do grupo controle (A); Tempo de contato da pata na superfície do grupo de craniotomia (B); Tempo de contato da pata na superfície do grupo tumoral (C). PAD: pata anterior direita; PPD: pata posterior direita; PAE: pata anterior esquerda; PPE: pata anterior esquerda.

Figura 62. Avaliação de marcha do animal no tempo de contato da pata na superfície

\subsection{Ciclo do passo}

As médias estimadas (Tabela 15) e as comparações entre grupos corrigidos pelo método de Bonferroni, feitas separadamente por momento (Tabela 16), mostram que há evidências de alteração ao longo do tempo principalmente, para o grupo tumor.

Tabela 15. Médias estimadas para ciclo do passo (s)

\begin{tabular}{|c|c|c|c|c|c|c|}
\hline \multirow{2}{*}{ Pata } & \multirow{2}{*}{ Grupo } & \multicolumn{5}{|c|}{ Momento } \\
\hline & & Basal & 7 dias & 14 dias & 21 dias & 28 dias \\
\hline \multirow{3}{*}{ PE } & Tumor & $0,49(0,46 ; 0,51)$ & $0,60(0,57 ; 0,63)$ & $0,66(0,62 ; 0,70)$ & $0,78(0,72 ; 0,84)$ & $1,07(0,97 ; 1,18)$ \\
\hline & Craniotomia & $0,47(0,45 ; 0,49)$ & $0,53(0,51 ; 0,56)$ & $0,55(0,52 ; 0,58)$ & $0,53(0,50 ; 0,56)$ & $0,56(0,53 ; 0,59)$ \\
\hline & Controle & $0,50(0,47 ; 0,52)$ & $0,48(0,45 ; 0,51)$ & $0,54(0,52 ; 0,57)$ & $0,46(0,44 ; 0,49)$ & $0,52(0,49 ; 0,55)$ \\
\hline \multirow{3}{*}{ PD } & Tumor & $0,56(0,54 ; 0,58)$ & $0,60(0,58 ; 0,63)$ & $0,64(0,61 ; 0,68)$ & $0,74(0,68 ; 0,80)$ & $1,02(0,92 ; 1,12)$ \\
\hline & Craniotomia & $0,54(0,52 ; 0,56)$ & $0,54(0,52 ; 0,56)$ & $0,54(0,52 ; 0,57)$ & $0,51(0,48 ; 0,53)$ & $0,54(0,51 ; 0,57)$ \\
\hline & Controle & $0,57(0,56 ; 0,59)$ & $0,49(0,47 ; 0,51)$ & $0,54(0,51 ; 0,57)$ & $0,44(0,42 ; 0,46)$ & $0,50(0,47 ; 0,52)$ \\
\hline \multirow{3}{*}{$\mathrm{AE}$} & Tumor & $0,41(0,39 ; 0,43)$ & $0,52(0,50 ; 0,54)$ & $0,59(0,56 ; 0,62)$ & $0,70(0,66 ; 0,75)$ & $1,00(0,93 ; 1,08)$ \\
\hline & Craniotomia & $0,38(0,37 ; 0,39)$ & $0,45(0,43 ; 0,46)$ & $0,48(0,45 ; 0,50)$ & $0,46(0,43 ; 0,49)$ & $0,51(0,47 ; 0,54)$ \\
\hline & Controle & $0,42(0,41 ; 0,43)$ & $0,42(0,41 ; 0,44)$ & $0,49(0,47 ; 0,52)$ & $0,42(0,39 ; 0,45)$ & $0,49(0,45 ; 0,53)$ \\
\hline \multirow{3}{*}{$A D$} & Tumor & $0,44(0,42 ; 0,45)$ & $0,51(0,49 ; 0,53)$ & $0,58(0,55 ; 0,61)$ & $0,70(0,65 ; 0,76)$ & $1,01(0,92 ; 1,11)$ \\
\hline & Craniotomia & $0,42(0,40 ; 0,45)$ & $0,46(0,44 ; 0,48)$ & $0,49(0,47 ; 0,51)$ & $0,48(0,46 ; 0,50)$ & $0,54(0,51 ; 0,56)$ \\
\hline & Controle & $0,44(0,42 ; 0,46)$ & $0,41(0,39 ; 0,43)$ & $0,48(0,46 ; 0,50)$ & $0,41(0,39 ; 0,44)$ & $0,49(0,46 ; 0,51)$ \\
\hline
\end{tabular}

PE: pata posterior esquerda; PD: pata posterior direita; $A E$ : pata anterior esquerda; AD: pata anterior direita. 
Tabela 16. Comparações entre grupos corrigidas por Bonferroni para ciclo do passo (s)

\begin{tabular}{|c|c|c|c|c|c|c|}
\hline \multirow{2}{*}{ Pata } & \multirow{2}{*}{ Contraste } & \multicolumn{5}{|c|}{ Momento } \\
\hline & & Basal & 7 dias & 14 dias & 21 dias & 28 dias \\
\hline \multirow{3}{*}{ PE } & Tumor - Craniotomia & $>0,99$ & 0,289 & 0,002 & $<0,001$ & $<0,001$ \\
\hline & Tumor - Controle & $>0,99$ & $<0,001$ & $<0,001$ & $<0,001$ & $<0,001$ \\
\hline & Craniotomia - Controle & 0,566 & 0,428 & $>0,99$ & $<0,001$ & $<0,001$ \\
\hline \multirow{3}{*}{ PD } & Tumor - Craniotomia & $>0,99$ & $<0,001$ & $<0,001$ & $<0,001$ & $<0,001$ \\
\hline & Tumor - Controle & $>0,99$ & $<0,001$ & $<0,001$ & $<0,001$ & $<0,001$ \\
\hline & Craniotomia - Controle & 0,006 & $<0,001$ & $>0,99$ & $<0,001$ & 0,296 \\
\hline \multirow{3}{*}{$A E$} & Tumor - Craniotomia & 0,178 & $<0,001$ & $<0,001$ & $<0,001$ & $<0,001$ \\
\hline & Tumor - Controle & $>0,99$ & $<0,001$ & $<0,001$ & $<0,001$ & $<0,001$ \\
\hline & Craniotomia - Controle & $<0,001$ & 0,344 & $>0,99$ & $<0,001$ & $>0,99$ \\
\hline \multirow{3}{*}{$A D$} & Tumor - Craniotomia & $>0,99$ & $<0,001$ & $<0,001$ & $<0,001$ & $<0,001$ \\
\hline & Tumor - Controle & $>0,99$ & $<0,001$ & $<0,001$ & $<0,001$ & $<0,001$ \\
\hline & Craniotomia - Controle & $>0,99$ & $<0,001$ & $>0,99$ & $<0,001$ & 0,037 \\
\hline
\end{tabular}

PE: pata posterior esquerda; PD: pata posterior direita; AE: pata anterior esquerda; AD: pata anterior direita.

A figura 63A-C demonstra os gráficos relacionados ao ciclo de passos da mesma pata (por segundos) dos grupos estudados. Observa-se um aumento contínuo do ciclo em questão, na escala de tempo do grupo tumoral.

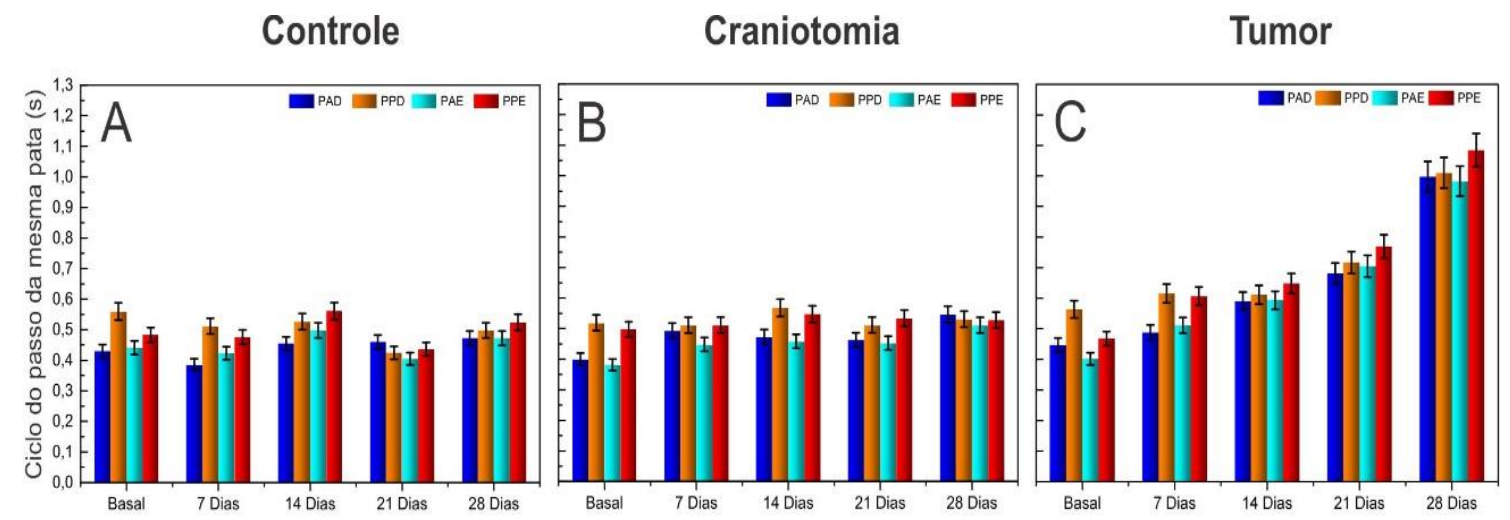

Figura 63. Avaliação de marcha do animal no ciclo de passo da mesma pata. Ciclo de passo da mesma pata no grupo controle (A); Ciclo de passo da mesma pata no grupo de craniotomia (B); Ciclo de passo da mesma pata no grupo tumoral (C). PAD: Pata Anterior Direita; PPD (Pata Posterior Direita); PAE (Pata Anterior Esquerda); PPE (Pata Anterior Esquerda)

\subsection{Cadência}

As médias estimadas (Tabela 17) e as comparações múltiplas corrigidas por Bonferroni (Tabela 18) mostram que as alterações ao longo do tempo são mais frequentes para o grupo tumor e que grupo tumor apresenta diferenças do 
grupo controle a partir de sete dias e diferenças de Craniotomia a partir de 21 dias. Há também evidências de diferenças entre Craniotomia e controle em sete, 14 e 21 dias.

Tabela 17. Médias estimadas para Cadência (passo/segundo)

\begin{tabular}{lccccc}
\hline \multirow{2}{*}{ Grupo } & \multicolumn{5}{c}{ Momento } \\
\cline { 2 - 6 } & Basal & 7 dias & 14 dias & 21 dias & 28 dias \\
\hline Tumor & $8,32(7,92 ; 8,75)$ & $7,38(7,02 ; 7,76)$ & $6,77(6,28 ; 7,29)$ & $5,51(4,99 ; 6,08)$ & $3,99(3,61 ; 4,41)$ \\
Craniotomia & $8,77(8,34 ; 9,23)$ & $7,51(7,15 ; 7,89)$ & $7,19(6,83 ; 7,56)$ & $8,93(8,51 ; 9,37)$ & $7,34(6,99 ; 7,72)$ \\
Controle & $7,89(7,52 ; 8,29)$ & $8,61(8,17 ; 9,07)$ & $8,28(7,93 ; 8,64)$ & $7,98(7,63 ; 8,34)$ & $7,87(7,56 ; 8,20)$ \\
\hline
\end{tabular}

Tabela 18. Comparações entre grupos corrigidas por Bonferroni para Cadência (passo/segundo)

\begin{tabular}{lccccc}
\hline \multirow{2}{*}{ Contraste } & \multicolumn{5}{c}{ Momento } \\
\cline { 2 - 6 } & Basal & $\mathbf{7}$ dias & 14 dias & 21 dias & 28 dias \\
\hline Tumor - Craniotomia & $>0,99$ & $>0,99$ & $>0,99$ & $<0,001$ & $<0,001$ \\
Tumor - Controle & $>0,99$ & 0,001 & $<0,001$ & $<0,001$ & $<0,001$ \\
Craniotomia - Controle & 0,146 & 0,010 & 0,001 & 0,034 & $>0,99$ \\
\hline
\end{tabular}

A figura 64 representa a análise de cadência (passos por segundo) nos grupos de estudo, com decaimento expressivo do grupo tumoral a partir do $7^{\circ}$ dia quando comparado com o grupo controle. 


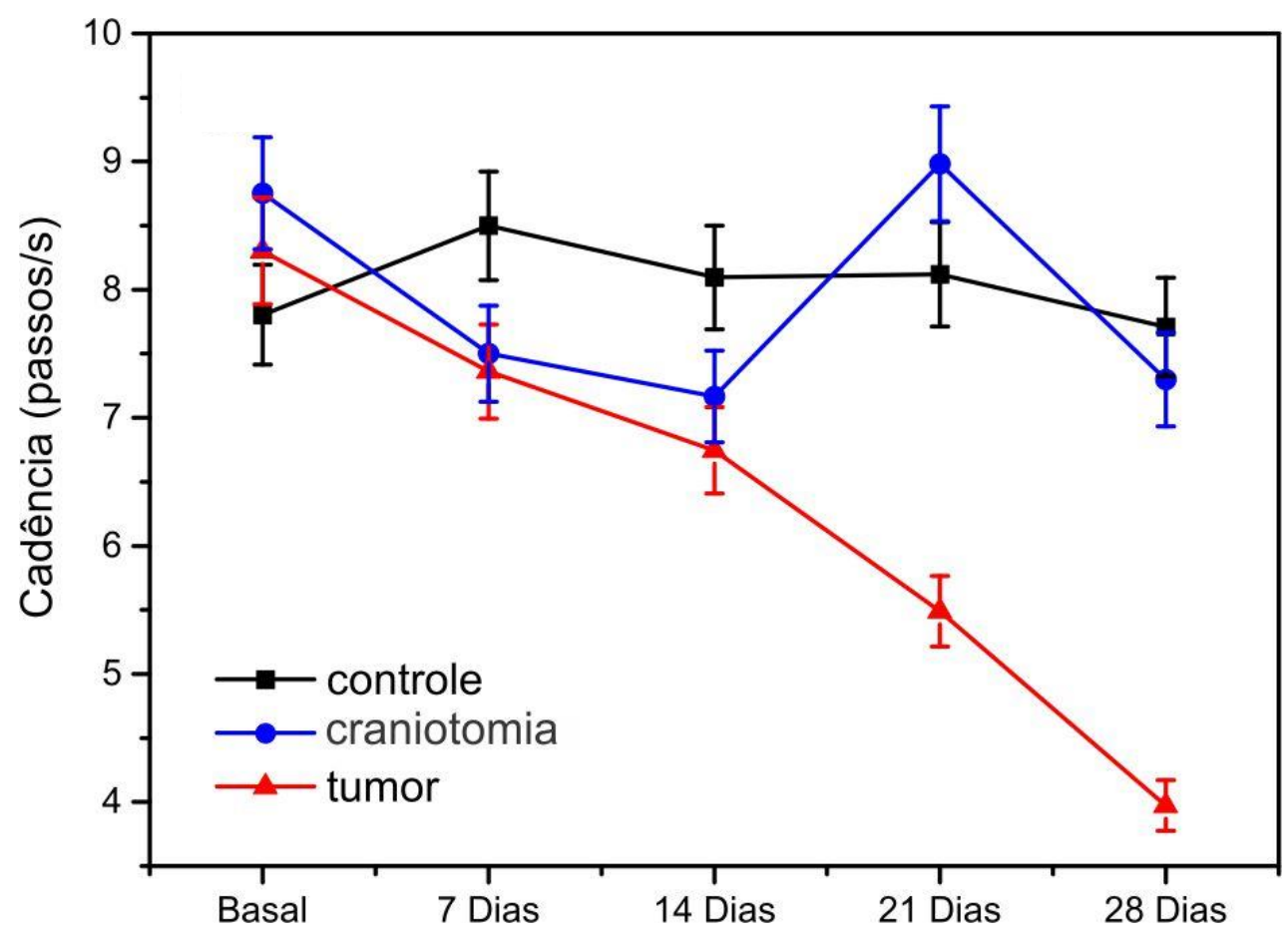

Figura 64. Avaliação da cadência no grupo tumoral quando comparado aos demais grupos.

\subsection{Duração}

As médias estimadas (Tabela 19) e as comparações múltiplas corrigidas por Bonferroni (Tabela 20) mostram que as alterações ao longo do tempo para os três grupos e que grupo tumor apresenta diferenças do controle a partir de 14 dias, tumor difere de Craniotomia em todos os momentos à exceção de 14 dias e Craniotomia difere de controle em sete, 14 e 21 dias.

Tabela 19. Médias estimadas para duração (s)

\begin{tabular}{lccccc}
\hline \multirow{2}{*}{ Grupo } & \multicolumn{5}{c}{ Momento } \\
\cline { 2 - 6 } & Basal & $\mathbf{7}$ dias & 14 dias & 21 dias & 28 dias \\
\hline Tumor & $4,05(3,86 ; 4,25)$ & $4,79(4,57 ; 5,03)$ & $5,24(4,87 ; 5,64)$ & $7,95(7,21 ; 8,77)$ & $10,10(9,17 ; 11,12)$ \\
Craniotomia & $3,49(3,33 ; 3,66)$ & $3,20(3,05 ; 3,36)$ & $4,65(4,44 ; 4,87)$ & $4,02(3,82 ; 4,23)$ & $4,29(4,08 ; 4,51)$ \\
Controle & $3,78(3,61 ; 3,96)$ & $4,33(4,11 ; 4,56)$ & $3,92(3,73 ; 4,12)$ & $5,09(4,88 ; 5,30)$ & $3,86(3,67 ; 4,06)$ \\
\hline
\end{tabular}

Tabela 20. Comparações entre grupos corrigidas por Bonferroni para duração (s)

\begin{tabular}{lccccc}
\hline \multirow{2}{*}{ Contraste } & \multicolumn{5}{c}{ Momento } \\
\cline { 2 - 6 } & Basal & 7 dias & 14 dias & 21 dias & 28 dias \\
\hline Tumor - Craniotomia & $<0,001$ & $<0,001$ & 0,386 & $<0,001$ & $<0,001$ \\
Tumor - Controle & $>0,99$ & 0,228 & $<0,001$ & $<0,001$ & $<0,001$ \\
Craniotomia - Controle & 0,875 & $<0,001$ & $<0,001$ & $<0,001$ & 0,176 \\
\hline
\end{tabular}


Na figura 65, observa-se a alta elevação do tempo no grupo tumoral após o $21^{\circ}$ dia, na duração do percurso realizado pelo animal na plataforma.

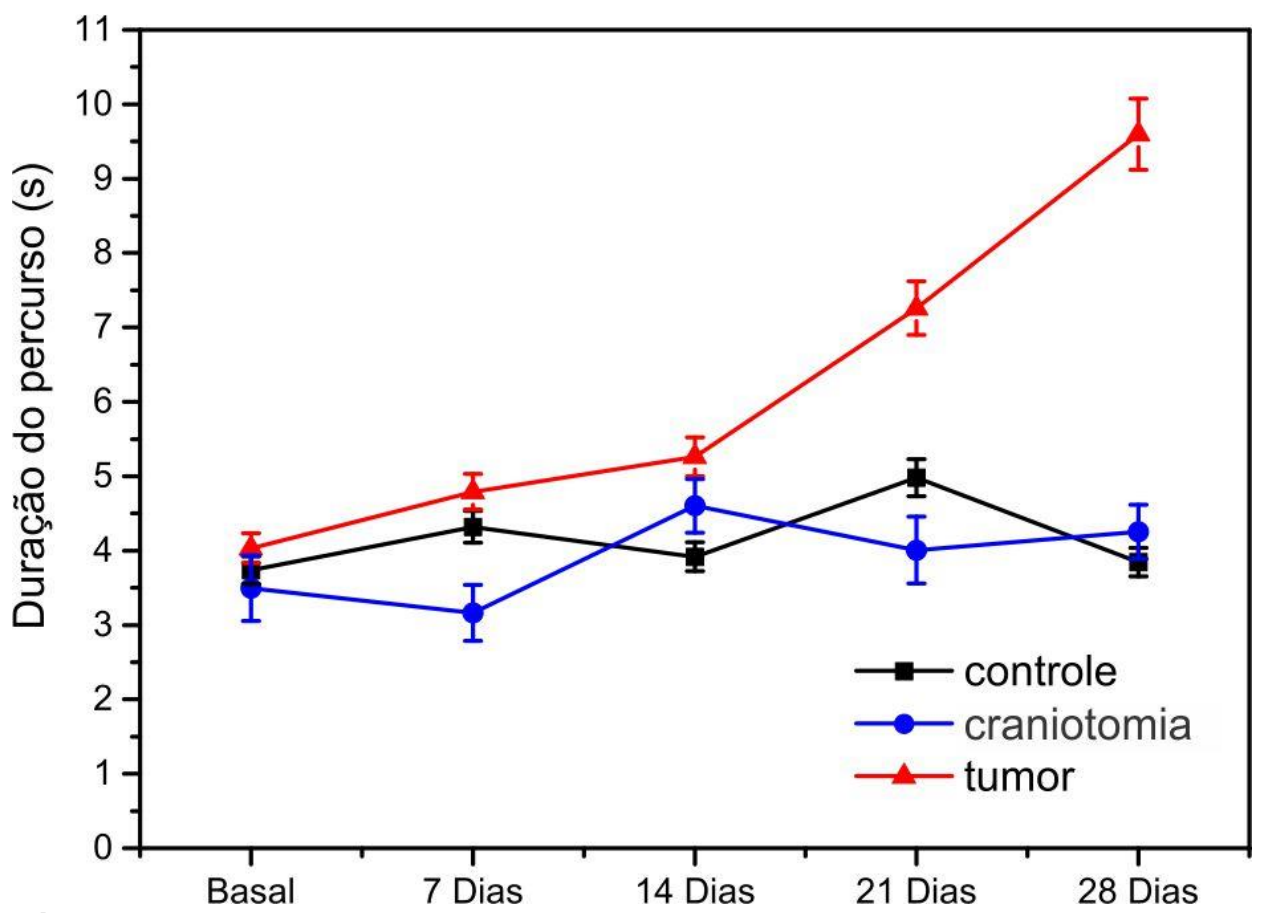

Figura 65. Avaliação da duração do percurso realizado no grupo tumoral em comparação com os demais grupos

\subsubsection{Avaliação locomotora espontânea - Actômetro}

Os parâmetros analisados quanto avaliação locomotora espontânea incluíram movimentos horizontais em duas frequências (lentos e rápidos), como: movimento espontâneo (MOV-L e MOV-R) e movimento espontâneo da cabeça do animal (STE-L e STE-R); e movimento na direção vertical (erguidas), como o movimento de levantar (REA-L e REA-R).

\subsection{Movimento espontâneo lento do animal na plataforma (MOV-L)}

As médias estimadas (Tabela 21) e as comparações entre grupos corrigidos pelo método de Bonferroni (Tabela 22 e Figura 66) mostram que não há evidências de diferenças significativas entre os grupos controle e Craniotomia em qualquer dos momentos considerados, e também não há evidências de alteração nas 
medidas ao longo do tempo para o grupo controle. As comparações entre os grupos tumor e controle mostram diferenças a partir de 21 dias e entre tumor e Craniotomia as diferenças são evidentes a partir de sete dias.

Tabela 21. Médias estimadas para MOV-L

\begin{tabular}{cccc}
\hline Momento & \multicolumn{3}{c}{ Grupo } \\
\cline { 2 - 4 } & $\begin{array}{c}\text { Controle } \\
\text { Média estimada } \\
(\text { IC 95\%) }\end{array}$ & $\begin{array}{c}\text { Craniotomia } \\
\text { Média estimada } \\
\text { (IC 95\%) }\end{array}$ & $\begin{array}{c}\text { Tumor } \\
\text { Média estimada } \\
\text { (IC 95\%) }\end{array}$ \\
\hline 0 & $338,8(320,8 ; 357,7)$ & $374,5(355,6 ; 394,4)$ & $343,0(325,0 ; 362,0)$ \\
7 & $324,0(306,5 ; 342,5)$ & $362,0(343,5 ; 381,5)$ & $301,0(284,1 ; 318,9)$ \\
14 & $311,2(294,1 ; 329,4)$ & $345,0(326,9 ; 364,1)$ & $283,0(266,7 ; 300,3)$ \\
21 & $314,5(297,2 ; 332,8)$ & $290,3(273,7 ; 307,8)$ & $220,8(206,4 ; 236,1)$ \\
28 & $314,7(297,5 ; 333,0)$ & $280,8(264,5 ; 298,0)$ & $160,8(148,6 ; 173,9)$ \\
\hline
\end{tabular}

IC: Intervalo de confiança.

Tabela 22. Comparações entre grupos corrigidas por Bonferroni para MOV-L

\begin{tabular}{cccc}
\hline \multirow{2}{*}{ Momento } & \multicolumn{3}{c}{ Contraste } \\
\cline { 2 - 4 } & $\begin{array}{c}\text { Craniotomia - Controle } \\
\text { Valor-p }\end{array}$ & $\begin{array}{c}\text { Tumor - Controle } \\
\text { Valor-p }\end{array}$ & $\begin{array}{c}\text { Tumor - Craniotomia } \\
\text { Valor-p }\end{array}$ \\
\hline 0 & 0,444 & $>0,99$ & $>0,99$ \\
7 & 0,245 & $>0,99$ & $<0,001$ \\
14 & 0,495 & $>0,99$ & $<0,001$ \\
21 & $>0,99$ & $<0,001$ & $<0,001$ \\
28 & 0,333 & $<0,001$ & $<0,001$ \\
\hline
\end{tabular}

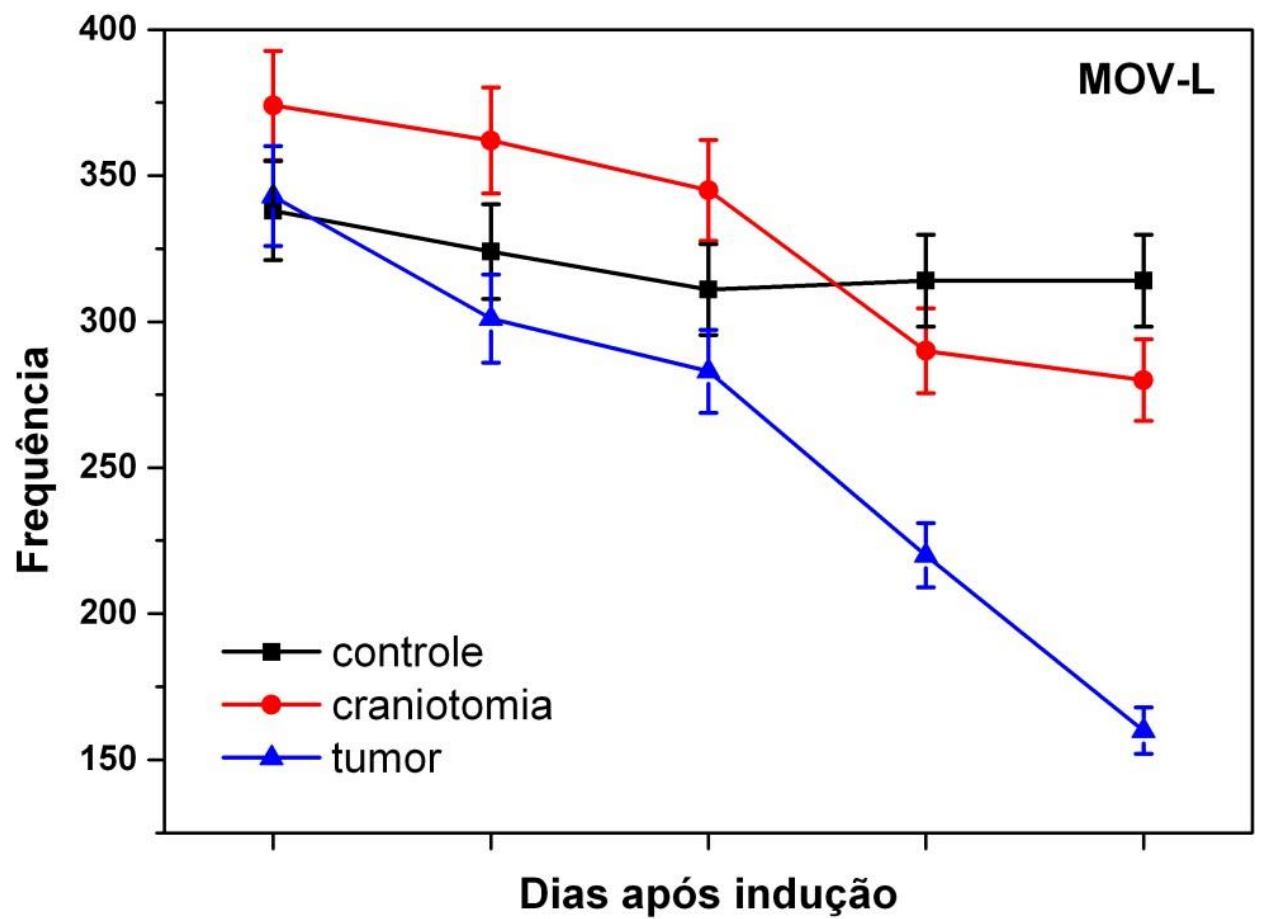

Figura 66. Avaliação do MOV-L entre o grupo de tumor e o grupo controle a partir de 21 dias 


\subsection{Movimento espontâneo rápido do animal na plataforma (MOV-R)}

As médias estimadas (Tabela 23) e as comparações entre grupos corrigidos pelo método de Bonferroni (Tabela 24 e a figura 67) mostram que não há evidências de diferenças entre os grupos controle e Craniotomia em qualquer dos momentos considerados, e as comparações com o grupo tumor mostram diferenças a partir de 14 dias, tanto para o grupo controle quanto para o grupo Craniotomia.

Tabela 23. Médias estimadas para MOV-R

\begin{tabular}{cccc}
\hline Momento & \multicolumn{3}{c}{ Grupo } \\
\cline { 2 - 4 } & $\begin{array}{c}\text { Controle } \\
\text { Média estimada } \\
(\text { IC 95\%) }\end{array}$ & $\begin{array}{c}\text { Craniotomia } \\
\text { Média estimada } \\
(\text { IC 95\%) }\end{array}$ & $\begin{array}{c}\text { Tumor } \\
\text { Média estimada } \\
\text { (IC 95\%) }\end{array}$ \\
\hline 0 & $951,5(902,1 ; 1003,6)$ & $923,0(874,3 ; 974,4)$ & $990,2(939,8 ; 1043,4)$ \\
7 & $938,7(889,7 ; 990,5)$ & $956,8(907,2 ; 1009,0)$ & $890,3(842,5 ; 940,7)$ \\
14 & $940,8(891,6 ; 992,6)$ & $980,8(930,6 ; 1033,7)$ & $760,8(716,7 ; 807,5)$ \\
21 & $924,0(875,3 ; 975,4)$ & $850,3(803,6 ; 899,6)$ & $282,0(255,7 ; 311,0)$ \\
28 & $810,3(764,7 ; 858,5)$ & $760,8(716,7 ; 807,5)$ & $171,3(151,0 ; 194,2)$ \\
\hline
\end{tabular}

IC: Intervalo de confiança.

Tabela 24. Comparações entre grupos corrigidas por Bonferroni para MOV- $R$

\begin{tabular}{cccc}
\hline \multirow{2}{*}{ Momento } & \multicolumn{3}{c}{ Contraste } \\
\cline { 2 - 4 } & $\begin{array}{c}\text { Craniotomia - Controle } \\
\text { Valor-p }\end{array}$ & $\begin{array}{c}\text { Tumor - Controle } \\
\text { Valor-p }\end{array}$ & $\begin{array}{c}\text { Tumor - Craniotomia } \\
\text { Valor-p }\end{array}$ \\
\hline 0 & $>0,99$ & $>0,99$ & $>0,99$ \\
7 & $>0,99$ & $>0,99$ & $>0,99$ \\
14 & $>0,99$ & $<0,001$ & $<0,001$ \\
21 & $>0,99$ & $<0,001$ & $<0,001$ \\
28 & $>0,99$ & $<0,001$ & $<0,001$ \\
\hline
\end{tabular}




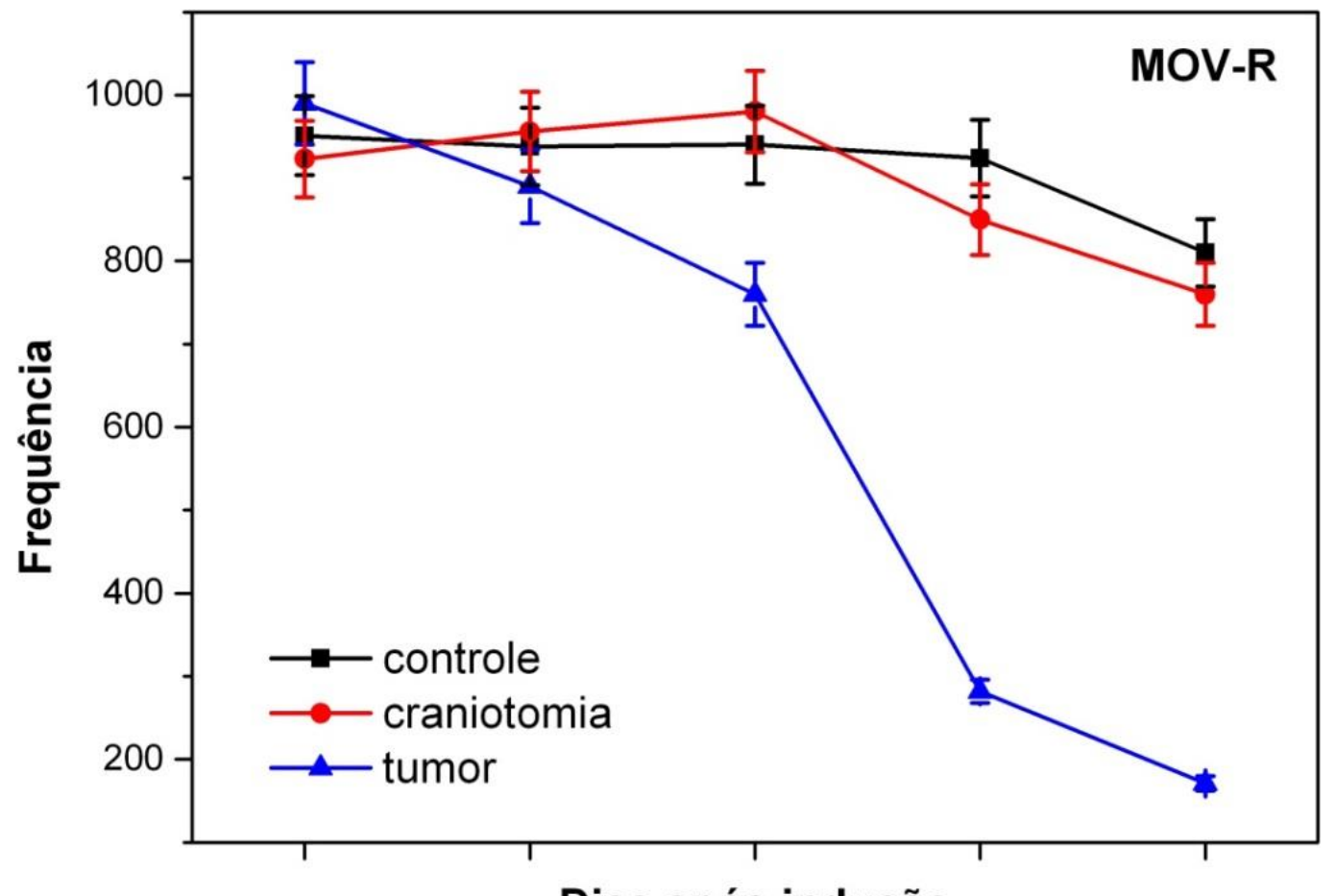

Dias após indução

Figura 67. Avaliação do MOV-R entre o grupo de tumor e o grupo controle a partir de 14 dias

\subsection{Movimento lento da cabeça (STE-L)}

As médias estimadas (Tabela 25) e as comparações entre grupos corrigidos pelo método de Bonferroni (Tabela 26 e Figura 68) mostram que não há evidências de diferenças entre os grupos controle e Craniotomia em qualquer dos momentos considerados, e as comparações com o grupo tumor mostram diferenças a partir de 14 dias para o grupo controle e diferenças no início e em 14, 21 e 28 dias em relação ao grupo Craniotomia.

Tabela 25. Médias estimadas para STE-L

\begin{tabular}{cccc}
\hline \multirow{2}{*}{ Momento } & \multicolumn{3}{c}{ Grupo } \\
\cline { 2 - 4 } & $\begin{array}{c}\text { Controle } \\
\text { Média estimada } \\
(\text { IC 95\%) }\end{array}$ & $\begin{array}{c}\text { Craniotomia } \\
\text { Média estimada } \\
\text { (IC 95\%) }\end{array}$ & $\begin{array}{c}\text { Tumor } \\
\text { Média estimada } \\
(\text { IC 95\%) }\end{array}$ \\
\hline 0 & $178,5(169,0 ; 188,5)$ & $157,5(148,6 ; 166,9)$ & $190,3(180,5 ; 200,5)$ \\
7 & $179,5(170,0 ; 189,5)$ & $188,3(178,5 ; 198,5)$ & $180,8(171,2 ; 190,8)$ \\
14 & $190,2(180,5 ; 200,5)$ & $174,5(165,2 ; 184,4)$ & $147,0(138,4 ; 156,1)$ \\
21 & $177,5(168,1 ; 187,5)$ & $159,5(150,6 ; 169,0)$ & $120,8(113,0 ; 129,0)$ \\
28 & $171,3(162,0 ; 181,0)$ & $162,0(153,0 ; 171,5)$ & $88,0(81,4 ; 95,1)$ \\
\hline
\end{tabular}

IC: Intervalo de confiança. 
Tabela 26. Comparações entre grupos corrigidas por Bonferroni para STE-L

\begin{tabular}{cccc}
\hline \multirow{2}{*}{ Momento } & \multicolumn{3}{c}{ Contraste } \\
\cline { 2 - 4 } & $\begin{array}{c}\text { Craniotomia - Controle } \\
\text { Valor-p }\end{array}$ & $\begin{array}{c}\text { Tumor - Controle } \\
\text { Valor-p }\end{array}$ & $\begin{array}{c}\text { Tumor - Craniotomia } \\
\text { Valor-p }\end{array}$ \\
\hline 0 & 0,122 & $>0,99$ & $<0,001$ \\
7 & $>0,99$ & $>0,99$ & $>0,99$ \\
14 & $>0,99$ & $<0,001$ & 0,005 \\
21 & 0,421 & $<0,001$ & $<0,001$ \\
28 & $>0,99$ & $<0,001$ & $<0,001$ \\
\hline
\end{tabular}

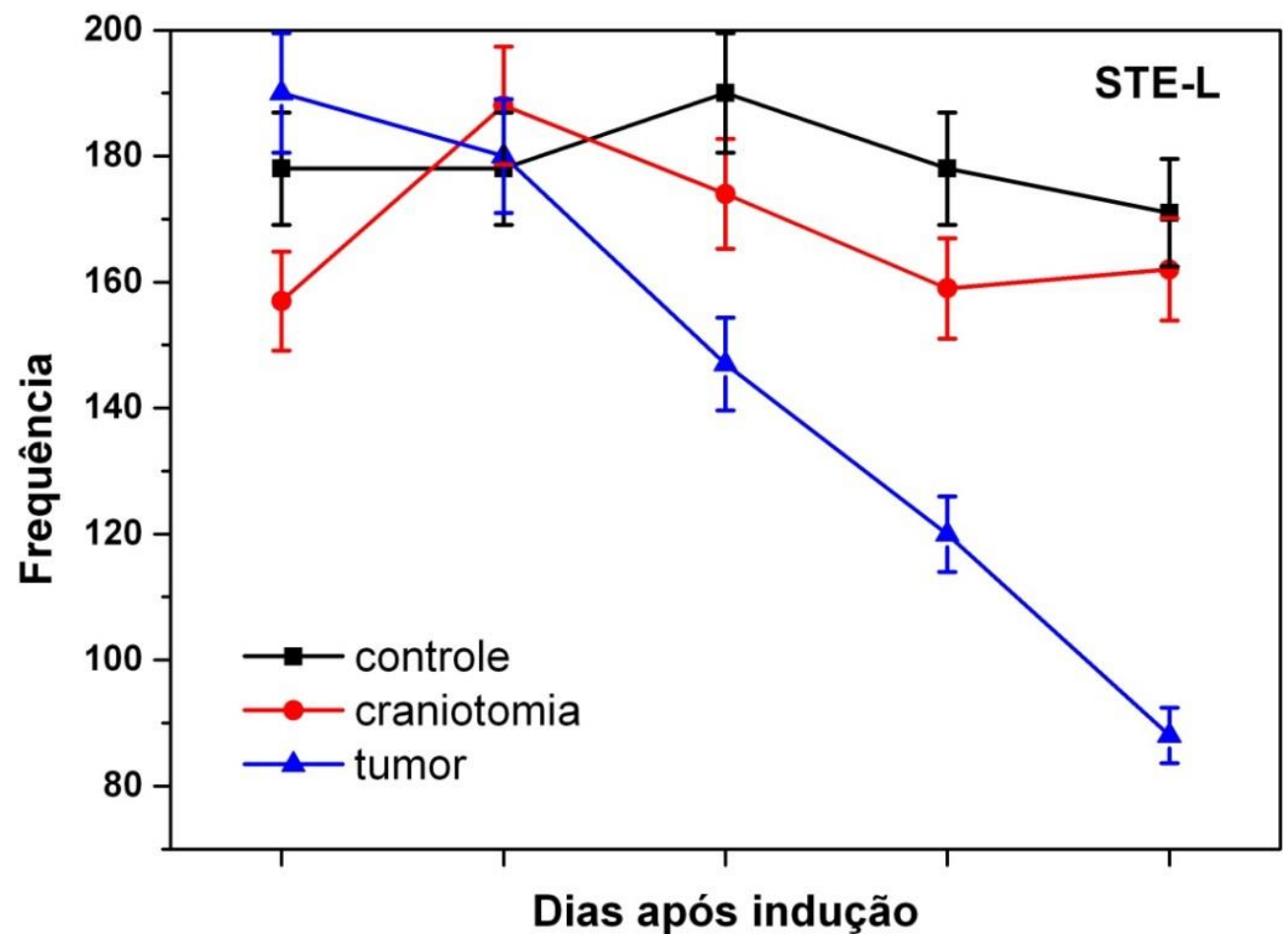

Figura 68. Alteração significativa do STE-L entre o grupo tumoral e os demais grupos a partir de 14 dias

\subsection{Movimento rápido da cabeça (STE-R)}

As médias estimadas (Tabela 27) e as comparações entre grupos corrigidos pelo método de Bonferroni (Tabela 28 e Figura 69) mostram diferenças do grupo tumor a partir de sete dias para o grupo controle e diferenças em 7, 21 e 28 dias em relação ao grupo Craniotomia. 
Tabela 27. Médias estimadas para STE-R

\begin{tabular}{cccc}
\hline Momento & \multicolumn{3}{c}{ Grupo } \\
\cline { 2 - 4 } & $\begin{array}{c}\text { Controle } \\
\text { Média estimada } \\
\text { (IC 95\%) }\end{array}$ & $\begin{array}{c}\text { Craniotomia } \\
\text { Média estimada } \\
(\text { IC 95\%) }\end{array}$ & $\begin{array}{c}\text { Tumor } \\
\text { Média estimada } \\
(\text { IC 95\%) }\end{array}$ \\
\hline 0 & $537,8(508,0 ; 569,2)$ & $543,0(513,1 ; 574,6)$ & $531,2(501,7 ; 562,6)$ \\
7 & $637,7(605,3 ; 672,0)$ & $600,7(569,3 ; 634,0)$ & $500,8(472,1 ; 531,2)$ \\
14 & $615,5(583,6 ; 649,1)$ & $580,8(549,8 ; 613,4)$ & $533,5(503,9 ; 564,9)$ \\
21 & $520,7(491,5 ; 551,8)$ & $590,3(559,0 ; 623,2)$ & $420,8(394,5 ; 448,7)$ \\
28 & $562,0(531,6 ; 594,2)$ & $501,0(472,3 ; 531,4)$ & $220,8(202,0 ; 241,3)$ \\
\hline
\end{tabular}

IC: Intervalo de confiança.

Tabela 28. Comparações entre grupos corrigidas por Bonferroni para STE- $R$

\begin{tabular}{cccc}
\hline \multirow{2}{*}{ Momento } & \multicolumn{3}{c}{ Contraste } \\
\cline { 2 - 4 } & $\begin{array}{c}\text { Craniotomia - Controle } \\
\text { Valor-p }\end{array}$ & $\begin{array}{c}\text { Tumor - Controle } \\
\text { Valor-p }\end{array}$ & $\begin{array}{c}\text { Tumor - Craniotomia } \\
\text { Valor-p }\end{array}$ \\
\hline 0 & $>0,99$ & $>0,99$ & $>0,99$ \\
7 & $>0,99$ & $<0,001$ & 0,002 \\
14 & $>0,99$ & 0,027 & $>0,99$ \\
21 & 0,119 & $<0,001$ & $<0,001$ \\
28 & 0,292 & $<0,001$ & $<0,001$ \\
\hline
\end{tabular}

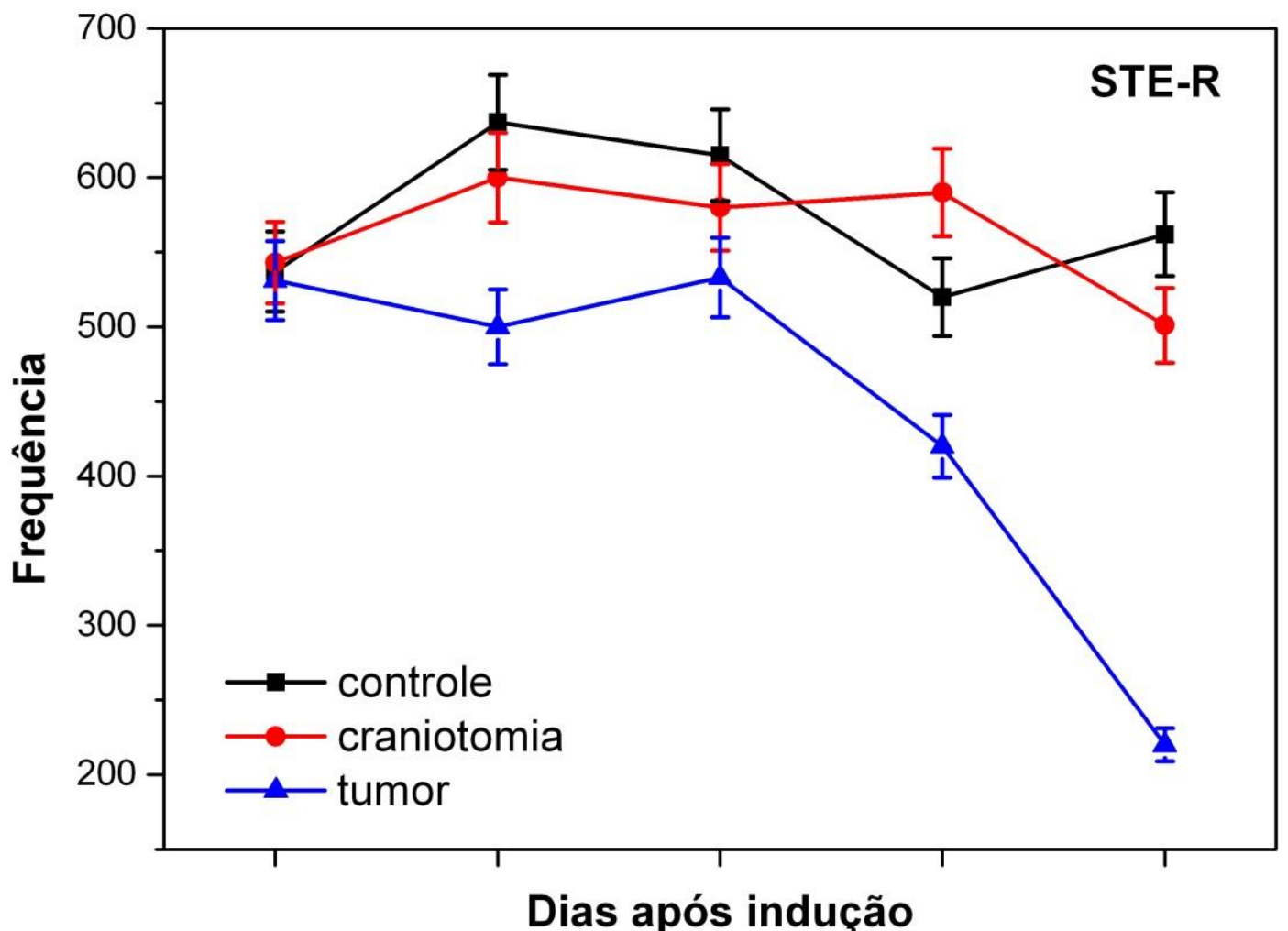

Figura 69. Avaliação do STE-R entre o grupo tumoral e os demais grupos a partir de 7 dias 


\subsection{Movimento lento de erguida do animal (REA-L)}

As médias estimadas (Tabela 29) e as comparações entre grupos corrigidos pelo método de Bonferroni (Tabela 30 e Figura 70) mostram que não há evidências de diferenças entre os grupos controle e Craniotomia em qualquer dos momentos considerados, e as comparações com o grupo tumor mostram diferenças a partir de sete dias para os grupos controle e Craniotomia.

Tabela 29. Médias estimadas para REA-L

\begin{tabular}{cccc}
\hline \multirow{2}{*}{ Momento } & \multicolumn{3}{c}{ Grupo } \\
\cline { 2 - 4 } & $\begin{array}{c}\text { Controle } \\
\text { Média estimada } \\
\text { (IC 95\%) }\end{array}$ & $\begin{array}{c}\text { Craniotomia } \\
\text { Média estimada } \\
\text { (IC 95\%) }\end{array}$ & $\begin{array}{c}\text { Tumor } \\
\text { Média estimada } \\
\text { (IC 95\%) }\end{array}$ \\
\hline 0 & $23,5(20,7 ; 26,6)$ & $28,5(25,4 ; 31,9)$ & $22,5(19,8 ; 25,6)$ \\
7 & $26,5(23,5 ; 29,8)$ & $22,5(19,8 ; 25,6)$ & $15,5(13,3 ; 18,1)$ \\
14 & $24,5(21,7 ; 27,7)$ & $20,5(17,9 ; 23,4)$ & $12,5(10,5 ; 14,8)$ \\
21 & $22,5(19,8 ; 25,6)$ & $21,5(18,9 ; 24,5)$ & $8,5(6,9 ; 10,5)$ \\
28 & $25,5(22,6 ; 28,8)$ & $22,5(19,8 ; 25,6)$ & $5,3(4,0 ; 6,8)$ \\
\hline
\end{tabular}

IC: Intervalo de confiança.

Tabela 30. Comparações entre grupos corrigidas por Bonferroni para REA-L

\begin{tabular}{cccc}
\hline \multirow{2}{*}{ Momento } & \multicolumn{3}{c}{ Contraste } \\
\cline { 2 - 4 } & $\begin{array}{c}\text { Craniotomia - Controle } \\
\text { Valor-p }\end{array}$ & $\begin{array}{c}\text { Tumor - Controle } \\
\text { Valor-p }\end{array}$ & $\begin{array}{c}\text { Tumor - Craniotomia } \\
\text { Valor-p }\end{array}$ \\
\hline 0 & $>0,99$ & $>0,99$ & 0,352 \\
7 & $>0,99$ & $<0,001$ & 0,022 \\
14 & $>0,99$ & $<0,001$ & 0,001 \\
21 & $>0,99$ & $<0,001$ & $<0,001$ \\
28 & $>0,99$ & $<0,001$ & $<0,001$ \\
\hline
\end{tabular}




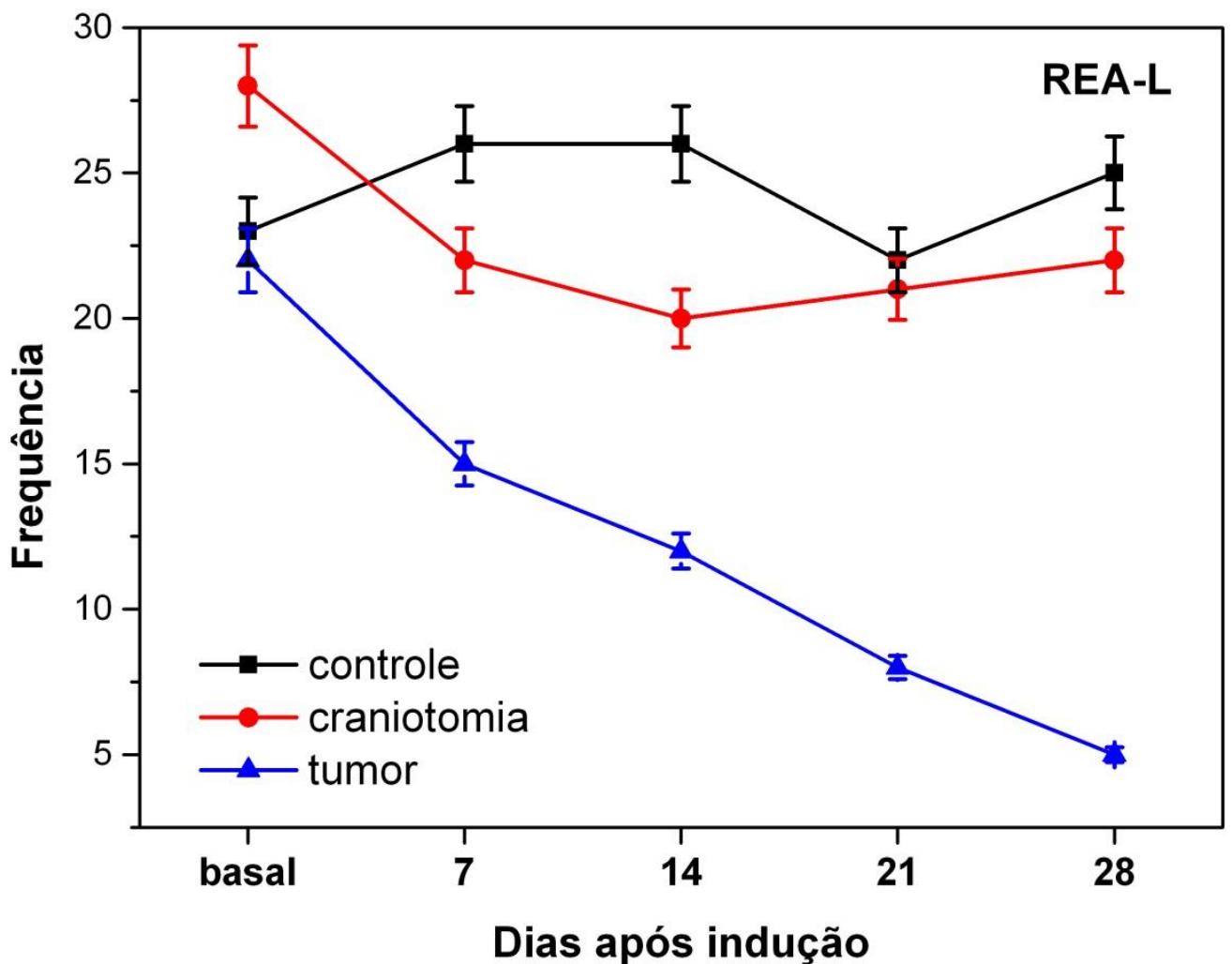

Figura 70. Avaliação do REA-L entre o grupo tumoral e os demais grupos a partir de 7 dias

\subsection{Movimento rápido de erguida do animal (REA-R)}

As médias estimadas (Tabela 31) e as comparações entre grupos corrigidos pelo método de Bonferroni (Tabela 32 e Figura 71) mostram que não há evidências de diferenças entre os grupos controle e Craniotomia em qualquer dos momentos considerados, e as comparações com o grupo tumor mostram diferenças a partir de 21 dias para o grupo controle e a partir de 14 dias para o grupo Craniotomia.

Tabela 31. Médias estimadas para REA-R

\begin{tabular}{cccc}
\hline \multirow{2}{*}{ Momento } & \multicolumn{3}{c}{ Grupo } \\
\cline { 2 - 4 } & $\begin{array}{c}\text { Controle } \\
\text { Média estimada } \\
\text { (IC 95\%) }\end{array}$ & $\begin{array}{c}\text { Craniotomia } \\
\text { Média estimada } \\
(\text { IC 95\%) }\end{array}$ & $\begin{array}{c}\text { Tumor } \\
\text { Média estimada } \\
\text { (IC 95\%) }\end{array}$ \\
\hline 0 & $30,5(27,4 ; 33,9)$ & $27,5(24,6 ; 30,8)$ & $28,5(25,5 ; 31,8)$ \\
7 & $24,5(21,8 ; 27,6)$ & $22,5(19,9 ; 25,5)$ & $25,5(22,7 ; 28,6)$ \\
14 & $19,5(17,1 ; 22,3)$ & $24,5(21,8 ; 27,6)$ & $15,5(13,4 ; 18,0)$ \\
21 & $20,5(18,0 ; 23,3)$ & $18,5(16,1 ; 21,2)$ & $12,5(10,6 ; 14,8)$ \\
28 & $22,5(19,9 ; 25,5)$ & $19,5(17,1 ; 22,3)$ & $7,5(6,1 ; 9,3)$ \\
\hline
\end{tabular}

IC: Intervalo de confiança. 
Tabela 32. Comparações entre grupos corrigidas por Bonferroni para REA-R

\begin{tabular}{cccc}
\hline \multirow{2}{*}{ Momento } & \multicolumn{3}{c}{ Contraste } \\
\cline { 2 - 4 } & $\begin{array}{c}\text { Craniotomia - Controle } \\
\text { Valor-p }\end{array}$ & $\begin{array}{c}\text { Tumor - Controle } \\
\text { Valor-p }\end{array}$ & $\begin{array}{c}\text { Tumor - Craniotomia } \\
\text { Valor-p }\end{array}$ \\
\hline 0 & $>0,99$ & $>0,99$ & $>0,99$ \\
7 & $>0,99$ & $>0,99$ & $>0,99$ \\
14 & 0,590 & $>0,99$ & $<0,001$ \\
21 & $>0,99$ & $<0,001$ & 0,027 \\
28 & $>0,99$ & $<0,001$ & $<0,001$ \\
\hline
\end{tabular}

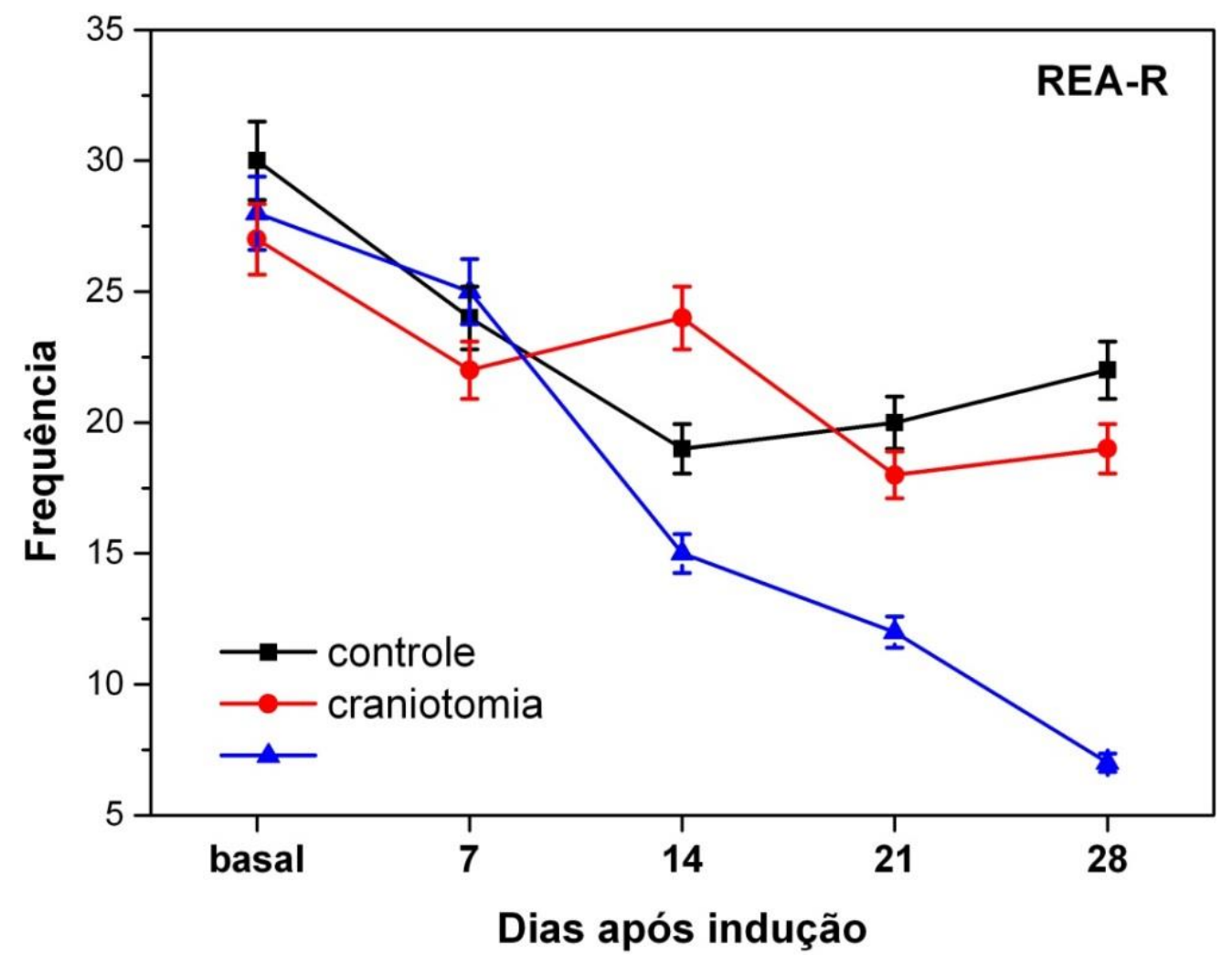

Figura 71. Avaliação do REA-R do grupo tumoral em relação aos demais grupos 


\subsubsection{Magneto hipertermia em modelo animal}

Com o intuito de entender a possível influência do sangue (devido transporte no plasma do ferro na sua forma férrica pela transferrina) no aquecimento do tumor quando é aplicado o CMA, foi adquirida a curva de aquecimento do sangue, água, Agua + NSOF-Amine e Sangue + NSOF-Amine conforme mostrado na figura 72.

Observou-se que não houve elevação de temperatura nas amostras de água e de sangue animal que foram submetidas ao campo magnético de 300 gauss e frequência de $551 \mathrm{kHz}$, sem a presença de NSOF obtendo um SAR de aproximadamente 0,3 para ambas as amostras. Porém, houve elevação de temperatura nestas amostras, quando as mesmas continham a presença de NSOF. Os resultados das curvas demonstram a eficiência do uso de NSOF na geração de elevação de temperatura nas amostras das quais se faz presente, sendo confirmada pelos valores de SAR obtidos, conforme observado na figura 72 .

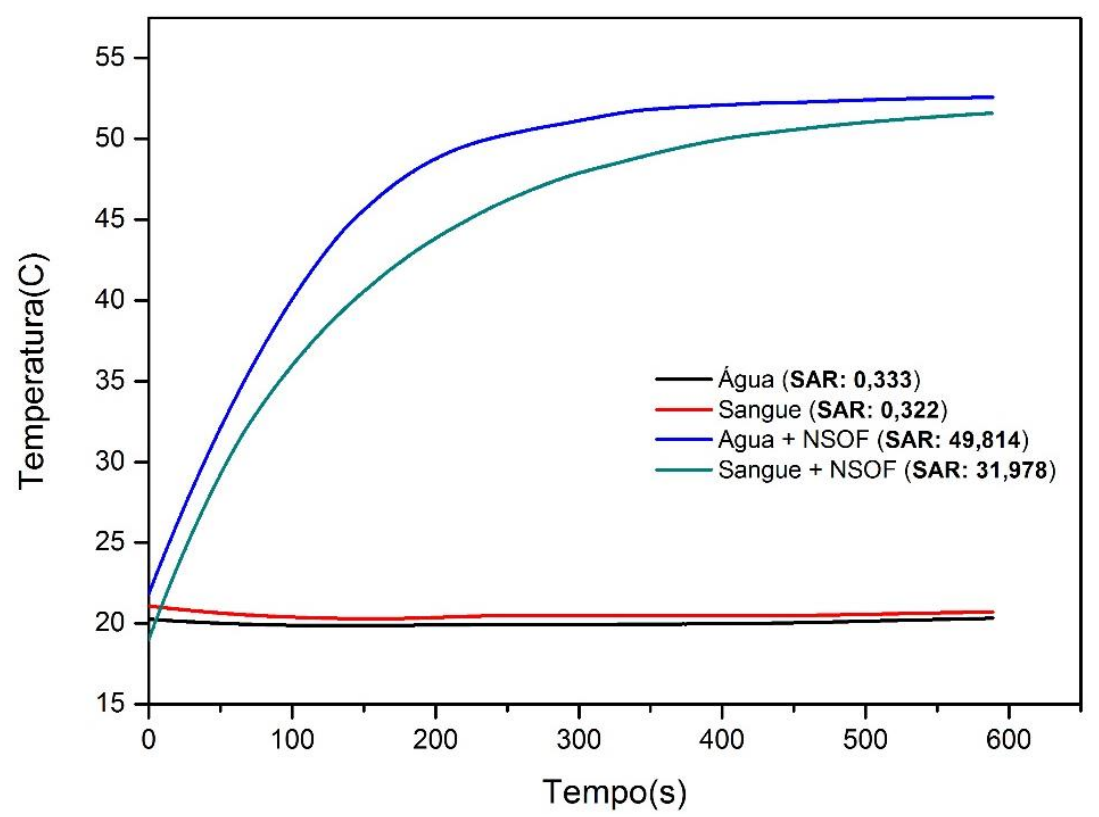

Figura 72. Curvas de aquecimento após magneto hipertermia em água, sangue e estes com adição de nanopartículas superparamagnéticas de óxido de ferro 


\subsubsection{Avaliação por bioluminescência da aplicação de magneto hipertermia in} vivo

Após a aplicação de MHT em ratos wistar com glioblastoma, foi realizada aquisição de imagens por bioluminescência. Observou-se que não houve geração de sinal bioluminescente sem administração de luciferina (Figura 73A), obtendo sinal somente após a administração de luciferina no animal (Figura 73B). Verificou-se que após 40 minutos de exposição do animal à MHT com $871 \mathrm{kHz}$ de frequência e 200 Gauss de campo magnético, houve decaimento de sinal bioluminescente, resultando em $67,2 \%$ de viabilidade celular quando comparada a imagem de pré-MHT (100\%) (Figura 73D). O cabo de fibra óptica inserido na região tumoral detectou a temperatura de $47^{\circ} \mathrm{C}$ de forma pontual no tumor, não obtendo temperatura espacial total. 


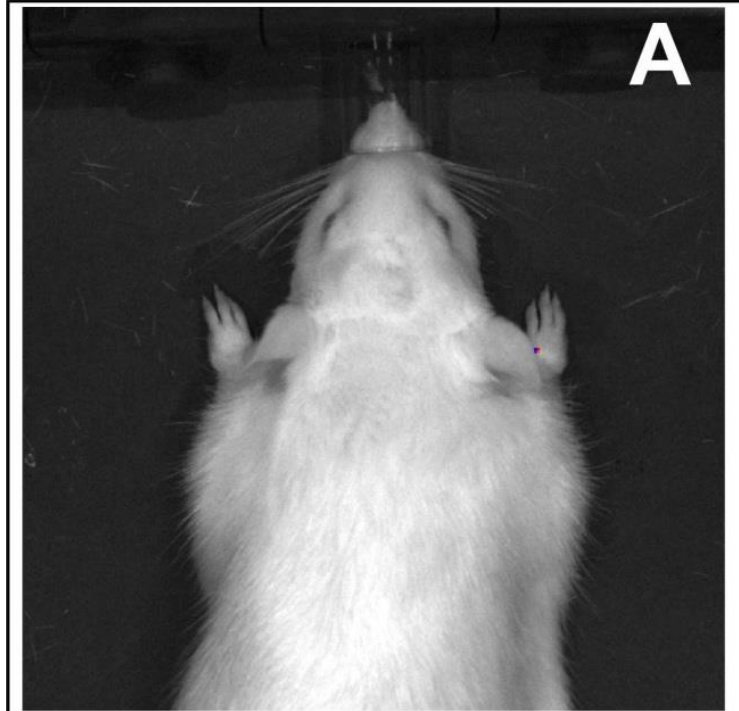

Controle - Sem luciferina

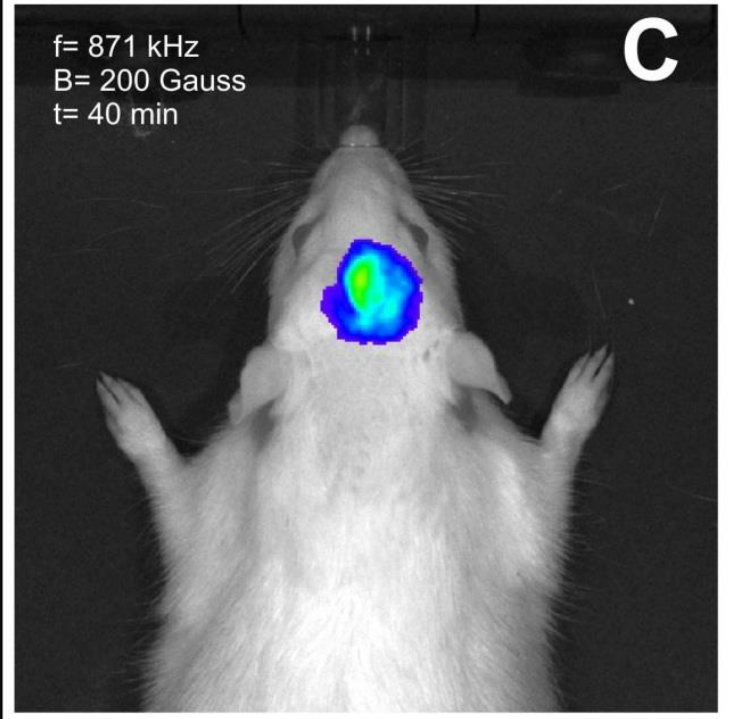

Pós - MHT

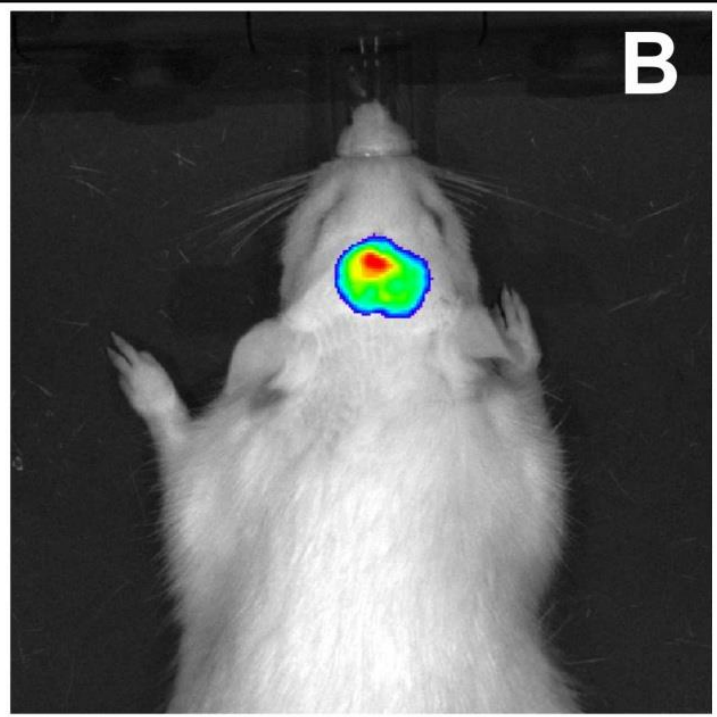

Pré - MHT

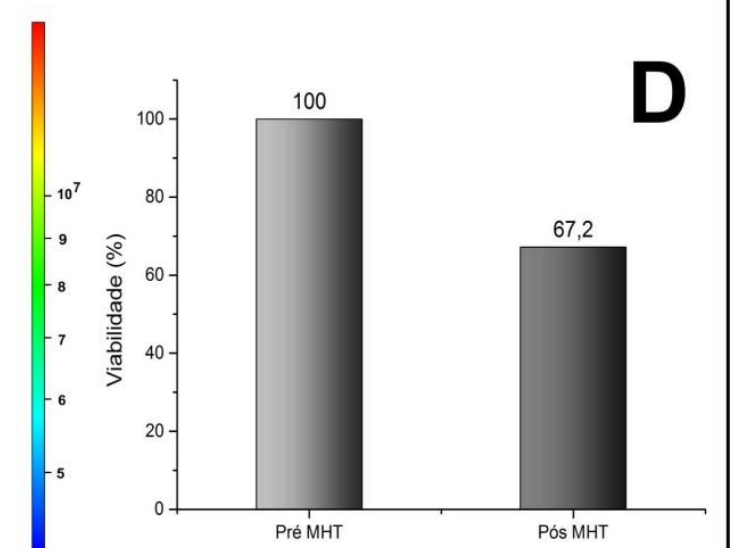

$\mathrm{p} / \mathrm{s} / \mathrm{cm}^{2} / \mathrm{sr}$

Imagem do animal sem administração de luciferina (A); após a administração de luciferina anterior a aplicação de terapia por MHT (B); após realização de terapia por MHT por 40min com frequência de campo magnético de $871 \mathrm{kHz}$ e $200 \mathrm{Gauss}$ de intensidade de campo (C); viabilidade celular conforme a diminuição da intensidade de sinal bioluminescente pré e após terapia (D).

Figura 73. Análise de bioluminescência in vivo após magneto hipertermia 


\section{DISCUSSÃO}

Ao analisar os resultados físico-químicos das NSOF para aquisição do cálculo de SAR, observou-se que os valores de SAR são dependentes do diâmetro e sua relação de mono e multi-domínios, da cobertura da NSOF, bem como do CMA e da frequência de campo aplicado.

Há a relação de diâmetro das NSOF nos valores de SAR, como já identificado na literatura ${ }^{(148)}$ em que o tamanho da nanopartícula interfere diretamente nos valores de $\operatorname{SAR}^{(149)}$ e em relação com domínio magnético, em que notou-se uma resistência de mudança de spin de NSOF de mono-domínio quando exposta ao CMA. ${ }^{(69)}$ A NSOF com muti-domínio, não possuiu grande resistência na mudança dos seus domínios, sendo assim facilmente influenciada pelo CMA, para alinhamento dos domínios, obtendo assim elevação de temperatura mais rápida quando comparada com as NSOF de diâmetros menores e consequentemente maiores valores de SAR quando comparadas aos outros diâmetros. ${ }^{(69)}$

Neste estudo as NSOF de 50nm (mono-domínio) com exceção da NSOF-Quit, demandaram um tempo maior para elevação de temperatura quando comparas aos diâmetros de 100 e 200nm (multi-domínios) (Figuras 28 e 29), obtendo assim menores valores de SAR (Figura 30), se contrapondo ao resultado encontrado em um estudo, que observou que nanopartículas magnéticas mono-domínio obtiveram maiores valores de SAR quando comparadas com as de multi-domínios. ${ }^{(95)}$

Ao analisar as NSOF com multi-domínios, as com diâmetro de $100 \mathrm{~nm}$ obtiveram maiores valores de SAR quando comparadas às com $200 \mathrm{~nm}$, pois as de 200nm devido possuir mais áreas de domínios magnéticos (por conta do seu maior diâmetro) do que as NSOF de 100nm (Figura 74) demandaram um tempo maior para alinhar todos os seus domínios magnéticos em direção ao CMA resultando em perda de magnetização por conta das muitas paredes de domínios magnéticos gerados conforme observado em outro estudo. ${ }^{(150)}$ Porém, observou-se neste estudo que a NSOF-Quit de 50nm obteve maior valor de SAR quando comparada com a NSOF de 200nm, condição esta que pode ter sido influenciada pela composição de polissacarídeo, linear, D-glucosamina ligada ao B- (1-4) e N-acetil-D-glucosamina que na presença de um maior número de NSOF/g presentes na NSOF-Quit 50nm $\left(1,3 \times 10^{16}\right)$ em relação à amostra de NSOF-Quit $200 \mathrm{~nm}\left(1,3 \times 10^{14}\right)$ gerou maior valor de 
SAR na NSOF-Quit de 50nm. Porém, esta discrepância em relação das NSOF-Quit de $50 \mathrm{~nm}$ em relação às outras NSOF de $50 \mathrm{~nm}$ precisa ser melhor investigada afim de buscar a razão pela qual a NSOF-Quit de $50 \mathrm{~nm}$ alcançou maiores valores de SAR em comparação com a de 200nm, se diferenciando das respostas das demais NSOF.

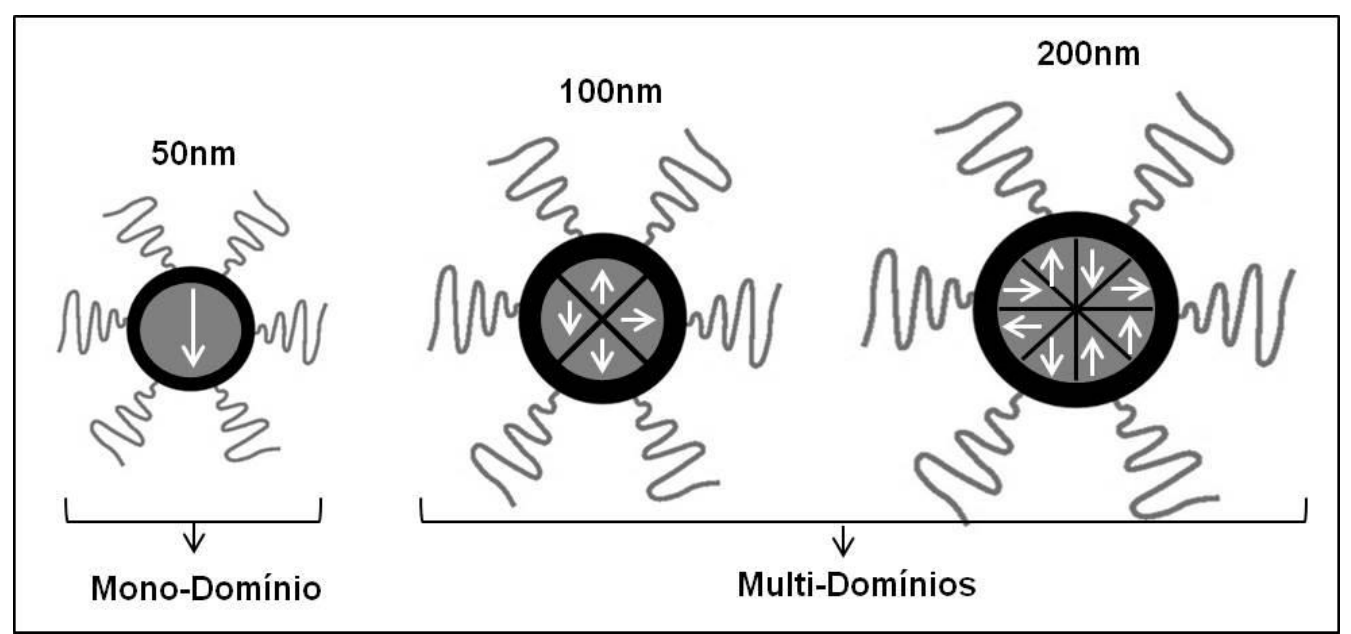

Figura 74. Diâmetro das nanopartículas magnéticas e os seus domínios magnéticos

A cobertura da NSOF possui influência nos valores de SAR, pois foi observado que as NSOF recobertas com aminosilana e quitosana obtiveram valores de SAR maiores do que as recobertas com dextrana e starch, em discordância com o resultado encontrado no estudo de Ludwig et al. ${ }^{(95)}$ que não observou influência da cobertura das nanopartículas magnéticas nos valores de SAR.

Foi detectado que a frequência de $551 \mathrm{kHz}$, obteve maiores valores de SAR quando comparada a frequência $305 \mathrm{kHz}$ (Figura 30). Em um estudo, as análises de valores de SAR realizados para avaliar a dependência de frequência, concluiu que a frequência de $551 \mathrm{kHz}$, obteve maior valor de $\mathrm{SAR}$, quando comparada com frequências de $200 \mathrm{kHz}$ e $1 \mathrm{MHz}$, obtendo maior elevação de temperatura em menor decorrência de tempo ${ }^{(96)}$ o que corrobora com o que foi observado neste estudo, em que valores de SAR foram maiores na aplicação de campo de 300 gauss, quando 0 mesmo foi aplicado com frequência de $551 \mathrm{kHz}$, em relação aos campos de 50 e 150 gauss (Figura 30). Essas dependências se remetem ao fato de que maiores intensidades de campo magnético e maiores frequências geram maior magnetização das NSOF, pois os domínios magnéticos das NSOF adquirem uma única direção paralela ao CMA, obedecendo aos valores máximos de saturação magnética. ${ }^{(96,150)}$ 
$\mathrm{Na}$ avaliação in vitro, percebeu-se que as marcações das C6-Luc com NSOF sem o uso de ímã necessitam do uso de PLL para uma internalização que acompanhe a morfologia celular, porém na condição de uso de ímã para marcação o uso do IE proporcionou um ambiente magnético constante e uniforme que atraiu as NSOF às células gerando assim uma adequada internalização das NSOF nas células C6-Luc, como observado na figura 52, não necessitando de uso de PLL. A quantidade de NSOF internalizadas nas células C6-Luc na marcação com ímã dinâmico foi adequada com concentração de $200 \mu \mathrm{g}$ NSOF/mL, porém foi inferior a observada na marcação com IE (Figura 52). Este fato poderia ser justificado com a escolha da frequência inadequada para NSOF, sendo necessário realizar mudanças nas frequências, especificamente com valores menores para causar pequenos deslocamentos das NSOF e movimentar estas de setores da placa de cultura onde não contêm células cultura e assim contribuir com uma marcação eficiente comparada com o IE. Este tipo de estudo não consta na literatura, sendo este, o primeiro.

O sinal bioluminescente é mensurado devido expressão da proteína de luciferase transfectada nas células viáveis em resposta a luciferina, na presença de oxigênio e ATP. ${ }^{(151)}$ Houve aumento da intensidade do sinal bioluminescente conforme aumento da concentração celular na aquisição de imagens de bioluminescência e decaimento de intensidade de sinal bioluminescente devido diminuição de viabilidade celular após MHT, corroborando com o estudo de Zhang et al em que também observou aumento de intensidade de sinal conforme aumento de concentração celular e decaimento da intensidade de sinal bioluminescente de células submetidas à MHT, quando comparou a concentração máxima de $25 \times 103$ de células da linhagem de câncer de mama humano MDA-MB-231-luc submetidas à MHT na temperatura de $43^{\circ}$ C durante 10 a 120 min. Observou-se que após 10 min da exposição à MHT, a intensidade do sinal bioluminescente das células tratadas diminuiu para $77 \%$ da intensidade das células de controle (não tratadas). Uma diminuição da intensidade da luz detectada aos 20 minutos, mostrou apenas $22 \%$ de intensidade nas células tumorais quando comparada a intensidade do grupo controle. ${ }^{(151)}$ A diminuição de intensidade de sinal bioluminescente observada neste estudo não foi gerada por uma possível alteração de proteína Luc devido ser exposta à elevação de temperatura, e sim pela terapia de MHT, pois células C6-Luc foram submetidas na estufa a $44^{\circ} \mathrm{C}$ por 45 minutos, não alterando de forma sua resposta de sinal bioluminescente ao se 
adquirir imagens de bioluminescência, garantindo assim a eficiência da técnica de bioluminescência na avaliação da eficiência terapêutica de MHT.

A análise de viabilidade celular com anexina $\mathrm{V}$ e PI após realização de MHT foi utilizada em vários estudos, mostrando em seus resultados morte celulartumoral, ${ }^{(152,153)}$ além de realizar análise de toxicidade de NSOF, mostrando o seguro uso de nanopartículas magnéticas quando as mesmas não interferem na viabilidade das células ${ }^{(154)}$ reforçando os resultados obtidos neste estudo em que foi analisado viabilidade celular após aplicação de $\mathrm{MHT}$ in vitro de $30,8 \%$ em $44^{\circ} \mathrm{C}$ por 40 minutos e de $21,7 \%$ por $48^{\circ} \mathrm{C}$ por 40 minutos. Observando que a diferença de decaimento de viabilidade das duas condições é de apenas 9,1\%, sugerindo-se, portanto, realizar duas aplicações de $\mathrm{MHT}$ de $44^{\circ} \mathrm{C}$ por 40 minutos ao invés da aplicação de $48^{\circ} \mathrm{C}$ em estudos futuros.

No estudo in vivo, ao se avaliar o tecido tumoral por IRM, bioluminescência (Figura 55 e 56), observou-se que a área tumoral detectada foi condizente com a massa tumoral obtida por imagem histológica (Figura 55), garantindo assim um acompanhamento comparativo da evolução tumoral.

No âmbito experimental de modelo animal com tumor, alterações comportamentais e hipoatividade são observadas, ${ }^{(155)}$ que se assemelham com alterações observadas em humanos. ${ }^{(156,157)}$ Por essas razões, o estudo das alterações resposta motora em modelo animal é de grande importância para análises de perda de funções derivadas de lesões cerebrais como os tumores e para estudo de reabilitação de funções após realização de terapia. ${ }^{(158)}$

Sabe-se que tumores geram aumento de pressão intracraniana e edema vasogênico e efeitos de massa tumoral, provocando compressão de regiões cerebrais e deslocamento das mesmas, como o giro do cíngulo cerebral e do uncus

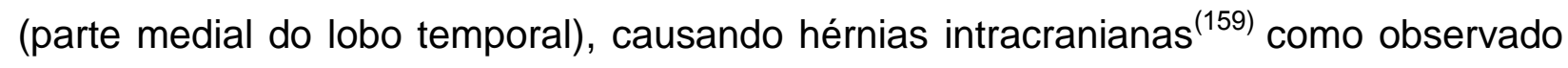
na figura 55 deste estudo. As hérnias de cíngulo e de uncus são decorrentes do deslocamento de cíngulo e do uncus devido aumento de massa tumoral em um hemisfério do cérebro. A hérnia de cíngulo insinua-se entre a borda da foice do cérebro e o corpo caloso, gerando alterações de função motora comandada pelo lobo frontal do cérebro. ${ }^{(160)}$ Já a hérnia de uncus consiste na geração de déficit motor corporal contralateral ao tumor devido compressão do trato corticoespinhal no mesencéfalo (anterior ao cruzamento de vias motoras na decussação das pirâmides antes de dar continuidade a medula espinhal). ${ }^{(159)}$ Sabendo disto, foi realizado análises estatísticas 
de respostas motoras do animal, buscando detectar alterações de marcha e locomoção espontânea nos mesmos.

Observaram-se alterações de marcha e de locomoção espontânea em animais com glioblastoma em comparação com grupo controle e o grupo de craniotomia sem indução de tumor. Constatou-se assimetria de movimentos com alterações de déficit motor espacial primariamente iniciado nas patas esquerdas do animal na análise de marcha por CatWalk, em concordância com a resposta contralateral à massa tumoral localizada no hemisfério direito do cérebro do animal (Figura 55). Ao analisar os resultados dos parâmetros espaciais, observou-se uma diminuição de todos os parâmetros analisados, principalmente no grupo tumoral, como no caso do comprimento do passo dos animais, observado a partir de 7 dias de indução (Figura 57), com elevada diminuição do comprimento do passo com 28 dias (Figura 61Dpi), inferindo limitação de posicionamento corporal padrão (controle) por provável alterações corporais devido ao aumento do tumor e comprometimento do sistema sensório motor contralateral ao tumor, pois foi possível detectar desvios de estruturas do cérebro como lobo frontal, comprometimento de lobo parietal e presença de hérnias do cíngulo e de uncus, devido crescimento da massa tumoral, como observado na figura $55 \mathrm{E}-\mathrm{F}-\mathrm{I}-\mathrm{J}$.

Observou-se diminuição significativa da área de máximo contato das patas PE, AE e AD a partir dos 21 dias e a partir de 28 dias na pata PD (Figura 58), acompanhado de um aumento de ciclo de passo de mesma pata a partir de 7 dias (Figura 63), e diminuição da distância entre patas esquerdas a partir de 7 dias e direitas a partir de 21 dias, observando predominância de alterações primeiramente no lado esquerdo (Tabela 11 e Figura 59) em resposta contralateral à localização hemisférica do tumor e alterações de distância entre patas anteriores e posteriores com 28 dias (Figura 60 e 61Dp).

Ao avaliar os resultados dos parâmetros temporais na análise de marcha do animal, observou-se aumento progressivo ao longo do tempo de todos os parâmetros temporais analisados, principalmente no grupo tumoral, como o aumento do tempo de contato das patas no grupo tumoral, a partir de 14 dias, quando comparado aos demais grupos, sem diferenças entre o grupo controle e o de craniotomia (Tabela 15 e Figura 62). Com isso entende-se que os animais com tumor com crescimento a partir de 14 dias permaneceram com as patas na plataforma por mais tempo do que os demais grupos, por provável alteração de equilíbrio, utilizando 
um tempo maior de apoio para dar o passo seguinte, destacando o aumento mais significativo nas patas esquerdas do que nas direitas e na pata posterior esquerda comparada à anterior.

Observou-se uma diminuição contínua da cadência do grupo tumoral a partir de 7 dias (comparado ao grupo controle) e de 21 dias (comparado ao grupo de craniotomia) (Figura 64). Visualizou-se aumento da duração de percurso a partir de 14 dias no grupo tumoral (Figura 65).

No estudo de comportamento animal em que se analisou a atividade de locomoção espontânea, observaram-se diversas alterações no grupo tumoral com glioblastoma comparado aos demais grupos. Observou-se diminuição de movimentos lentos e rápidos na plataforma, de cabeça e de erguidas no grupo tumoral. Houve decaimento de movimentos lentos e rápidos na plataforma a partir de 7 dias (Figuras 66 e 67), movimento lentos e rápidos da cabeça a partir de 14 dias (Figuras 68 e 69) e de erguidas lentas a partir de 7 dias (Figura 70) e erguidas rápidas a partir de 14 dias (Figura 71). Com isso, observa-se que houve uma diminuição geral de movimentos espontâneos no grupo tumoral, gerado pelo deslocamento de áreas cerebrais, edema $\mathrm{e}$ formação de hérnias ocasionada pelo crescimento tumoral, acarretando déficit de locomoção conforme caracterizado pelo Comitê de Traumas do Colégio Americano de Cirurgiões. ${ }^{(159)}$ Os movimentos verticais lentos observados neste estudo, foram os mais sensíveis de detecção precoce das variáveis analisadas, pois este movimento requer um maior planejamento motor de controle do movimento.

Em um estudo realizado em humanos com glioblastoma, observouse a presença predominante de hemiparesia como déficit motor gerado com acometimento de lobo parietal pela presença de massa tumoral. ${ }^{(156)} \mathrm{O}$ que corrobora com a presença de hemiparesia de PPE observada neste estudo no $28^{\circ}$ dia, assimetrias e alterações nas patas esquerdas ( 7 dias) captadas anteriormente às alterações de patas direitas (21 dias) por CatWalk, conforme observado na tabela 11, em concordância com lesão tumoral parietal induzida no hemisfério direito com deslocamento de lobo frontal e presença de hérnias intracranianas geradas pelo crescimento tumoral anterior ao cruzamento de nervos motores na discussão das pirâmides.

A realização de estudo comportamental em modelo animal por meio da técnica de CatWalk tem sido utilizada para diversos estudos cerebrais como lesões derivadas de trauma, ${ }^{(161,162)}$ estudos de acidente vascular cerebral (AVC), ${ }^{(163,164)}$ 
Parkinson, ${ }^{(165,166)}$ porém, não consta na literatura estudo de análise comportamental de alterações de marcha por CatWalk visando estudar alterações motoras decorrentes de evolução de massa tumoral, este seria portanto o primeiro estudo.

Houve decaimento de sinal bioluminescente in vivo na região tumoral após terapia por MHT, assim como observado em um estudo, em que foi detectado decaimento da intensidade de sinal bioluminescente no animal com tumor, após o mesmo ser exposto à MHT combinada com farmacoterapia. ${ }^{(110)}$ Vários estudos também observaram decaimento de sinal bioluminescente em tumores após exposição dos mesmos à terapia por $\mathrm{MHT},{ }^{(167-169)}$ sendo portanto observado que a técnica de bioluminescência foi sensível na detecção de morte celular gerada por MHT, por captar decaimento de sinal bioluminescente devido diminuição de células viáveis após aplicação terapêutica. 


\section{CONCLUSÃO}

1. A aplicação in vitro da técnica por magneto hipertermia foi eficiente na geração de morte celular tumoral realizando a exposição de intensidade de campo magnético de 300 Gauss e frequência de campo de $551 \mathrm{kHz}$, utilizando nanopartículas superparamagnéticas de óxido de ferro com cobertura de aminosilana com diâmetro de $100 \mathrm{~nm}$, resultando no decaimento de viabilidade celular tumoral por bioluminescência e por citometria de fluxo após exposição à magneto hipertermia por 40 minutos em $44^{\circ} \mathrm{C}$ e $48^{\circ} \mathrm{C}$. No estudo in vivo, foi observado que o crescimento tumoral gera ao longo do tempo, alterações comportamentais detectadas pela alteração de marcha do animal por CatWalk como: decaimento de comprimento de passo, área de máximo contato e distâncias entres patas, aumento do tempo de contato da pata na superfície da plataforma, ciclo de passo da mesma pata (detectado primariamente do lado esquerdo do corpo do animal, como resultado contralateral ao crescimento do tumor) e duração do percurso com diminuição de cadência (no de passos/segundo). Além de diminuição de movimentos espontâneos, de cabeça e de erguidas do grupo tumoral nas análises de locomoção espontânea por Actômetro. Quando submetidos à MHT com $871 \mathrm{kHz}$ e 200 gauss, os animais com tumor de glioblastoma obtiveram decaimento de viabilidade celular captada por bioluminescência após MHT por 40 minutos de aplicação de terapia à $47^{\circ} \mathrm{C}$ de temperatura pontualmente. 


\section{ANEXOS}

Anexo 1. Análise de bioluminescência após adição de luciferina em evolução temporal (t: $\min )$

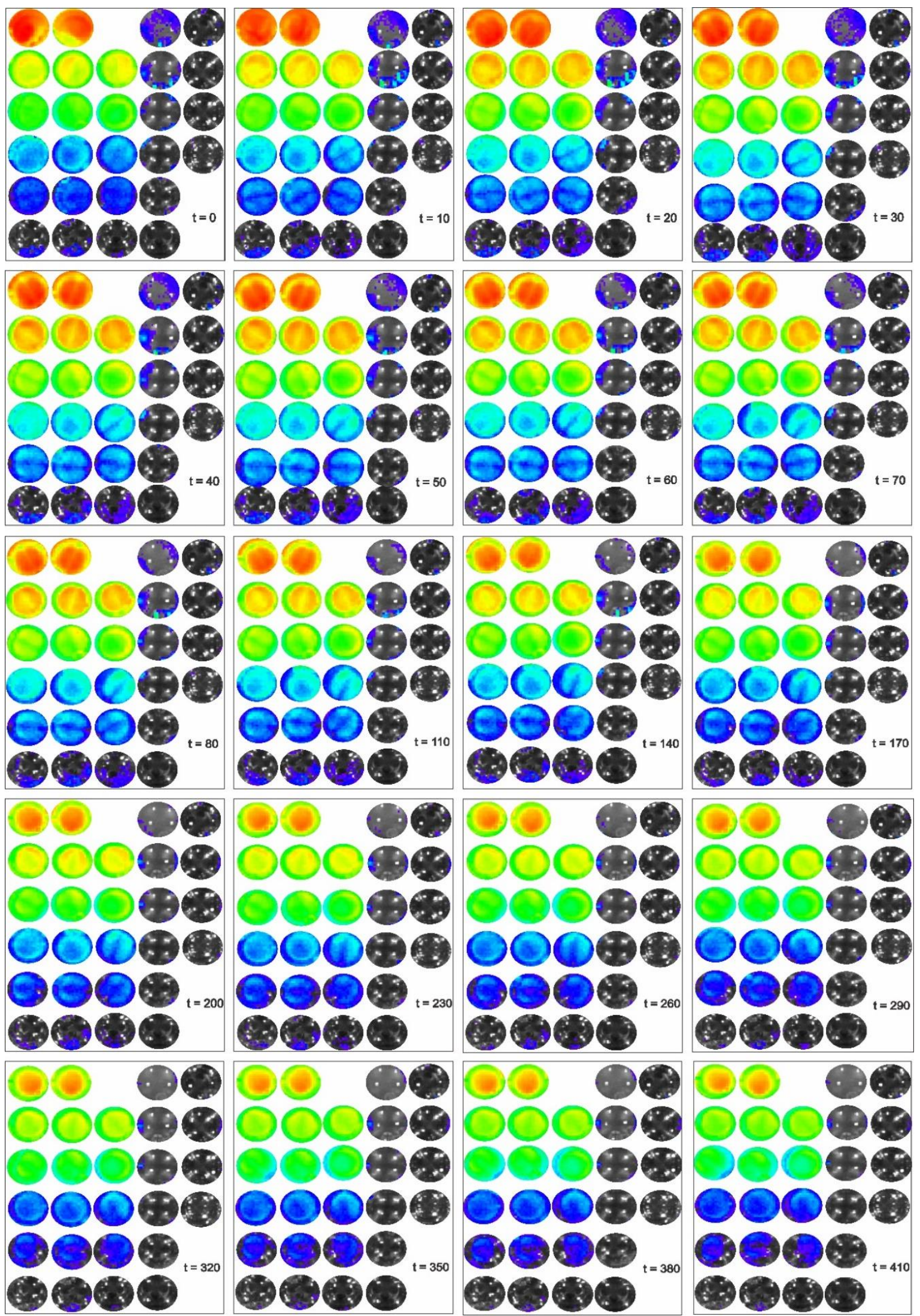




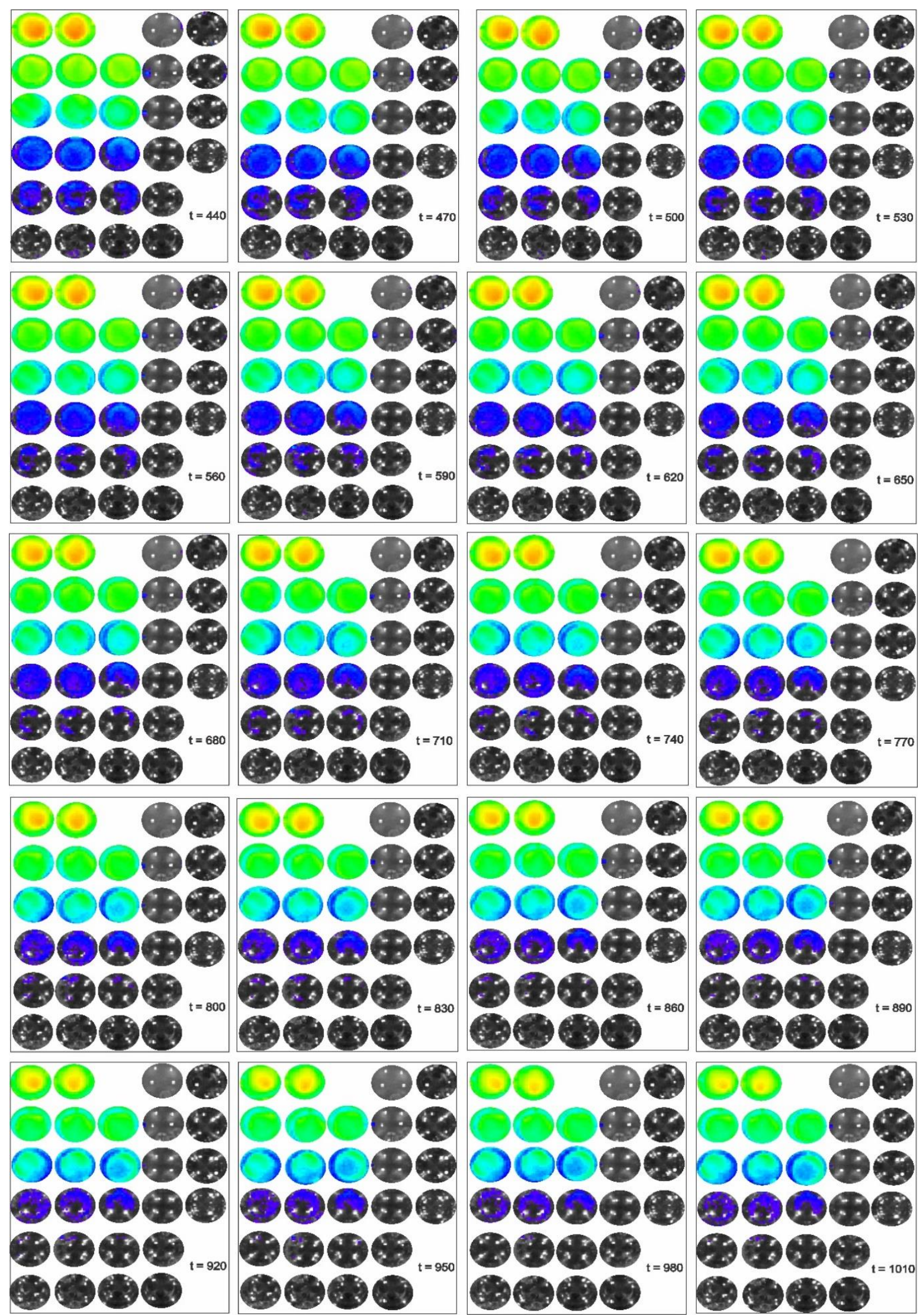




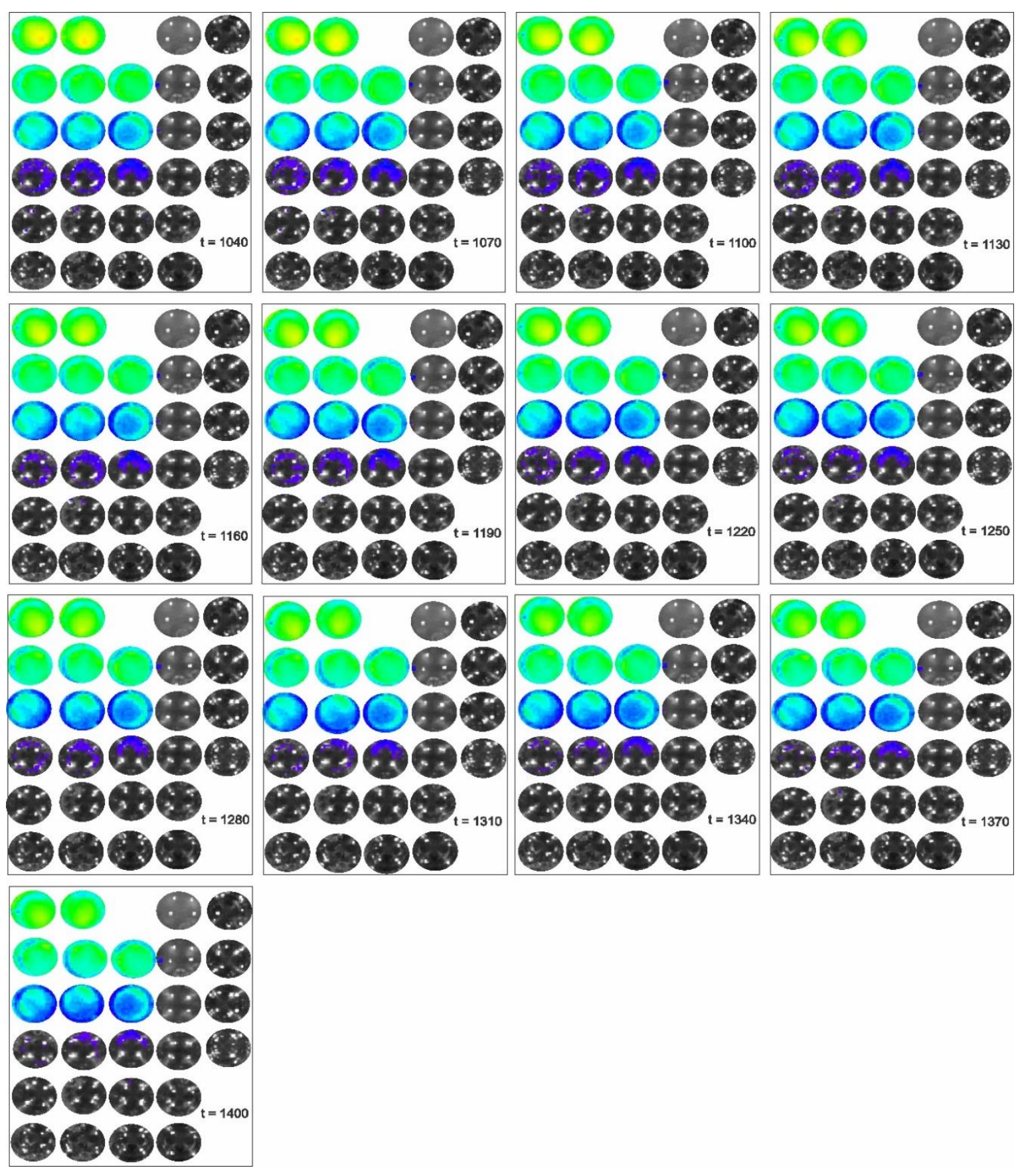




\section{REFERÊNCIAS}

1. Ostrom QT, Gittleman H, Fulop J, Liu M, Blanda R, Kromer C, et al. CBTRUS Statistical Report: primary brain and central nervous system tumors diagnosed in the United States in 2008-2012. Neuro Oncol. 2015;17 Suppl 4:iv1-iv62.

2. Brandes AA, Tosoni A, Franceschi E, Reni M, Gatta G, Vecht C. Glioblastoma in adults. Crit Rev Oncol Hematol. 2008;67(2):139-52. Review.

3. Sarkar A, Chiocca EA. Glioblastoma and malignant astrocytoma. In: Kaye AH, Laws ER, editors. Brain tumors: an encyclopedic approach. 3rd ed. Churchill Livingstone; Edinburgh, New York: 2011. pp. 384-407.

4. Advisory Committee Briefing Document. Pediatric Oncology Subcommittee of the Oncologic Drugs. ABT-414 for the treatment of pediatric patients with high-grade gliomas. [S.I]: AbbVie Inc; 2015

5. Badke GL, Panagopoulos AT, de Aguiar GB, Veiga JCE. Glioblastoma multiforme em idosos: uma revisão sobre seu tratamento com ênfase na abordagem cirúrgica. Arq Bras Neurocir. 2014;33(1):45-51.

6. Lopes TG, Castilho-Fernandes A, Tedesco AC. Ampla caracterização do Glioblastoma e abordagens terapêuticas. Rev Univ Vale Rio Verde. 2012;10(2):12-25.

7. Maier-Hauff K, Rothe R, Scholz R, Gneveckow U, Wust P, Thiesen B, et al. Intracranial thermotherapy using magnetic nanoparticles combined with external beam radiotherapy: results of a feasibility study on patients with glioblastoma multiforme. J Neurooncol. 2007;81(1):53-60.

8. Wankhede M, Bouras A, Kaluzova M, Hadjipanayis CG. Magnetic nanoparticles: an emerging technology for malignant brain tumor imaging and therapy. Expert Rev Clin Pharmacol. 2012;5(2):173-86. Review.

9. Johannsen $M$, Thiesen $B$, Wust $P$, Jordan $A$. Magnetic nanoparticle hyperthermia for prostate cancer. Int J Hyperthermia. 2010;26(8):790-5. Review.

10. Cherukuri P, Glazer ES, Curley SA. Targeted hyperthermia using metal nanoparticles. Adv Drug Deliv Rev. 2010;62(3):339-45. Review.

11. Giovanella BC, Mondovi B. Selective heat sensitivity of cancer cells: Introduction. Recent Results Cancer Res. 1977;(59):1-6.

12. Gilchrist RK, Medal R, Shorey WD, Hanselman RC, Parrott JC, Taylor CB. Selective inductive heating of lymph nodes. Ann Surg. 1957;146(4):596-606.

13. Baronzio GF, Hager ED. Hyperthermia in cancer treatment: a primer [Internet]. Boston, MA: Springer US; 2006 [cited 2017 Feb 20]. Available from: http://link.springer.com/10.1007/978-0387-33441-7

14. Sellins KS, Cohen JJ. Hyperthermia induces apoptosis in thymocytes. Radiat Res. 1991;126(1):88-95. Erratum in: Radiat Res. 1992;129(3):370-1.

15. Christophi C, Winkworth A, Muralihdaran V, Evans $P$. The treatment of malignancy by hyperthermia. Surg Oncol. 1998;7(1-2):83-90. Review. 
16. Falleiros JP, Brandl AL, Fonseca AR. Aplicações da nanotecnologia no diagnóstico e tratamento de câncer. Nucleus. 2011;8(1):151-70.

17. Dennis CL, Ivkov R. Physics of heat generation using magnetic nanoparticles for hyperthermia. Int J Hyperthermia. 2013;29(8):715-29. Review.

18. Landi GT. Simulações estocásticas de nanopartículas magnéticas [tese]. São Paulo: Universidade de São Paulo; 2012 [citado 2017 Fev 20]. Disponível em: http://www.teses.usp.br/teses/disponiveis/43/43134/tde-17042012-124736/publico/landi2.pdf

19. Van Landeghem FK, Maier-Hauff K, Jordan A, Hoffmann KT, Gneveckow U, Scholz R, et al. Post-mortem studies in glioblastoma patients treated with thermotherapy using magnetic nanoparticles. Biomaterials. 2009;30(1):52-7.

20. Shinkai M, Yanase M, Honda H, Wakabayashi T, Yoshida J, Kobayashi T. Intracellular hyperthermia for cancer using magnetite cationic liposomes: in vitro study. Jpn J Cancer Res. 1996;87(11):1179-83.

21. Hilger I. In vivo applications of magnetic nanoparticle hyperthermia. Int J Hyperthermia. 2013;29(8):828-34. Review.

22. Petryk AA, Giustini AJ, Gottesman RE, Trembly BS, Hoopes PJ. Comparison of magnetic nanoparticle and microwave hyperthermia cancer treatment methodology and treatment effect in a rodent breast cancer model. Int J Hyperthermia. 2013;29(8):819-27.

23. Silva AC, Oliveira TR, Mamani JB, Malheiros SM, Malavolta L, Pavon LF, et al. Application of hyperthermia induced by superparamagnetic iron oxide nanoparticles in glioma treatment. Int J Nanomedicine. 2011;6:591-603. Review.

24. Moriyama EH, Zângaro RA, Pacheco MT, Villaverde AB, Wilson BC. Resposta in vitro de células gliossarcoma $9 \mathrm{~L}$ após terapia fotodinâmica utilizando imagem de bioluminescência. Rev Bras Cancerol. 2005;51(1):15-22.

25. Nakajima Y, Yamazaki T, Nishii S, Noguchi T, Hoshino H, et al. Enhanced beetle luciferase for high-resolution bioluminescence imaging. PLoS One. 2010;5(4):e10011.

26. Latorre M, Rinaldi C. Applications of magnetic nanoparticles in medicine: magnetic fluid hyperthermia. P R Health Sci J. 2009;28(3):227-38. Review.

27. Sadhukha T, Niu L, Wiedmann TS, Panyam J. Effective elimination of cancer stem cells by magnetic hyperthermia. Mol Pharm. 2013;10(4):1432-41.

28. Goya GF, Asín L, Ibarra MR. Cell death induced by AC magnetic fields and magnetic nanoparticles: current state and perspectives. Int J Hyperth. 2013;29(8):810-8. Review.

29. Ostrom QT, Gittleman H, Farah P, Ondracek A, Chen Y, Wolinsky Y, et al. CBTRUS statistical report: Primary brain and central nervous system tumors diagnosed in the United States in 2006-2010. Neuro Oncol. 2013;15 Suppl 2:ii1-56. Erratum in: Neuro Oncol. 2014;16(5):760.

30. Ostrom QT, Gittleman H, Peter M, de Blank MD, Jonathan L.FinlayM.B., Ch.B. FRCP, Gurney JG, et al. American brain tumor association adolescent and young adult primary brain and central nervous system tumors diagnosed in the United States in 2008-2012. Neuro Oncol. 2015;18(50). 
31. Adamson DC, Rasheed BA, McLendon RE, Bigner DD. Central nervous system. Cancer Biomark. 2010;9(1-6):193-210. Review.

32. Neuroglia of the central nervous system [Internet]. New York: John Wiley \& Sons; 2011 [cited 2017 Jun 13]. Available from:

http://higheredbcs.wiley.com/legacy/college/tortora/0470565101/hearthis_ill/pap13e_ch12_illust r_audio_mp3_am/simulations/hear/neuroglia.html

33. Moreira TS. Síntese de nanopartículas poliméricas por polimerização radicalar (RAFT) para vetorização biodirigida de tamoxifeno [tese]. Rio de Janeiro: Universidade Federal do Rio de Janeiro; 2015 [citado 2017 Fev 20]. Disponível em:

http://portal.peq.coppe.ufrj.br/index.php/producao-academica/teses-de-doutorado/2015-1/27-

sintese-de-nanoparticulas-polimericas-por-polimerizacao-radicalar-raft-para-vetorizacao-

biodirigida-de-tamoxifeno/file

34. Teixeira M. Explicação diversa para a origem do câncer, com foco nos cromossomos, e não nos genes, ganha corpo no establishment científico. Rev Latinoam Psicopat Fund.

2007;10(4):664-76.

35. Miura FK, Alves MJ, Rocha MC, Silva RS, Oba-Shinjo SM, Uno M, et al. Experimental nodel of $\mathrm{C} 6$ brain tumors in athymic rats. Arq Neuropsiquiatr. 2008;66(2A):238-41.

36. Chen L, Zhang Y, Yang J, Hagan JP, Li M. Vertebrate animal models of glioma: understanding the mechanisms and developing new therapies. Biochim Biophys Acta. 2013;1836(1):158-65. Review.

37. Jacobs VL, Valdes PA, Hickey WF, De Leo JA. Current review of in vivo GBM rodent models: emphasis on the CNS-1 tumour model. ASN Neuro. 2011;3(3):e00063. Review.

38. Barth RF, Kaur B. Rat brain tumor models in experimental neuro-oncology: the C6, 9L, T9, RG2, F98, BT4C, RT-2 and CNS-1 gliomas. J Neurooncol. 2009;94(3):299-312. Review.

39. Kemerli Ç, Taskin MM, Sütpideler N, Kaplan N, Ethemoğlu B. Histopathology, invasion, migration and tumorigenicity in the C6 rat glioma model. Turk Neurosurg. 2005;15(3):109-15.

40. Instituto Nacional de Cancer. Quimioterapia [Internet]. Rio de Janeiro: INCA; sd. [citado 2017 Abr 26]. Disponível em: http://www.inca.gov.br/conteudo_view.asp?id=101

41. Stupp R, Toms SA, Kesari S. Treatment for patients with newly diagnosed glioblastoma-reply. JAMA. 2016;315(21):2348-9.

42. Stupp R, Brada M, van den Bent MJ, Tonn JC, Pentheroudakis G; ESMO Guidelines Working Group. High-grade glioma: ESMO Clinical Practice Guidelines for diagnosis, treatment and follow-up. Ann Oncol. 2014;25 Suppl 3:iii93-101.

43. MacDiarmid JA, Amaro-Mugridge NB, Madrid-Weiss J, Sedliarou I, Wetzel S, Kochar K, et al. Sequential treatment of drug-resistant tumors with targeted minicells containing siRNA or a cytotoxic drug. Nat Biotechnol. 2009;27(7):643-51.

44. Galanis E, Buckner JC, Maurer MJ, Kreisberg JI, Ballman K, Boni J, Peralba JM, Jenkins RB, Dakhil SR, Morton RF, Jaeckle KA, Scheithauer BW, Dancey J, Hidalgo M, Walsh DJ; North Central Cancer Treatment Group. Phase II trial of temsirolimus (CCl-779) in recurrent glioblastoma multiforme: a North Central Cancer Treatment Group Study. J Clin Oncol. 2005;23(23):5294-304. 
45. Wenger C, Salvador R, Basser PJ, Miranda PC. Improving tumor treating fields treatment efficacy in patients with glioblastoma using personalized array layouts. Int $\mathrm{J}$ Radiat Oncol Biol Phys. 2016;94(5):1137-43.

46. de Groot JF, Fuller G, Kumar AJ, Piao Y, Eterovic K, Ji Y, et al. Tumor invasion after treatment of glioblastoma with bevacizumab: radiographic and pathologic correlation in humans and mice. Neuro Oncol. 2010;12(3):233-42.

47. Cohen $\mathrm{MH}$, Shen $\mathrm{YL}$, Keegan $\mathrm{P}$, Pazdur R. FDA drug approval summary: bevacizumab (Avastin) as treatment of recurrent glioblastoma multiforme. Oncologist. 2009;14(11):1131-8.

48. Dolmans DE, Fukumura D, Jain RK. Photodynamic therapy for cancer. Nat Rev Cancer. 2003;3(5):380-7. Review.

49. Koukourakis MI, Mitrakas AG, Giatromanolaki A. Therapeutic interactions of autophagy with radiation and temozolomide in glioblastoma: evidence and issues to resolve. $\mathrm{Br} \mathrm{J}$ Cancer. 2016;114(5):485-96. Review.

50. Li J, Zhang Z, Lv L, Qiao H, Chen X, Zou C. A bispecific antibody (ScBsAbAgn-2/TSPO) target for Ang-2 and TSPO resulted in therapeutic effects against glioblastomas. Biochem Biophys Res Commun. 2016;472(2):384-91.

51. Soares PI, Ferreira IM, Igreja RA, Novo CM, Borges JP. Application of hyperthermia for cancer treatment: recent patents review. Recent Pat Anticancer Drug Discov. 2012;7(1):64-73. Review.

52. Mahmoudi K, Hadjipanayis CG. The application of magnetic nanoparticles for the treatment of brain tumors. Front Chem. 2014;2:109.

53. Rosca EV, Wright M, Gonitel R, Gedroyc W, Miller AD, Thanou M. Thermosensitive, nearinfrared-labeled nanoparticles for topotecan delivery to tumors. Mol Pharm. 2015;12(5):1335-46.

54. Hayashi K, Nakamura M, Miki H, Ozaki S, Abe M, Matsumoto T, et al. Magnetically responsive smart nanoparticles for cancer treatment with a combination of magnetic hyperthermia and remote-control drug release. Theranostics. 2014;4(8):834-44.

55. Thiesen B, Jordan A. Clinical applications of magnetic nanoparticles for hyperthermia. Int J Hyperthermia. 2008;24(6):467-74.

56. Liu J, Li N, Li L, Li D, Liu K, Zhao L, et al. Local hyperthermia for esophageal cancer in a rabbit tumor model: Magnetic stent hyperthermia versus magnetic fluid hyperthermia. Oncol Lett. 2013;6(6):1550-8.

57. Huang HS, Hainfeld JF. Intravenous magnetic nanoparticle cancer hyperthermia. Int $\mathrm{J}$ Nanomedicine. 2013;8:2521-32.

58. Miotello A. Nanocápsulas contendo selol e fluído magnético: preparação, caracterização e avaliação da atividade antitumoral in vitro. Faculdade de Ciências Farmacêuticas de Ribeirão Preto. Universidade de São Paulo, 2011.

59. Aguiar MF, Bustamante Mamani J, Klei Felix T, Ferreira dos Reis R, Rodrigues da Silva H, Nucci LP, et al., et al. Magnetic targeting with superparamagnetic iron oxide nanoparticles for in vivo glioma. Nanotechnol Rev. Published Online 2017-03-16. DOI:

https://doi.org/10.1515/ntrev-2016-0101 
60. Ramanujan R, Lao L. Magnetic particles for hyperthermia treatment of cancer. Proc First Int Bioengg Conf [Internet]. Singapore: 2004. p.69. Available from:

http://www3.ntu.edu.sg/home/ramanujan/reprints/IBECpaper2RVR.pdf

61. Etheridge ML, Manucherabadi N, Franklin R, Bischof JC. Superparamagnetic iron oxide nanoparticle heating: a basic tutorial. In: Minkowycz WJ, Sparrow EM, Abraham JP. nanoparticle heat transf fluid flow. Boca Raton: CRC Press. 2012. Chap. 4. p. 97-122.

62. Leite RC. Coercividade e anisotropia magnética e magneto-óticas em nanocolóides magnéticos [dissertação]. Brasília (DF): Universidade de Brasília; 2011.

63. Deatsch AE, Evans BA. Heating efficiency in magnetic nanoparticle hyperthermia. J Magn Magn Mater. 2014;354:163-72.

64. Effenberger FB. Nanomateriais magnéticos para aplicações em terapia e imagem [tese]. São Paulo: Universidade de São Paulo; 2012.

65. Rosensweig RE. Heating magnetic fluid with alternating magnetic field. J Magn Magn Mater. 2002;252:370-4.

66. Brown R. A brief account of microscopical observations made in the months of June, July and August 1827, on the particles contained in the pollen of plants; and on the general existence of active molecules in organic and inorganic bodies. Philos Mag Ser 2. 1828;4(21):161-73.

67. Laurent S, Dutz S, Häfeli UO, Mahmoudi M. Magnetic fluid hyperthermia: Focus on superparamagnetic iron oxide nanoparticles. Adv Colloid Interface Sci. 2011;166(1-2):8-23.

68. Vieira CA. Efeitos das interações magnéticas entre partículas nas propriedades de bloqueio de nanocristais de ferrita de cobalto [tese].Brasília (DF): Universidade de Brasília; 2013.

69. Verde EL. Hipertermia magnética em nanopartículas: da instrumentação biomédica in vitro ao estudo das propriedades magneto-térmicas de diferentes ferritas. Universidade Federal de Goías; 2012.

70. Castro GM. Estudo das propriedades estruturais magnéticas e magnetorresistivas em multicamadas magnéticas de Co/Pt acopladas a IrMn [tese]. Porto Alegre: Universidade Federal do Rio Grande do Sul; 2010.

71. Horikoshi S, Serpone N. Microwaves nanoparticle synthesis: fundamentals and applications. USA: Wiley; 2013. Introduction to nanoparticles. p.1-24.

72. Sargentelli V, Ferreira AP. Nanopartículas magnéticas: o cobalto. Eclet Quím. 2010;35(4):153-63.

73. Buzea C, Pacheco II, Robbie K. Nanomaterials and nanoparticles: sources and toxicity. Biointerphases. 2007;2(4):MR17-71.

74. University of New South Wales. School of Chemical Engineering. WichLab [Internet]. Sydney: University of New South Wales;. 2017 [cited 2017 Feb 8]. Available from: http://www.wichlab.com/research/

75. Akbarzadeh A, Samiei M, Davaran S. Magnetic nanoparticles: preparation, physical properties, and applications in biomedicine. Nanoscale Res Lett. 2012;7(1):144. 
76. Jin Xie, Gang Liu, Henry S. Eden HA and XC. Surface-Engineered Magnetic Nanoparticle Platforms for Cancer Imaging and Therap. Acc Chem Res. 2011;44(10):883-92.

77. Wu W, He Q, Jiang C. Magnetic iron oxide nanoparticles: synthesis and surface functionalization strategies. Nanoscale Res Lett. 2008;3(11):397-415.

78. Wu W, Wu Z, Yu T, Jiang C, Kim WS. Recent progress on magnetic iron oxide nanoparticles: synthesis, surface functional strategies and biomedical applications. Sci Technol Adv Mater. 2015;16(2):023501. eCollection 2015. Review.

79. Umut E. Surface modification of nanoparticles used in biomedical applications. In: Aliofkhazraei M, editor. Modern surface engineering treatments.Croatia: InTech; 2013. Chap. 8. DOI: $10.5772 / 55746$

80. Gossuin Y, Gillis P, Hocq A, Vuong QL, Roch A. Magnetic resonance relaxation properties of superparamagnetic particles. Wiley Interdiscip Rev Nanomed Nanobiotechnol. 2009;1(3):299-310. Review.

81. Oliveira LC, Fabris JD, Pereira MC. Óxidos de ferro e suas aplicações em processos catalíticos: uma revisão. Quim Nova. 2013;36(1):123-30.

82. Nadeem K, Krenn H, Traussnig T, Würschum R, Szabó DV, Letofsky-Papst I. Effect of dipolar and exchange interactions on magnetic blocking of maghemite nanoparticles. J Magn Magn Mater. 2011;323(15):1998-2004.

83. Mørup S, Hansen MF, Frandsen C. Magnetic interactions between nanoparticles. Beilstein J Nanotechnol. 2010;1:182-90.

84. Wikiwand.com. Força magnética [Internet]. 2017. [cited 2017 Feb 11]. Available from: http://www.wikiwand.com/pt/Força_magnética

85. Silva SC. Nanocompósitos à base de Pr2Fe14B/ Fe-a para aplicações térmicas [tese]. São Paulo: Universidade de São Paulo; 2012.

86. Pessoa MS. Anisotropia magnética em tricamadas epitaxiais Fe / Mn / Fe [tese]. Goiânia: Universidade Federal de Goiás; 2010.

87. Colombo M, Carregal-Romero S, Casula MF, Gutiérrez L, Morales MP, Böhm IB, et al. Biological applications of magnetic nanoparticles. Chem Soc Rev. 2012;41(11):4306-34. Review.

88. JAHSChem. Electron address [Internet]. 2017 [cited 2017 Feb 21]. Available from: https://jahschem.wikispaces.com/Electron+Address

89. Vallejo-Fernandez G, Whear O, Roca AG, Hussain S, Timmis J, Patel V, et al. Mechanisms of hyperthermia in magnetic nanoparticles. J Phys D Appl Phys. 2013;46(31):312001.

90. Zhang Y, Zhai Y. Magnetic induction heating of nano-sized ferrite particle . In: Grundas S. Advances in induction and microwave heating of mineral and organic materials.Croatia: InTech; 2011. Chap. 21. p. 483-500.

91. Soares PI, Lochte F, Echeverria C, Pereira LC, Coutinho JT, Ferreira IM, et al. Thermal and magnetic properties of iron oxide colloids: influence of surfactants. Nanotechnology.

2015;26(42):425704. 
92. Kozissnik B, Bohorquez AC, Dobson J, Rinaldi C. Magnetic fluid hyperthermia: advances, challenges, and opportunity. Int J Hyperthermia. 2013;29(8):706-14. Review.

93. Kallumadil M, Tada M, Nakagawa T, Abe M, Southern P, Pankhurst QA. Suitability of commercial colloids for magnetic hyperthermia. J Magn Magn Mater. 2009;321(10):1509-13.

94. Blanco-Andujar C, Ortega D, Southern P, Pankhurst QA, Thanh NT. High performance multi-core iron oxide nanoparticles for magnetic hyperthermia: microwave synthesis, and the role of core-to-core interactions. Nanoscale. 2015;7(5):1768-75.

95. Ludwig R, Stapf M, Dutz S, Müller R, Teichgräber U, Hilger I. Structural properties of magnetic nanoparticles determine their heating behavior - an estimation of the in vivo heating potential. Nanoscale Res Lett. 2014;9(1):602.

96. Cervadoro A, Giverso C, Pande R, Sarangi S, Preziosi L, Wosik J, et al. Design maps for the hyperthermic treatment of tumors with superparamagnetic nanoparticles. PLoS One. 2013;8(2):e57332.

97. Gkanas El. In vitro magnetic hyperthermia response of iron oxide MNP's incorporated in DA3, MCF-7 and HeLa cancer cell lines. Cent Eur J Chem. 2013;11(7):1042-54.

98. Tomitaka A, Yamada T, Takemura Y. Magnetic nanoparticle hyperthermia using pluroniccoated fe3o4 nanoparticles: an in vitro study. J Nanomater. 2012;2012:1-5.

99. Zamora-Mora V, Fernández-Gutiérrez M, González-Gómez Á, Sanz B, Román JS, Goya GF, et al. Chitosan nanoparticles for combined drug delivery and magnetic hyperthermia: From preparation to in vitro studies. Carbohydr Polym. 2017;157:361-370.

100. Stocke NA, Sethi P, Jyoti A, Chan R, Arnold SM, Hilt JZ, et al. Toxicity evaluation of magnetic hyperthermia induced by remote actuation of magnetic nanoparticles in $3 \mathrm{D}$ micrometastasic tumor tissue analogs for triple negative breast cancer. Biomaterials. 2017;120:115-25.

101. Sanz B, Calatayud MP, Torres TE, Fanarraga ML, Ibarra MR, Goya GF. Magnetic hyperthermia enhances cell toxicity with respect to exogenous heating. Biomaterials. 2017;114:62-70.

102. Sharifabad ME, Mercer T, Sen T. Drug-loaded liposome-capped mesoporous core-shell magnetic nanoparticles for cellular toxicity study. Nanomedicine (Lond). 2016 Oct 19. [Epub ahead of print]

103. Oh Y, Lee N, Kang HW, Oh J. In vitro study on apoptotic cell death by effective magnetic hyperthermia with chitosan-coated $\mathrm{MnFe}_{2} \mathrm{O}_{4}$. Nanotechnology. 2016;27(11):115101.

104. Hilger I, Hergt R, Kaiser WA. Towards breast cancer treatment by magnetic heating. J Magn Magn Mater. 2005;293(1):314-9.

105. Zhao Q, Wang L, Cheng R, Mao L, Arnold RD, Howerth EW, et al. Magnetic nanoparticlebased hyperthermia for head \& neck cancer in mouse models. Theranostics. 2012;2:113-21.

106. Lee JH, Jang JT, Choi JS, Moon SH, Noh SH, Kim JW, et al. Exchange-coupled magnetic nanoparticles for efficient heat induction. Nat Nanotechnol. 2011;6(7):418-22. 
107. Arriortua OK, Garaio E, Herrero de la Parte B, Insausti M, Lezama L, Plazaola F, et al. Antitumor magnetic hyperthermia induced by RGD-functionalized Fe 304 nanoparticles, in an experimental model of colorectal liver metastases. Beilstein J Nanotechnol . 2016;7:1532-42.

108. Di Corato R, Béalle G, Kolosnjaj-Tabi J, Espinosa A, Clément O, Silva AK, et al. Combining magnetic hyperthermia and photodynamic therapy for tumor ablation with photoresponsive magnetic liposomes. ACS Nano. 2015 24;9(3):2904-16.

109. Kossatz S, Grandke J, Couleaud P, Latorre A, Aires A, Crosbie-Staunton K, et al. Efficient treatment of breast cancer xenografts with multifunctionalized iron oxide nanoparticles combining magnetic hyperthermia and anti-cancer drug delivery. Breast Cancer Res. 2015;17(1):66.

110. Jeon MJ, Ahn C-H, Kim H, Chung IJ, Jung S, Kim Y-H, et al. The intratumoral administration of ferucarbotran conjugated with doxorubicin improved therapeutic effect by magnetic hyperthermia combined with pharmacotherapy in a hepatocellular carcinoma model. $J$ Exp Clin Cancer Res. 2014;33(1):57.

111. Rivet CJ, Yuan Y, Gilbert RJ, Borca-Tasciuc DA. Effect of magnetic nanoparticle heating on cortical neuron viability. Int J Hyperthermia. 2014;30(2):79-85.

112. Trujillo-Romero, J, Garc S, la-Jimeno, Vera, A. L. Leija A, Estelrich J. Focusing heating effect of an external waveguide applicator for oncology hyperthermia: Evaluation in muscle and tumor phantoms. Prog Electromagn Res. 2011;121:343-63.

113. Drayer B, Burger $P$, Darwin R, Riederer S, Herfkens R. Magnetic resonance imaging of brain iron. AJNR Am J Neuroradiol. 1986;7(3):373-80.

114. Yallapu MM, Othman SF, Curtis ET, Gupta BK, Jaggi M, Chauhan SC.Multi-functional magnetic nanoparticles for magnetic resonance imaging and cancer therapy. Biomaterials. 2011;32(7):1890-905.

115. Stephen ZR, Kievit FM, Zhang M. Magnetite Nanoparticles for Medical MR Imaging. Mater Today. 2011;14(7-8):330-8.

116. Moriyama EH, Bisland SK, Lilge L, Wilson BC. Bioluminescence imaging of the response of rat gliosarcoma to ALA-PpIX-mediated photodynamic therapy. Photochem Photobiol. 2004;80(2):242-9.

117. de Almeida PE, van Rappard JR, Wu JC. In vivo bioluminescence for tracking cell fate and function. Am J Physiol Heart Circ Physiol. 2011;301(3):H663-71. Review.

118. Oliveira AG, Carvalho RP, Waldenmaier HE, Stevani CV. Bioluminescência de fungos: Distribuição, função e mecanismo de emissão de luz. Quim Nova. 2013;36(2):314-9.

119. Marques SM, Esteves da Silva JC. Firefly bioluminescence: a mechanistic approach of luciferase catalyzed reactions. IUBMB Life. 2009;61(1):6-17. Review.

120. Almeida PE, van Rappard JRM, Wu JC. In vivo bioluminescence for tracking cell fate and function. Am J Physiol Heart Circ Physiol. 2011;301(3):H663-71.

121. Hwang DW, Park KM, Shim HK, Jin Y, Oh HJ, Oh SW, et al. In vivo bioluminescence imaging for viable human neural stem cells incorporated within in situ gelatin hydrogels.

EJNMMI Res. 2014;4(1):61. 
122. Im HJ, Hwang DW, Lee HK, Jang J, Lee $S$, Youn $H$, et al. In vivo visualization and monitoring of viable neural stem cells using noninvasive bioluminescence imaging in the 6hydroxydopamine-induced mouse model of Parkinson disease. Mol Imaging. 2013;12(4):22434.

123. Hutchens M, Luker GD. Applications of bioluminescence imaging to the study of infectious diseases. Cell Microbiol. 2007;9(10):2315-22. Review.

124. Vasquez ES, Feugang JM, Willard ST, Ryan PL, Walters KB. Bioluminescent magnetic nanoparticles as potential imaging agents for mammalian spermatozoa. J Nanobiotechnology. 2016;14:20.

125. Tse BW, Cowin GJ, Soekmadji C, Jovanovic L, Vasireddy RS, Ling MT, et al. PSMAtargeting iron oxide magnetic nanoparticles enhance MRI of preclinical prostate cancer. Nanomedicine (Lond). 2015;10(3):375-86.

126. Pavlov AM, Gabriel SA, Sukhorukov GB, Gould DJ. Improved and targeted delivery of bioactive molecules to cells with magnetic layer-by-layer assembled microcapsules. Nanoscale. 2015;7(21):9686-93.

127. Roda A, Cevenini L, Borg S, Michelini E, Calabretta MM, Schüler D. Bioengineered bioluminescent magnetotactic bacteria as a powerful tool for chip-based whole-cell biosensors. Lab Chip. 2013;13(24):4881-9.

128. Xu Y, Li C, Zhu X, Huang WE, Zhang D. Application of magnetic nanoparticles in drinking water purification. Environ Eng Manag J. 2014;13(8):2023-9.

129. Verkhratsky A, Butt AM. Glial physiology and pathophysiology. USA: Wiley; 2013. Neuroglia: definition, classification, evolution, numbers, development 3.1. p.73-104.

130. Chandana SR, Movva S, Arora M, Singh T. Primary brain tumors in adults. Am Fam Physician. 2008;77(10):1423-30. Review.

131. Burgos JS, Rosol M, Moats RA, Khankaldyyan V, Kohn DB, Nelson MD Jr, et al. Time course of bioluminescent signal in orthotopic and heterotopic brain tumors in nude mice.

Biotechniques. 2003;34(6):1184-8.

132. Nakage APM, Santana AE, Cápua MLB de, Coelho PS. Metodologia e aplicação da citometria de fluxo na hematologia veterinária. Ciência Rural. 2005;35(4):966-73.

133. Sato I, Umemura M, Mitsudo K, Kioi M, Nakashima H, Iwai T, et al. Hyperthermia generated with ferucarbotran (Resovist??) in an alternating magnetic field enhances cisplatininduced apoptosis of cultured human oral cancer cells. J Physiol Sci. 2014;64(3):177-83.

134. Palma P. Avaliação da Anexina V e Calceína AM como marcadores de apoptose em linfócitos [dissertação]. Florianópolis: Universidade Federal de Santa Catarina; 2005.

135. Maecker H, Trotter J. [Selecting reagents for multicolor BD flow cytometry]. Postepy Biochem. 2009;55(4):461-7. Polish.

136. Sturm A, Amino R, van de Sand C, Regen T, Retzlaff S, Rennenberg A, et al. Manipulation of host hepatocytes by the malaria parasite for delivery into liver sinusoids. Science.

2006;313(5791):1287-90. 
137. Riccardi C, Nicoletti I. Analysis of apoptosis by propidium iodide staining and flow cytometry. Nat Protoc. 2006;1(3):1458-61.

138. Rieger AM, Nelson KL, Konowalchuk JD, Barreda DR. Modified annexin V/propidium iodide apoptosis assay for accurate assessment of cell death. J Vis Exp. 2011;(50). pii: 2597.

139. Roti Roti JL. Cellular responses to hyperthermia (40-46 degrees C): cell killing and molecular events. Int J Hyperthermia. 2008;24(1):3-15. Review.

140. Roemer RB. Engineering aspects of hyperthermia therapy. Annu Rev Biomed Eng. 1999;1:347-76. Review.

141. Abakar MH, Imbuga MO, Osir EO, Morgan HG. Purification And Characterization Of G. M. Morsitans Midgut Trypanolysin. Int J Sci e Technol Res. 2016;5(12).

142. Zhou J, Lu Z, Zhu X, Wang X, Liao Y, Ma Z, et al. NIR photothermal therapy using polyaniline nanoparticles. Biomaterials. 2013;34(37):9584-92.

143. Wang G, Xu D, Chai Q, Tan X, Zhang Y, Gu N, et al. Magnetic fluid hyperthermia inhibits the growth of breast carcinoma and downregulates vascular endothelial growth factor expression. Oncol Lett. 2014;7(5):1370-1374.

144. Wang L, Dong J, Ouyang W, Wang X, Tang J. Anticancer effect and feasibility study of hyperthermia treatment of pancreatic cancer using magnetic nanoparticles. Oncol Rep. 2012;27(3):719-26.

145. Tanaka T, Kobayashi T, Takahashi T, Hattori K. Effect of combined treatment with magnetic induction hyperthermia and chemotherapy in a rabbit brain tumor model. Neurol Med Chir (Tokyo). 1989;29(5):377-81.

146. Sibov TT, Aya L, Miyaki M, Mamani JB, Marti LC, Sardinha LR, et al. Evaluation of umbilical cord mesenchymal stem cell labeling with superparamagnetic iron oxide nanoparticles coated with dextran and complexed with Poly-L-lysine com Dextran e complexadas a Poli-LLisina. einstein (Sao Paulo). 2012;10(55 11):180-8.

147. Swanson L. Brain maps: structure of the rat brain. Third Edit. Philadelphia: Elsevier; 1992.

148. Giustini AJ, Petryk AA, Cassim SM, Tate JA, Baker I, Hoopes PJ. Magnetic nanoparticle hypertermia in cancer. Nano Life1(01n02), 2010.

149. Kolhatkar AG, Jamison AC, Litvinov D, Willson RC, Lee TR. Tuning the magnetic properties of nanoparticles. Int J Mol Sci. 2013;14(8):15977-6009. Review.

150. Incio JL. Funcionalização de nanopartículas magnéticas de óxido de ferro com fármacos hidrofóbicos e construção de um sistema para controle de liberação [dissertação]. Rio de Janeiro: Pontifícia Universidade Católica do Rio de Janeiro; 2014.

151. Zhang R, Zhou Y, Wang PC, Sridhar and R. Evaluation of tumor cell response to hyperthermia with bioluminescent imaging. J Basic Clin Med. 2012;1(1):16-9.

152. Blanco-Andujar C, Ortega D, Southern P, Nesbitt SA, Thanh NT, Pankhurst QA. Real-time tracking of delayed-onset cellular apoptosis induced by intracellular magnetic hyperthermia. Nanomedicine (Lond). 2016;11(2):121-36.

153. Hou CH, Lin FL, Hou SM, Liu JF. Hyperthermia induces apoptosis through endoplasmic 
reticulum and reactive oxygen species in human osteosarcoma cells. Int J Mol Sci. 2014;15(10):17380-95.

154. Poller JM, Zaloga J, Schreiber E, Unterweger H, Janko C, Radon P, et al. Selection of potential iron oxide nanoparticles for breast cancer treatment based on in vitro cytotoxicity and cellular uptake. Int J Nanomedicine. 2017;12:3207-3220.

155. Michailowsky C, Niura FK, do Valle AC, Sonohara S, Meneguin TD, Tsanaclis AM. [Experimental tumors of the central nervous system: standardisation of a model in rats using the 9L glioma cells]. Arq Neuropsiquiatr. 2003;61(2A):234-40. Portuguese.

156. Lucena Rde C, de Mello RJ, Lessa JR Jr, Cavalcante GM, Ribeiro M. [Clinical topographic findings in glioblastoma multiforme and the relation with motor impairment]. Arq Neuropsiquiatr. 2006;64(2B):441-5. Portuguese.

157. Mukand JA, Blackinton DD, Crincoli MG, Lee JJ, Santos BB. Incidence of neurologic deficits and rehabilitation of patients with brain tumors. Am J Phys Med Rehabil. $2001 ; 80(5): 346-50$.

158. Deacon RM. Measuring motor coordination in mice. J Vis Exp. 2013;(75):e2609.

159. American College of Surgeons. Committee on Trauma. Advanced trauma life support: student course manual. American College of Surgeons; 2012. 366 p.

160. Saade N, Veiga JC, Cannoni LF, Haddad L, Araújo JL. Evaluation of prognostic factors of decompressive craniectomy in the treatment of severe traumatic brain injury. Rev Col Bras Cir. 2014 Jul-Aug;41(4):256-62.

161. Neumann M, Wang Y, Kim S, Hong SM, Jeng L, Bilgen M, et al. Assessing gait impairment following experimental traumatic brain injury in mice. J Neurosci Methods. 2009;176(1):34-44.

162. Lee MJ, Chang CP, Lee YH, Wu YC, Tseng HW, Tung YY, et al. Longitudinal evaluation of an $\mathrm{N}$-ethyl-N-nitrosourea-created murine model with normal pressure hydrocephalus. PLoS One. 2009;4(11):e7868.

163. Balkaya M, Kröber J, Gertz K, Peruzzaro S, Endres M. Characterization of long-term functional outcome in a murine model of mild brain ischemia. J Neurosci Methods.

2013;213(2):179-87.

164. Liu Y, Ao LJ, Lu G, Leong E, Liu Q, Wang XH, et al. Quantitative gait analysis of long-term locomotion deficits in classical unilateral striatal intracerebral hemorrhage rat model. Behav Brain Res. 2013;257:166-77.

165. Chuang CS, Su HL, Cheng FC, Hsu SH, Chuang CF, Liu CS. Quantitative evaluation of motor function before and after engraftment of dopaminergic neurons in a rat model of Parkinson's disease. J Biomed Sci. 2010;17:9.

166. Vandeputte C, Taymans JM, Casteels C, Coun F, Ni Y, Van Laere K, et al. Automated quantitative gait analysis in animal models of movement disorders. BMC Neurosci. 2010;11:92.

167. Sadhukha T, Wiedmann TS, Panyam J. Inhalable magnetic nanoparticles for targeted hyperthermia in lung cancer therapy. Biomaterials. 2013;34(21):5163-71.

168. Yin PT, Shah S, Pasquale NJ, Garbuzenko OB, Minko T, Lee KB. Stem cell-based gene therapy activated using magnetic hyperthermia to enhance the treatment of cancer. 
Biomaterials. 2016;81:46-57.

169. Hundt W, Schink C, Steinbach S, O'Connell-Rodwell CE, Mayer D, Burbelko M, et al. Use of in vivo bioluminescence and MRI to determine hyperthermia-induced changes in luciferase activity under the control of an hsp70 promoter. NMR Biomed. 2012;25(12):1378-91. 


\begin{abstract}
Purpose: To evaluate the efficacy of hypertension by means of the bioluminescence technique, without treatment of glioblastoma in animal model, administering superparamagnetic iron oxide nanoparticles to assist in the tumor cellular motto. Methods: Heat wave curves of hyperthermia magneto were obtained from colloidal samples of iron oxide nanoparticles with different coatings (aminosilane, dextran, chitosan and starch) in different sets (50, 100 and 200nm), exposed to three field intensities Magnetic (50, 150 and 300 gauss) and twice (305 and $551 \mathrm{kHz}$ ) for acquisition of specific absorption rate values. After an acquisition of the specific absorption rate values, as C6 cells with luciferase were labeled as two iron oxide nanoparticles that obtained higher heating potential under 3 magnetic labeling conditions (without magnet, with static and dynamic magnet) and without poly Lysine for cell transfection and $0.45 \mu \mathrm{m}$ filter. As cells were submitted to two conditions of exposure to magneto hyperthermia ( 44 and $48^{\circ} \mathrm{C}$ for $40 \mathrm{~min}$ ) and evaluated by flow cytometry and bioluminescence for analysis of therapeutic efficacy in vitro. Volumetry of the tumors induced in Wistar rats was performed by magnetic resonance imaging and bioluminescence. Animal behavioral studies were performed to analyze the gait and spontaneous locomotion forces generated by tumor induction. Then the animals were submitted to hyperthermia magneto for 40 minutes and analyzed by bioluminescence.
\end{abstract} Results: The best technical parameters for the application of magneto hyperthermia were: 300 gauss magnetic field strength and $551 \mathrm{kHz}$ field frequency, with a higher specific absorption rate value generated by iron oxide nanoparticles with aminosilane coverage and diameter of $100 \mathrm{~nm}$. In vitro hyperthermia magnetism, tumor cell viability of 31.11 and $20.86 \%$ by bioluminescence and 65.7 and $75.2 \%$ of cell death were analyzed by flow cytometry after the performance of magneto hyperthermia for 40 minutes in 44 and $48^{\circ} \mathrm{C}$, respectively. In the in vivo analyzes, according to the gait evolution, no tumor group was observed, such as: step length decay, contact area and distances between legs, increase in paw contact time, step cycle and duration of the course With a decrease in cadence. There was a decrease in the movements of the tumor group in the analyzes of spontaneous locomotion by Actometer. Tumor cell viability by bioluminescence after magneto hyperthermia for 40 minutes of $67.2 \%$. 
Conclusion: Hyperthermia magnetotherapy has shown efficiency in the death of C6 tumor cells in both in vitro and in vivo studies. 